\title{
Die parasitophore Vakuole des Mikrosporidiums Encephalitozoon cuniculi: Biogenese und Metabolitaustausch
}

\author{
Dissertation \\ zur Erlangung des Doktorgrades \\ der Mathematisch-Naturwissenschaftlichen Fakultäten \\ der Georg-August-Universität zu Göttingen
}

vorgelegt von

Karin Rönnebäumer

aus Coesfeld

Göttingen, den 16.09.2008 
D 7

Referent: Prof. Dr. Uwe Groß

Korreferent: Prof. Dr. Jörg Stülke

Tag der mündlichen Prüfung: 


\section{Danksagung}

An dieser Stelle möchte ich mich sehr herzlich bedanken.

Bei Herrn Prof. Dr. Uwe Groß möchte ich mich sehr herzlich für die Möglichkeit, die Arbeit im Institut für medizinische Mikrobiologie anfertigen zu dürfen, sowie die Begutachtung der Arbeit bedanken.

Herrn Prof. Dr. Jörg Stülke möchte ich für die Übernahme des Zweitgutachtens danken.

Herrn Prof. Dr. Gerhard Braus, Herrn Prof. Dr. Ivo Feußner, Frau Prof. Dr. Stefanie Pöggeler und Herrn Prof. Dr. Ernst A. Wimmer möchte ich für die Breitschaft, Mitglied meiner Prüfungskommission zu werden, danken.

Mein besonderer Dank gilt Herrn Dr. Wolfgang Bohne, der das interessante Thema bereitgestellt, und mich während meiner Doktorarbeit außerordentlich engagiert betreut hat. Durch seine immerwährende Bereitschaft, neue Ergebnisse und Ideen zu diskutieren, ist eine produktive Arbeitsatmosphäre entstanden.

Ein großes Dankeschön gilt meinen Kollegen Tobias, Andrea G., Oliver, San San und Diana für die Unterstützung im Labor, die vielen Diskussionen, sowie die unvergessliche Zeit, die wir miteinander verbracht haben. Außerdem möchte ich mich bei Britta, Andrea H., Nicole M., Kristin, Anna, Malik, Philipp, Valeska, Friedrich, Christian, Jonas und Javid für die gute Zusammenarbeit und die nette Arbeitsatmosphäre bedanken.

Bedanken möchte ich mich auch bei meiner Familie, die mich moralisch unterstützt und sich immer für das Vorankommen im Labor interessiert hat.

Ein letzter, aber besonderer Dank gilt auch meinem Freund Jens Böttcher für die oft endlos langen fachlichen Diskussionen, die für das Entstehen dieser Arbeit von unschätzbarem Wert waren. Durch seine verständnisvolle und geduldige Art hat er mich immer wieder aufgemuntert und in den richtigen Momenten auch für Ablenkung gesorgt. 


\section{Inhaltsverzeichnis}

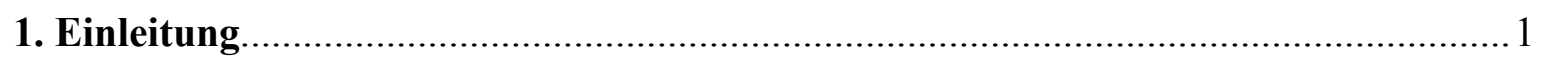

1.1 Allgemeine Merkmale der Mikrosporidien............................................................

1.2 Ursprung und Evolution von Mikrosporidien....................................................... 1

1.3 Medizinische und Veterinärmedizinische Bedeutung......................................... 2

1.4 Therapie von Mikrosporidien-Infektionen....................................................... 4

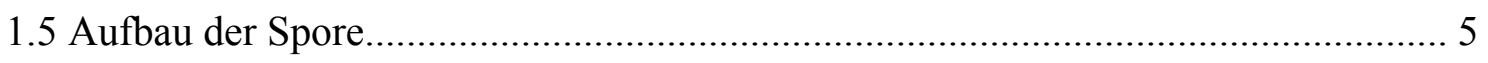

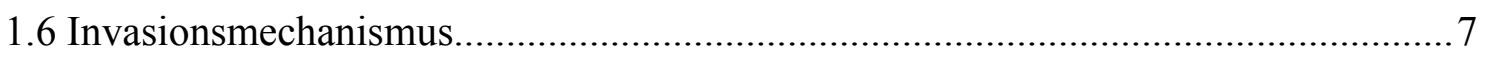

1.7 Die Sporenphagocytose als zusätzlicher Invasionsmechanismus............................ 10

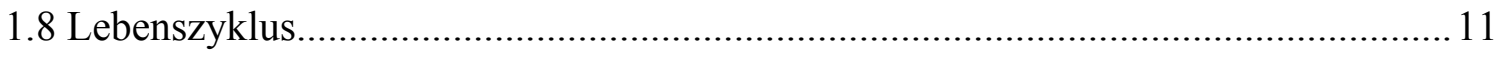

1.9 Encephalitozoon cuniculi als Modellorganismus...................................................... 13

1.10 Ursprung und Eigenschafen der parasitophoren Vakuole........................................ 14

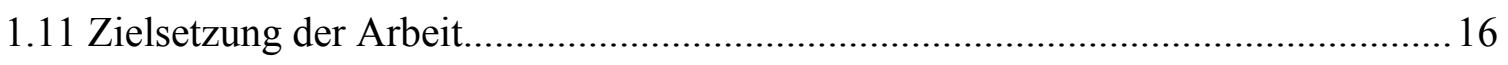

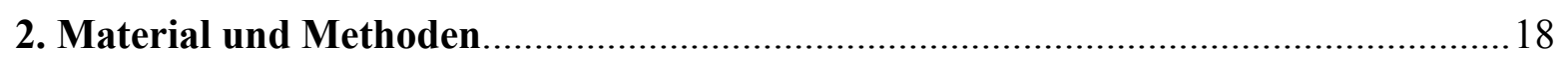

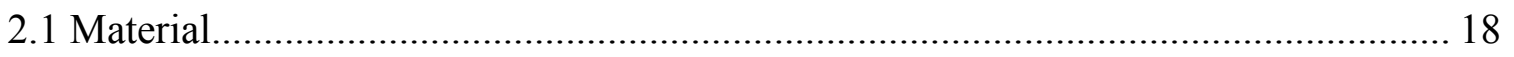

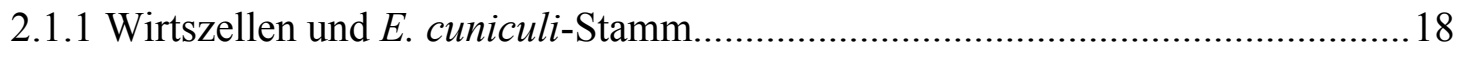

2.1.2 Medien und Medienzusätze für die Zellkultur................................................ 18

2.1.3 Verbrauchsmaterialien für die Zellkultur....................................................... 19

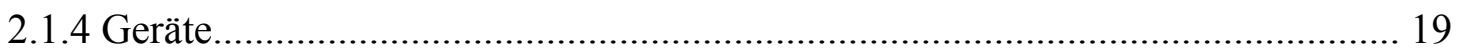

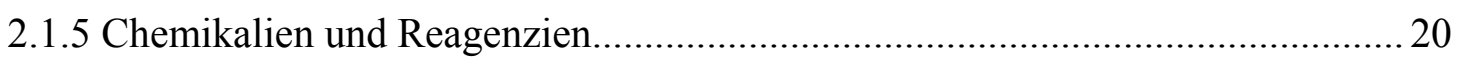

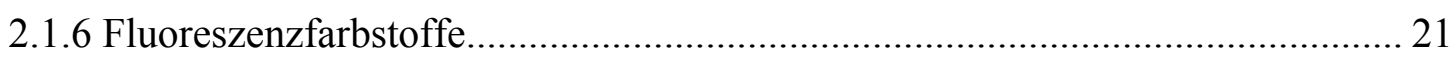

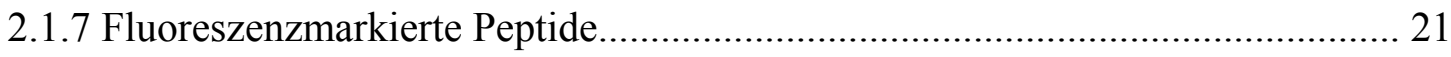

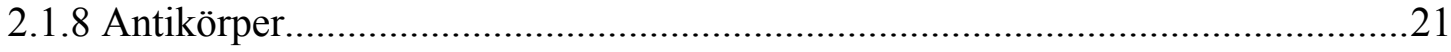

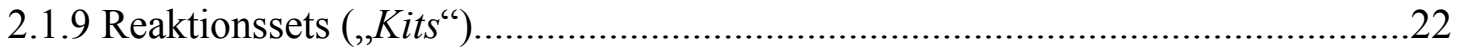

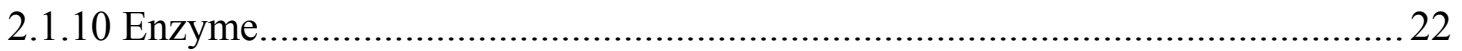

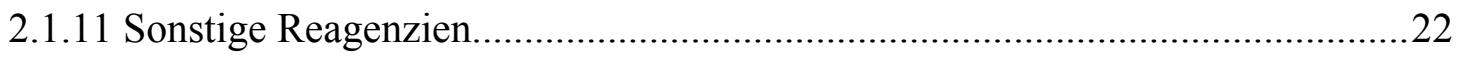

2.1.12 Oligonukleotide (,Primer $\left.{ }^{6}\right)$ für die quantitative Real-time-PCR.....................23

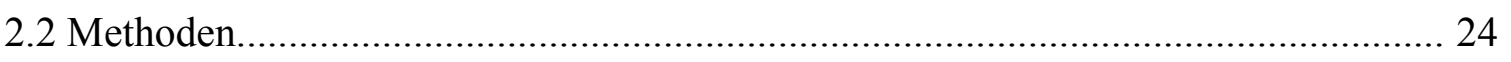

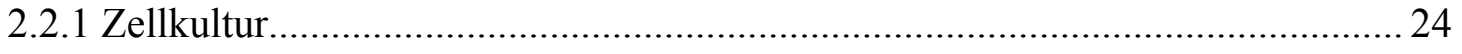

2.2.1.1 Kultivierung und Konservierung der humanen Vorhaut-Fibroblasten........24

2.2.1.2 Kultivierung und Konservierung von BHK- und L929-Zellen................... 25

2.2.1.3 Kultivierung und Konservierung von E. cuniculi....................................25

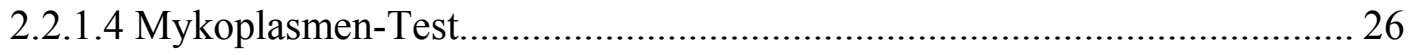


2.2.1.5 Kultur von E. cuniculi in Aminosäure-Mangelmedien.............................27

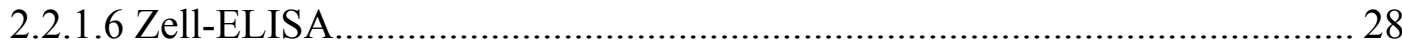

2.2.1.7 Ermittlung der E. cuniculi Sensitivität gegenüber Markierung

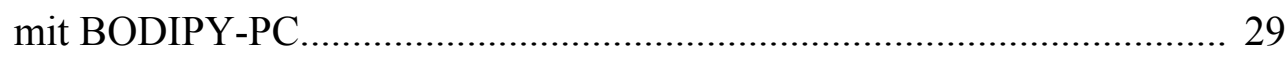

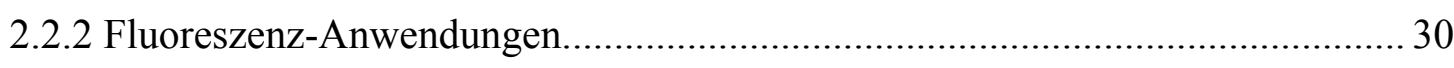

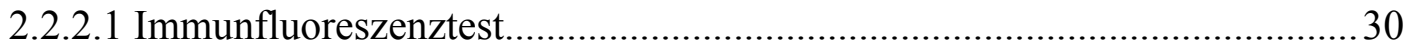

2.2.2.2 Markierung von E. cuniculi mit fluoreszierenden Lipidfarbstoffen.......... 32

2.2.2.3 Markierung von Wirtszellen mit DiIC $_{16}$ und SPEEDY DiO..................... 33

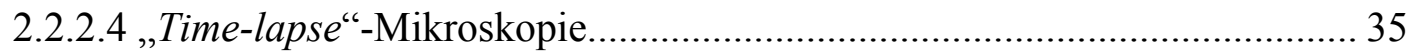

2.2.2.5 Biotinylierung von Wirtszell-Oberflächenproteinen.................................. 36

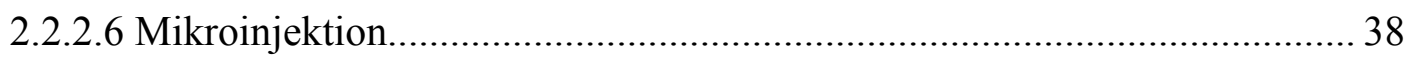

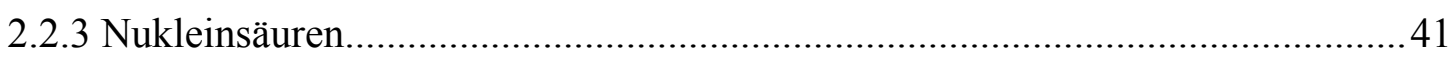

2.2.3.1 RNA-Isolierung aus Encephalitozoon cuniculi........................................ 41

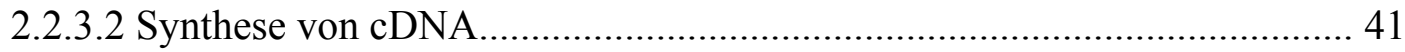

2.2.3.3 Ermittlung der relativen mRNA-Expression mit Hilfe der quantitativen Real-time-PCR ................................................................. 42

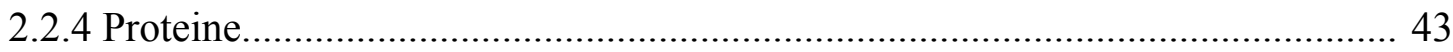

2.2.4.1 SDS-Polyacrylamid-Gelelektrophorese (SDS-PAGE)........................... 43

2.2.4.2 Western Blot-Analyse und Immunfärbung............................................. 44

2.2.4.3 Generierung eines anti-Peptid-Antikörpers............................................. 46

2.2.4.4 Membranfraktionierung von Sporen....................................................... 46

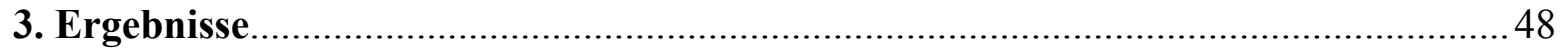

3.1 Die Biogenese der parasitophoren Vakuolenmembran............................................. 48

3.1.1 Herkunft der Lipide für die Bildung der parasitophoren Vakuolenmembran..... 48

3.1.2 Vorkommen von Wirtszell-Oberflächenproteinen in der Vakuolenmembran.... 58

3.2 Die parasitophore Vakuolenmembran enthält Poren................................................ 62

3.2.1 Mikroinjektion in das Cytosol der infizierten Wirtszelle....................................62

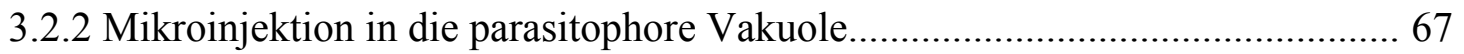

3.2.3 Das E. cuniculi-Hämolysin III als mögliches Poren-bildendes Protein.............. 69

3.3 E. cuniculi ist auf eine externe Versorgung mit Aminosäuren angewiesen.................77

3.3.1 Etablierung eines Wachstumsassays für E. cuniculi........................................ 77

3.3.2 Depletion essentieller Aminosäuren führt zu einer

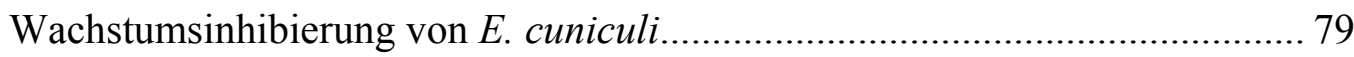


3.3.3 Depletion nichtessentieller Aminosäuren führt zu einer

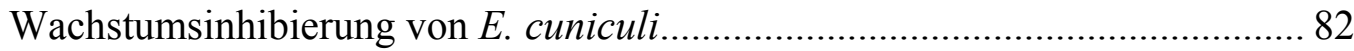

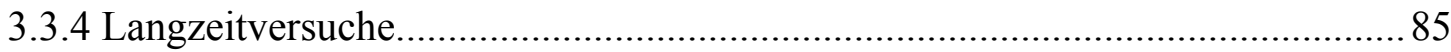

3.3.5 Aminosäure-Mangelbedingungen haben keine Auswirkung auf die

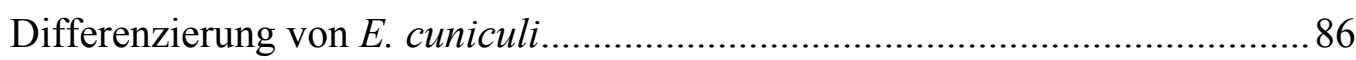

3.3.6 E. cuniculi besitzt für die Aufnahme von Aminosäuren sechs

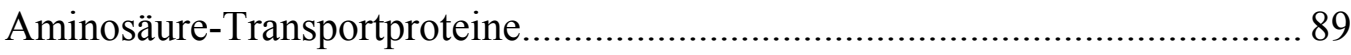

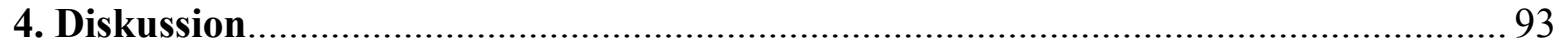

4.1 Die Biogenese der parasitophoren Vakuolenmembran und der

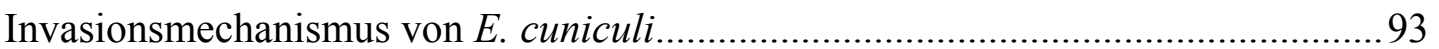

4.2 Die parasitophore Vakuole bildet eine optimale Nische für E. cuniculi.................... 99

4.2.1 Die PVM enthält keine Wirtszell-Oberflächenproteine..................................... 99

4.2.2 Die parasitophore Vakuolenmembran enthält Poren, um Nährstoffe zur Versorgung von E. cuniculi bereitzustellen............................................ 102

4.2.3 Das E. cuniculi-Hämolysin III als mögliches Poren-bildendes Protein.............. 106

4.3 E. cuniculi ist metabolisch in hohem Maße auf seine Wirtszelle angewiesen............. 107

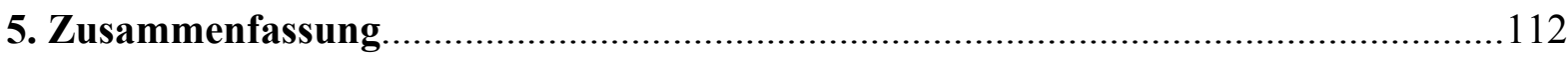

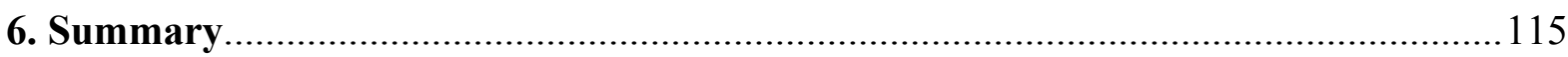

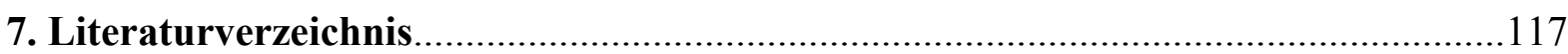




\section{Abbildungsverzeichnis}

Abb. 1.1: Schematische Darstellung des Aufbaus der Mikrosporidienspore ......................7

Abb. 1.2: Schematische Darstellung des Lebenszyklus von E. cuniculi........................... 12

Abb.3.1: Markierung von Sporen mit den lipophilen Fluoreszenzfarbstoffen

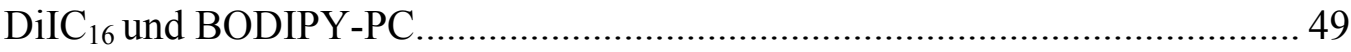

Abb. 3.2: Effekt der BODIPY-PC-Markierung auf die Infektiosität von Sporen...............50

Abb. 3.3: Lipide des injizierten Sporoplasmas tragen nicht zur Biogenese der Vakuolenmembran bei

Abb. 3.4: Strukturformeln von DiIC $_{16}$ und SPEEDY DiO sowie unterschiedliche Sensibilität der Farbstoffe gegenüber Extraktion mit kalter TritonX-100-Lösung..... 52

Abb. 3.5: Raft-Lipide der Wirtszelle tragen zur Biogenese der Vakuolenmembran bei.... 54

Abb. 3.6: Nonraft-Lipide der Wirtszelle tragen zur Biogenese der

Vakuolenmembran bei 55

Abb. 3.7: Untersuchung der Invasion mit Hilfe der „time-lapse“- Mikroskopie.................57

Abb. 3.8: Die entstehende PVM enthält keine Wirtszell-Oberflächenproteine..................59

Abb. 3.9: Statistische Auswertung der Biotinylierung....................................................60

Abb. 3.10: Die E. cuniculi PVM besitzt Poren mit einer Ausschlussgröße von 3-10 kDa...64

Abb. 3.11: Mikroinjektion einer Farbstoffmischung aus Alexa Fluor 488 hydrazide $(0,5 \mathrm{kDa})$ und dem $10 \mathrm{kDa}$ Dextran-Farbstoff. 65

Abb. 3.12: Die Expression der Poren ist unabhängig von Alter oder Größe der Vakuole... 66

Abb. 3.13: „Time-lapse“-Aufnahmen der parasitophoren Vakuole im Phasenkontrast.

Abb. 3.14: Mikroinjektion des 10 kDa Tetramethylrhodamine-Dextran-Farbstoffs in die parasitophore Vakuole. 68

Abb. 3.15: Aminosäuresequenzvergleich des E. cuniculi HlyIII mit einem Hämolysin III von Leifsonia xyli (LxHlyIII)

Abb. 3.16: Sequenz und Transmembranregionen von EcHlyIII.......................................70

Abb. 3.17: Analyse der EcHlyIII-mRNA-Expression mit der quantitativen Real-time-PCR.

Abb. 3.18: Reaktivität der EcHlyIII-Seren von Ratte 2 gegen HFF- und E. cuniculi-Proteine im Western Blot.

Abb. 3.19: Reaktivität des EcHlyIII-Serums nach Affinitätsreinigung gegen Peptid 1 und Peptid 2 im Western Blot.............................................................................. 73

Abb. 3.20: Reaktivität der EcHlyIII-Seren von Ratte 2 in der Immunfluoreszenz. 
Abb. 3.21: Nachweis von EcHlyIII in einer Membranfraktion im Western Blot. 76

Abb. 3.22: Eichkurve zur Etablierung des Zell-ELISAs als Wachstums-Test für E. cuniculi. 78

Abb. 3.23: Einfluss eines Mangels individueller essentieller Aminosäuren auf das Wachstum von E. cuniculi. 80

Abb. 3.24: Einfluss eines Mangels individueller essentieller Aminosäuren auf das Wachstum von E. cuniculi nach Vorinkubation der Wirtszellen in Mangelmedium 81

Abb. 3.25: Empfindlichkeit von E. cuniculi gegenüber verschiedenen TryptophanMangelbedingungen. 82

Abb. 3.26: Einfluss eines Mangels individueller nichtessentieller Aminosäuren auf das Wachstum von E. cuniculi.

Abb. 3.27: Einfluss eines Mangels individueller nichtessentieller Aminosäuren auf das Wachstum von E. cuniculi nach Vorinkubation der Wirtszellen in Mangelmedium. 84

Abb. 3.28: Nachweis von Meronten nach Kultur von E. cuniculi in den Aminosäure-Mangelmedien.

Abb. 3.29: Nachweis von Sporenstadien nach Kultur von E. cuniculi in den Aminosäure-Mangelmedien.

Abb. 3.30: Nach Wachstum in Threonin- und Methionin-freiem Medium zeigen die Sporen starke morphologische Veränderungen .88

Abb. 3.31: Untersuchung der Aminosäure-Transporter auf eine differentielle Regulation..91

Abb. 3.32: Expressionsanalyse der Aminosäure-Transporter in Aminosäure-Mangelmedien.

Abb. 4.1: Schematische Darstellung des modifizierten Invasionsmodells von E. cuniculi. .96 


\section{Tabellenverzeichnis}

Tab. 1.1: Wichtigste humanpathogene Mikrosporidien-Arten sowie Ort

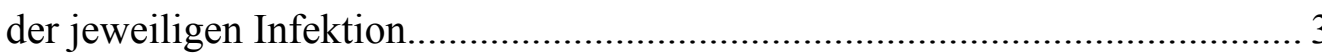

Tab. 2.1: In der Arbeit verwendete Antikörper sowie deren Bezugsquelle

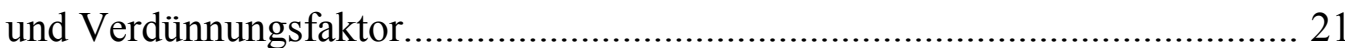

Tab. 2.2: Oligonukleotidsequenzen sowie die dazugehörige Produktgröße und

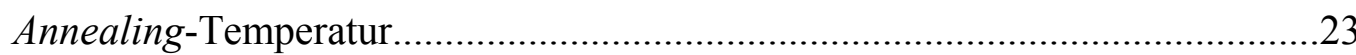

Tab. 2.3: Ansetzen der Aminosäure-Stammlösungen..................................................... 27

Tab. 2.4: Ansetzen der Fluoreszenzfarbstoffe und Peptide für die Mikroinjektion........... 39

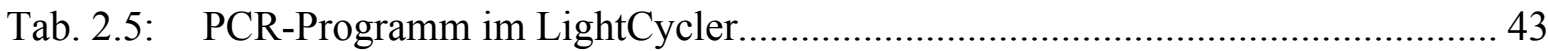

Tab. 3.1: Eigenschaften der für die Mikroinjektion verwendeten Fluoreszenzfarbstoffe und Peptide.

Tab. 3.2: Einfluss verschiedener Aminosäure-Mangelmedien auf die Fähigkeit von E. cuniculi einen HFF-Monolayer zu lysieren. 86

Tab. 3.3: Interne Abkürzung, „NCBI-accession “, „locus identifier “ und allgemeingültiger Name für die 7 Transportproteine .89

Tab. 3.4: Molekülgröße, Anzahl von Transmembranhelices, Vorkommen eines Signalpeptids oder Signalankers und Proteinfamilie der 7 Transportproteine....90 


\section{Abkürzungsverzeichnis}

\begin{tabular}{|c|c|}
\hline Abb. & Abbildung \\
\hline Abs. & Absorption \\
\hline $\mathrm{Ak}$ & Antikörper \\
\hline As. & Aminosäuren \\
\hline ADP & Adenosindiphosphat \\
\hline ATP & Adenosintriphosphat \\
\hline ATPase & Adenosintriphosphatasen \\
\hline $\mathrm{BHK}$ & Baby hamster kidney-Zellen \\
\hline bidest. & doppelt destilliert \\
\hline BODIPY-PC & $\begin{array}{l}\text { 2-(4,4-difluoro-5-methyl-4-bora-3a,4a-diaza-s-indacene- 3- } \\
\text { dodecanoyl)-1-hexadecanoyl-sn-glycero-3-phosphocholine }\end{array}$ \\
\hline bp & Basenpaar \\
\hline BSA & bovine serum albumin \\
\hline bzw. & beziehungsweise \\
\hline${ }^{\circ} \mathrm{C}$ & Grad Celsius \\
\hline ca. & circa \\
\hline cDNA & complementary DNA \\
\hline $\mathrm{cm}^{2}$ & Quadratzentimeter \\
\hline $\mathrm{CO}_{2}$ & Kohlendioxid \\
\hline $\mathrm{cp}$ & crossing point \\
\hline Су2 & Carbocyanin \\
\hline $\mathrm{Cy} 3$ & Indocarbocyanin \\
\hline CytD & Cytochalasin-D \\
\hline dest. & destilliert \\
\hline $\mathrm{DiIC}_{16}$ & 1,1'-Dihexadecyl-3,3,3',3'-tetramethylindocarbocyanine perchlorate \\
\hline DMEM & Dulbecco's Modified Eagles Medium \\
\hline DMSO & Dimethylsulfoxid \\
\hline DNA & Desoxyribonukleinsäure \\
\hline DNase & Desoxyribonuklease \\
\hline dNTP & Desoxynukleosid-5' -triphosphat \\
\hline E.c. & Encephalitozoon cuniculi \\
\hline EDTA & Ethylendiamintetraacetat \\
\hline EEA1 & early endosomal autoantigen 1 \\
\hline ELISA & Enzyme-Linked ImmunoSorbent Assay \\
\hline ER & Endoplasmatisches Retikulum \\
\hline et al. & et alii (und andere) \\
\hline 5-FAM & 5-Carboxyfluorescein \\
\hline FKS & fötales Kälberserum \\
\hline g & Gramm \\
\hline Gesamt. & Gesamtprotein-Fraktion \\
\hline $\mathrm{h}$ & Stunde \\
\hline HEPES & 4-(2-Hydroxyethyl)-1-Piperazin-Ethansulfonsäure \\
\hline HFF & Humane Vorhaut-Fibroblasten \\
\hline IFN $\gamma$ & Interferon- $\gamma$ \\
\hline IFT & Immunfluoreszenztest \\
\hline $\operatorname{IgG}$ & Immunglobulin \\
\hline HlyIII & Hämolysin-III \\
\hline $\mathrm{hPa}$ & Hektopascal \\
\hline Kap. & Kapitel \\
\hline
\end{tabular}




\begin{tabular}{|c|c|}
\hline $\mathrm{kb}$ & Kilobasen \\
\hline $\mathrm{kDa}$ & Kilodalton \\
\hline konj & konjugiert \\
\hline 1 & Liter \\
\hline LAMP1 & lysosomal-associated membrane protein 1 \\
\hline M & molar \\
\hline $\mathrm{mg}$ & Milligramm \\
\hline$\mu \mathrm{g}$ & Mikrogramm \\
\hline $\min$ & Minute \\
\hline $\mathrm{ml}$ & Milliliter \\
\hline $\mathrm{mm}$ & Millimeter \\
\hline$\mu 1$ & Mikroliter \\
\hline $\mathrm{mM}$ & millimolar \\
\hline$\mu \mathrm{M}$ & mikromolar \\
\hline mRNA & messenger RNA \\
\hline $\mathrm{N}$ & normale \\
\hline $\mathrm{Na}$ & Natrium \\
\hline Neg.kontr & Negativkontrolle \\
\hline ng & Nanogramm \\
\hline n. I. & nach Infektion \\
\hline $\mathrm{nm}$ & Nanometer \\
\hline NPP & nichtprofessionelle Phagocyten \\
\hline P. & Pellet \\
\hline PAGE & Polyacrylamidgelelektrophorese \\
\hline PBS & phosphate buffered saline \\
\hline PFA & Paraformaldehyd \\
\hline PCR & Polymerasekettenreaktion \\
\hline Pen/Strep & Penicillin/Streptomycin $(10.000 \mathrm{U} / 10.000 \mu \mathrm{g} / \mathrm{ml})$ \\
\hline PV & parasitophore Vakuole \\
\hline PVM & parasitophore Vakuolenmembran \\
\hline Rel. & Relative \\
\hline RNA & Ribonukleinsäure \\
\hline RNase & Ribonuklease \\
\hline rpm & rotations per minute (Umdrehungen pro Minute) \\
\hline RT & Raumtemperatur \\
\hline SDS & Natriumdodecylsulfat \\
\hline $\sec$ & Sekunde \\
\hline SPEEDY DiO & 3,36-Dilinoleyloxacarbocyanine perchlorate \\
\hline S.pl. & Sporoplasma \\
\hline SWP1 & Sporenwandprotein 1 \\
\hline Tab. & Tabelle \\
\hline TBS & tris buffered saline \\
\hline Tris & Tris(hydroxymethyl)-aminomethan \\
\hline $\operatorname{Trp}$ & Tryptophan \\
\hline Tub. & Tubulus \\
\hline $\mathrm{U}$ & Unit (Einheit für Enzymaktivität) \\
\hline Üs. & Überstand \\
\hline var. & variabel \\
\hline vgl. & vergleiche \\
\hline Vorink. & Vorinkubation \\
\hline z. B. & zum Beispiel \\
\hline
\end{tabular}




\section{Einleitung}

\subsection{Allgemeine Merkmale der Mikrosporidien}

Mikrosporidien sind eine äußerst ungewöhnliche Gruppe obligat intrazellulärer, sporenbildender Eukaryoten, die nach neueren Erkenntnissen zu den Pilzen gehören (Hibbett et al., 2007). Allen Mikrosporidien gemeinsam ist ihr einzigartiger Invasionsmechanismus, sowie eine Anpassung an das intrazelluläre Leben, die vor allem durch eine Reduktion des Metabolismus und der Genomgröße geprägt ist (Keeling und Fast, 2002). Bis heute sind 150 Gattungen mit ca. 1200 Arten bekannt, davon gelten 14 Arten als humanpathogen (Didier und Weiss, 2006). Neben dem Menschen infizieren Mikrosporidien verschiedenste Tiere, darunter sowohl Wirbeltiere als auch Wirbellose. Besonders häufig sind Mikrosporidien jedoch bei Fischen und Insekten zu finden. Mikrosporidien bilden umweltresistente Sporen aus, die als einziges extrazelluläres Stadium der Verbreitung dienen. Die Spore enthält Zellorganellen, die von den typisch eukaryotischen Organellen abweichen, sowie ein um das Sporoplasma aufgewundenes polares Filament, das zum Invasionsapparat gehört.

\subsection{Ursprung und Evolution von Mikrosporidien}

Da ursprünglich angenommen wurde, dass Mikrosporidien keine Mitochondrien enthalten, sie einen atypischen Golgi-Apparat besitzen und die Ribosomen denen der Prokaryoten ähneln, wurden Mikrosporidien eine lange Zeit mit anderen amitochondrialen Organismen wie Giardia und Entamoeba zur Klasse der Archezoa zusammengefasst (Cavalier-Smith, 1983). Die Archezoa wurden als primitive Eukaryoten angesehen, die sich vor dem Erwerb von Mitochondrien entwickelt hatten. Mikrosporidien wurden daher den ursprünglichsten Eukaryoten zugeordnet. Mit der Weiterentwicklung molekularbiologischer Methoden wurden bei verschiedenen mikrosporidialen Genen wie $\alpha$ - und $\beta$-tubulin Homologien zu Pilzsequenzen festgestellt (Edlind et al., 1996; Keeling und Doolittle, 1996). Zusätzlich wurden verschiedene Gene mitochondrialen Ursprungs wie z. B. hsp70 bei Mikrosporidien entdeckt, was darauf hindeutete, dass die Vorfahren der Mikrosporidien Mitochondrien enthielten, und Mikrosporidien diese Organellen entweder verloren hatten, oder sehr stark reduzierte Mitochondrien enthielten (Germot et al., 1997; Hirt et al., 1997). So wurde die Sicht, dass Mikrosporidien ursprüngliche Eukaryoten sind, revidiert. Vielmehr wird heute 
davon ausgegangen, dass Mikrosporidien evolutionär hoch spezialisierte Pilze sind, die durch die Anpassung an den intrazellulären Parasitismus auf verschiedenste Weise reduziert wurden (Keeling und Fast, 2002).

\subsection{Medizinische und Veterinärmedizinische Bedeutung}

Mikrosporidien wurden erstmals im Jahre 1857 als Erreger der Fleckenkrankheit der Seidenspinnerraupe beschrieben (Nägeli, 1857). Seitdem wurden immer mehr Mikrosporidien bekannt, die Krankheiten in wirtschaftlich genutzten Tieren verursachen. Bei Insekten nimmt vor allem Nosema apis, der Erreger der Ruhr bei Honigbienen eine wichtige Stellung ein (Becnel und Andreadis, 1999). Auch in der Fischzucht gibt es diverse Mikrosporidien-Arten, die in Fischen und Krabben vorkommen können (Shaw und Kent, 1999). Encephalitozoon cuniculi war die erste Mikrosporidien-Art, die in Säugetieren (Kaninchen) nachgewiesen wurde (Wright und Craighead, 1922), und ist sowohl in Labortieren wie Mäusen, Ratten und Kaninchen als auch in Haustieren wie Hunden und Meerschweinchen zu finden (Snowden und Shadduck, 1999). Mikrosporidien können jedoch auch Nützlinge sein. Untersuchungen des insektenpathogenen Mikrosporidiums Nosema locustae konnten zeigen, dass Mikrosporidien dieser Art nur Springschrecken (Orthoptera) befallen, so dass N. locustae als mikrobielles Insektizid gegen Heuschrecken eingesetzt wurde (Becnel und Andreadis, 1999). Lange Zeit wurde angenommen, dass Mikrosporidien nur als Erreger von Tieren auftreten. Ende der 50er Jahre erfolgte jedoch die erste zweifelsfreie Dokumentation einer Mikrosporidiose beim Menschen (Matsubayashi et al., 1959). Mikrosporidiosen des Menschen waren bis Mitte der 70er Jahre relativ selten. Mit zunehmender Anzahl immunsupprimierter Individuen, entweder durch AIDS-Erkrankungen oder die Einnahme immunsupprimierender Medikamente, stieg die Zahl der humanen Mikrosporidiosen jedoch deutlich an. Mikrosporidien sind vor allem opportunistische Erreger, die sich eine Immunschwäche des Menschen zu Nutze machen. Es gibt jedoch auch einige Fälle von Mikrosporidiosen bei immunkompetenten Individuen, vor allem bei Kindern und älteren Menschen (Fogla et al., 2005; Wichro et al., 2005). Die 14 humanpathogenen Mikrosporidien-Arten können, je nach Art verschiedenste Krankheitsbilder hervorrufen (siehe Tab. 1.1). Am häufigsten tritt eine chronische Diarrhö mit teilweise starkem Gewichtsverlust verursacht durch Enterocytozoon bieneusi oder Encephalitozoon intestinalis auf (Didier und Weiss, 2006). Erreger der Gattung Encephalitozoon verursachen außerdem häufig 
disseminierte Infektionen mit Befall nahezu aller Organsysteme. Bei E. cuniculi treten besonders häufig Entzündungen der Niere, des Gehirns, der Lunge und des Auges auf (Didier und Weiss, 2006; Orenstein et al., 2005; Kodjikian et al., 2005).

Tab. 1.1: Wichtigste humanpathogene Mikrosporidien-Arten sowie Ort der jeweiligen Infektion (Didier und Weiss, 2006; Weber et al., 1994).

\begin{tabular}{|l|l|}
\hline \multicolumn{1}{|c|}{ Mikrosporidien-Art } & \multicolumn{1}{|c|}{ Ort der Infektion } \\
\hline Enterocytozoon bieneusi & Darm, Gallenwege, Atemwege \\
\hline Encephalitozoon (Septata) intestinalis & $\begin{array}{l}\text { Darm, Gallenwege, Atemwege, Knochen, Haut, } \\
\text { systemisch }\end{array}$ \\
\hline Encephalitozoon hellem & Auge, Atemwege, Harnwege, systemisch \\
\hline Encephalitozoon cuniculi & $\begin{array}{l}\text { systemisch, Auge, Atemwege, Harnwege, Leber, } \\
\text { Bauchfell, Gehirn }\end{array}$ \\
\hline Anncaliia (Nosema) algerae & Auge, Muskeln \\
\hline Vittaforma corneae & Auge, Harnwege \\
\hline Trachipleistophora hominis & Muskeln, Auge \\
\hline Trachipleistophora anthropopthera & systemisch, Auge \\
\hline
\end{tabular}

Verlässliche epidemiologische Daten zur humanen Mikrosporidiose sind bislang vor allem aufgrund unzureichender diagnostischer Methoden relativ selten. Viele Studien wurden außerdem unter HIV-Infizierten durchgeführt, so dass die Zielgruppe nicht zufällig ausgewählt war. Serologische Studien verschiedener Bevölkerungsgruppen ergaben, dass 0 - 38 \% der untersuchten Individuen Antikörper gegen Encephalitozoon spp. besaßen (Bryan und Schwartz, 1999). Bislang ist noch ungeklärt, ob Mikrosporidien in einem latenten Stadium im Menschen persistieren und ob es während zwischenzeitlicher Phasen der Immunsuppression zu einer Reaktivierung der Mikrosporidiose kommen kann (Didier und Weiss, 2006).

Auch die Übertragungswege von Mikrosporidien sind noch nicht vollständig geklärt. Da sowohl für E. cuniculi als auch für E. hellem, E. intestinalis und E. bieneusi ein Tierreservoir vorhanden ist, gelten Erkrankungen mit diesen Mikrosporidien als Zoonose (Mathis, 2000). Neben einer fäkal-oralen Übertragung durch Urin oder Kot erkrankter Tiere können Sporen auch über verunreinigtes Wasser aufgenommen werden. So wurden humanpathogene Mikrosporidien in Flusswasser nachgewiesen (Sparfel et al., 1997). Einige Studien 
dokumentieren sogar den Kontakt mit Fluss- oder Seewasser und das Trinken ungefilterten Leitungswassers als Risikofaktor für das Auftreten einer intestinalen Mikrosporidiose (Watson et al., 1996). Durch eine Bewässerung von Feldfrüchten mit kontaminiertem Wasser ist auch eine Lebensmittelinfektion im Gespräch (Calvo et al., 2004). Einige MikrosporidienArten, besonders E. hellem verursachen besonders häufig respiratorische Erkrankungen. Da E. hellem in Vögeln wie z. B. Wellensittichen und Papageien vorkommt, und Sporen von E. hellem auch im Vogel-Kot nachgewiesen wurden, ist es möglich, dass auch die Inhalation von kontaminierten Aerosolen zur Infektion führen kann (Schwartz et al., 1992). Die in zahlreichen Körperflüssigkeiten nachgewiesenen Sporen weisen außerdem darauf hin, dass auch die Übertragung von Mensch zu Mensch, möglicherweise sogar durch sexuellen Kontakt als Infektionsweg in Frage kommt (Weber et al., 1994; Hutin et al., 1998). Infektionen mit Mikrosporidien, die normalerweise Mücken befallen, deuten darauf hin, dass selbst eine Vektor-vermittelte Übertragung in Betracht gezogen werden kann (Coyle et al., 2004). Eine transplazentale Übertragung wurde bisher nur bei verschiedenen Krallenaffen jedoch noch nie beim Menschen festgestellt (Juan-Salles et al., 2006).

\subsection{Therapie von Mikrosporidien-Infektionen}

Die Therapie von Mikrosporidien-Infektionen, vor allem die Therapie des häufigsten humanpathogenen Erregers E. bieneusi gestaltet sich schwierig. Die heute am meisten genutzten Medikamente sind Albendazol und Fumagillin. Albendazol, das auch gegen Parasitosen mit verschiedenen Würmern eingesetzt wird (Venkatesan, 1998), ist ein Benzimidazolderivat, welches das Wachstum verschiedener Mikrosporidien hemmt (Canning und Hollister, 1991). Durch die Bindung von Albendazol an monomeres $\beta$-Tubulin der Mikrosporidien wird die Mikrotubuli-Polymerisierung und damit die Zellteilung inhibiert (MacDonald et al., 2004). Da das E. bieneusi $\beta$-Tubulin einige Aminosäure-Substitutionen trägt, ist E. bieneusi allerdings resistent gegenüber Albendazol (Akiyoshi et al., 2007). Der Methionin-Aminopeptidase-2-Inhibitor Fumagillin, der auch in der Krebstherapie eingesetzt und durch Aspergillus fumigatus produziert wird, wirkt sowohl gegen Encephalitozoon spp. als auch gegen E. bieneusi. Bei systemischer Verabreichung wirkt Fumagillin allerdings toxisch, so dass die Einnahme häufig problematisch ist.

Für die Entwicklung neuer Medikamente gewinnen auch andere Angriffsziele, wie die ChitinSynthese oder Topoisomerasen an Bedeutung (Zhang et al., 2005; Didier et al., 2005). Das 
Vorkommen von Mikrosporidiosen in HIV-Patienten ist auch bei durchgeführter antiretroviraler Therapie und der damit verbundenen Verbesserung des Immunstatus rückläufig (Wiwanitkit, 2006; Morpeth und Thielman, 2006). Weltweit haben aber nur $80 \%$ der HIV-infizierten Menschen Zugang zu antiretroviraler Therapie (Bartelsman und Veeken, 2007), so dass opportunistische Infektionen wie die Mikrosporidiose auch weiterhin von großer Bedeutung für diese Patientengruppe sind.

\subsection{Aufbau der Spore}

Die meisten Mikrosporidiensporen sind mit einer Größe von $1-3 \mu \mathrm{m}$ x 1,5 - $4 \mu \mathrm{m}$ recht klein (Didier und Weiss, 2006). Es gibt allerdings auch Arten wie Bacillidium filiferum, deren Sporen eine Größe von $40 \mu \mathrm{m}$ erreichen (Vavra und Larsson, 1999). Die Spore, die das einzige extrazelluläre und infektiöse Stadium der Mikrosporidien ist, ist meist oval, kann je nach Art jedoch auch rund, stäbchen- oder sichelförmig sein.

Die Spore ist von einer rigiden, umweltresistenten Sporenhülle, die aus einer Exospore und einer Endospore besteht, umgeben (siehe Abb. 1.1). Die Exospore ist eine elektronenundurchlässige Proteinschicht, die bei den meisten Mikrosporidien eine gleichmäßig strukturierte Oberfläche bildet. Bei einigen aquatischen Arten kann die Exospore auch stark modifiziert sein und verschiedene Anhängsel tragen (Vavra, 1963). Mit Hilfe von hochauflösender Elektronenmikroskopie konnte festgestellt werden, dass die Exospore von Encephalitozoon spp. 25 - $30 \mathrm{~nm}$ dick ist, und ihrerseits aus einer äußeren stacheligen Schicht, einer elektronendurchlässigen Intermediärlamina und einer inneren faserig strukturierten Schicht besteht (Bigliardi et al., 1996).

Die Endospore ist eine elektronendurchlässige Schicht, die aus Chitin und Proteinen aufgebaut ist (Keeling und Fast, 2002). Bei Encephalitozoon spp. besitzt die Endospore eine Dicke von 30 - 35 nm (Bigliardi et al., 1996), in der Region der Ankerscheibe ist sie allerdings häufig nur halb so dick. Die Endospore, die während der Differenzierung zur Spore relativ spät gebildet wird, separiert die reife, metabolisch inaktive Spore vom Cytoplasma der Wirtszelle (Vavra und Larsson, 1999).

Unterhalb der Endospore liegt die Plasmamembran, die das Sporoplasma, das infektiöse Material der Spore umhüllt. Das Sporoplasma enthält entweder einen Nukleus, oder zwei Nuklei, die als Diplokaryon sehr nah aneinander liegen (Vavra und Larsson, 1999). Des Weiteren ist das Sporoplasma mit vielen Ribosomen angereichert (Canning und Lom, 1986). 
Mikrosporidiensporen besitzen keine typisch eukaryotischen Zellorganellen wie GolgiApparat oder endoplasmatisches Retikulum (ER), ihr Sporoplasma wird vielmehr von Strukturen des Invasionsapparates dominiert. Zum Invasionsapparat gehören der Polaroplast, ein polares Filament oder Polartubulus und eine posteriore Vakuole. Der Polaroplast ist aus zwei Teilen, dem lamellaren und dem vesikularen Polaroplasten aufgebaut. Der lamellare Polaroplast befindet sich im anterioren Sporenteil und besteht aus einer Anordnung dicht gepackter lamellenartig angeordneter Membranen. Der posteriore Teil des Polaroplasten ist weniger stark geordnet und daher eher vesikularer Natur (Vavra und Larsson, 1999).

Das polare Filament, der wohl wichtigste Teil des Invasionsapparates, dient der Injektion des infektiösen Sporoplasmas in die neue Wirtszelle. In der reifen Spore bildet das polare Filament eine schlauchartige Struktur mit einem Durchmesser von 0,1-0,2 $\mu \mathrm{m}$, die aus mehreren Membran- und Glykoproteinschichten aufgebaut und von einer Hüllmembran umgeben ist (Vavra und Larsson, 1999). Am anterioren Ende der Spore ist das polare Filament mit einer Ankerscheibe verbunden. Bis zur Hälfte der Spore ist der polare Schlauch gerade und windet sich dann helikal um das Sporoplasma. Die Anzahl der Windungen, ihre relative Anordnung zueinander und der Winkel der einzelnen Windungen ist konserviert, so dass diese Eigenschaften zur Bestimmung einiger Mikrosporidien-Arten genutzt werden können (Sprague et al., 1992). Das Ende des polaren Filaments steht mit der posterioren Vakuole in Kontakt. Ob das polare Filament allerdings bis in die posteriore Vakuole hineinragt, oder nur an der Vakuole endet, konnte bisher noch nicht festgestellt werden (Keeling und Fast, 2002).

In der von einer Membran umgebenen posterioren Vakuole sind viele für Peroxisomen spezifische Enzyme und Bestandteile enthalten. Dies deutet darauf hin, dass die posteriore Vakuole neben der Funktion bei der Sporulation auch als Peroxisom fungiert (Findley et al., 2005).

Mit Hilfe histochemischer Färbemethoden konnten verschiedene Golgi- und ERMarkerenzyme im polaren Filament und im Polaroplasten nachgewiesen werden. Daher wird angenommen, dass der Invasionsapparat während der Differenzierung aus rauem ER und Golgi-Membranen gebildet wird (Takvorian und Cali, 1994; Takvorian und Cali, 1996). 


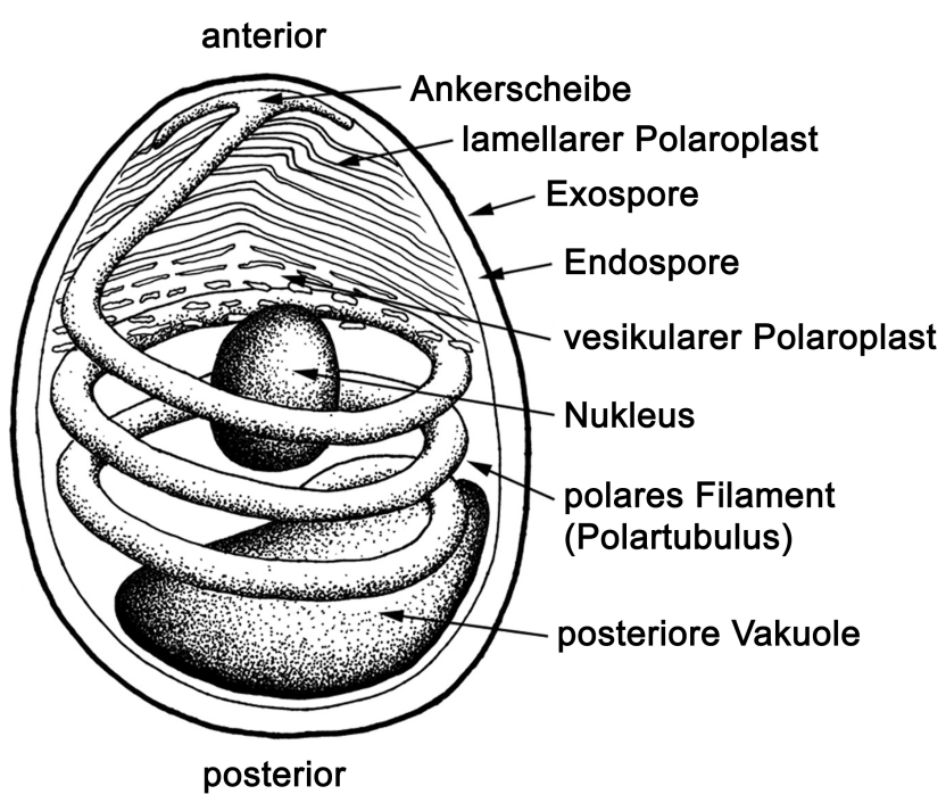

Abb. 1.1: Schematische Darstellung des Aufbaus der Mikrosporidienspore (modifiziert nach Keeling und Fast, 2002).

Neben Ribosomen enthält das Sporoplasma noch kleine, von zwei Membranen umgebene Vesikel, die in früheren Publikationen als polare Vesikel bezeichnet wurden (Vavra, 2005). Mittels eines Antikörpers gegen das mitochondriale HSP70 von Trachipleistophora hominis wurde zum ersten Mal nachgewiesen, das es sich bei diesen Organellen wahrscheinlich um sehr stark rückgebildete Mitochondrien, Mitosomen genannt, handelt (Williams et al., 2002)

\subsection{Invasionsmechanismus}

Die Sporulation der Mikrosporidienspore wird generell in vier Phasen unterteilt, die Aktivierung der Spore, den Anstieg des osmotischen Drucks in der Spore, das Ausschleudern des polaren Filaments und die Passage des Sporoplasmas durch den Polartubulus (Xu und Weiss, 2005). Die Bedingungen, die zu einer Aktivierung der Spore führen, variieren sehr stark zwischen den verschiedenen Arten. In vitro wurden verschiedene physikalische und chemische Reize gefunden, die die Sporulation auslösen, wie pH-Veränderungen, Dehydrierung gefolgt von Rehydrierung, hyperosmotische Bedingungen, die Anwesenheit von Anionen oder Kationen und ultraviolettes Licht (Keohane und Weiss, 1999). In vivo ist vermutlich die Erkennung von Wirtszellen und möglicherweise eine Anheftung an die Wirtszelle wichtig für die Aktivierung der Spore. Neuere Studien mit E. intestinalis zeigen, dass Sporen an sulfatierte Glykosaminoglykane wie Heparin oder Chondroitinsulfat der 
Wirtszelloberfläche binden, und dass die Blockierung dieser Bindestellen zu einer reduzierten Infektionsrate führt (Hayman et al., 2005). Dabei scheint das Sporenwandprotein EnP1, das sowohl in der Endo- als auch in der Exospore vorkommt, und mehrere Heparin-Bindemotive besitzt, eine wichtige Rolle zu spielen (Southern et al., 2007).

Das erste Zeichen, das auf eine Sporulation hindeutet, ist ein generelles Anschwellen der Spore sowie ein Anschwellen des Polaroplasten und der posterioren Vakuole (Lom und Vavra, 1963). Dies ist das Resultat eines Anstiegs des osmotischen Drucks in der Spore (Undeen und Frixione, 1990). Um den Wassereinstrom zu ermöglichen, besitzt die Spore Aquaporine (Ghosh et al., 2006), der genaue Mechanismus, der zur Erhöhung des osmotischen Drucks führt, ist allerdings noch ungeklärt. Bei Nosema algerae wurde festgestellt, dass während der Sporulation der Trehalose-Gehalt der Spore signifikant sinkt (Undeen et al., 1987). Trehalose ist ein Glukose-Glukose-Disaccharid, das als wichtiges Speichermolekül bei Mikrosporidien und anderen Pilzen fungiert (Arguelles, 2000). Durch die Spaltung von Trehalose zu Glukose-Monomeren kommt es zu einem Anstieg löslicher Moleküle in der Spore, was den Einstrom von Wasser und damit die Erhöhung des osmotischen Drucks verursachen könnte (Undeen und Frixione, 1990; Undeen und Vander Meer, 1994). Allerdings konnte die Spaltung von Trehalose während der Sporulation vorwiegend für aquatische, nicht aber für terrestrische Mikrosporidien nachgewiesen werden (Undeen und Vander Meer, 1999). Für Pilze wurde außerdem gezeigt, dass Trehalose weniger als Speichermolekül sondern vielmehr als Anti-Stress-Metabolit dient (Arguelles, 2000). Dies macht es unwahrscheinlich, dass der Trehalose-Abbau die alleinige Ursache für den Anstieg des osmotischen Drucks ist. In einem weiteren Modell wird ein Anstieg der intrazellulären Calcium-Konzentration für den Wassereinstrom verantwortlich gemacht. Durch den Zusammenbruch von Membransystemen der Spore könnten Calcium-Ionen aus intrazellulären Speichern in das Sporoplasma entlassen werden (Keohane und Weiss, 1998). Die hohe Calcium-Konzentration könnte einerseits den Einstrom von Wasser bewirken, und andererseits Enzyme, wie die Trehalase aktivieren. Durch die Spaltung von Trehalose könnte es somit noch zu einem weiteren Anstieg des osmotischen Drucks kommen.

Der hohe osmotische Druck im Inneren der Spore kombiniert mit der Degeneration von Sporoplasma-Membranen führt zum Bruch der Sporenhülle in der Region der Ankerscheibe. Das polare Filament wird explosionsartig aus der Spore geschleudert und erreicht dabei Geschwindigkeiten von $100 \mu \mathrm{m} / \mathrm{sec}$ (Frixione et al., 1992). Elektronenmikroskopische Aufnahmen zeigen, dass das polare Filament in der Spore aus mehreren Schichten besteht. Nach dem Ausschleudern bildet es einen hohlen Tubulus, auch Polartubulus genannt, der je 
nach Mikrosporidien-Art die doppelte oder dreifache Länge des polaren Filaments in der Spore erreicht (Xu und Weiss, 2005). Die Verlängerung des Polartubulus beim Ausschleudern wird vermutlich durch das Material aus dem Inneren des Filaments bewerkstelligt (Weidner, 1972; Weidner, 1976). Möglicherweise funktioniert die Verlängerung wie das Herausziehen eines Fingers aus einem Handschuh (Lom und Vavra, 1963; Ishihara, 1968; Frixione et al., 1992).

Da die Sporulation insgesamt weniger als zwei Sekunden benötigt, und das polare Filament einem Projektil-ähnlich ausgeschleudert wird, gilt ein Modell, bei dem der Polartubulus die Plasmamembran angrenzender Wirtszellen durchschlägt, als allgemein anerkannt (Weidner, 1976; Bigliardi und Sacchi, 2001; Keeling und Fast, 2002; Franzen, 2005). Das Sporoplasma kann so vor den Abwehrmechanismen der Zelle geschützt, direkt in das Cytosol der neuen Wirtszelle injiziert werden (Keeling und Fast, 2002). Elektronenmikroskopische Untersuchungen der Invasion von Nosema michaelis deuten ebenfalls an, dass das polare Filament die Wirtszell-Plasmamembran penetriert (Weidner, 1972). Nach der Passage des Sporoplasmas durch den Polartubulus ist das Sporoplasma bzw. der neu entstandene Meront von einer neuen Plasmamembran umhüllt, die vermutlich aus Polaroplast-Membranen, die durch den Polartubulus gedrückt werden, entsteht (Weidner et al., 1984). Die entleerte Sporenhülle, die nur noch die alte Plasmamembran sowie die Hüllmembran des polaren Filaments enthält, verbleibt extrazellulär (Weidner, 1976). Hat der Polartubulus keine Wirtszelle getroffen, so erscheint das Sporoplasma als Tropfen am distalen Ende des Tubulus (Weidner, 1972).

Einige Studien schlagen eine induzierte Phagocytose von Sporoplasma als Invasionsmodell vor. Elektronenmikroskopische Untersuchungen der Invasion von Encephalitozoon spp. zeigen, dass das ausgeschleuderte polare Filament eine Invagination der Plasmamembran verursacht, und deuten dies als eine phagocytotische Aufnahme des Polartubulus in die Zelle (Magaud et al., 1997; Schottelius et al., 2000; Bigliardi und Sacchi, 2001). Diesem Modell zufolge wird die Phagocytose des Sporoplasmas durch die Wechselwirkung des anterioren Sporenteils oder aber des ausgeschleuderten Polartubulus mit der Wirtszelle ausgelöst. Versuche mit Cytochalasin-D, die zeigen, dass die Invasion von E. intestinalis ein Aktinabhängiger Prozess ist, unterstützen dieses Invasionsmodell (Foucault und Drancourt, 2000). Untersuchungen von E. cuniculi durch die eigene Arbeitsgruppe konnten die Abhängigkeit der Invasion von Aktin allerdings nicht bestätigen. Die Anwesenheit von Cytochalasin-D hat bei E. cuniculi keinen Einfluss auf die Infektionsrate (Orlik, 2007). 


\subsection{Die Sporenphagocytose als zusätzlicher Invasionsmechanismus}

Untersuchungen zur phagocytotischen Aufnahme von E. cuniculi in verschiedene Zellen haben gezeigt, dass intakte, unsporulierte Mikrosporidiensporen auch von nichtprofessionellen Phagocyten (NPP), wie Epithelzellen, Endothelialzellen und Bindegewebszellen phagocytiert werden können (Couzinet et al., 2000). Im Gegensatz zu Makrophagen oder Neutrophilen sind diese Zellen keine professionellen Phagocyten. Es ist jedoch bekannt, dass NPP teilweise in der Lage sind, apoptotische Zellen und einige Organismen über Phagocytose aufzunehmen (Rabinovitch, 1995), für Protozoa konnte dies allerdings noch nicht dokumentiert werden (Couzinet et al., 2000). Nach der Phagocytose der Mikrosporidienspore entwickelt sich das Phagosom sehr schnell zu einem Lysosom weiter (Couzinet et al., 2000; Franzen et al., 2005). Da NPP allerdings keine antimikrobiellen Sauerstoff- oder Stickstoffintermediate produzieren, ist es noch unklar, ob die Spore im Lysosom zerstört werden kann. Die Phagocytose ganzer Sporen könnte daher der erste Schritt für eine Transcytose von Geweben sein, die zu einer Dissemination der MikrosporidienInfektion beitragen könnte (Couzinet et al., 2000). Die Beobachtung, dass phagocytierte Sporen ihren Polartubulus ausschleudern können, führte $\mathrm{zu}$ der Annahme, dass Mikrosporidien die Sporulation nutzen können, um aus dem Lysosom zu entfliehen und sich anschließend im Cytosol der Wirtszelle zu vermehren (Franzen, 2004; Franzen et al., 2005). Eine anschließende Vermehrung konnte bisher allerdings noch nicht gezeigt werden, und auch die Untersuchung der Invasion von E. intestinalis in humane Enterocyten weist der Sporenphagocytose eine eher untergeordnete Rolle zu (Leitch et al., 2005). Untersuchungen der eigenen Arbeitsgruppe zur Sporenphagocytose als alternativem Invasionsmechanismus zeigen ebenfalls eine Phagocytose ganzer Sporen bei verschiedenen nichtprofessionellen Phagocyten. Eine Inhibierung der Sporenphagocytose um $90 \%$ durch Cytochalasin-D hat allerdings keinen Einfluss auf die Infektionsrate, was darauf hindeutet, dass die Sporenphagocytose keinen signifikanten Beitrag zur Infektiosität von E. cuniculi leistet (Orlik, 2007). 


\subsection{Lebenszyklus}

Der Lebenszyklus von E. cuniculi ist ein relativ einfacher asexueller Zyklus (siehe Abb. 1.2), der in eine infektiöse Umweltphase, eine Proliferationsphase (Merogonie) und eine Differenzierungsphase (Sporogonie) unterteilt wird (Cali und Takvorian, 1999). Die Spore ist das extrazelluläre Stadium, das die Wirtszelle mit Hilfe des einzigartigen Invasionsmechanismus (siehe 1.6) infiziert. Einmal in der Zelle wird das Sporoplasma als Meront bezeichnet. Mikrosporidien der Gattung Encephalitozoon besitzen einen einzelnen Zellkern und entwickeln sich in der Wirtszelle in einer parasitophoren Vakuole (PV). Die Meronten vermehren sich durch wiederholte Zweiteilung, teilweise entstehen durch eine verspätete Zellteilung auch perlschnurartige Ketten von Meronten (Vavra und Larsson, 1999). Die metabolisch aktiven Meronten bleiben mit Hilfe einer tight junction-ähnlichen Verbindung mit der parasitophoren Vakuolenmembran (PVM) verbunden, dadurch sind sie immer im äußeren Teil der Vakuole lokalisiert (Weidner, 1975). Der Übergang zur Sporogonie ist durch die Sekretion von Sporenwandmaterial und damit einer Verdickung der Sporenhülle gekennzeichnet. Gleichzeitig verändert sich die Struktur einiger Zellorganellen. Das endoplasmatische Retikulum (ER) wird stärker geordnet, und Ribosomen kommen vermehrt als Polyribosomen, gebunden an das raue ER vor (Vavra und Larsson, 1999). Das nun als Sporont bezeichnete Stadium löst sich von der PVM und die weitere Sporogonie findet im Inneren der Vakuole statt (Vavra und Larsson, 1999). Sporonten durchlaufen eine weitere Phase der Zellteilung, bei der jeweils zwei Sporoblasten entstehen (Cali und Owen, 1988). Sporoblasten differenzieren schließlich zu Sporen. Bei dieser Differenzierung werden die Zellen deutlich verkleinert, der Invasionsapparat wird gebildet und die Chitin-haltige Endospore entwickelt sich. Im letzten Schritt platzt die Vakuole und die reifen Sporen werden aus der Wirtszelle entlassen. Vermutlich gelangen E. cuniculi-Sporen mit dem Kot oder Urin des Wirtstiers in die Umwelt, und können dann einen neuen Wirt infizieren (siehe auch 1.3). 


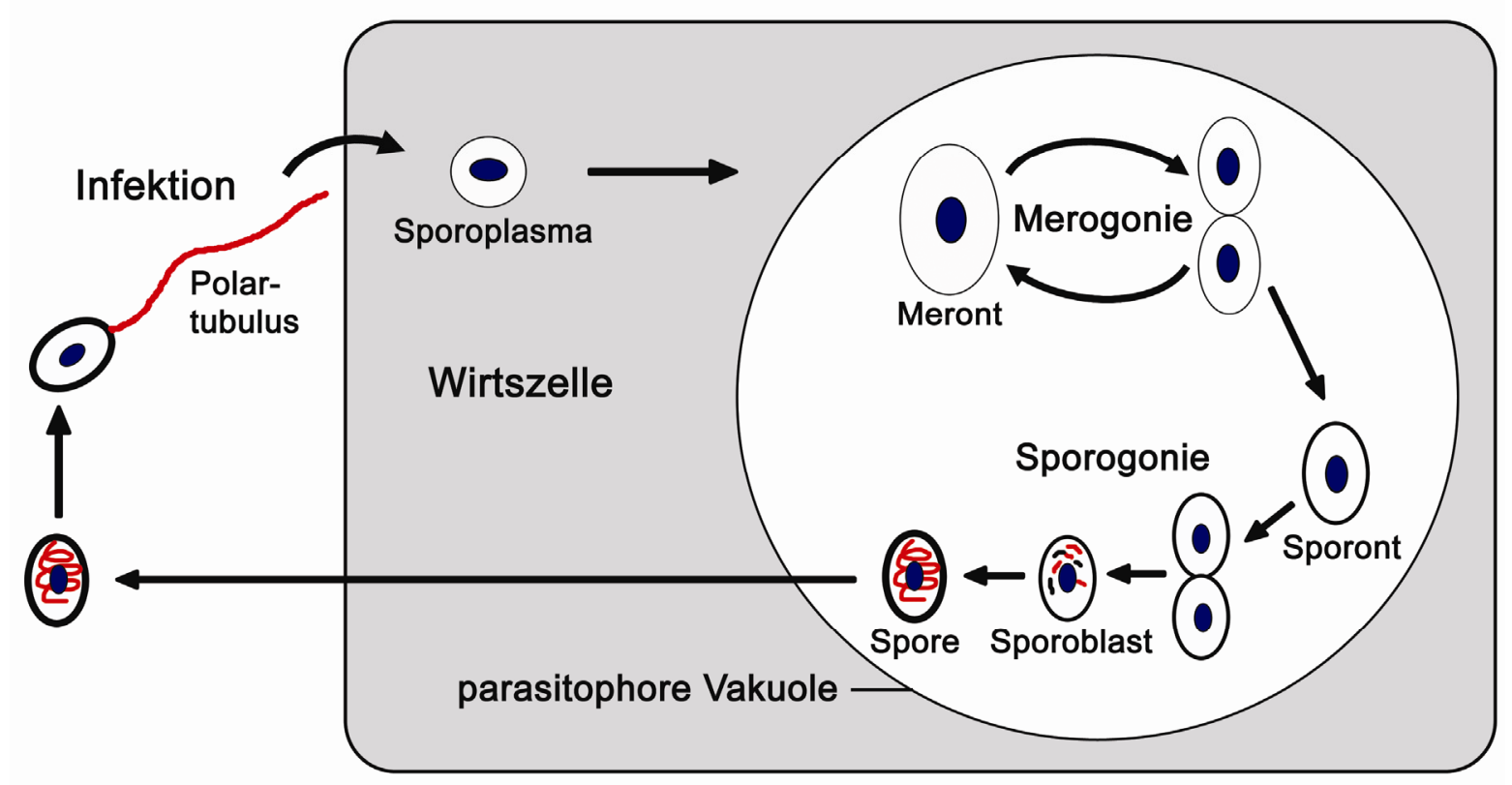

Abb. 1.2: Schematische Darstellung des Lebenszyklus von $\boldsymbol{E}$. cuniculi. Nach Injektion des Sporoplasmas in die Wirtszelle findet die weitere Entwicklung von E. cuniculi in einer parasitophoren Vakuole (PV) statt. Das nun als Meront bezeichnete Stadium durchläuft zunächst mehrere Runden der Zellteilung (Merogonie), bevor die Differenzierung zur Spore (Sporogonie) stattfindet. Schließlich platzt die PV und die reifen Sporen werden frei gelassen. Diese können dann eine neue Wirtszelle infizieren.

Während der Lebenszyklus von E. cuniculi relativ einfach ist, zeigt die Vermehrung einiger anderer Mikrosporidien diverse Besonderheiten. So findet bei etwa 20 MikrosporidienGattungen eine Meiose und damit eine sexuelle Vermehrung statt (Loubes, 1979; Larsson, 1986). Bei E. bieneusi, dem häufigsten humanpathogenen Erreger findet die Kernteilung während der Merogonie ohne eine folgende Zellteilung statt. Dies führt zu der Bildung eines merogonialen Plasmodiums. Die weitere Entwicklung sowie die Anlage des Invasionsapparates findet im Plasmodium statt. Das späte sporogoniale Plasmodium invaginiert schließlich und separiert einzelne Zellkerne voneinander, so dass individuelle Sporoblasten entstehen, die dann zu Sporen reifen (Cali und Takvorian, 1999).

Die Infektion einer Zelle mit Mikrosporidien kann verschiedene morphologische Auswirkungen haben. Ein weit verbreiteter Effekt ist die Vergrößerung der Wirtszelle, sowie des Wirtszell-Nukleus (Weissenberg, 1976). Einige Mikrosporidien entwickeln eine sehr enge Assoziation mit dem Zellkern oder vermehren sich sogar im Zellkern (Sprague et al., 1972; Takizawa et al., 1973; Hendrick, 1991).

Mikrosporidien der Gattung Encephalitozoon scheinen außerdem in der Lage zu sein, den Zellzyklus der Wirtszelle zu unterbrechen (Scanlon et al., 2000) und die Wirtszell-Apoptose zu inhibieren (del Aguila et al., 2006), um das intrazelluläre Überleben zu sichern. 


\subsection{Encephalitozoon cuniculi als Modellorganismus}

Das häufigste humanpathogene Mikrosporidium E. bieneusi kann bislang noch nicht dauerhaft in vitro kultiviert werden (Visvesvara, 2002; Didier und Weiss, 2006). Aufgrund der einfachen Kultivierbarkeit in einer Vielzahl eukaryotischer Zellen hat sich aber E. cuniculi als Modellorganismus für humanpathogene Mikrosporidien etabliert (Tsaousis et al., 2008; Goldberg et al., 2008; Williams et al., 2008). Aus Tieren isolierte E. cuniculi-Präparationen konnten mit Hilfe genetischer und immunologischer Analysen in insgesamt drei Stämme unterteilt werden. Entsprechend ihres natürlichen Wirtes wurden die Stämme rabbit strain (Stamm I), mouse strain (Stamm II) und dog strain (Stamm III) genannt (Didier et al., 1995). Die drei Stämme weisen eine unterschiedliche geographische Verbreitung auf. Während der Maus-Stamm nur in Europa vorkommt, kommt der Kaninchen-Stamm in Europa, Amerika und Australien vor. Der Hunde-Stamm ist nur in Amerika und Süd-Afrika zu finden. Zwei der drei Genotypen, der Kaninchen-Stamm in Europa und der Hunde-Stamm in Amerika verursachen humane Infektionen. Der Maus-Stamm wurde bisher noch nicht im Menschen identifiziert (Mathis, 2000).

Das Genom von E. cuniculi ist vollständig sequenziert und gehört mit einer Größe von ca. 2,9 Millionen Basenpaaren zu den kleinsten bisher bekannten eukaryotischen Genomen (Katinka et al., 2001). Das diploide Genom besteht aus 11 Chromosomen und kodiert für 1997 potentielle Proteine. Die Reduktion des Genoms spiegelt sich nicht nur in der Gesamtgröße sondern auch in weiteren Merkmalen wieder. So existieren im Genom von E. cuniculi nur sehr wenige Introns und Gene werden typischerweise nur von sehr kurzen nicht-kodierenden Bereichen flankiert. Einige E. cuniculi-Gene zeichnen sich außerdem durch eine überlappende Transkription aus, bei der der Transkriptionsstartpunkt im upstream-Gen liegt (Corradi et al., 2008). Selbst die generelle Länge von E. cuniculi-Proteinen ist im Vergleich zu den homologen Proteinen von Saccharomyces cerevisiae reduziert. Im Zuge der Anpassung an die intrazelluläre Lebensweise hat E. cuniculi sehr viele Biosynthesewege verloren, was ebenfalls zur Genomreduktion beigetragen hat. Für die Biosynthese von Aminosäuren besitzt E. cuniculi nur zwei Gene, eine Asparagin-Synthethase und eine SerinHydroxymethyl-Transferase. Gene für die de novo Synthese von Nukleotiden fehlen, ebenso wie der Syntheseweg für Fettsäuren. Daher ist E. cuniculi wahrscheinlich auf die Aufnahme von Fettsäuren von der Wirtszelle angewiesen. Die Gene für die Synthese und Umwandlung von Phospholipiden sind jedoch vorhanden (El Alaoui et al., 2001; Katinka et al., 2001). Da 
E. cuniculi Cholesterin enthält, das Gen für die Umwandlung von Farnesyl-PP in Cholesterin aber fehlt, stammt das E. cuniculi-Cholesterin vermutlich ebenfalls von der Wirtszelle.

Für den katabolen Stoffwechsel besitzt E. cuniculi zwar die Gene für eine vollständige Glykolyse, die Gene für den Zitronensäure-Zyklus, die $\beta$-Oxidation der Fettsäuren und die Elektronentransportkette sowie der $\mathrm{F}_{0} \mathrm{~F}_{1}$-ATPase-Komplex fehlen jedoch. Die ATP-Synthese ist daher nur durch Substratkettenphosphorylierung während der Glykolyse möglich. E. cuniculi besitzt jedoch vier ATP/ADP-Carrier-Proteine, die es wahrscheinlich machen, dass E. cuniculi ATP von der Wirtszelle aufnimmt. Die kürzlich durchgeführte Charakterisierung der ATP/ADP-Carrier deutet ebenfalls auf eine ATP-Aufnahme von der Wirtszelle hin. Alle vier Carrier sind in der Lage, ATP zu transportieren, und drei Carrier sind in der Plasmamembran von E. cuniculi lokalisiert (Tsaousis et al., 2008).

Eine lange Zeit galten Mikrosporidien als ursprüngliche Eukaryoten, die keine Mitochondrien besitzen (siehe auch 1.2). Die Genomsequenz von E. cuniculi kodiert jedoch für mehrere Proteine der Eisen-Schwefel (Fe-S)-Cluster-Synthese, einer essentiellen Funktion von Mitochondrien. Daher wurde die Existenz eines kryptischen Mitochondrions, des so genannten Mitosoms für Mikrosporidien vorgeschlagen (Katinka et al., 2001). Die Lokalisation von mitochondrialem HSP70 in Mitosomen von Trachipleistophora hominis bestätigte die Existenz von Mitosomen bei Mikrosporidien (Williams et al., 2002). Die Funktion des Mitosoms als Ort der Eisen-Schwefel-Cluster-Synthese konnte daraufhin durch die Lokalisation verschiedener Proteine der Fe-S-Cluster-Synthese im Mitosom geklärt werden (Goldberg et al., 2008). Da der vierte ATP-ADP-Carrier von E. cuniculi in den Mitosomen lokalisiert ist, liefert dieser möglicherweise das für die Fe-S-Cluster-Synthese benötigte ATP. Die traditionelle Beziehung zwischen Mitochondrion und Wirt ist bei E. cuniculi daher vermutlich umgedreht. Nicht das Mitosom liefert ATP für E. cuniculi, sondern E. cuniculi versorgt das Mitosom mit ATP (Tsaousis et al., 2008).

\subsection{Ursprung und Eigenschafen der parasitophoren Vakuole}

Die Schnittstelle zwischen Mikrosporidium und Wirtszelle kann bei verschiedenen Mikrosporidien-Gattungen unterschiedlicher Natur sein. Theoretisch sind vier Kategorien möglich, die direkte Vermehrung der Mikrosporidien im Wirtszell-Cytosol und die Abtrennung vom Wirtszell-Cytosol durch eine Hüllmembran, wobei diese von der Wirtszelle, vom Mikrosporidium oder von beiden stammen kann. Auf der Basis von 
elektronenmikroskopischen Aufnahmen ordnete Ann Cali verschiedene MikrosporidienGattungen in diese vier Kategorien ein (Cali, 1971; Cali und Takvorian, 1999).

E. cuniculi gilt als Beispiel für die Gruppe von Vakuolenmembranen mit Wirtszell-Ursprung (Cali, 1986). Das Material für die Bildung der Vakuolenmembran sollte dabei, bedingt durch einen phagocytotischen Aufnahmeprozess, von der Wirtszell-Plasmamembran bzw. von Phagosomen-Membranen stammen (Cali und Takvorian, 1999). Während die meisten Mikrosporidien-Arten der Umhüllung durch eine Vakuolenmembran entgehen können, schien E. cuniculi die Ausnahme zu sein. Eine Vakuole mit Wirtszell-Ursprung wurde bei Mikrosporidien daraufhin als ,parasitophore Vakuole“ definiert (Cali und Takvorian, 1999; Cali, 1971). Die Untersuchung der E. cuniculi-Vakuole mit Ferritin-markierten Endosomen zeigte jedoch sehr bald, dass die PV nicht mit endocytotischen Vesikeln wie Phagosomen und Lysosomen fusioniert (Weidner, 1975). Kolokalisationsstudien der eigenen Arbeitsgruppe zeigten zudem, dass die Vakuolenmembran sowohl direkt nach der Invasion als auch zu späteren Zeitpunkten keine endosomalen oder lysosomalen Wirtszell-Markerproteine enthält. Der Transferrin-Rezeptor, ein häufig verwendeter Marker für frühe Endosomen und die Wirtszell-Oberfläche, Early Endosomal Autoantigen (EEA1) ein Markerprotein für frühe Endosomen, Calnexin, ein Markerprotein für das ER und das lysosomale Markerprotein LAMP1 kommen in der PVM nicht vor (Fasshauer et al., 2005). Auch Texas-Red-ZymosanPartikel, die als Marker für den Phagosomen- und Lysosomen-Inhalt gelten, sind in der E. cuniculi-PV nicht zu finden (Fasshauer et al., 2005). Die E. cuniculi-Vakuole besitzt dementsprechend nicht die typischen Eigenschaften eines Phagosoms. Aufgrund des ungewöhnlichen Invasionsmechanismus von Mikrosporidien und der Abwesenheit von Wirtszell-Markerproteinen in der PVM von E.cuniculi ist der Ursprung der Vakuolenmembran bisher noch ungeklärt.

Elektronenmikroskopische Studien zeigen, dass die Vakuolenmembran schon bei sehr frühen Entwicklungsstadien vorhanden ist (Vavra und Larsson, 1999). Die PVM ist eine Einzelmembran, die mittels einer tight junction-ähnlichen Verbindung an die Plasmamembran der Meronten gebunden ist (Weidner, 1975). Während der Sporogonie löst sich die PVM von der Mikrosporidien-Oberfläche, und Sporoblasten und Sporen liegen frei im Inneren der Vakuole (Vavra und Larsson, 1999). Elektronenmikroskopische Aufnahmen zeigen, dass die PVM sehr viele pinocytotische Vesikel in das Innere der Vakuole abschnürt (Weidner, 1975). Mikrosporidien der Gattung Encephalitozoon sind in der Lage, Wirtszell-Mitochondrien an die PVM zu rekrutieren (Shadduck und Pakes, 1971; Canning und Hollister, 1992), um möglicherweise das ATP der Mitochondrien in die Vakuole zu importieren. Die enge Bindung 
der Mitochondrien an die Vakuolenmembran bleibt unabhängig von einer Behandlung mit Mikrotubuli-Inhibitoren bestehen, so dass ein Protein in der PVM für die Assoziation mit Mitochondrien verantwortlich sein könnte (Scanlon et al., 2004).

Mit Hilfe des pH-sensitiven Farbstoffs BCECF und des Calcium-Sensors Fura-2 konnte gezeigt werden, dass das Lumen der Encephalitozoon-Vakuole die gleiche $\mathrm{H}^{+}$- und $\mathrm{Ca}^{2+}$ Konzentration wie das Wirtszelle-Cytosol aufweist (Leitch et al., 1995). Damit kommt es entsprechend der Fusions-Inkompetenz mit Endosomen und Lysosomen (Weidner, 1975; Fasshauer et al., 2005) zu keiner Ansäuerung der Vakuole, so dass ein Abbau durch lysosomale Enzyme verhindert wird.

\subsection{Zielsetzung der Arbeit}

Mikrosporidien besitzen einen einzigartigen Invasionsmechanismus, bei dem ein als polares Filament bezeichneter Tubulus explosionsartig aus der Spore geschleudert wird. Trifft das polare Filament eine benachbarte Zelle wird das infektiöse Sporoplasma durch den hohlen Tubulus in die neue Wirtszelle injiziert, während die entleerte Sporenhülle extrazellulär verbleibt. Das nun als Meront bezeichnete intrazelluläre Stadium entwickelt sich bei der Gattung Encephalitozoon in einer parasitophoren Vakuole. Eine Untersuchung der parasitophoren Vakuolenmembran (PVM) von Encephalitozoon cuniculi zeigte, dass die PVM keine Wirtszell-Markerproteine wie den Transferrin-Rezeptor, ein Markerprotein für frühe Endosomen und die Zell-Oberfläche enthält (Fasshauer et al., 2005). Aufgrund des einzigartigen Invasionsmechanismus von Mikrosporidien und der Abwesenheit von WirtszellMarkerproteinen in der parasitophoren Vakuolenmembran ist der Ursprung der PVM bisher noch ungeklärt. In dieser Arbeit sollte daher mit Hilfe einer selektiven FluoreszenzMarkierung von Wirtszell- und E. cuniculi-Membranen untersucht werden, ob die PVM von der Wirtszelle oder vom Mikrosporidium selbst stammt. Die mikroskopische Untersuchung der Invasion von E. cuniculi in lebende, Fluoreszenz-markierte Wirtszellen sollte zudem Hinweise auf die molekularen Mechanismen der Invasion geben, die zur Bildung der Vakuolenmembran führen. Neben der Biogenese der PVM sollte die Vakuolenmembran auch hinsichtlich des generellen Vorkommens von Wirtszell-Oberflächenproteinen näher charakterisiert werden.

Im Zuge der Anpassung an die intrazelluläre Lebensweise hat E. cuniculi eine Vielzahl an Biosynthese-Wegen, unter anderem die Biosynthese von Aminosäuren verloren (Katinka et 
al., 2001). Dies deutet auf eine extreme metabolische Abhängigkeit von der Wirtszelle hin. Da Nährstoffe zunächst die PVM passieren müssen, um für E. cuniculi zugänglich zu sein, bildet die parasitophore Vakuolenmembran besonders im Hinblick auf Transport-Prozesse und Metabolit-Austausch eine wichtige Schnittstelle zwischen Mikrosporidium und Wirtszelle. Eine weit verbreitete Ernährungsstrategie intrazellulärer Erreger ist es, in die sie umgebende PVM Poren-Proteine einzulagern (Saliba und Kirk, 2001a). In dieser Arbeit sollte daher eine cytosolische Mikroinjektion Membran-impermeabler Farbstoffe verwendet werden, um zu überprüfen, ob die Vakuolenmembran von E. cuniculi Poren enthält, die einen Metabolit-Austausch mit dem Wirtszell-Cytosol ermöglichen könnten. Um die Abhängigkeit von E. cuniculi von der externen Nährstoffzufuhr näher zu untersuchen, sollte getestet werden, wie das Wachstum bzw. die Differenzierung von E. cuniculi unter AminosäureMangelbedingungen beeinflusst wird. Mit Hilfe einer Genomanalyse sollte zudem ermittelt werden, welche Proteine an der Aufnahme von Aminosäuren beteiligt sein könnten. 


\section{Material und Methoden}

\subsection{Material}

\subsubsection{Wirtszellen und $E$. cuniculi-Stamm}

Humane Vorhaut-Fibroblasten (human foreskin fibroblasts, HFF)

Baby hamster kidney-Zellen (BHK-21)

Murine L929 Fibroblasten

E. cuniculi (Peter Deplazes, Zürich)

\subsubsection{Medien und Medienzusätze für die Zellkultur}

DMEM (Dulbecco’s Modified Eagles Medium) mit 4,5 g/l Glukose, 580 mg/l L-Glutamin, und $3,7 \mathrm{~g} / 1 \mathrm{NaHCO}_{3}$

DMEM (10x) mit 4,5 g/l Glukose, 8 g/l Phenol-Rot ohne $\mathrm{NaHCO}_{3}$, Natrium-Pyruvat und L-Glutamin

DMEM mit 4,5 g/l Glukose, 580 mg/l L-Glutamin, 25 mM HEPES, ohne Phenol-Rot, ohne Natrium-Pyruvat

DMEM modifiziert, mit 3,7 g/1 $\mathrm{NaHCO}_{3}$, ohne D-Glukose, ohne Natrium-Pyruvat, ohne Aminosäuren

Penicillin/ Streptomycin (Pen/Strep), $10.000 \mathrm{U} / 10.000 \mu \mathrm{g} / \mathrm{ml}$

Fötales Kälberserum (FKS); inaktiviert durch 45 min Inkubation bei $56{ }^{\circ} \mathrm{C}$

EDTA (Versen) $1 \%$ in PBS ohne $\mathrm{Ca}^{2+}, \mathrm{Mg}^{2+}$

Trypsin-EDTA $(1 \mathrm{x})$ in HBSS ohne $\mathrm{Ca}^{2+}, \mathrm{Mg}^{2+}$

HEPES, $1 \mathrm{M}$

Natrium-Pyruvat (100 mM)

L-Glutamin, $200 \mathrm{mM}$

Nichtessentielle Aminosäuren (100 x)

Tryptose-Phosphate Broth (1 x)

$\mathrm{NaHCO}_{3}, 7,5 \%$ in PBS

PBS (phosphate buffered saline) 
Das DMEM ohne Phenol-Rot, sowie der Medienzusatz Tryptose-Phosphate Broth wurden von Gibco Invitrogen, Karlsruhe bezogen. Alle anderen Medien und Zusätze stammen von Biochrom, Berlin.

\subsubsection{Verbrauchsmaterialien für die Zellkultur}

Corning Bottle Top Filter, 0,22 $\mu \mathrm{m}$ CA (Cellulose Acetate)

Corning $26 \mathrm{~mm}$ Syringe Filter, 0,2 $\mu \mathrm{m}$ Micron Membran

Die Schälchen für die Mikroinjektion ( $\mu$-Dish 35mm, Katalog-Nr. 80136) wurden von ibidi (Integrated BioDiagnostics, Martinsried) bezogen. Die für die „time-lapse“-Mikroskopie verwendeten 24-Well-Platten mit dünnem Glasboden (Sensoplatte, Katalog-Nr. 662892) stammten von Greiner Bio-One, Frickenhausen. Alle weiteren Verbrauchsmaterialien für die Zellkultur wurden von Corning/ Costar, Bodenheim bezogen.

\subsubsection{Geräte}

Brutschränke

Fluoreszenzmikroskop

Glassbead-Schüttler

Konfokales Laserscan Mikroskop

LightCycler

Magnetrührer

Mikroinjektionsanlage

Mikroskop-Kamera

Mikroskop-Zubehör (,,life-cell imaging“)
Heraeus, Hanau

Modell DM R, Leica, Heidelberg

Axiovert 200M, Zeiss AG, Göttingen

Modell FastPrep FP120, Thermo Savant Bio 101, Langenselbold

Modell TCS SP2, Leica, Heidelberg

Roche, Basel, Schweiz

RCT basic, IKA Labortechnik, Staufen

Mikromanipulator 5171, Eppendorf, Hamburg

Transjektor 5246, Eppendorf, Hamburg

Modell AxioCam MRm, Zeiss AG, Göttingen

XL-3 Incubator, PeCon, Erbach

Tempcontrol 37-2, PeCon, Erbach

$\mathrm{CO}_{2}$-Cover HM, PeCon, Erbach

$\mathrm{CO}_{2}$-Controller, PeCon, Erbach 
Mikrotiterschüttelplatte

pH-Meter

Pipetten

Pipettierhilfe

Photometer

Semi-Dry Elektroblotter

Spannungsgerät

Sterilbank

Thermomixer

Ultrazentrifuge

Vortexer

Waagen

Zellkulturmikroskop

Zentrifugen
Humidifier (3), PeCon, Erbach

Heating Unit, PeCon, Erbach

Modell MTS 4, IKA Labortechnik, Staufen

Modell 766, Calimatic, Knick, Berlin

Modell Research, Eppendorf, Hamburg

Modell Reference, Eppendorf, Hamburg

Hirschmann Laborgeräte, Eberstadt

BioPhotometer, Eppendorf, Hamburg

Sartorius, Göttingen

Standard Power Pack P25, Biometra, Göttingen

BDK-S 1800, BDK Luft- und Reinraum Technik, Sonnenbühl

Modell Compact, Hoefer, San Francisco, CA, USA

Modell Optima LE-80K, Beckmann Coulter, Krefeld

Reax Top, Heidolph, Kelheim

BP 221 S, Sartorius, Göttingen

LP 6200 S, Sartorius, Göttingen

Modell DM IL, Leica, Heidelberg

Megafuge 2.0 RS, Heraeus, Hanau

Megafuge 2.0, Heraeus, Hanau

Modell 5417 R, Eppendorf, Hamburg

\subsubsection{Chemikalien und Reagenzien}

Die im Laufe dieser Arbeit verwendeten Chemikalien und Reagenzien wurden, falls im Text nicht anders erwähnt, von den Firmen Boehringer (Mannheim), Calbiochem (Bad Soden), Merck (Darmstadt), Roth (Karlsruhe) und Sigma-Aldrich (Deisenhofen) bezogen. Alle Chemikalien und Reagenzien wurden soweit nicht anders angeben mit doppelt destilliertem Wasser angesetzt. 


\subsubsection{Fluoreszenzfarbstoffe}

DiIC $_{16}$ (3) [1,1'-Dihexadecyl-3,3,3',3'-tetramethylindocarbocyanine perchlorate] (AnaSpec, San Jose, CA, USA)

SPEEDY DiO [3,3‘-Dilinoleyloxacarbocyanine perchlorate] (AnaSpec, San Jose, CA, USA) $\beta$-BODIPY 500/510 $\mathrm{C}_{12}$-HPC [2-(4,4-difluoro-5-methyl-4-bora-3a,4a-diaza-s-indacene- 3dodecanoyl)-1-hexadecanoyl-sn-glycero-3-phosphocholine] (Molecular Probes, Eugene, OR, USA)

Alexa Fluor 488 hydrazide, sodium salt (Molecular Probes, Eugene, OR, USA)

MFP488 hydrazide, sodium salt (MoBiTec, Göttingen)

Dextran, Alexa Fluor 488; 3,000 MW, anionic (Molecular Probes, Eugene, OR, USA)

Dextran, Tetramethylrhodamine, 10,000 MW, neutral (Molecular Probes, Eugene, OR, USA)

Dextran, Tetramethylrhodamine, 70,000 MW, neutral (Molecular Probes, Eugene, OR, USA)

Hoechst 33258, pentahydrate (bis-benzimide) (Sigma-Aldrich, Deisenhofen)

\subsubsection{Fluoreszenzmarkierte Peptide}

RSR-Carboxyfluorescein (5-FAM) (JPT Peptide Technologies, Berlin)

SGALDVLQ-Carboxyfluorescein (5-FAM) (JPT Peptide Technologies, Berlin)

\subsubsection{Antikörper}

Tab. 2.1: In der Arbeit verwendete Antikörper sowie deren Bezugsquelle und Verdünnungsfaktor.

\begin{tabular}{|l|c|c|}
\hline \multicolumn{1}{|c|}{ Antikörper } & Bezugsquelle & $\begin{array}{c}\text { Verdünnungs- } \\
\text { faktor }\end{array}$ \\
\hline monoklonaler anti-Meronten-Antikörper (6G2) & $\begin{array}{c}\text { Entwicklung der } \\
\text { Arbeitsgruppe }\end{array}$ & $1: 50$ \\
\hline $\begin{array}{l}\text { monoklonaler Sporenwandprotein 1 (SWP1)- } \\
\text { Antikörper }\end{array}$ & $\begin{array}{c}\text { Entwicklung der } \\
\text { Arbeitsgruppe }\end{array}$ & $1: 100$ \\
\hline Ziege anti-Human/Maus-EEA1-IgG & $\begin{array}{c}\text { Santa Cruz Biotechnology, } \\
\text { Santa Cruz, CA, USA }\end{array}$ & $1: 250$ \\
\hline Ziege anti-Human/Maus-LAMP1, polyklonal & $\begin{array}{c}\text { Santa Cruz Biotechnology, } \\
\text { Santa Cruz, CA, USA }\end{array}$ & $1: 25$ \\
\hline
\end{tabular}




\begin{tabular}{|l|c|c|}
\hline \multicolumn{1}{|c|}{ Antikörper } & Bezugsquelle & $\begin{array}{c}\text { Verdünnungs- } \\
\text { faktor }\end{array}$ \\
\hline Cy2-konj. Esel anti-Maus IgG & Dianova, Hamburg & $1: 300$ \\
\hline Cy3-konj. Esel anti-Maus IgG & Dianova, Hamburg & $1: 500$ \\
\hline Cy3-konj. Esel anti-Ziege IgG & Dianova, Hamburg & $1: 1000$ \\
\hline Cy2-konj. Esel anti-Ratte IgG & Dianova, Hamburg & $1: 500$ \\
\hline Peroxidase-konj. Ziege anti-Maus IgG & Dianova, Hamburg & $\begin{array}{c}1: 2000 \\
\text { (Western Blot) }\end{array}$ \\
\hline $\begin{array}{l}\text { Peroxidase-konj. AffiniPure F(ab')2 Fragment } \\
\text { Ziege anti-Maus IgG }\end{array}$ & Dianova, Hamburg & $\begin{array}{c}1: 4000 \\
\text { (Zell-ELISA) }\end{array}$ \\
\hline Peroxidase-konj. Esel anti-Ratte IgG & Dianova, Hamburg & $1: 10.000$ \\
\hline
\end{tabular}

\subsubsection{Reaktionssets (,Kits")}

RNA Isolierung GenElute Mammalian Total RNA Kit (Sigma-Aldrich, Deisenhofen)

DNA Aufreinigung QIAquick PCR Purification Kit (Qiagen, Hilden)

LightCycler-PCR LightCycler FastStart DNA MasterPlus SYBR Green I (Roche, Mannheim)

Enhanced Chemiluminescence (ECL)-Kit

Amersham Biosciences, Freiburg

\subsubsection{Enzyme}

Desoxyribonuklease I (DNase I) (Sigma-Aldrich, Deisenhofen)

M-MLV Reverse Transkriptase RNase H Minus, Point Mutant (Promega, Mannheim)

\subsubsection{Sonstige Reagenzien}

Prestained Protein Marker: 175, 83, 62, 47.5, 32.5, 25, 16.5, 6.5 kDa (New England Biolabs, Frankfurt)

RNase Inhibitor RNasin $40 \mathrm{U} / \mu 1$ (Promega, Mannheim) 


\subsubsection{Oligonukleotide (,Primer ${ }^{6}$ ) für die quantitative Real-time-PCR}

Alle verwendeten Oligonukleotide wurden von Sigma-Genosys, Steinheim synthetisiert.

Tab. 2.2: Oligonukleotidsequenzen sowie die dazugehörige Produktgröße und Annealing-Temperatur.

\begin{tabular}{|c|c|c|c|}
\hline Gen & Sequenz $\left(5^{\circ} \rightarrow 3^{\circ}\right)$ & Produktgröße & $\begin{array}{l}\text { Annealing- } \\
\text { Temperatur }\end{array}$ \\
\hline Act + & TGGGGGATGAGGCACAAACC & \multirow{2}{*}{$317 \mathrm{bp}$} & \multirow{2}{*}{$57^{\circ} \mathrm{C}$} \\
\hline Act- & ACACCCCGTCACCAGAGTCAAAC & & \\
\hline $\mathrm{POR}+$ & ATTCGGCGTAAGCAGCACATA & \multirow{2}{*}{$319 \mathrm{bp}$} & \multirow{2}{*}{$57^{\circ} \mathrm{C}$} \\
\hline POR- & GTCACTTACCGGCACACTCTTCA & & \\
\hline Aatrans1+ & GTCGGGCTTTGCGGATACATTG & \multirow{2}{*}{$246 \mathrm{bp}$} & \multirow{2}{*}{$55^{\circ} \mathrm{C}$} \\
\hline Aatrans 1- & ATCCTCGTTGCTTCCCTCTTTCAT & & \\
\hline Aatrans $2+$ & TCAACATCCAGCTATCTCACACCA & \multirow{2}{*}{$300 \mathrm{bp}$} & \multirow{2}{*}{$55^{\circ} \mathrm{C}$} \\
\hline Aatrans2- & AAGCAAACGGAAAGAAAAACGATA & & \\
\hline Aatrans3+ & CCGACCCTGTGTATGCTTGGAGT & \multirow{2}{*}{$282 \mathrm{bp}$} & \multirow{2}{*}{$55^{\circ} \mathrm{C}$} \\
\hline Aatrans3- & CGCTGTCTTGTCGCTTACCTTCA & & \\
\hline Aatrans4+ & ATAGTGGTCATGGGCGTCTCGTA & \multirow{2}{*}{$271 \mathrm{bp}$} & \multirow{2}{*}{$55^{\circ} \mathrm{C}$} \\
\hline Aatrans4- & GTCCTCTTGGCTTGGTGATGTTTG & & \\
\hline Aatrans5+ & GGCCTTTTCGGATACCTTGTGTTT & \multirow{2}{*}{$247 \mathrm{bp}$} & \multirow{2}{*}{$55^{\circ} \mathrm{C}$} \\
\hline Aatrans5- & TTCTGCTCATCTCCGTCCTTCTCT & & \\
\hline MetPer1+ & GACGGATGGAACTGCGGAAACTAT & \multirow{2}{*}{$288 \mathrm{bp}$} & \multirow{2}{*}{$55^{\circ} \mathrm{C}$} \\
\hline MetPer1- & TCCAGACCCGACAATGAACGAACA & & \\
\hline Oligotrans1+ & TTCATCCTGCTCTTCATTCCACTG & \multirow{2}{*}{$253 \mathrm{bp}$} & \multirow{2}{*}{$55^{\circ} \mathrm{C}$} \\
\hline Oligotrans1- & TCCCGGTCACGTTTAGCATTATTT & & \\
\hline
\end{tabular}




\subsection{Methoden}

\subsubsection{Zellkultur}

Die Anzucht aller eukaryotischen Wirtszellen sowie die Anzucht von E. cuniculi erfolgte bei $37^{\circ} \mathrm{C}$ in einem wasserdampfgesättigten Brutschrank in $5 \% \mathrm{CO}_{2}$-Atmosphäre.

\subsubsection{Kultivierung und Konservierung der humanen Vorhaut-Fibroblasten (HFF)}

Als Wirtszelllinie zur Kultivierung von E. cuniculi wurden standardmäßig humane VorhautFibroblasten (human foreskin fibroblasts, HFF) verwendet. Diese wurden in $175 \mathrm{~cm}^{2}$ (T175) oder $25 \mathrm{~cm}^{2}$ (T25) Zellkulturflaschen bzw. 24-Napf-Zellkulturschalen (24-Well-Platten) kultiviert. Als Medium diente DMEM mit $10 \%$ FKS, $100 \mathrm{U} / \mathrm{ml}$ Penicillin und $100 \mu \mathrm{g} / \mathrm{ml}$ Streptomycin (Pen/Strep). Um die Zellen zu passagieren, wurden sie zunächst mit $1 \%$ EDTA in PBS gewaschen und anschließend mit Trypsin-EDTA vom Boden der Zellkulturflasche abgelöst. Je nach gewünschter Splitrate wurden die Zellen dann in frischem Medium aufgenommen und auf neue Zellkulturflaschen verteilt. Aufgrund der Kontaktinhibierung der HFF konnten diese nach Erreichen der Konfluenz noch ca. 4 Wochen zur Anzucht von E. cuniculi verwendet werden.

Die Konservierung von HFF erfolgte in flüssigem Stickstoff bei $196{ }^{\circ} \mathrm{C}$. Dazu wurden HFFZellen mit einer möglichst geringen Anzahl von Passagen verwendet. Die Zellen einer T175Flasche wurden vom Boden der Zellkulturflasche abgelöst, einmal in frischem Zellkulturmedium gewaschen und in $5 \mathrm{ml}$ Medium resuspendiert. Nach einer Inkubation für 5 min auf Eis wurde ein Volumen Einfriermedium (DMEM + $20 \%$ FKS $+20 \%$ DMSO) zugesetzt. Anschließend wurde die Zellsuspension in $1 \mathrm{ml}$ Aliquots in Kryo-Röhrchen aufgeteilt und über Nacht bei $-80{ }^{\circ} \mathrm{C}$ eingefroren. Am nächsten Tag wurden die Röhrchen in flüssigen Stickstoff überführt. Zum Auftauen wurden die Röhrchen in einem $37{ }^{\circ} \mathrm{C}$ warmen Wasserbad inkubiert und zügig in angewärmtes Zellkulturmedium überführt. Nach Inkubation für $24 \mathrm{~h}$ im Inkubator erfolgte ein Mediumwechsel, um das restliche DMSO aus dem Einfriermedium zu entfernen, da dieses das Wachstum der Zellen beeinträchtigt. 


\subsubsection{Kultivierung und Konservierung von BHK- und L929-Zellen}

BHK (baby hamster kidney)-Zellen wurden in $75 \mathrm{~cm}^{2}$ (T75) Zellkulturflaschen oder 24-WellPlatten in DMEM mit 3 \% FKS, $1 \%$ Glutamin (200 mM), 10 \% Tryptose-Phosphate Broth ( $1 \mathrm{x})$ und $1 \%$ Pen/Strep kultiviert. Nach einer Inkubation von 2 - 3 Tagen waren die Zellen konfluent und wurden mit Hilfe eines Zellschabers vom Boden der Zellkulturflasche gelöst. Je nach Splitrate wurden die Zellen in 15 - $25 \mathrm{ml}$ frischem Medium resuspendiert. Von dieser Zellsuspension wurde $1 \mathrm{ml}$ in eine neue Zellkulturflasche überführt und mit frischem Medium aufgefüllt, der Rest wurde verworfen.

Die Kultur der L929-Maus-Fibroblasten erfolgte in T75-Flaschen oder 24-Well-Platten in DMEM mit Zusatz von $3 \%$ FKS, 1 \% nicht-essentiellen Aminosäuren (100 x), 1 \% NatriumPyruvat (100 mM) und $1 \%$ Pen/Strep. Eine erneute Passage war nach 3 - 4 Tagen notwendig. Dabei wurden die L929-Zellen ähnlich wie die BHK-Zellen mit einem Zellschaber vom Boden der Zellkulturflasche gelöst und mit dem Faktor 1:7 verdünnt.

Für die Konservierung dieser beiden Zelllinien wurden die Zellen vom Boden der Zellkulturflasche abgelöst und die Zellsuspension auf 1 x $10^{7}$ Zellen/ml eingestellt. Nach einer kurzen Inkubation der Zellen auf Eis wurde ein Volumen Einfriermedium aus 40 \% DMEM, 40 \% FKS und 20 \% DMSO zugesetzt, die Zellen in $1 \mathrm{ml}$ Aliquots in KryoRöhrchen aufgeteilt und über Nacht bei $-80{ }^{\circ} \mathrm{C}$ eingefroren. Am nächsten Tag erfolgte der Transfer in den flüssigen Stickstoff. Zur Rekultivierung wurden die Zellen bei $37{ }^{\circ} \mathrm{C}$ aufgetaut, einmal in frischem Medium gewaschen und in angewärmtes Zellkulturmedium überführt. Nach 24 h erfolgte auch bei diesen Zellen ein Mediumwechsel zur Entfernung des DMSO.

\subsubsection{Kultivierung und Konservierung von E. cuniculi}

Als Wirtszellen zur Vermehrung von E. cuniculi dienten standardmäßig HFF-Zellen in T25Flaschen. Diese wurden mit E. cuniculi-Sporen infiziert, wenn sie einen konfluenten Monolayer gebildet hatten. Nach 24 - 48 h wurden die infizierten HFFs einmal mit frischem Medium gewaschen, um im Medium vorhandene weniger infektiöse Sporen zu entfernen. Nach insgesamt 5 - 7 Tagen konnten die Sporen isoliert werden. Dazu wurden die infizierten Zellen mit einem Zellschaber vom Boden der Zellkulturflasche in das Medium gekratzt. Anschließend wurde die Zellsuspension durch Kanülen ( 2 x $0,9 \mathrm{~mm}$ und 2 x $0,45 \mathrm{~mm}$ ) 
passagiert, um die Zellen und die darin enthaltenen Vakuolen aufzubrechen und die Sporen freizusetzen. In einem ersten Zentrifugationsschritt bei $400 \mathrm{U} / \mathrm{min}$ für $10 \mathrm{~min}$ konnten die Wirtszelltrümmer entfernt werden. Das Pelletieren der Sporen erfolgte anschließend bei $2500 \mathrm{U} / \mathrm{min}$ für $20 \mathrm{~min}$. Die Sporen wurden dann einmal in PBS gewaschen, mit Hilfe einer Neubauer-Zählkammer ausgezählt und mit PBS auf 5 x $10^{7}$ Sporen/ml eingestellt. Diese Sporensuspension konnte bei $4{ }^{\circ} \mathrm{C}$ gelagert und ca. 4 Wochen zur Infektion von Zellen verwendet werden. Danach wurde ein neuer Infektionsstock angelegt, um eine gleichbleibende Qualität der Sporen zu gewährleisten.

Zur Infektion von 24-Well-Platten für die Immunfluoreszenz oder den Zell-ELISA wurden die Platten nach Zugabe der Sporen für $5 \mathrm{~min}$ bei $2000 \mathrm{U} / \mathrm{min}$ zentrifugiert. So konnte eine weitestgehend gleichzeitige Infektion der Wirtszellen und ebenfalls eine erhöhte Infektionsrate erreicht werden.

E. cuniculi wurde intrazellulär, mit Hilfe der HFF konserviert. Dazu wurde ein konfluenter Monolayer einer T25-Flasche mit ca. 1,5 x 107 Sporen infiziert. Nach 2,5 Tagen wurden die infizierten HFF auf die gleiche Weise konserviert, wie die nicht infizierten HFF (siehe 2.2.1.1). Für die Rekultivierung wurde die aufgetaute Zellsuspension dann allerdings auf eine semikonfluente T25-Flasche gegeben. So wurde sichergestellt, dass schon freigesetzte Sporen neue Wirtszellen zur Vermehrung nutzen konnten.

\subsubsection{Mykoplasmen-Test}

Um sicherzustellen, dass die Wirtszellen oder E. cuniculi nicht mit Mykoplasmen kontaminiert waren, wurde in regelmäßigen Abständen ein Mykoplasmentest mit HoechstFärbung durchgeführt. Hierzu wurden auf Glasplättchen angewachsene Wirtszellen in 24Well-Platten mit E. cuniculi infiziert und über Nacht bei $37{ }^{\circ} \mathrm{C}$ in DMEM/ $10 \% \mathrm{FKS} / 1 \%$ Pen/Strep im Zellkulturinkubator inkubiert. Nach $24 \mathrm{~h}$ wurden die Zellen zwei Mal mit PBS gewaschen, mit 4 \% Paraformaldehyd (PFA) in PBS für 15 min fixiert und 15 min mit 0,25\% Triton X-100 in PBS permeabilisiert.

Anschließend wurden sie $60 \mathrm{~min}$ mit $100 \mathrm{ng} / \mathrm{ml}$ Hoechst 33258 in PBS inkubiert, drei Mal 10 min mit PBS gewaschen und wie in der Immunfluoreszenzfärbung mit Mowiol eingedeckelt. Der Hoechst 33258-Farbstoff färbt DNA intensiv an und kann durch blaue Fluoreszenz an einem Fluoreszenzmikroskop sichtbar gemacht werden. Da sowohl die DNA der Wirtszellen, als auch der Mikrosporidien und möglicher Mykoplasmen angefärbt wurde, 
konnten mit Mykoplasmen infizierte Zelllinien ausgesondert werden. Diese wurden sofort vernichtet und neue Chargen an Zellen aufgetaut.

\subsubsection{Kultur von E. cuniculi in Aminosäure-Mangelmedien}

Um die Auswirkungen individueller Aminosäure-Mangelbedingungen auf das Wachstum von E. cuniculi zu untersuchen, wurde E. cuniculi in DMEM-Medium, in dem jeweils eine Aminosäure fehlte, kultiviert. Dazu wurde modifiziertes DMEM ohne Aminosäuren, ohne Na-Pyruvat und ohne Glukose (Biochrom, Berlin) bestellt. Die Aminosäuren die normalerweise im DMEM enthalten sind, wurden von Sigma-Aldrich, Deisenhofen bezogen und als individuelle Stammlösungen in Aminosäure-freiem Medium oder in $1 \mathrm{M} \mathrm{HCl}$ angesetzt (siehe Tab. 2.3). Eine Glukose-Stammlösung (225 mg/ml, 50 x) wurde ebenfalls mit DMEM ohne Aminosäuren hergestellt. Zum Lösen wurden die Stammlösungen noch für ca. 30 min bei $37{ }^{\circ} \mathrm{C}$ im Wasserbad inkubiert. Anschließend wurden sie steril filtriert und konnten dann für ca. 3 Wochen bei $4{ }^{\circ} \mathrm{C}$ gelagert werden, bevor neue Stammlösungen hergestellt werden mussten. Um die einzelnen Aminosäure-Mangelmedien anzusetzen, wurden bis auf die Aminosäure, die ausgespart wurde, alle Aminosäuren mit der in Tab. 2.3 genannten Konzentration zugefügt. Zur Kontrolle der Aminosäure-Mangelmedien wurde auch Komplettmedium angesetzt, in dem keine Aminosäure fehlte. So konnte das Wachstum in selbst gemischtem Komplettmedium mit dem in gekauftem Komplettmedium verglichen werden. Neben 4,5 mg/ml Glukose wurde außerdem noch $1 \%$ Na-Pyruvat, $1 \%$ Pen/Strep und $10 \%$ dialysiertes FKS (Biochrom, Berlin) zugegeben. Diese Komponenten wurden vor dem Zusatz ebenfalls steril filtriert.

Tab. 2.3: Ansetzen der Aminosäure-Stammlösungen.

\begin{tabular}{|l|c|c|c|}
\hline \multicolumn{1}{|c|}{ Aminosäure } & $\begin{array}{c}\text { Endkonzentration } \\
\text { im Medium [ng/ml] }\end{array}$ & $\begin{array}{c}\text { Konzentration der } \\
\text { Stammlösung }\end{array}$ & $\begin{array}{c}\text { Stammlösung } \\
\text { angesetzt mit... }\end{array}$ \\
\hline L-Arginin & 84 & $8,4 \mathrm{mg} / \mathrm{ml} \quad(100 \mathrm{x})$ & DMEM ohne As. \\
\hline L-Histidin & 42 & $4,2 \mathrm{mg} / \mathrm{ml} \quad(100 \mathrm{x})$ & DMEM ohne As. \\
\hline L-Isoleucin & 105 & $10,5 \mathrm{mg} / \mathrm{ml} \quad(100 \mathrm{x})$ & DMEM ohne As. \\
\hline L-Leucin & 105 & $10,5 \mathrm{mg} / \mathrm{ml} \quad(100 \mathrm{x})$ & DMEM ohne As. \\
\hline L-Lysin & 146 & $14,6 \mathrm{mg} / \mathrm{ml} \quad(100 \mathrm{x})$ & DMEM ohne As. \\
\hline L-Methionin & 30 & $3 \mathrm{mg} / \mathrm{ml} \quad(100 \mathrm{x})$ & DMEM ohne As. \\
\hline
\end{tabular}




\begin{tabular}{|l|c|c|c|}
\hline \multicolumn{1}{|c|}{ Aminosäure } & $\begin{array}{c}\text { Endkonzentration } \\
\text { im Medium }[\mathrm{ng} / \mathrm{ml}]\end{array}$ & $\begin{array}{c}\text { Konzentration der } \\
\text { Stammlösung }\end{array}$ & $\begin{array}{c}\text { Stammlösung } \\
\text { angesetzt mit... }\end{array}$ \\
\hline L-Phenylalanin & 66 & $6,6 \mathrm{mg} / \mathrm{ml} \quad(100 \mathrm{x})$ & DMEM ohne As. \\
\hline L-Threonin & 95 & $9,5 \mathrm{mg} / \mathrm{ml} \quad(100 \mathrm{x})$ & DMEM ohne As. \\
\hline L-Tryptophan & 16 & $1,6 \mathrm{mg} / \mathrm{ml} \quad(100 \mathrm{x})$ & DMEM ohne As. \\
\hline L-Valin & 94 & $9,4 \mathrm{mg} / \mathrm{ml} \quad(100 \mathrm{x})$ & DMEM ohne As. \\
\hline Glycin & 30 & $3,0 \mathrm{mg} / \mathrm{ml} \quad(100 \mathrm{x})$ & DMEM ohne As. \\
\hline L-Serin & 42 & $4,2 \mathrm{mg} / \mathrm{ml} \quad(100 \mathrm{x})$ & DMEM ohne As. \\
\hline L-Cystein & 48 & $48 \mathrm{mg} / \mathrm{ml} \quad(1000 \mathrm{x})$ & $1 \mathrm{M} \mathrm{HCl}$ \\
\hline L-Tyrosin & 72 & $72 \mathrm{mg} / \mathrm{ml} \quad(1000 \mathrm{x})$ & $1 \mathrm{M} \mathrm{HCl}$ \\
\hline L-Glutamin & 580 & $29 \mathrm{mg} / \mathrm{ml} \quad(50 \mathrm{x})$ & DMEM ohne As. \\
\hline
\end{tabular}

Um die Auswirkungen des Aminosäuremangels auf E. cuniculi zu untersuchen, wurden konfluente HFF-Wirtszellen in 24-Well-Platten mit sterilem PBS gewaschen. Der Austausch des HFF-Zellkulturmediums gegen Aminosäure-Mangelmedium erfolgte entweder 3 Tage vor Infektion, oder zeitgleich mit der E. cuniculi-Infektion. Das Wachstum von E. cuniculi unter individuellen Aminosäure-Mangelbedingungen wurde daraufhin mit einem Zell-ELISA (siehe 2.2.1.6) untersucht.

\subsubsection{Zell-ELISA}

Bei einem Zell-ELISA (Enzyme-linked Immunosorbent Assay) wird eine Nachweisreaktion auf einem Monolayer von Zellen durchgeführt. Die Nachweisreaktion für E. cuniculi basiert dabei auf zwei monoklonalen Maus-Antikörpern, die alle Stadien der Mikrosporidien erkennen, und einer Peroxidase-Enzymreaktion.

Um das Wachstum von E. cuniculi zu messen, wurden HFF-Zellen in 24-Well-Platten ausgesät und bei Konfluenz mit E. cuniculi infiziert. Der Zell-ELISA wurde standardmäßig nach 64 h durchgeführt. Die HFF-Zellen wurden zu Versuchsbeginn für 15 min mit 4 \% PFA in TBS fixiert, kurz mit TBS gewaschen und anschließend mit 0,25\% TritonX-100 in TBS für 15 min permeabilisiert. Nach einer kurzen Inkubation in TBS erfolgte die Blockierung unspezifischer Bindestellen mit $1 \%$ BSA in TBS für $1 \mathrm{~h}$ bei RT. Für die Antikörperinkubation wurden der Meronten-spezifische Antikörper 6G2 und der Sporenwandprotein 1 (SWP1)-Antikörper zusammen in $1 \%$ BSA/ TBS auf die Zellen 
gegeben und für $1 \mathrm{~h}$ bei RT inkubiert. Nicht gebundene Primärantikörper wurden durch ein dreimaliges Waschen in TBS entfernt, woraufhin die Inkubation mit dem Peroxidase-antiMaus-Sekundärantikörper in $1 \% \mathrm{BSA} / \mathrm{TBS}$ für $1 \mathrm{~h}$ bei RT folgte. Anschließend wurden die Wells erneut drei Mal für 5 min mit TBS gewaschen, bevor die Enzymreaktion durchgeführt werden konnte. Während der letzten Waschschritte wurde die benötigte o-PhenylenediaminDihydrochlorid (OPD)-Substratlösung hergestellt, indem eine OPD- und eine Puffer-Tablette des SIGMAFAST ${ }^{\text {тм }}$ OPD Tablet-Sets (Sigma-Aldrich, Deisenhofen) in $20 \mathrm{ml}$ destilliertem Wasser gelöst wurden. Pro Well wurde daraufhin $1 \mathrm{ml}$ der Substratlösung zugegeben und die Ansätze bis zu einer deutlichen Gelbfärbung ( $20 \mathrm{~min})$ bei RT inkubiert. Nach dieser Inkubation wurde die Substratlösung aus den Wells in Eppendorf-Gefäße gefüllt, und für 2 min bei $12.000 \mathrm{U} / \mathrm{min}$ zentrifugiert, um mögliche Zelltrümmer, die die photometrische Messung beeinflussen könnten, zu entfernen. Um die Enzymreaktion schließlich abzustoppen, wurden $500 \mu \mathrm{l} 4 \mathrm{~N} \mathrm{H}_{2} \mathrm{SO}_{4}$ als Stoppreagenz in eine Küvette vorgelegt, und mit $800 \mu \mathrm{l}$ der abzentrifugierten Substratlösung vermischt. Dabei wechselte die Farbe der Substratlösung von gelb nach orange. Die Auswertung erfolgte schließlich durch photometrische Messung bei $492 \mathrm{~nm}$.

\author{
TBS (tris buffered saline) \\ $20 \mathrm{mM}$ Tris- $\mathrm{HCl}, \mathrm{pH} 7,5$ \\ $150 \mathrm{mM} \quad \mathrm{NaCl}$
}

\title{
2.2.1.7 Ermittlung der E. cuniculi Sensitivität gegenüber Markierung mit BODIPY-PC
}

Um die Sensitivität von E. cuniculi gegenüber der Markierung mit dem Phospholipid $\beta$ BODIPY 500/510 C 12 -HPC (BODIPY-PC) zu bestimmen, wurde die Infektiosität der Sporen nach Farbstoffbehandlung überprüft. Dazu wurden die Sporen wie unter 2.2.2.2 beschrieben, mit $0 \mu \mathrm{M}, 25 \mu \mathrm{M}, 50 \mu \mathrm{M}$ und $100 \mu \mathrm{M}$ BODIPY-PC markiert, mehrmals mit PBS gewaschen und schließlich auf eine Konz. von 1 x $10^{8}$ Sporen/ml eingestellt. Daraufhin wurden HFFZellen, die konfluent auf Deckgläschen in 24-Well-Platten gewachsen waren, mit $1 \times 10^{6}$ Sporen/Well infiziert. Die Platten wurden dann kurz geschüttelt und schließlich bei $2000 \mathrm{U} / \mathrm{min}$ für $5 \mathrm{~min}$ abzentrifugiert, um eine gleichzeitige Infektion in den jeweiligen Wells zu erreichen. Nach 24 h Inkubation im Brutschrank wurden die Zellen mit 4 \% PFA in PBS fixiert, und zum besseren Nachweis der Vakuolen wurde eine Immunfluoreszenzfärbung mit dem Meronten-spezifischen Antikörper 6G2 (siehe 2.2.2.1) durchgeführt. Zur Auswertung 
wurde die Anzahl der entstandenen Vakuolen pro Gesichtsfeld ausgezählt. Dabei wurden auf jeweils 2 Deckgläschen mindestens 10 Gesichtsfelder ausgezählt. Um die Sensitivität von E. cuniculi gegenüber der Farbstoffmarkierung darzustellen, wurde schließlich die jeweilige durchschnittliche Anzahl an Vakuolen pro Gesichtsfeld gegen die BODIPY-PCKonzentration aufgetragen.

\subsubsection{Fluoreszenz-Anwendungen}

\subsubsection{Immunfluoreszenztest}

Um einen Immunfluoreszenztest durchzuführen, wurden zunächst Wirtszellen in 24-WellPlatten, die mit Deckgläschen (Durchmesser $13 \mathrm{~mm}$ ) ausgelegt waren, ausgesät. Dabei wurde bei HFF mit einem konfluenten Monolayer gearbeitet, während BHK- oder L929-Zellen nur in semikonfluentem Zustand verwendet wurden. Die Zellen wurden mit Sporen infiziert, und die Infektion nach Ablauf der gewünschten Inkubationszeit gestoppt. Dazu wurden die Deckgläschen einmal mit PBS (1 x) gewaschen, um nicht sporulierte Sporen zu entfernen, und anschließend mit $4 \%$ Paraformaldehyd (PFA) in PBS für 15 min fixiert. Nach einem erneuten Waschschritt mit PBS erfolgte die Permeabilisierung der Zellen mit 0,25\% TritonX100 in PBS für 20 min, um die Zellmembranen für die Antikörper durchlässig zu machen. Zur Blockierung von unspezifischen Bindestellen erfolgte dann eine Inkubation der Proben in $1 \%$ BSA in PBS für $1 \mathrm{~h}$. Nach einem kurzen Waschschritt in PBS wurden die Deckgläschen dann für $1 \mathrm{~h}$ mit dem ersten Antikörper inkubiert. Dieser wurde dazu in der $1 \%$ igen BSA/ PBS Lösung entsprechend den Angaben des Herstellers verdünnt. Zur Entfernung von nicht gebundenen Antikörpern wurden die Proben dann 3 x für jeweils 5 min mit PBS gewaschen. Daraufhin erfolgte die Inkubation mit einem geeigneten fluoreszenzgekoppelten Sekundärantikörper, welcher ebenfalls in $1 \%$ BSA/ PBS entsprechend den Angaben des Herstellers verdünnt wurde. Da der Sekundärantikörper gegen den Primärantikörper gerichtet ist, kommt es während dieser einstündigen Inkubation zu einer Bindung des Sekundärantikörpers an den Primärantikörper. Es folgten erneut drei Waschschritte für jeweils $5 \mathrm{~min}$ in PBS, um überschüssigen Antikörper zu entfernen. Anschließend wurden die Deckgläschen mit einer Pinzette aus den Wells gehoben, kurz in entmineralisiertes Wasser getaucht, und mit $10 \mu \mathrm{l}$ Moviol auf einen Objektträger aufgebracht. Dabei wurde die Seite der Deckgläschen, die mit den Zellen beschichtet war, nach unten gedreht, so dass die Zellen in 
den Tropfen mit Moviol eingebettet wurden. Nach dem Trocknen des Moviols erlaubte diese Einbettung eine Lagerung der Deckgläschen für ca. 3 Wochen im Dunkeln bei $4{ }^{\circ} \mathrm{C}$. Da der Sekundärantikörper an einen Fluoreszenzfarbstoff gekoppelt ist, kann die Lokalisation des Primärantikörpers bzw. des Antigens nun mit Hilfe eines Fluoreszenzmikroskops analysiert werden.

Da einige Antikörper nicht in Kombination mit einer PFA-Fixierung funktionieren, wurde in diesen Fällen eine Fixierung mit eiskaltem Aceton, Methanol oder $100 \%$ Ethanol für 10 min bei $-20{ }^{\circ} \mathrm{C}$ durchgeführt. Bei der Fixierung mit diesen organischen Lösungsmitteln entfiel die Permeabilisierung.

Bei Zellen, die zuvor mit fluoreszierenden Lipiden gefärbt wurden, wurde für den Immunfluoreszenztest ein alternatives Permeabilisierungs-Protokoll verwendet, um eine starke Auswaschung der Lipide zu verhindern. Dieses Protokoll kam auch bei der Markierung der Wirtszell-Oberflächenproteine mit Biotin zum Einsatz. Bei diesen Versuchen folgte nach der Fixierung für 15 min mit 4 \% PFA/ PBS und einem kurzen Waschschritt eine Inkubation in $0,3 \mathrm{mg} / \mathrm{ml}$ Saponin, 1 \% BSA/ PBS für $1 \mathrm{~h}$, so dass die Permeabilisierung und Blockierung gleichzeitig erreicht wurde. Da die Permeabilisierung mit Saponin jedoch reversibel ist, wurde die Konzentration von $0,3 \mathrm{mg} / \mathrm{ml}$ Saponin in allen folgenden Lösungen beibehalten. Folglich diente PBS mit $0,3 \mathrm{mg} / \mathrm{ml}$ Saponin als Waschlösung, während die Inkubation mit den Antikörpern in 0,3 mg/ml Saponin, $1 \%$ BSA/ PBS durchgeführt wurde. Nach den finalen Waschschritten wurden die Deckgläschen mit der Zellseite nach unten auf den Objektträger gelegt und anschließend mit Nagellack umpinselt. Eine Verwendung von Moviol wurde bei diesen Versuchen vermieden, da das in der Moviol-Lösung enthaltenen Glycerol die Lokalisation von Lipiden in fixierten Zellen beeinflussen kann.

Um DNA bzw. den Zellkern zu markieren, konnte im Anschluss an eine Immunfärbung noch eine Hoechst-Färbung durchgeführt werden. Dazu wurden die Proben nach den drei letzten Waschschritten für $30 \mathrm{~min}$ mit $100 \mathrm{ng} / \mathrm{ml}$ Hoechst 33258-Farbstoff in PBS bei RT inkubiert. Überschüssiger Farbstoff wurde daraufhin mit PBS weggewaschen, bevor die Deckgläschen auf die Objektträger aufgebracht wurden. 
$\underline{\text { Moviol }}$

$\begin{array}{rl}2,4 \mathrm{~g} & \text { Moviol 4-88 } \\ 6,0 \mathrm{~g} & \text { Glycerol } \\ 6 \mathrm{ml} & \mathrm{H}_{2} \mathrm{O} \text { bidest. } \\ 12 \mathrm{ml} & 0,2 \mathrm{M} \text { Tris-HCl, } \mathrm{pH} 8,5\end{array}$

Bei $4{ }^{\circ} \mathrm{C}$ rühren, bis eine klare Lösung entsteht,

Inkubation bei $50^{\circ} \mathrm{C}$ für $10 \mathrm{~min}$,

Zentrifugation für $15 \mathrm{~min}, 5000 \mathrm{xg}$

Überstand aliquotieren und bei $-20^{\circ} \mathrm{C}$ lagern.

\subsubsection{Markierung von $E$. cuniculi mit fluoreszierenden Lipidfarbstoffen}

Zur Markierung intrazellulärer Membranen von E. cuniculi sollten das fluoreszierende Phospholipid $\beta$-BODIPY 500/510 $\quad \mathrm{C}_{12}$-HPC (BODIPY-PC), sowie die lipophilen Carbocyanin-Farbstoffe DiIC 16 und SPEEDY DiO ausgetestet werden.

Das fluoreszierende Phospholipid BODIPY-C ${ }_{12}$-Phosphocholine wurde für die Markierung von E. cuniculi ausgewählt, da Phosphocholine eines der häufigsten Phospholipide innerhalb von E. cuniculi Membranen ist (El Alaoui et al., 2001). BODIPY-PC wurde zunächst in $100 \%$ Ethanol gelöst, so dass eine Stammlösung mit einer Konzentration von $10 \mathrm{mM}$ entstand. Um ein Verdampfen der Lösung zu verhindern, wurde das Probengefäß immer gut mit Parafilm verschlossen, und bei $-80{ }^{\circ} \mathrm{C}$ gelagert. Die Färbung wurde aufgrund der geringen Gesamtmenge an Farbstoff und der gleichzeitig hohen erforderlichen Konzentration in kleinem Maßstab in den Kammern eines Lab-Tec-Objektträgers (8 Kammersystem) (Nunc, Roskilde, Dänemark) durchgeführt. Dazu wurden zunächst HFF in die Kammern ausgesät. Bei Konfluenz erfolgte die Infektion mit 2,5 x $10^{5}$ Sporen pro Kammer. Nach $48 \mathrm{~h}$ wurden die Kammern jeweils zwei Mal mit frischem Medium gewaschen, anschließend erfolgte der Austausch des Mediums gegen Medium mit $100 \mu \mathrm{M}$ BODIPY-PC. Das Fluoreszenzmarkierte Phospholipid konnte in der folgenden Inkubation dann von den Wirtszellen und den Mikrosporidien aufgenommen und in Membranen integriert werden. Nach weiteren 3 Tagen, insgesamt $120 \mathrm{~h}$ nach der Infektion, konnten die Fluoreszenz-markierten Sporen geerntet werden. Dazu wurde das Phospholipid-haltige Medium entfernt und gegen PBS ausgetauscht. Die HFF in der Kammer wurden dann mit Hilfe einer gelben Pipettenspitze unter mikroskopischer Kontrolle vom Boden des Lab-Tec-Objektträgers gekratzt und die darin 
enthaltenen Sporen wurden wie unter 2.2.1.3 beschrieben aus den Wirtszellen befreit. Nach dem Abtrennen von Wirtszelltrümmern durch Zentrifugation bei $400 \mathrm{U} / \mathrm{min}$ wurden die Sporen bei $2500 \mathrm{U} / \mathrm{min}$ für $20 \mathrm{~min}$ abzentrifugiert. Um noch enthaltenes BODIPY-PC zu entfernen, wurden die Sporen 2 - 3 mal in einem großen Volumen PBS gewaschen, ausgezählt und in ca. $60 \mu \mathrm{l}$ PBS aufgenommen. Für die anschließende Infektion von HFF auf Deckgläschen in 24-Well-Platten wurden ca. 1,25 x 106 Sporen/Well verwendet.

Um E. cuniculi mit den Carbocyanin-Farbstoffen zu markieren, wurden zunächst FarbstoffStammlösungen der Konzentration $1 \mathrm{mM}$ angesetzt. Die DiIC 16 -Stammlösung wurde in $100 \%$ Ethanol angesetzt, während SPEEDY DiO mit Hilfe von Ultraschall und Erhitzung $\left(50{ }^{\circ} \mathrm{C}\right)$ in Dimethylformamid (DMF) gelöst wurde. Als Wirtszellen dienten HFF, die in 24Well-Platten ausgesät wurden. Nachdem die Zellen einen konfluenten Monolayer gebildet hatten, erfolgte die Infektion mit E. cuniculi und zunächst eine weitere Inkubation für $48 \mathrm{~h} \mathrm{im}$ Brutschrank. Nachdem die Mikrosporidien angewachsen waren, wurden die Wells mit frischem Medium gewaschen, und das Medium gegen Medium mit $4 \mu \mathrm{M} \mathrm{DiIC}_{16}$ oder SPEEDY DiO ausgetauscht. Während der folgenden 3 tägigen Inkubation konnten die Sporen die Farbstoffe über die Wirtszelle aufnehmen und in intrazelluläre Membranen integrieren. Nach insgesamt $120 \mathrm{~h}$ wurden die Sporen wie unter 2.2.1.3 isoliert, mehrmals in PBS gewaschen und für die Infektion neuer Wirtszellen verwendet.

\subsubsection{Markierung von Wirtszellen mit DiIC 16 und SPEEDY DiO}

Die Markierung von Wirtszellen mit DiIC 16 und SPEEDY DiO wurde, analog zu dem von Charron und Sibley beschriebenen Protokoll durchgeführt (Charron und Sibley, 2004). Dazu wurden BHK-Zellen $24 \mathrm{~h}$ vor dem Versuch semikonfluent in 24-Well-Platten auf Deckgläschen mit einer Zelldichte von 7 x $10^{4}$ Zellen/Well ausgesät. Die Zellen wurden zu Versuchsbeginn zunächst zwei Mal für 5 min bei RT in Medium 1 gewaschen. Während dieser Zeit wurden die DiIC $_{16^{-}}$und SPEEDY DiO-Stammlösungen (1 $\left.\mathrm{mM}\right)$ mit Inkubationslösung auf eine Konzentration von $2 \mu \mathrm{M}$ verdünnt. Daraufhin folgte die Färbung mit den verdünnten Farbstofflösungen für 3 min bei ca. $8{ }^{\circ} \mathrm{C}$ im Kühlschrank. Die Zellen wurden dann kurz mit Medium 1 bei RT gewaschen, um restlichen Farbstoff zu entfernen. Anschließend wurde frisches Zellkulturmedium zugegeben, und die Infektion mit E. cuniculi durchgeführt. Um eine mögliche Phagocytose von Sporoplasma zu inhibieren, wurde der Versuch auch in Anwesenheit von Cytochalasin-D (CytD) (Katalog-Nr. C8273, Sigma- 
Aldrich, Deisenhofen) durchgeführt. Cytochalasin-D ist ein Zell-permeables Toxin des Pilzes Zygosporium mansonii, das die Aktin-Polymerisierung der Wirtszelle inhibiert und AktinFilamente sogar zerstört (Cooper, 1987). Die Zelle ist somit nicht mehr in der Lage, Aktinabhängige Prozesse wie z. B. Phagocytose auszuführen. Cytochalasin-D wurde als $5 \mathrm{mM}$ Stammlösung in DMSO angesetzt. Um den Versuch in Anwesenheit von Cytochalasin-D durchzuführen, wurde das Medium 1, die Farbstofflösungen sowie das im Anschluss verwendete Zellkulturmedium mit $5 \mu \mathrm{M}$ Cytochalasin-D versetzt.

Für die Infektion der gefärbten Zellen wurde eine große Anzahl frisch isolierter Sporen verwendet, die $5 \mathrm{~min}$ vor Zugabe zu den Zellen in ca. $100 \mu \mathrm{l}$ destilliertem Wasser vorinkubiert wurden. Die Vorinkubation in destilliertem Wasser erhöht die Sporulationsrate der Sporen, und sollte die Infektion der Wirtszellen beschleunigen. Pro Well wurden dann $5 \mu 1$ der so vorbehandelten Sporen zu den Zellen gegeben, die 24-Well-Platte geschüttelt und kurz bis auf ca. $1500 \mathrm{U} / \mathrm{min}$ anzentrifugiert. Dies sollte eine möglichst schnelle Sedimentation der Sporen ermöglichen. Die Zellen wurden daraufhin bei RT weiterinkubiert, und die Infektion in den einzelnen Wells wurde in einer Kinetik (1 - 5 min) abgestoppt. Dazu wurden die einzelnen Deckgläschen mit einer Pinzette aus den Wells gehoben und direkt in eine neue Platte mit $4 \quad \%$ PFA gelegt. Nach der Fixierung für 15 min wurde eine Immunfluoreszenzfärbung mit dem 6G2-Antikörper durchgeführt, um die entstandenen Meronten sichtbar $\mathrm{zu}$ machen. Dabei wurde das alternative SaponinPermeabilisierungsprotokoll (siehe 2.2.2.1) verwendet, um die Lipidfarbstoffe nicht wegzuwaschen. Bei der DiIC 16 -Färbung (rot) diente ein Cy2-Konjugat (grün), bei der SPEEDY DiO-Färbung (grün) ein Cy3-Konjugat (rot) als Sekundärantikörper.

Als Negativkontrolle für den Versuch dienten BHK-Zellen, die vor der Markierung bereits Vakuolen enthielten. Dazu wurden die BHK-Zellen für $1 \mathrm{~h}$ im Brutschrank mit den vorbehandelten Sporen infiziert. Extrazelluläre Sporen wurden daraufhin durch gründliches Waschen mit Medium 1 entfernt, bevor die Färbung mit $2 \mu \mathrm{M}$ DiIC $_{16}$ oder SPEEDY DiO für 3 min im Kühlschrank durchgeführt wurde. Nach einem erneuten Waschritt mit Medium 1 folgte direkt die Fixierung ohne eine weitere Inkubation. Die Negativkontrolle wurde anschließend analog zu den anderen Proben mit einer 6G2-Immunfluoreszenzfärbung angefärbt. 


\begin{tabular}{rlrl}
\multicolumn{2}{c}{ Medium 1} & \multicolumn{3}{c}{ Inkubationslösung } \\
$150 \mathrm{mM}$ & $\mathrm{NaCl}$ & $10 \mathrm{mM}$ & HEPES, pH 7,4 \\
$5 \mathrm{mM}$ & $\mathrm{KCl}$ & $1 \mathrm{mM}$ & $\mathrm{CaCl}_{2}$ \\
$1 \mathrm{mM}$ & $\mathrm{CaCl}_{2}$ & $300 \mathrm{mM}$ & Sorbitol \\
$1 \mathrm{mM}$ & $\mathrm{MgCl}_{2}$ & & \\
$20 \mathrm{mM}$ & HEPES, pH 7,4 & & \\
$2 \mathrm{~g} / 1$ & Glukose & &
\end{tabular}

\subsubsection{4 „Time-lapse“"-Mikroskopie}

Um die Entstehung der Vakuolenmembran in Echtzeit zu untersuchen, wurden „time-lapse“Aufnahmen gemacht. Dazu wurden die HFF-Zellen semikonfluent in ein Well einer 24-WellPlatte mit dünnem Glasboden (Sensoplatte, Greiner Bio-One, Frickenhausen) ausgesät. Die Färbung der HFF-Zellen wurde analog zur Färbung der BHK-Zellen (siehe 2.2.2.3) durchgeführt. Nach der Färbung wurde allerdings farbloses DMEM-Medium zu den Zellen gegeben, da dieses Medium bei den späteren Aufnahmen eine kürzere Belichtungszeit erlaubte. Die Zellen wurden daraufhin ebenfalls mit vorinkubierten Sporen infiziert, die Platte kurz geschüttelt und schließlich kurz mit einer Drehzahl von 1500 U/min zentrifugiert, um die Sporen zu sedimentieren. Die Platte wurde dann sehr schnell in die auf $37{ }^{\circ} \mathrm{C}$ vorgewärmte Mikroskopkammer (XL-3 Incubator) des Zeiss Axiovert 200M-Mikroskops gebracht. Die Beheizung der Kammer erfolgte mit einer Heating Unit in Kombination mit einem Tempcontrol 37-2-Gerät. Die 24-Well-Platte wurde dann mit einem $\mathrm{CO}_{2}$-Cover HM abgedeckt, und die $\mathrm{CO}_{2}$-Zufuhr durch einen $\mathrm{CO}_{2}$-Controller wurde eingeschaltet. Um ein Verdampfen von Wasser aus dem Zellkulturmedium zu verhindern, war in die Gaszuleitung zusätzlich ein Humidifier (3) zwischengeschaltet, der das $\mathrm{CO}_{2}$-Luft-Gemisch anfeuchtete. Nach einer kurzen Aufwärmphase der Platte konnte das „,time-lapse“-Experiment gestartet werden. Dazu wurden in 630 x Vergrößerung einige schön gefärbte HFF-Zellen, die von Sporen umgeben waren scharf gestellt, um eine mögliche Invasion aufzunehmen. Die Aufnahme der Phasenkontrast- und DiIC 16 -Fluoreszenz-Bilder erfolgte dabei alternierend mit einer AxioCam MRm (Zeiss AG, Göttingen) mit maximaler Geschwindigkeit, so dass zwischen den Bildern nur jeweils 1,3 sec lagen. 
farbloses DMEM

DMEM mit 4,5 g/1 Glukose, 580 mg/l L-Glutamin,

25 mM HEPES, ohne Phenol-Rot, ohne Natrium-Pyruvat

$$
\begin{aligned}
10 \% & \text { FKS } \\
1 \% & \text { Pen/Strep }
\end{aligned}
$$

\subsubsection{Biotinylierung von Wirtszell-Oberflächenproteinen}

Biotin ist ein Vitamin, das als prosthetische Gruppe vieler Enzyme eine entscheidende Rolle im Stoffwechsel des Menschen spielt. Da Biotin mit 244 kDa ein relativ kleines Molekül ist, kann es an viele Proteine gebunden werden, ohne deren biologische Aktivität zu verändern. Biotin bildet eine sehr starke, nicht kovalente Bindung mit Streptavidin aus. Dieses aus vier identischen Untereinheiten aufgebaute Protein aus Streptomyces avidinii kann mit sehr hoher Affinität ein Biotin-Molekül pro Untereinheit binden. Die starke Wechselwirkung kann genutzt werden, um mit Biotin markierte Proteine aufzureinigen oder nachzuweisen (Pierce Biotechnology, 2005). Die durchgeführte Biotinylierung erfolgte mit Sulfo-NHS-LC-Biotin (Pierce, Rockford, IL, USA). Die N-Hydroxysuccinimide (NHS)-Gruppe des so aktivierten Biotins reagiert mit primären Aminogruppen in den Seitenketten von Lysin oder mit dem Amino-Terminus von Proteinen und bildet kovalente Amid-Bindungen. Da Sulfo-NHS-LCBiotin Membran-impermeabel ist, kann es für die Markierung von Oberflächenproteinen verwendet werden.

Um Wirtszell-Oberflächenproteine mit Biotin zu markieren, wurden BHK- oder L929-Zellen $24 \mathrm{~h}$ vor Versuchsbeginn auf Deckgläschen in 24-Well-Platten semikonfluent ausgesät. Das Aussäen erfolgte dabei für BHK-Zellen mit einer Zelldichte von 7 x $10^{4}$ Zellen/ Well. Bei L929-Zellen wurden 2 × $10^{5}$ Zellen/ Well ausgesät. Um eine mögliche Phagocytose von Sporoplasma zu inhibieren, wurde der Versuch in Anwesenheit des Phagocytose-Inhibitors Cytochalasin-D durchgeführt (siehe 2.2.2.3). Dazu wurde $\mathrm{zu}$ Versuchsbeginn das Zellkulturmedium mit $1 \mu \mathrm{M}$ CytD versetzt, und die Zellen für eine Stunde bei $37^{\circ} \mathrm{C}$ mit CytD vorinkubiert. Die 24-Well-Platten wurden daraufhin auf Eis gekühlt, um eine endocytotische Aufnahme des Biotin-Moleküls zu verhindern. Da Komponenten des Zellkulturmediums um die NHS-Biotin-Moleküle konkurrieren können, wurden die Zellen drei Mal mit eiskaltem PBS (pH 8) gewaschen. Der relativ hohe pH-Wert beschleunigt dabei die NHS-Reaktion mit den Aminogruppen. Das Sulfo-NHS-LC-Biotin wurde dann mit einer Konzentration von 
$1 \mathrm{mg} / \mathrm{ml}$ in PBS (pH 8) frisch angesetzt und auf Eis gekühlt. Die Zellen wurden auf Eis mit $400 \mu \mathrm{l}$ dieser Biotinylierungs-Lösung pro Well für 30 min auf einem Schüttler inkubiert. Um eine Beeinflussung der Biotinylierung zu vermeiden, wurde während dieser Zeit kein CytD zugesetzt. Anschließend wurde die Biotinylierung durch Waschen mit kaltem Zellkulturmedium mit $5 \mu \mathrm{M}$ CytD für drei Mal 5 min gestoppt. Während dieser Zeit reagieren alle restlichen NHS-Biotin-Moleküle mit Aminogruppen des Mediums. Daraufhin wurde das kalte Medium durch $37{ }^{\circ} \mathrm{C}$ warmes Medium mit $5 \mu \mathrm{M}$ CytD ausgetauscht, und die Zellen mit einer großen Anzahl frisch isolierter Sporen infiziert. Um die Infektion zu beschleunigen, wurden die Sporen auch hier 5 min vor der Infektion in destilliertem Wasser vorinkubiert (siehe 2.2.2.3). Die 24-Well-Platten wurden zur Sedimentation der Sporen kurz bei $1500 \mathrm{U} / \mathrm{min}$ zentrifugiert, und schließlich zurück in den $37^{\circ} \mathrm{C}$ warmen Brutschrank gestellt. Nach unterschiedlichen Inkubationszeiten $(1 \mathrm{~min}-24 \mathrm{~h})$ wurde die Infektion durch eine 15 minütige Inkubation des Deckgläschens in 4 \% PFA gestoppt. Die Mikrosporidien wurden dann in einer Immunfluoreszenzfärbung (siehe 2.2.2.1) mit dem 6G2- oder SWP1-Antikörper und einem Cy2-gekoppelten Sekundärantikörper nachgewiesen. Der Nachweis der biotinylierten Oberflächenproteine erfolgte mit Cy3-gekoppteltem Streptavidin (Verdünnung 1:800; Dianova, Hamburg). Die Inkubation der Proben mit dem Cy2-konjugierten Sekundärantikörper und dem Cy3-konjugierten Streptavidin wurde dabei parallel durchgeführt. Um die biotinylierten Membranproteine nicht wegzuwaschen wurde auch hier das alternative Saponin-Permeabilisierungs-Protokoll verwendet.

Neben der Auswertung im Konfokal-Mikroskop sollte der Versuch auch statistisch durch Auszählen der biotinylierten und unbiotinylierten Vakuolenmembranen ausgewertet werden. Dabei sollte eine mögliche Phagocytose von Sporoplasma durch eine Kolokalisation der 6G2positiven Meronten mit den endosomalen und lysosomalen Markerproteinen EEA1 und LAMP1 analysiert werden. Der Versuch wurde mit L929-Maus-Fibroblasten durchgeführt, weil die EEA1- und LAMP1-Antikörper gegen murine Proteine gerichtet waren. Die L929Zellen in diesen Kontrollansätzen wurden nicht biotinyliert, vielmehr wurden sie während der Biotinylierungs-Inkubationen in PBS (pH 8) parallel mitgeführt. Die Infektion mit E. cuniculi erfolgte dann jedoch analog zu den biotinylierten Proben. Die Zellen wurden dann zu den entsprechenden Zeitpunkten fixiert, und in einer Immunfluoreszenzfärbung mit dem MausAntikörper 6G2 und den Ziegen-Antikörpern EEA1 oder LAMP1 angefärbt. Die Inkubation der Primärantikörper erfolgte dabei parallel. Die Meronten wurden dann mit einem Cy2konjugierten anti-Maus Sekundärantikörper, EEA1 oder LAMP1 mit einem Cy3konjugierten anti-Ziege Sekundärantikörper in paralleler Inkubation nachgewiesen. Die 
Auswertung der Immunfluoreszenzen erfolgte mit dem Zeiss Axiovert 200M Mikroskop. Als Kolokalisation wurde ein den Meronten umgebender fluoreszierender Ring, aber auch eine fleckige Anhäufung von EEA1 oder LAMP1 am Meronten gewertet.

\subsubsection{Mikroinjektion}

Um verschiedene Fluoreszenzfarbstoffe in infizierte HFF zu mikroinjizieren, wurden zunächst HFF-Zellen in kleine Schälchen mit dünnem Boden ( $\mu$-Dish, ibidi, Martinsried) ausgesät. Dabei wurden die HFF-Zellen einer T25-Flasche mit dem Faktor 1:6 verdünnt, so dass sichergestellt war, dass zum Zeitpunkt der Mikroinjektion noch kein konfluenter Monolayer vorhanden war. Von dieser Zellsuspension wurden 1,5 $\mathrm{ml}$ in das Schälchen gefüllt. Nach 16$24 \mathrm{~h}$ wurden die Zellen mit 7,5 x $10^{5}$ Sporen infiziert. Diese hohe Infektionsdosis wurde verwendet, um sicherzustellen, dass trotz der geringen Anzahl an Wirtszellen viele infizierte HFF für die Injektion vorhanden waren. Die Mikroinjektion wurde dann nach Ablauf der gewünschten Inkubationszeiten durchgeführt. Dafür wurde das HFF-Zellkulturmedium gegen „low $\mathrm{CO}_{2}$ “- Medium, welches den $\mathrm{pH}$-Wert auch ohne $\mathrm{CO}_{2}-\mathrm{Zufuhr}$ konstant bei $\mathrm{pH}$ 7,4 hält, ausgetauscht. Zur Vorbereitung der Fluoreszenzfarbstoffe wurden die jeweiligen Stammlösungen mit dest. $\mathrm{H}_{2} \mathrm{O}$ oder Cytomix (siehe Tabelle 2.4) auf eine Konzentration von $0,5 \mathrm{mg} / \mathrm{ml}$ verdünnt.

Bei den Dextran-Molekülen wurde zusätzlich zwei Mal eine Butanol-Extraktion durchgeführt, um möglicherweise abgespaltene freie Farbstoffmoleküle aus der Lösung zu entfernen. Dabei wurde die Dextran-Gebrauchslösung mit einem Volumen 1-Butanol versetzt, kurz geschüttelt und anschließend abzentrifugiert. Die dabei entstehende Phasentrennung in organische und wässrige Phase ermöglichte eine Aufreinigung der Dextran-Gebrauchslösung. Abgespaltene Farbstoffmoleküle lösen sich in der Butanol-Phase, die daraufhin entfernt wurde, während mit der wässrigen Phase, die die fluoreszenzmarkierten Dextrane enthielt, weitergearbeitet werden konnte.

Die Farbstofflösungen wurden anschließend vor der Injektion noch für $10 \mathrm{~min}$ bei 14.000 U/min abzentrifugiert, um Schwebstoffe aus der Lösung zu entfernen, da diese die Beladung der Injektionsnadel stören. Die Injektionsnadel (Femtotip I, Eppendorf, Hamburg) wurde daraufhin mit Hilfe einer fein ausgezogenen Pipettenspitze (,Microloader“, Eppendorf, Hamburg) mit $5 \mu 1$ der Farbstofflösung beladen. Dabei wurde der „Microloader“ von hinten in die Öffnung der Nadel eingeführt und die Lösung luftblasenfrei in die Spitze der Nadel 
auspipettiert. Anschließend erfolgte das Einschrauben der Injektionsnadel in den Kapillarenhalter.

Tabelle 2.4: Ansetzen der Fluoreszenzfarbstoffe und Peptide für die Mikroinjektion.

\begin{tabular}{|l|c|c|c|}
\hline \multicolumn{1}{|c|}{$\begin{array}{c}\text { Fluoreszenzfarbstoff oder } \\
\text { Fluoreszenz-gekoppelte Peptide }\end{array}$} & gelöst in... & $\begin{array}{c}\text { Konz. der } \\
\text { Stammlösung }\end{array}$ & $\begin{array}{c}\text { Verdünnung } \\
\text { mit... }\end{array}$ \\
\hline Alexa Fluor 488 hydrazide & dest. $\mathrm{H}_{2} \mathrm{O}$ & $10 \mathrm{mg} / \mathrm{ml}$ & dest. $\mathrm{H}_{2} \mathrm{O}$ \\
\hline $\begin{array}{l}70.000 \text { MW dextran, } \\
\text { tetramethylrhodamine }\end{array}$ & dest. $\mathrm{H}_{2} \mathrm{O}$ & $10 \mathrm{mg} / \mathrm{ml}$ & dest. $\mathrm{H}_{2} \mathrm{O}$ \\
\hline $\begin{array}{l}10.000 \text { MW dextran, } \\
\text { tetramethylrhodamine, }\end{array}$ & dest. $\mathrm{H}_{2} \mathrm{O}$ & $10 \mathrm{mg} / \mathrm{ml}$ & dest. $\mathrm{H}_{2} \mathrm{O}$ \\
\hline $\begin{array}{l}3000 \text { MW dextran, } \\
\text { Alexa Fluor 488 }\end{array}$ & dest. $\mathrm{H}_{2} \mathrm{O}$ & $10 \mathrm{mg} / \mathrm{ml}$ & dest. $\mathrm{H}_{2} \mathrm{O}$ \\
\hline RSR-Carboxyfluorescein & $\begin{array}{c}\text { dest. } \mathrm{H}_{2} \mathrm{O} \text { mit } \\
10 \% \text { Essigsäure und } \\
43 \% \text { DMSO }\end{array}$ & $5 \mathrm{mg} / \mathrm{ml}$ & Cytomix \\
\hline $\begin{array}{c}\text { dest. } \mathrm{H}_{2} \mathrm{O} \text { mit } \\
\text { SGALDVLQ-Carboxyfluorescein } \\
10 \% \text { Ammonium- } \\
\text { hydrogencarbonat }\end{array}$ & $9 \mathrm{mg} / \mathrm{ml}$ & Cytomix \\
\hline
\end{tabular}

Mit Hilfe eines Joysticks konnte die Injektionsnadel bedient und in das Sichtfeld des 63XObjektivs bewegt werden. Die Mikroinjektion wurde dann mit dem Mikromanipulator 5171 in Kombination mit einem Transjektor 5246 (Eppendorf, Hamburg) durchgeführt. Um einen Einstrom von Medium in die Kapillare zu verhindern, wurde ein Kompensationsdruck angelegt, der dem Kapillarsog der Injektionsnadel entgegenwirkt. Geeignete Geräteparameter waren bei der Injektion in das Cytosol der infizierten Wirtszelle ein Kompensationsdruck $\left(\mathrm{P}_{\mathrm{c}}\right)$ von $30 \mathrm{hPa}$, ein Injektionsdruck $\left(\mathrm{P}_{\mathrm{i}}\right)$ von $180 \mathrm{hPa}$ und eine Injektionsdauer $\left(\mathrm{t}_{\mathrm{i}}\right)$ von 0,3 sec. Meistens erfolgte die Injektion schon durch den Kompensationsdruck beim vorsichtigen Berühren der Zelle mit der Kapillare, was durch eine „Welle“, die durch das Cytosol lief, sichtbar wurde. War der Kompensationsdruck nicht ausreichend, wurde für die Zelle eine geeignete Injektionsebene (Z-Limit) eingestellt, und die Injektion mit der automatischen Injektionsfunktion des Mikromanipulators entsprechend den genannten Einstellungen durchgeführt. Lediglich bei der Injektion des 70.000 MW Dextran-Moleküls musste der Injektionsdruck aufgrund des großen Molekulargewichts auf $400 \mathrm{hPa}$ erhöht werden, um eine erfolgreiche Injektion zu ermöglichen. Nach erfolgreicher Injektion wurde die Kapillare zügig aus dem Blickfeld gefahren und die injizierte Zelle entweder mit Hilfe von Einzelaufnahmen 
oder mit einem ,time-lapse“-Experiment untersucht. Dabei wurden direkt nach der Injektion $(\sim 30 \mathrm{sec})$ sowie nach 10 min Phasenkontrast- und Fluoreszenz-Aufnahmen gemacht.

Für die Injektion des $10 \mathrm{kDa}$-Dextran-Moleküls in die parasitophore Vakuole wurden die Geräteparameter auf einen Kompensationsdruck von $15 \mathrm{hPa}$ und einen Injektionsdruck von $60 \mathrm{hPa}$ verringert. Die Nadel wurde daraufhin sehr genau über der Vakuole lokalisiert, und dann vorsichtig heruntergefahren. Meistens funktionierte die Injektion auch hier beim vorsichtigen Berühren der Vakuole. War dies nicht der Fall, so wurde die automatische Injektionsfunktion genutzt.

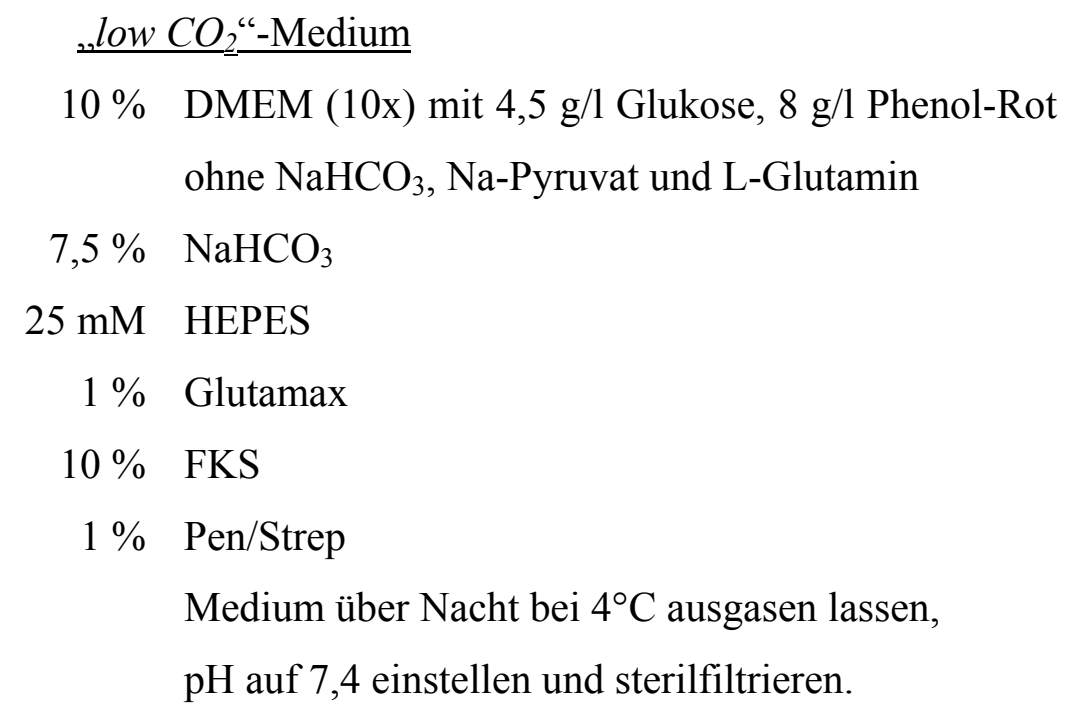

\section{Cytomix}

$\begin{array}{rll}120 \mathrm{mM} & \mathrm{KCl} \\ 0,15 \mathrm{mM} & \mathrm{CaCl}_{2} \\ 10 \mathrm{mM} & \mathrm{K}_{2} \mathrm{HPO}_{4} / \mathrm{KH}_{2} \mathrm{PO}_{4}, \mathrm{pH} 7,6 \\ 25 \mathrm{mM} & \mathrm{HEPES} \\ 2 \mathrm{mM} & \text { EDTA } \\ 5 \mathrm{mM} & \mathrm{MgCl}_{2} \\ & \text { auf pH 7,6 mit KOH einstellen. }\end{array}$




\subsubsection{Nukleinsäuren}

\subsubsection{RNA-Isolierung aus Encephalitozoon cuniculi}

Die Analyse von Genexpressionen erfolgte durch eine quantitative Real-time-PCR. Dafür wurde zunächst die Gesamt-RNA der Kultur, also die RNA von E. cuniculi zusammen mit der RNA von HFF-Wirtszellen isoliert. Die Isolierung erfolgte mit Hilfe des „GenElute Mammalian Total RNA miniprep Kits“ (Sigma-Aldrich, Deisenhofen). Dabei wurde der Zellrasen einer infizierten Kultur zunächst mit Hilfe des Lysepuffers aufgelöst und das lysierte Zellmaterial über eine Säule filtriert. Das Filtrat wurde mit 70 \% Ethanol versetzt, und die Nukleinsäuren durch Zentrifugation an eine zweite Säule gebunden. Die gebundene RNA wurde anschließend mehrmals gewaschen und schließlich mit Elutionspuffer von der Säule eluiert.

Um noch vorhandene DNA aus der RNA-Probe zu entfernen wurde nach der Isolierung ein Verdau mit einer RNase-freien DNaseI (Sigma-Aldrich, Deisenhofen) entsprechend den Herstellerangaben durchgeführt.

\subsubsection{Synthese von cDNA}

Um die in der RNA enthaltenen mRNAs in komplementäre DNA (cDNA von engl. complementary DNA) umzuschreiben, wurde die M-MLV Reverse Transkriptase, RNase H minus, Point Mutant (Promega, Mannheim) eingesetzt. Dabei diente die Bindung eines OligodT-Primers an den für eukaryotische mRNAs charakteristischen Poly-A-Schwanz zur Einleitung der reversen Transkription. Die RNA wurde dazu mit entsprechenden Volumina Reaktionspuffer, dNTPs, dem Oligo-dT-Primer, der Reversen Transkriptase und einem RNase-Inhibitor RNasin (Promega, Mannheim) versetzt. Nach einer Inkubation für 3 - $4 \mathrm{~h}$ bei $37{ }^{\circ} \mathrm{C}$ wurde die Reaktion durch eine Hitzeinaktivierung für 15 min bei $70{ }^{\circ} \mathrm{C}$ gestoppt und die erhaltene DNA mit Hilfe des „PCR Purification Kits“ (Qiagen, Hilden) aufgereinigt. Die so erhaltene cDNA konnte über längere Zeit bei $-20{ }^{\circ} \mathrm{C}$ gelagert und für die Analyse der Transkription verschiedener Gene mit Hilfe des LightCyclers genutzt werden. 


\subsubsection{Ermittlung der relativen mRNA-Expression mit Hilfe der quantitativen Real-time-PCR}

Um die mRNA-Expression verschiedener Gene quantitativ zu bestimmen, wurden die cDNAProben mit Hilfe der Real-time-PCR im LightCycler (Roche, Mannheim) untersucht (Higuchi et al., 1992). Unter Verwendung des „Fast Start DNA SYBR Green I Kits“ (Roche, Mannheim) wurden für die PCR jeweils $4 \mu$ Enzym-Mix, $1 \mu 1$ der entsprechenden genspezifischen Primer und $12 \mu \mathrm{H}_{2} \mathrm{O}$ gemischt und in eine Glas-Kapillare pipettiert. Anschließend wurden $2 \mu \mathrm{l}$ cDNA in die jeweilige Kapillare hinzugefügt und die Genexpression im LightCycler mit Hilfe von Fluoreszenzmessungen während der PCR untersucht. Je nach verwendetem Primer-Paar wurde ein abgeändertes PCR-Protokoll verwendet. Der crossing point (cp) jeder Probe wurde dabei unter voreingestellten Bedingungen (Baseline Adjustment = Arithmetic) ermittelt.

Um die Transkription spezifischer Gene in unterschiedlichen Proben miteinander vergleichen zu können, wurden die berechneten mRNA-Mengen gegen den jeweiligen E. cuniculi aktinmRNA-Gehalt abgeglichen. Zur Ermittlung der relativen mRNA-Menge wurde jeweils ein crossing point als Referenzwert betrachtet. So diente zum Beispiel für die mRNA-Analyse der verschiedenen Aminosäure-Transporter in Aminosäure-Mangelmedium die mRNA-Menge in Komplettmedium als Referenzwert. Die mRNA-Expression jedes untersuchten spezifischen Gens wurde dementsprechend nach folgender Formel berechnet:

$$
\frac{\operatorname{Exp} 1}{\operatorname{Exp} 2}=\frac{2^{\Delta c p_{-} \operatorname{spez}(r e f-t \arg e t)}}{2^{\Delta c p_{-} a k t i n(r e f-t \arg e t)}}
$$

Exp $=$ Expression

cp_spez $=$ crossing point des spezifischen Gens

cp_aktin = crossing point des dazugehörigen aktin-Wertes

ref $=$ Referenzwert (z.B. Expression in Komplettmedium)

target $=$ zu untersuchender Wert (z.B. Expression unter Arginin-Mangel)

Der so errechnete Wert gab die relative mRNA-Expressionsstärke des zu untersuchenden Gens bezogen auf den Referenzwert (=1) an.

Die PCR-Programme im LightCyler waren nahezu identisch aufgebaut und bestanden aus einem anfänglichen Denaturierungsschritt mit nachfolgender Amplifikation der DNA- 
Sequenz. Um eine Verfälschung der ermittelten Transkriptionsstärken zu vermeiden, folgte eine Schmelzkurvenanalyse der entstandenen PCR-Produkte, mit deren Hilfe eine Identifizierung unspezifischer Fragmente möglich ist. Abschließend erfolgte ein Abkühlschritt. Die Annealing-Temperatur sowie die Elongationszeit wurde in Abhängigkeit zum verwendeten Primer-Paar und der Länge des zu erwartenden Fragments angepasst. Ein typisches LightCycler-PCR-Programm ist in Tabelle 2.5 dargestellt.

Tab. 2.5: PCR-Programm im LightCycler.

\begin{tabular}{|c|c|c|c|c|}
\hline $\begin{array}{l}\text { Segment } \\
\text { Nummer }\end{array}$ & $\begin{array}{c}\text { Temperatur } \\
\text { Target }\left({ }^{\circ} \mathrm{C}\right)\end{array}$ & Hold time (sec) & Slope $\left({ }^{\circ} \mathrm{C} / \mathrm{sec}\right)$ & $\begin{array}{l}\text { Acquisition } \\
\text { mode }\end{array}$ \\
\hline \multicolumn{5}{|c|}{ Denaturierung } \\
\hline 1 & 95 & 600 & 20 & none \\
\hline \multicolumn{5}{|c|}{ Amplifikation } \\
\hline 1 & 95 & 10 & 20 & none \\
\hline 2 & var. & 5 & 20 & none \\
\hline 3 & 72 & var. & 20 & single \\
\hline \multicolumn{5}{|c|}{ Schmelzkurve } \\
\hline 1 & 95 & 10 & 20 & none \\
\hline 2 & 65 & 15 & 20 & none \\
\hline 3 & 99 & 0 & 0,1 & continuous \\
\hline \multicolumn{5}{|l|}{ Kühlung } \\
\hline 1 & 40 & 30 & 20 & none \\
\hline
\end{tabular}

\subsubsection{Proteine}

\subsubsection{SDS-Polyacrylamid-Gelelektrophorese (SDS-PAGE)}

Um Proteine in einer Probe anhand ihrer Größe aufzutrennen, wurde eine denaturierende SDS-Polyacrylamid-Gelelektrophorese nach Laemmli durchgeführt (Laemmli, 1970). Dabei wurden die $\mathrm{zu}$ untersuchenden Proteine mit fünffach konzentriertem Probenpuffer im Verhältnis 1:5 gemischt, für 5 min auf $99^{\circ} \mathrm{C}$ erhitzt und schließlich auf ein 0,75 mm dickes, vertikales SDS-Polyacrylamidgel aufgetragen. Um das Molekulargewicht der $\mathrm{zu}$ analysierenden Proteine zu ermitteln, wurde parallel ein Gemisch von Markerproteinen bekannten Molekulargewichts aufgetragen (Prestained Protein Marker, NEB, Frankfurt). Die SDS-PAGE wurde dann bei $25 \mathrm{~mA}$ pro Gel für ca. 60 min durchgeführt. Nach der 
Auftrennung konnten individuelle Proteine in einer Western Blot-Analyse mit anschließender Immunfärbung nachgewiesen werden.

Um ein SDS-Polyacrylamidgel herzustellen, wurde zunächst ein $12 \%$ PolyacrylamidTrenngel in eine Mini Protean 3 Gelkammer (BioRad, München) gegossen, und mit Isopropanol überschichtet. Nach dem Auspolymerisieren wurde das Isopropanol gründlich entfernt und ein 4,4\% Sammelgel aufgegossen, in das ein Probenkamm für 10 Proben eingesetzt wurde.

Trenngel, $12 \%$
$0,94 \mathrm{ml} \quad 2 \mathrm{M}$ Tris-HCl, pH 8,8
$0,1 \mathrm{ml} \quad 10 \% \mathrm{SDS}$
$2 \mathrm{ml} \quad 30 \%$ AA, $0,8 \% \mathrm{BA}$
$1,94 \mathrm{ml} \quad$ Aqua bidest.
$20 \mu \mathrm{l} \quad 10 \%$ APS
$10 \mu \mathrm{TEMED}$
AA $=$ Acrylamid, BA = Bisacrylamid
Elekrophoresepuffer
$25 \mathrm{mM} \quad$ Tris-HCl, pH 8,3
$0,2 \mathrm{M} \quad$ Glycin
$0,1 \% \quad$ SDS

\begin{tabular}{rl}
\multicolumn{3}{c}{ Sammelgel, $4,4 \%$} \\
$1,25 \mathrm{ml}$ & $0,5 \mathrm{M}$ Tris-HCl, pH 6,8 \\
$0,1 \mathrm{ml}$ & $10 \%$ SDS \\
$0,73 \mathrm{ml}$ & $30 \%$ AA, $0,8 \% \mathrm{BA}$ \\
$0,73 \mathrm{ml}$ & Aqua bidest. \\
$12,5 \mu \mathrm{l}$ & $10 \%$ APS \\
$10 \mu \mathrm{l}$ & TEMED
\end{tabular}

SDS-Probenpuffer, $5 \mathrm{x}$

312,5 mM Tris-HCl, $\mathrm{pH} 6,8$

$10 \%$ SDS

$50 \%$ Glycerol

$162,5 \mathrm{mM}$ DTT

$0,005 \%$ Bromphenolblau

\subsubsection{Western Blot-Analyse und Immunfärbung}

Die durch SDS-PAGE aufgetrennten Proteine wurden durch Semi-dry-Blotting (KyhseAndersen, 1984) elektrophoretisch auf eine Nitrocellulose-Membran (Hybond ECL Nitrocellulose Membrane, Amersham Büchler, Braunschweig) übertragen. Dabei wurden folgende Komponenten in einem Semi-Dry Elektroblotter (Sartorius, Göttingen) übereinandergeschichtet: 


\section{$\underline{\text { Kathode }}$}

9 Whatman-Filterpapiere getränkt in $40 \mathrm{mM}$ Aminocapronsäure, $\mathrm{pH}$ 7,6 , 20 \% Methanol

\section{SDS-PAGE Gel}

Nitrozellulose-Membran

3 Whatman-Filterpapiere getränkt in 25 mM Tris-HCl, pH 10,4, $20 \%$ Methanol

6 Whatman-Filterpapiere getränkt in 0,3 M Tris-HCl, pH 10,4 , $20 \%$ Methanol

Anode

Die Proteine wurden mit $0,8 \mathrm{~mA} / \mathrm{cm}^{2}$ Gelfläche für ca. 90 min übertragen. Neben der Übertragung des Prestained-Markers diente zusätzlich eine Färbung der Proteine mit Ponceau S als Kontrolle des Transfers. Überschüssiges Ponceau S wurde mit destilliertem Wasser weggewaschen, und die gleichmäßige Beladung der einzelnen Spuren konnte überprüft werden.

Um spezifische Proteine mittels einer Immunfärbung nachzuweisen, wurden zunächst unspezifische Bindestellen der Membran für $1 \mathrm{~h}$ bei RT mit Blockierlösung abgesättigt. Nach einem kurzen Waschschritt mit Waschlösung wurde die Membran 1,5 h mit dem Primärantikörper, verdünnt in Inkubationslösung inkubiert. Sollten mehrere Seren untersucht werden, wurden entsprechend viele Spuren des SDS-Gels beladen, und die Membran nach dem Blotten in Einzelteile geschnitten. Die Teilmembranen konnten dann mit unterschiedlichen Primärantikörpern inkubiert werden. Ungebundener Primärantikörper wurde daraufhin durch dreimaliges Waschen für jeweils 5 min in Waschlösung entfernt, bevor die Inkubation für $1 \mathrm{~h}$ mit Peroxidase- gekoppeltem Sekundärantikörper in Inkubationslösung erfolgte. Schließlich wurde die Membran noch drei Mal für 5 min gewaschen und mit der ECL-Nachweislösung (Amersham, Freiburg) nach Herstellerangaben inkubiert. Überschüssige Lösung wurde entfernt, und die Membran mit einer Plastikfolie luftblasenfrei abgedeckt. Der Nachweis der Proteine erfolgte schließlich durch Auflegen eines Chemilumineszenz-sensitiven Hyperfilm ECL (Amersham, Freiburg) auf die Membran.

\begin{tabular}{|c|c|c|c|c|c|}
\hline \multicolumn{2}{|c|}{$\underline{\text { Blockierlösung }}$} & \multicolumn{2}{|c|}{ Waschlösung } & \multicolumn{2}{|c|}{ Inkubationslösung } \\
\hline $5 \%$ & Magermilchpulver & $0,05 \%$ & Tween-20 & $5 \%$ & Magermilchpulver \\
\hline $0,2 \%$ & Tween-20 & & in PBS, $\mathrm{pH} 7,4$ & $0,05 \%$ & Tween-20 \\
\hline $0,02 \%$ & $\begin{array}{l}\mathrm{NaN}_{3} \\
\text { in PBS, pH 7,4 }\end{array}$ & & & & in PBS, $\mathrm{pH} 7,4$ \\
\hline
\end{tabular}




\subsubsection{Generierung eines anti-Peptid-Antikörpers}

Um einen anti-Peptid-Antikörper gegen das E. cuniculi Hämolysin-III (EcHlyIII) zu generieren, wurden zwei Teilregionen von EcHlyIII ausgewählt, die Peptide synthetisiert, an ein Trägerprotein gekoppelt und als Antigene zur Immunisierung verwendet. Die Herstellung des Peptid-Antikörpers wurde von Eurogentec (Köln) durchgeführt. Bei der Auswahl der Peptide wurde darauf geachtet, dass diese nicht in den Membranregionen des Proteins liegen, damit spätere Antikörper in der Immunfluoreszenz-Färbung Zugang zu den entsprechenden Bindestellen von EcHlyIII haben. Die zwei Peptide (Sequenzen siehe Abb. 3.16) wurden dann über ein zusätzliches N-terminales Cystein an das Trägerprotein „Keyhole limpet hemocyanin“ (KLH) gebunden. Die Konjugate KLH-Peptid 1 und KLH-Peptid 2 wurden daraufhin zusammen für die Immunisierung von jeweils zwei Ratten verwendet. Dabei wurde das Antigen innerhalb von drei Monaten insgesamt vier Mal injiziert. Vor der ersten Immunisierung wurde ein Präimmun-Serum gewonnen, das in den Versuchen als Negativkontrolle dienen sollte. Während des Immunisierungsprozesses wurden eine kleine Blutung (small bleeding) und eine große Blutung (large bleeding) durchgeführt. Zum Schluss folgte eine Endblutung (final bleeding).

\subsubsection{Membranfraktionierung von Sporen}

Um Sporenproteine in eine lösliche Fraktion und eine Membranfraktion zu trennen, wurden zunächst $4 \times 10^{8}$ Sporen frisch geerntet. Die Sporen wurden anschließend zwei Mal in destilliertem Wasser gewaschen, um Wirtszell-Reste zu entfernen. Dazu wurden die Sporen bei $2500 \mathrm{U} / \mathrm{min}$ für $20 \mathrm{~min}$ abzentrifugiert, in einem großen Volumen destilliertem Wasser aufgenommen und die Sporensuspension ca. 1 min mit Hilfe eines Vortex gemischt. Die so aufgereinigten Sporen wurden dann in 1,92 ml PBS aufgenommen, und mit einem Verdünnungsfaktor von 1:25 mit Proteinase-Inhibitor-Cocktail (Roche, Mannheim) versetzt, so dass ein Endvolumen von $2 \mathrm{ml}$ resultierte. Um die Sporen anschließend aufzuschließen, wurden ca. $500 \mu \mathrm{l}$ Glassbeads $(0,5 \mathrm{~mm}$, Biospec Products, Bartlesville, OK, USA) in Eppendorf-Gefäße vorgelegt und mit $500 \mu 1$ der Sporensuspension aufgefüllt. Die EppendorfGefäße mit der Mischung aus Sporen und Glassbeads wurden daraufhin in einem GlassbeadSchüttler (Thermo Savant, Langenselbold) acht Mal für $40 \mathrm{sec}$ mit einer Stärke von 6,5 geschüttelt. Um eine Überhitzung der Proben und des Gerätes zu vermeiden wurde die 
Behandlung zwischendurch allerdings unterbrochen, und die Proben für ca. 5 min auf Eis gekühlt. Die bei der Behandlung entstehenden sehr starken Scherkräfte sind in der Lage die stabile Sporenwand von E. cuniculi zu zerstören, so dass eine Mischung von Membranfragmenten und löslichen Proteinen entsteht. Der Erfolg der Sporen-Disruption wurde dabei mikroskopisch überprüft. Anschließend wurde das Proteingemisch von den Glassbeads getrennt, indem die Proteinlösung mit einer gelben Pipettenspitze abgesaugt wurde. Diese erlaubt eine sehr effiziente Trennung von den Glassbeads, da ihre Öffnung zu klein ist, um Glassbeads aufzunehmen. Um restliche Proteine von den Beads zu entfernen, wurden diese noch ein Mal mit je $100 \mu$ PBS gewaschen, und die Proteinlösung in ein Zentrifugenröhrchen überführt. Ein Teil der Proteinlösung wurde als Gesamt-Proteinextrakt aufbewahrt, der Rest wurde bei $100.000 \mathrm{x}$ g und $4{ }^{\circ} \mathrm{C}$ für $1 \mathrm{~h}$ in einer Ultrazentrifuge abzentrifugiert. Nach Ablauf der Zentrifugationszeit wurde der Überstand mit den löslichen Proteinen abgenommen, und das Pellet mit den Membranproteinen wurde in $150 \mu 11 \mathrm{x}$ SDSProbenpuffer aufgenommen $\left(10 \mu \mathrm{l}=2 \times 10^{7}\right.$ Sporen $)$. Um äqimolare Proteinmengen auf die Spuren des SDS-Gels auftragen zu können, wurden die löslichen Proteine, sowie die Proteine des Gesamt-Proteinextrakts mit einer Fällung durch Trichloressigsäure (Trichloroacetic acid, TCA) präzipitiert. Dazu wurde den Proteinproben ein Volumen kalte, 10 \% TCA zugesetzt, und die Lösungen zunächst für 45 min auf Eis inkubiert. Die Proteine konnten dann durch eine Zentrifugation für $15 \mathrm{~min}$ bei $14.000 \mathrm{U} / \mathrm{min}$ und $4{ }^{\circ} \mathrm{C}$ quantitativ pelletiert werden. Nach einem Waschschritt in $500 \mu 1100 \%$ Ethanol und erneuter Zentrifugation (5 min, 14.000 $\mathrm{U} / \mathrm{min}, 4^{\circ} \mathrm{C}$ ) konnten die Proteinpellets schließlich an der Luft getrocknet und ebenfalls in $150 \quad \mu 1 \quad 1 \quad x \quad$ SDS-Probenpuffer aufgenommen werden. Für die anschließende Gelelektrophorese wurden jeweils $10 \mu 1$ der einzelnen Proteinfraktionen pro Spur aufgetragen. Das entspricht der Proteinmenge von ca. 2 x $10^{7}$ Sporen. 


\section{Ergebnisse}

\subsection{Die Biogenese der parasitophoren Vakuolenmembran}

Aufgrund des einzigartigen Invasionsmechanismus von E. cuniculi und der Abwesenheit von Wirtszell-Proteinen in der parasitophoren Vakuolenmembran (PVM) ist der Entstehungsmechanismus der parasitophoren Vakuole (PV) bislang ungeklärt. Um die Biogenese der PVM näher zu untersuchen, sollte zunächst die Herkunft der Lipide für die PVM ermittelt werden.

\subsubsection{Herkunft der Lipide für die Bildung der parasitophoren Vakuolenmembran}

Um die Herkunft der Lipide für die parasitophore Vakuolenmembran zu ermitteln, sollten entweder die Membranen von E. cuniculi, oder die der Wirtszelle selektiv mit Fluoreszenzfarbstoffen markiert werden. Nach erfolgter Infektion sollte ein Fluoreszenzsignal in der entstandenen Vakuolenmembran Aufschluss über die Beteiligung von Mikrosporidium und Wirtszelle an der Biogenese der Membran geben.

Um zu überprüfen, ob die PVM vom Mikrosporidium selbst stammt, wurde zunächst E. cuniculi mit lipophilen Farbstoffen markiert. Dazu wurden die lipophilen CarbocyaninFarbstoffe DiIC 16 und SPEEDY DiO, sowie das fluoreszierende Phospholipid $\beta$-BODIPY 500/510 $\mathrm{C}_{12}$-HPC (BODIPY-PC) ausgewählt. Die Markierung der Sporen erfolgte durch Kultivieren in Anwesenheit der Farbstoffe, wie unter 2.2.2.2 beschrieben. Die in Gegenwart von SPEEDY DiO kultivierten Sporen zeigten nur eine sehr schwache Fluoreszenz, weshalb sie von weiteren Untersuchungen ausgeschlossen wurden (Daten nicht gezeigt). Die DiIC $16^{-}$ und BODIPY-PC-markierten Sporen (siehe Abb. 3.1) zeigten dagegen eine sehr intensive Färbung. Bei beiden Farbstoffen wiesen die Sporen intrazelluläre Strukturen mit erhöhter Fluoreszenz auf. Während in den BODIPY-PC-gefärbten Präparationen alle Sporen gleichermaßen gefärbt waren, war die Färbung mit DiIC $_{16}$ uneinheitlich, da einige Sporen gar nicht, oder nur sehr schwach gefärbt waren (siehe Abb. 3.1). 


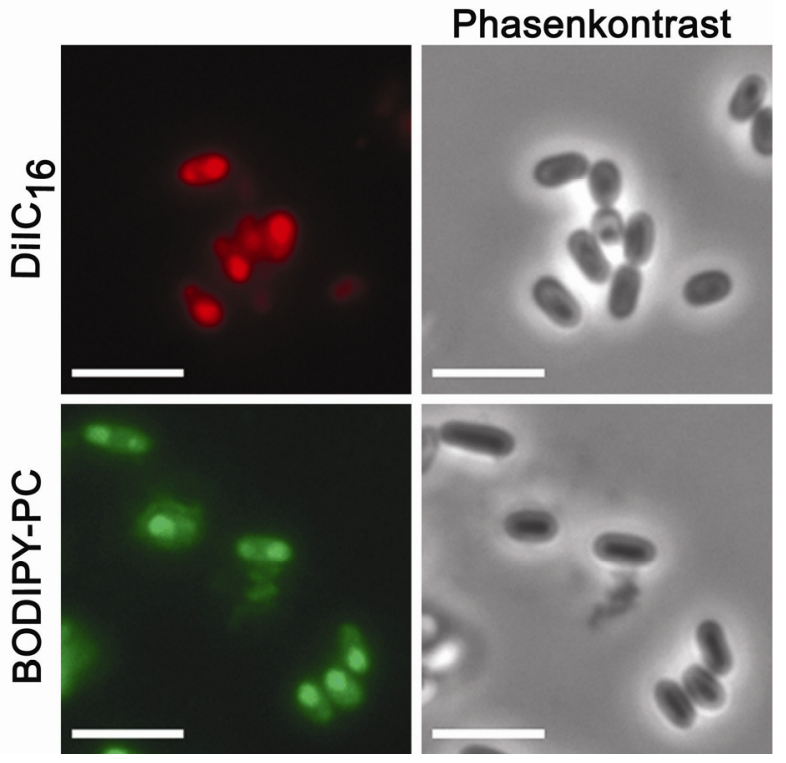

Abb.3.1: Markierung von Sporen mit den lipophilen Fluoreszenzfarbstoffen DiIC $_{16}$ und BODIPY-PC. Eine Kultivierung von E. cuniculi in Anwesenheit von DiIC 16 oder BODIPYPC führt mit beiden Farbstoffen zu einer Markierung der Sporen. Die Sporen weisen stark markierte intrazelluläre Strukturen auf. Während bei BODIPY-PC alle Sporen gleichermaßen angefärbt sind, ist die Markierung mit DiIC 16 unregelmäßig, da einige Sporen gar nicht, oder nur sehr leicht gefärbt sind. Maßstabsbalken $5 \mu \mathrm{m}$.

Wurden die mit BODIPY-PC-gefärbten Sporen für die Infektion von unmarkierten Wirtszellen verwendet, so war in den entstandenen Meronten ein Fluoreszenzsignal zu detektieren (siehe Abb. 3.3). Die Meronten, die von DiIC 16 -markierten Sporen stammten, wiesen kein Fluoreszenzsignal auf (Daten nicht gezeigt), so dass auch diese von weiteren Untersuchungen ausgeschlossen wurden. Um die Infektiosität der Sporen nach FarbstoffBehandlung zu überprüfen, wurde BODIPY-PC in verschiedenen Konzentrationen für die Fluoreszenzmarkierung der Sporen verwendet und im Anschluss das Ausmaß der Infektion eines HFF-Monolayers bestimmt. Die Auswertung zeigte, dass eine BODIPY-PC-Behandlung zu einer deutlichen Reduktion der Infektionsrate von E. cuniculi führt (siehe Abb. 3.2). Während ohne Farbstoff ca. 12 Vakuolen pro Gesichtsfeld ermittelt werden konnten, zeigten sich bei $25 \mu \mathrm{M}, 50 \mu \mathrm{M}$ und $100 \mu \mathrm{M}$ jeweils nur ca. zwei Vakuolen pro Gesichtsfeld. Somit reduziert die BODIPY-PC-Behandlung die Infektiosität der Sporen um ca. 84 \%. Trotz des stark negativen Effektes auf die Infektionsrate, zeigten die Vakuolen, die aus BODIPY-PCgefärbten Sporen hervorgingen, anschließend einen normalen Entwicklungsverlauf (Daten nicht gezeigt), so dass die Sporen für die nachfolgenden Versuche verwendet werden konnten. 


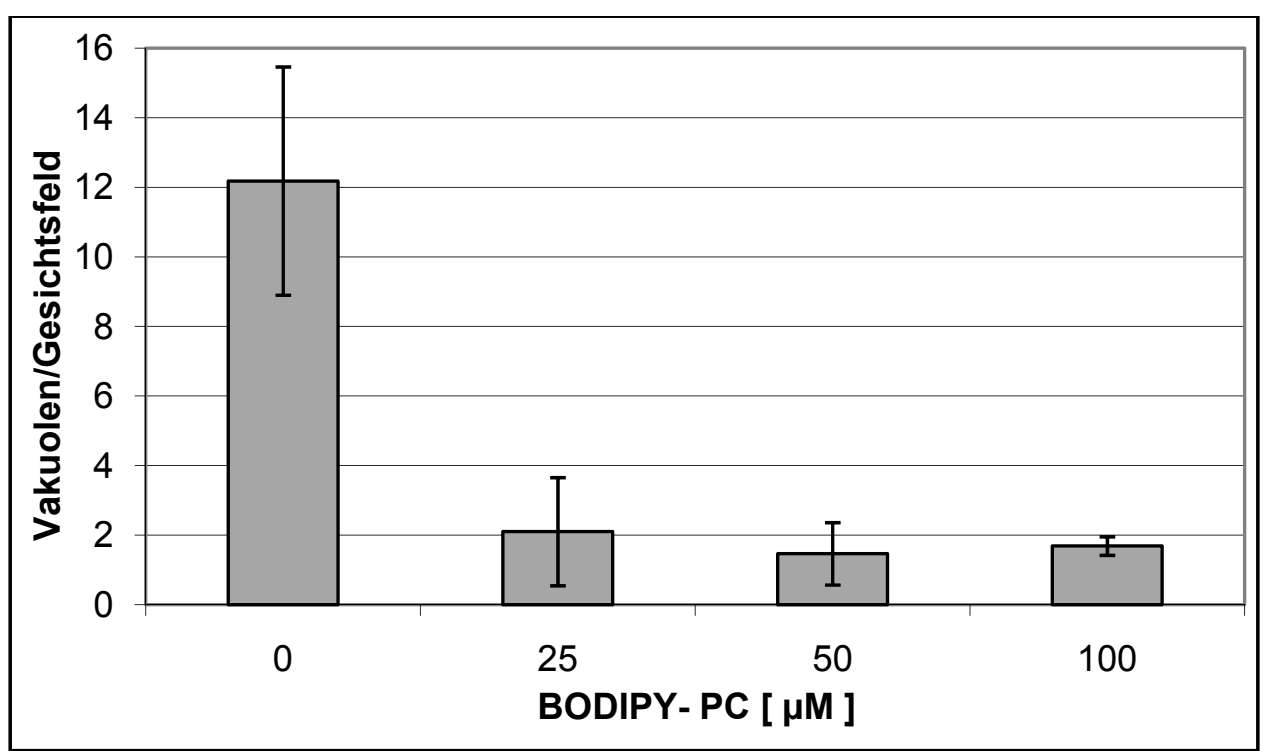

Abb. 3.2: Effekt der BODIPY-PC-Markierung auf die Infektiosität von Sporen. E. cuniculi Sporen wurden mit $0 \mu \mathrm{M}, 25 \mu \mathrm{M}, 50 \mu \mathrm{M}$ oder $100 \mu \mathrm{M}$ BODIPY-PC markiert, geerntet und für die Infektion eines HFF-Monolayers verwendet. Die Infektiosität der Sporen wurde durch Auszählen der resultierenden Vakuolen pro Gesichtsfeld ermittelt. BODIPY-PC hat unabhängig von der verwendeten Farbstoffkonzentration einen stark negativen Effekt auf die Infektionsrate. Die Infektiosität ist um ca. $84 \%$ reduziert.

Um zu untersuchen, ob die parasitophore Vakuolenmembran von E. cuniculi stammt, und während der Injektion des Sporoplasmas mit übertragen wird, wurden die BODIPY-PCgefärbten Sporen für die Infektion von unmarkierten HFF auf Deckgläschen verwendet. Die Infektion wurde zu unterschiedlichen Zeitpunkten durch Fixierung in 4 \% PFA gestoppt, und zur besseren Lokalisation der Meronten wurden diese mit dem Meronten-spezifischen Antikörper 6G2 und einem Cy3-markierten Sekundärantikörper angefärbt. Dazu wurde für die Immunfluoreszenzfärbung das alternative Protokoll mit Saponin-Permeabilisierung (siehe 2.2.2.1) verwendet, um das BODIPY-PC-Signal nicht wegzuwaschen. Die BODIPY-PCgefärbten Membranen erlaubten die Untersuchung der Meronten bis $\mathrm{zu} 24 \mathrm{~h}$ nach der Infektion. Zu späteren Zeitpunkten war das Signal durch die Zellteilung der Meronten zu schwach für weitere Analysen. Wie in Abb. 3.3 exemplarisch für $12 \mathrm{~h}$ und $24 \mathrm{~h}$ gezeigt, findet sich kein BODIPY-PC-Fluoreszenzsignal (grün) in der Vakuolenmembran. Das BODIPY-PCSignal zeigte $\mathrm{zu}$ allen untersuchten Zeitpunkten nur eine Kolokalisation mit den Meronten selbst (siehe BODIPY-PC + Ak 6G2), war jedoch nie in der im Phasenkontrast sichtbaren Vakuolenmembran zu finden (siehe Pfeile merge). Unter der Annahme, dass das BODIPYmarkierte Phospholipid nicht durch andere Gründe von der Vakuolenmembran ausgeschlossen wird, deutet dies darauf hin, dass die Vakuolenmembran nicht von E. cuniculi selbst stammt. 


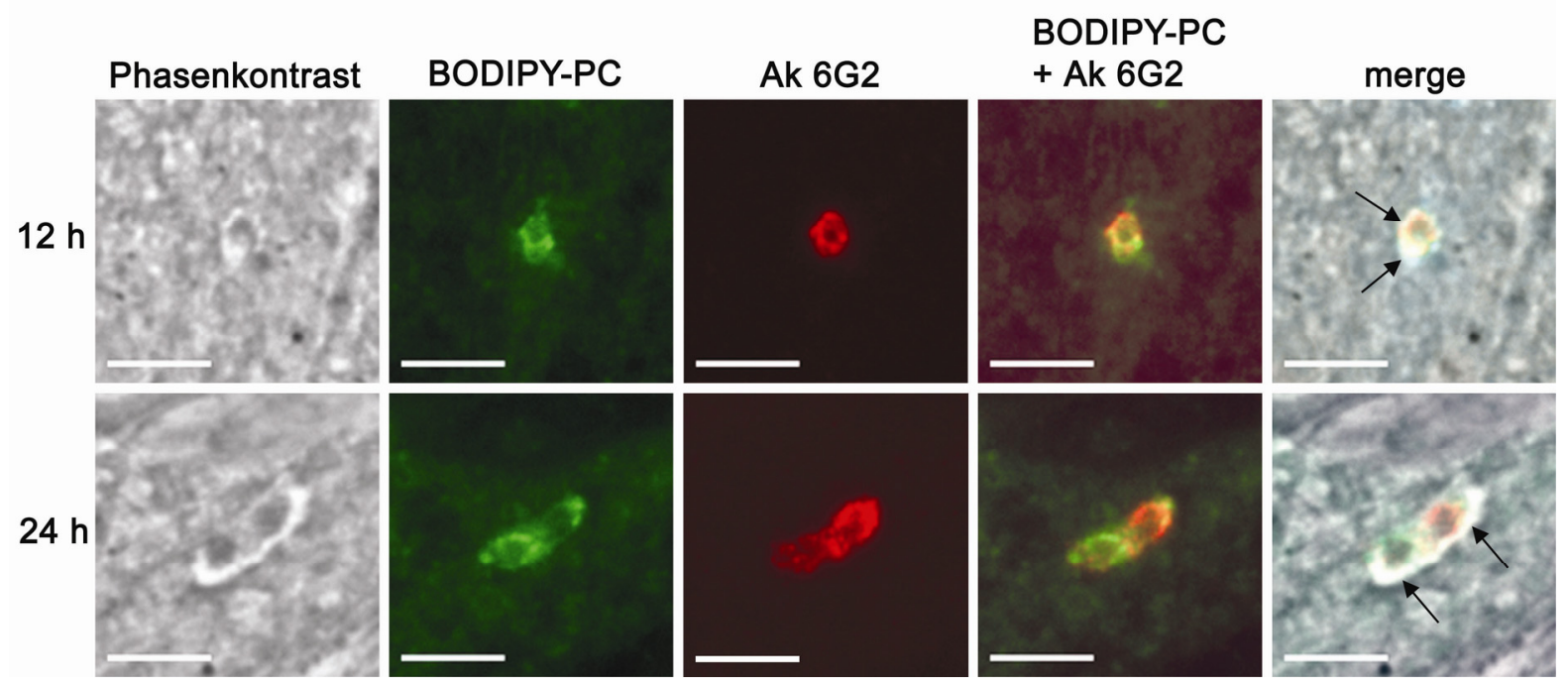

Abb. 3.3: Lipide des injizierten Sporoplasmas tragen nicht zur Biogenese der Vakuolenmembran bei. HFF-Zellen wurden mit BODIPY-PC-markierten Sporen infiziert, und die entstandenen Meronten mit dem Meronten-spezifischen Ak 6G2 und einem Cy3konjugierten Sekundärantikörper angefärbt. Das BODIPY-PC-Signal (grün) kolokalisiert sowohl $12 \mathrm{~h}$ als auch $24 \mathrm{~h}$ nach der Infektion mit dem 6G2 Antikörper-Signal (rot) (siehe BODIPY-PC + Ak 6G2). Das BODIPY-PC-Signal findet sich jedoch nur im Meronten selber, nicht aber in der im Phasenkontrast sichtbaren Vakuolenmembran wieder (siehe Pfeile, merge). Maßstabsbalken $5 \mu \mathrm{m}$.

Um die Beteiligung der Wirtszelle an der Biogenese der PVM zu ermitteln, wurde das gegenteilige Experiment, bei dem die Wirtszelle markiert werden sollte, durchgeführt. Für die Markierung der Wirtszellen wurden die lipophilen Carbocyanin-Farbstoffe DiIC 16 und SPEEDY DiO ausgewählt, die eine Unterscheidung von raft- und nonraft-Domänen ermöglichen. DiIC 16 enthält gerade, gesättigte Kohlenwasserstoff-Seitenketten, so dass dieser Farbstoff auf spezifische Weise in stark geordnete Domänen mit hohem Cholesterin- und Sphingolipid-Anteil (raft) integriert (Thomas et al., 1994). SPEEDY DiO dagegen enthält ungesättigte Kohlenwasserstoff-Seitenketten, welche eine Integration in ungeordnete und mehr fluide Membrandomänen (nonraft) verursacht (siehe Abb. 3.4) (Mouritsen und Jorgensen, 1995; Schroeder et al., 1994). Die Markierung der für diesen Versuch verwendeten BHK-Zellen mit DiIC 16 und SPEEDY DiO wurde wie unter 2.2.2.3 beschrieben, durchgeführt. Dazu wurden die Zellen zunächst gewaschen, und anschließend für 3 min bei ca. $8{ }^{\circ} \mathrm{C}$ mit $2 \mu \mathrm{M}$ DiIC $_{16}$ oder SPEEDY DiO gefärbt. Um die Spezifität der Farbstoffe für raft- oder nonraft-Domänen zu überprüfen, wurde mit den gefärbten Zellen eine TritonXExtraktion durchgeführt (siehe Abb. 3.4). Raft- und nonraft-Domänen unterscheiden sich in Bezug auf ihre Sensibilität gegenüber einer Behandlung mit kalter $1 \%$ TritonX-100-Lösung (Hao et al., 2001). Die fluiden, ungeordneten nonraft-Domänen sind sensibel gegenüber 
Detergentien. Somit wurde SPEEDY DiO, das bevorzugt in nonraft-Domänen integriert, durch TritonX-100 fast vollständig ausgewaschen (siehe SPEEDY DiO, TritonX-Extraktion). Die DiIC ${ }_{16}$-markierten raft-Domänen sind hingegen resistent gegenüber TritonX-100. In DiIC $_{16}$-gefärbten Zellen verursachte eine TritonX-Extraktion durch die Auswaschung von nonraft-Domänen den charakteristischen „swiss cheese“ Phänotyp, der einem löchrigen Schweizer Käse gleicht (siehe DiIC 16 , TritonX-Extraktion) (Hao et al., 2001).

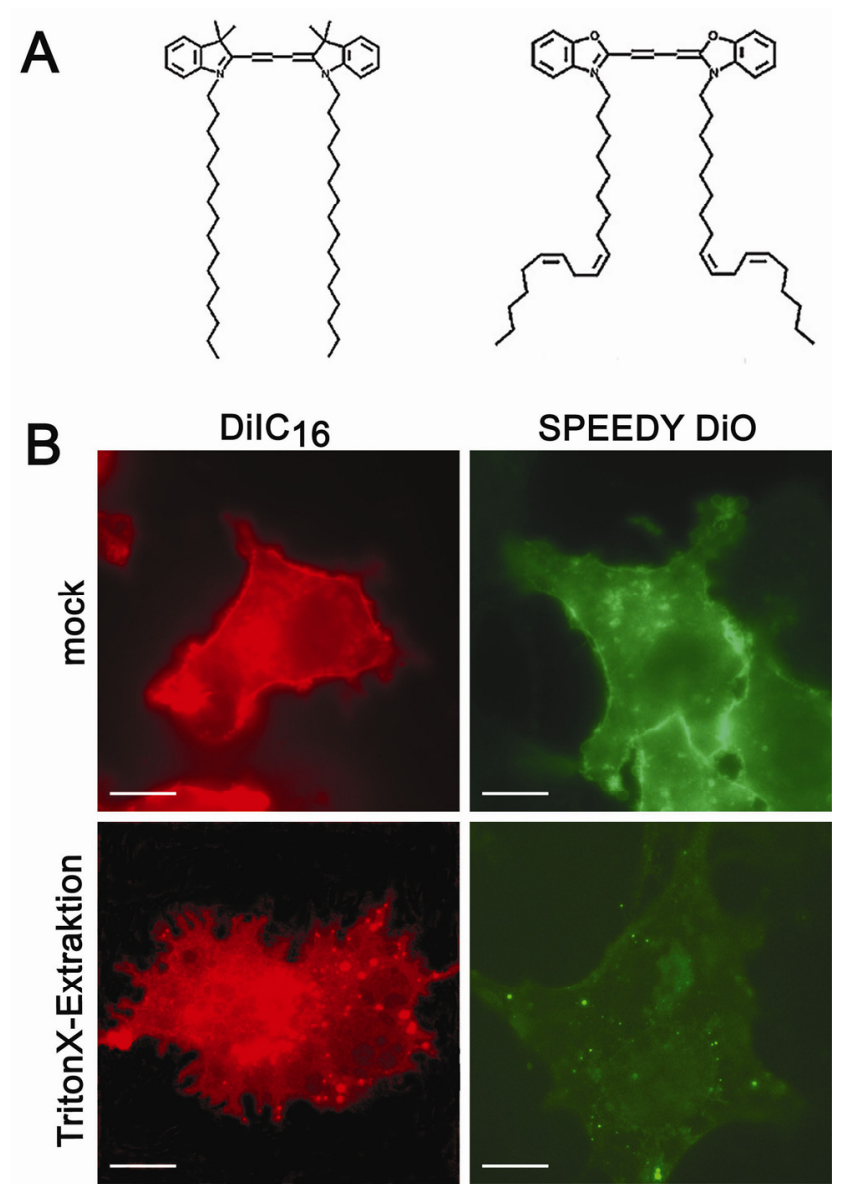

Abb. 3.4: Strukturformeln von DiIC $_{16}$ und SPEEDY DiO sowie unterschiedliche Sensibilität der Farbstoffe gegenüber Extraktion mit kalter TritonX-100-Lösung. A) DiIC $_{16}$ enthält gerade, gesättigte Kohlenwasserstoffketten, so dass es spezifisch in raftDomänen integriert. SPEEDY DiO enthält ungesättigte Kohlenwasserstoffketten, daher integriert dieser Farbstoff präferentiell in nonraft-Domänen. B) BHK-Zellen wurden mit DiIC $_{16}$ oder SPEEDY DiO angefärbt und entweder mit kaltem PBS+ (mock) oder mit kaltem PBS+ mit $1 \%$ TritonX-100 (TritonX-Extraktion) behandelt. Nonraft-Domänen, die von SPEEDY DiO (grün) markiert werden, sind sehr empfindlich gegenüber einer Extraktion mit TritonX-100. Der SPEEDY DiO-Farbstoff war nach der Behandlung fast vollständig ausgewaschen. Raft-Domänen, die durch $\operatorname{DiIC}_{16}$ (rot) markiert werden, sind resistent gegenüber einer Behandlung mit Detergentien. Durch das Auswaschen der nonraft-Domänen ergab sich nach der TritonX-Extraktion der charakteristische „swiss cheese“ Phänotyp, der einem löchrigen Schweizer Käse gleicht. Maßstabsbalken $10 \mu \mathrm{m}$. 
Um zu untersuchen, ob eine Markierung der Wirtszelle, gefolgt von einer Infektion mit E. cuniculi, zu einem Fluoreszenzsignal in der parasitophoren Vakuolenmembran führt, wurden die DiIC $16^{-}$bzw. SPEEDY DiO-markierten BHK-Zellen sehr schnell nach der Färbung mit einer großen Menge an frisch isolierten Sporen infiziert. Da es sich bei der DilC $_{16^{-}}$bzw. SPEEDY DiO-Färbung um keine stabile Plasmamembranfärbung handelt, sondern die Farbstoffe im Laufe der Zeit in das Zellinnere transportiert werden können, sollte die Inkubationszeit nach der Markierung möglichst kurz gehalten werden. Um die Infektionszeit zu reduzieren, wurden die Sporen deshalb für ca. 5 min in destilliertem Wasser vorinkubiert. Dies erhöht die Sporulationsrate der Sporen, wobei jedoch gleichzeitig auch die Selektivität der Sporen für ihre Wirtszelle nachlässt (Mitteilung von Prof. Louis Weiss, New York). Nach Zugabe der Sporen folgte eine kurze Zentrifugation der 24-Well-Platte, um die Sporen möglichst schnell zu sedimentieren. Die Infektion wurde dann 3 min nach Sporenzugabe durch Inkubation in 4 \% PFA gestoppt, und die Meronten wurden mit Hilfe des Meronten-spezifischen Antikörpers 6G2 und einem Cy2- oder Cy3-gekoppelten Sekundärantikörper nachgewiesen. Die Permeabilisierung für die Immunfluoreszenzfärbung wurde hier ebenfalls mit Saponin durchgeführt, um ein Auswaschen der Lipide zu minimieren. Zur Analyse der Zellen wurden konfokale Bilder angefertigt. Um eine Phagocytose von Sporoplasma als mögliche Ursache für ein Fluoreszenzsignal in der Vakuolenmembran auszuschließen, wurde der Versuch zusätzlich in Anwesenheit des Phagocytose-Inhibitors Cytochalasin-D durchgeführt. Dazu wurden die Zellen für 10 min mit $5 \mu \mathrm{M}$ Cytochalasin-D vorinkubiert, und zusätzlich wurde allen im Versuch verwendeten Puffern $5 \mu \mathrm{M}$ Cytochalasin-D zugesetzt. Als Negativkontrolle dienten BHK-Zellen, die vor der Färbung mit DiIC 16 oder SPEEDY DiO schon Vakuolen enthielten. Diese Zellen wurden zunächst für $1 \mathrm{~h}$ mit Sporen infiziert, dann gründlich gewaschen und anschließend mit den lipophilen Farbstoffen gefärbt. Die Ergebnisse dieser Versuche sind in Abb. 3.5 und 3.6 dargestellt. Wird die Wirtszelle vor der Infektion mit dem raft-Lipid DiIC 16 markiert, so sind die intrazellulären Meronten anschließend von einer fluoreszierenden Vakuolenmembran umgeben (siehe Abb. 3.5; ohne CytD, merge). Der im konfokalen Bild sichtbare Ring ist dabei jedoch nicht vollkommen ebenmäßig und besitzt teilweise Regionen mit erhöhter Fluoreszenz (siehe ohne CytD, DiIC 16 ). Die Entstehung der fluoreszierenden Vakuolenmembran ist unabhängig von der Behandlung mit Cytochalasin-D (siehe $5 \mu \mathrm{M}$ CytD, DiIC 16 ). Die untersuchten Vakuolen sind also durch eine natürliche Infektion mit Injektion des Sporoplasmas, und nicht durch eine Phagocytose von freiem Sporoplasma hervorgegangen. Werden die Zellen zuerst infiziert, und dann mit DiIC 16 gefärbt, entsteht 
keine gefärbte Vakuolenmembran (siehe Neg.kontr., DiIC 16 ), so dass ausgeschlossen werden kann, dass die Farbstoffe nach erfolgter Infektion auf unspezifische Weise, z. B. durch Diffusion in die Vakuolenmembran gelangen.

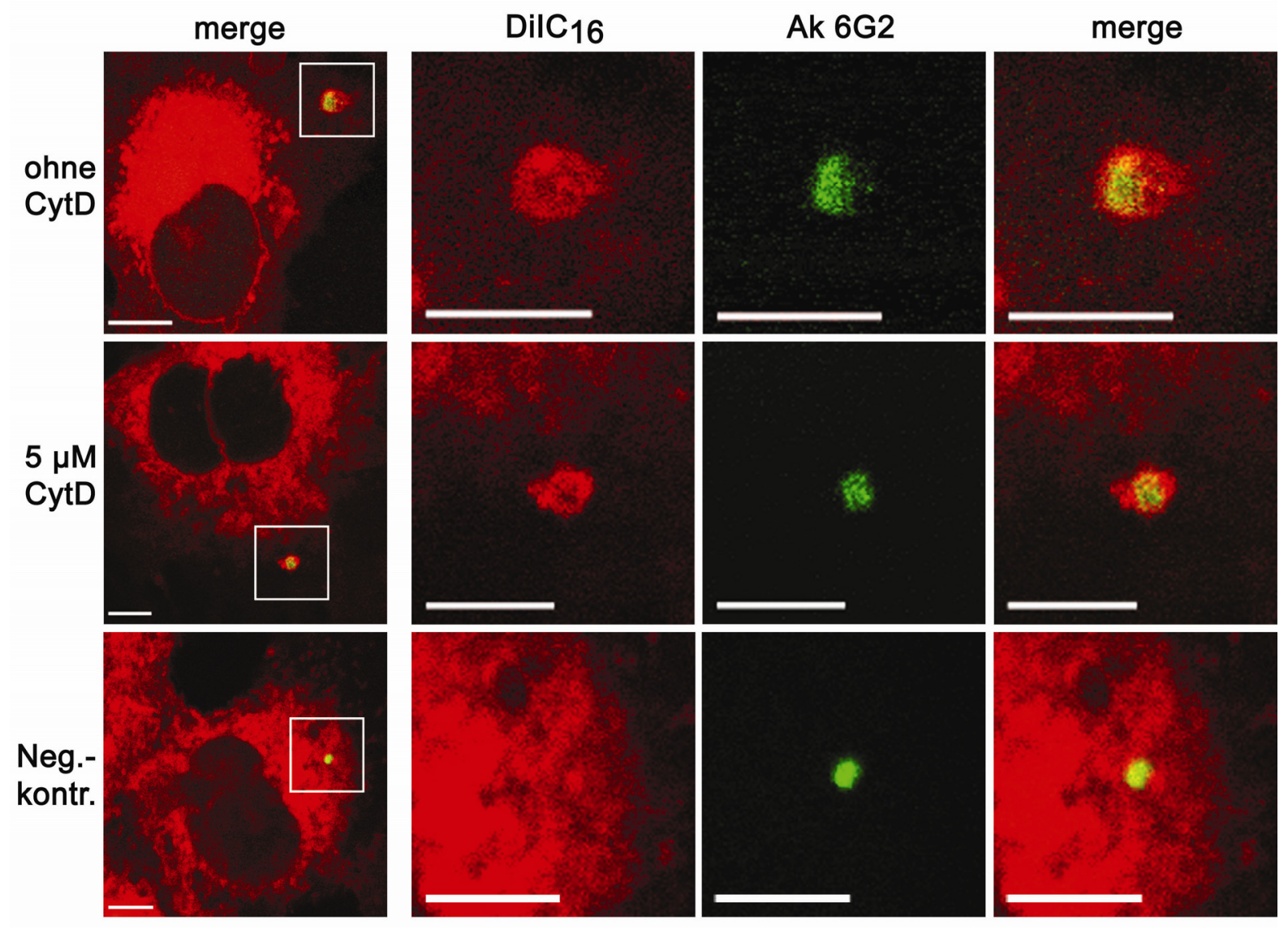

Abb. 3.5: Raft-Lipide der Wirtszelle tragen zur Biogenese der Vakuolenmembran bei. BHK-Zellen wurden mit dem raft-spezifischen Farbstoff $\mathrm{DiIC}_{16}$ (rot) gefärbt und anschließend mit frischen Sporen infiziert. 3 min nach der Infektion wurden die Zellen mit PFA fixiert und intrazelluläre Meronten mit dem Meronten-spezifischen Antikörper (Ak) 6G2 und einem Cy2-konjugierten Sekundärantikörper (grün) nachgewiesen. Der Versuch wurde in An- und Abwesenheit des Phagocytose-Inhibitors Cytochalasin-D (5 $\mu \mathrm{M}$ CytD) durchgeführt. Die linken Bilder zeigen die infizierten Zellen weniger stark vergrößert, während die drei rechten Bilder jeweils den durch das Quadrat gekennzeichneten Bildausschnitt in stärkerer Vergrößerung darstellen (Maßstabsbalken $5 \mu \mathrm{m}$ ). Bereits 3 min nach der Infektion sind die intrazellulären Meronten von einer DiIC $_{16}$-gefärbten Vakuolenmembran umgeben. Das Fluoreszenzsignal in der PVM entsteht dabei unabhängig von der Behandlung mit CytD. Als Negativkontrolle (Neg.kontr.) wurden bereits infizierte BHK-Zellen mit DiIC 16 markiert. Diese Meronten weisen keine fluoreszierende Vakuolenmembran auf.

Meronten, deren Wirtszellen vor der Infektion mit dem nonraft-Lipid SPEEDY DiO markiert wurden, sind ebenfalls von einer fluoreszierenden Vakuolenmembran umgeben (siehe Abb. 3.6; ohne CytD, merge). Ähnlich wie bei $\mathrm{DiIC}_{16}$ ist auch die Entstehung dieser 
Vakuolenmembran unabhängig von der Cytochalasin-D Behandlung (siehe $5 \mu \mathrm{M}$ CytD). Das Fehlen der gefärbten Membran in der Negativkontrolle zeigt, dass auch bei SPEEDY DiO eine unspezifische Integration des Farbstoffes in die Vakuolenmembran ausgeschlossen werden kann (siehe Neg.kontr.).
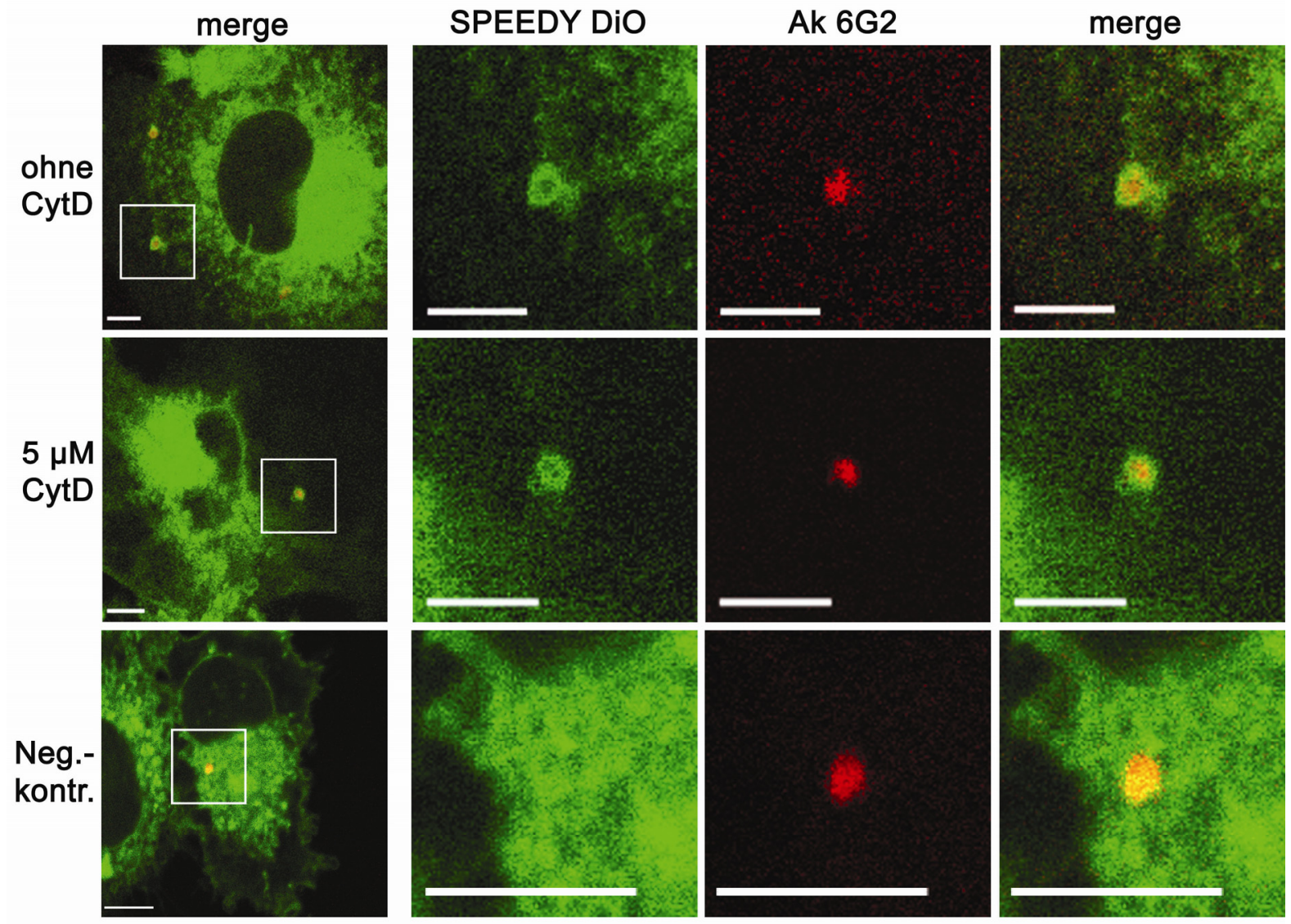

Abb. 3.6: Nonraft-Lipide der Wirtszelle tragen zur Biogenese der Vakuolenmembran bei. BHK-Zellen wurden mit dem nonraft-spezifischen Farbstoff SPEEDY DiO (grün) gefärbt und anschließend mit frischen Sporen infiziert. 3 min nach der Infektion wurden die Zellen mit PFA fixiert und intrazelluläre Meronten mit dem Meronten-spezifischen Antikörper (Ak) 6G2 und einem Cy3-konjugierten Sekundär-Ak (rot) nachgewiesen. Der Versuch wurde in An- und Abwesenheit des Phagocytose-Inhibitors Cytochalasin-D (5 $\mu \mathrm{M}$ CytD) durchgeführt. Die linken Bilder zeigen die infizierten Zellen weniger stark vergrößert, während die drei rechten Bilder jeweils den durch das Quadrat gekennzeichneten Bildausschnitt in stärkerer Vergrößerung darstellen (Maßstabsbalken $5 \mu \mathrm{m}$ ). Bereits 3 min nach der Infektion sind die intrazellulären Meronten von einer SPEEDY DiO-gefärbten Vakuolenmembran umgeben. Das Fluoreszenzsignal in der PVM entsteht dabei unabhängig von der Behandlung mit CytD. Als Negativkontrolle (Neg.kontr.) wurden bereits infizierte BHK-Zellen mit SPEEDY DiO markiert. Diese Meronten weisen keine fluoreszierende Vakuolenmembran auf.

Die Experimente deuten somit darauf hin, dass die Lipide für die parasitophore Vakuolenmembran zum größten Teil von der Wirtszelle stammen. Dabei tragen sowohl raft- 
als auch nonraft-Lipide zur Biogenese der PVM bei. Trotz einer möglichst schnellen Versuchsdurchführung konnte jedoch eine Internalisierung der Lipidfarbstoffe nicht vollständig verhindert werden (siehe Übersichtsbilder Abb. 3.5 und 3.6). Daher kann mit diesem Versuch nicht ausgeschlossen werden, dass neben der Plasmamembran auch interne Membrankompartimente an der Biogenese der PVM beteiligt sein könnten. Durch die Fixierung der Proben kann ferner keine Aussage darüber getroffen werden, ob die Vakuolenmembran während des Invasionsprozesses entsteht, oder ob erst die Injektion des Sporoplasmas stattfindet, und die Vakuolenmembran in den ersten Minuten nach der Invasion gebildet wird.

Um die Entstehung der Vakuolenmembran in Echtzeit zu untersuchen, sollte daher die Invasion von E. cuniculi in lebende, DiIC $_{16}$-gefärbte HFF-Zellen mit einem „time-lapse“Mikroskop analysiert werden. Dazu wurden HFF-Zellen in eine für die inverse Mikroskopie geeignete 24-Well-Platte semikonfluent ausgesät, und wie für die BHK-Zellen beschrieben mit dem lipophilen Carbocyanin-Farbstoff $\mathrm{DiIC}_{16}$ markiert. Anschließend wurden frisch isolierte Sporen zugegeben und die Platte zur schnelleren Sedimentation der Sporen kurz zentrifugiert. Die Zellen wurden dann sehr schnell in die auf $37{ }^{\circ} \mathrm{C}$ vorgeheizte Mikroskopkammer des ,time-lapse“- Mikroskops gebracht, und dort mit Hilfe eines „, $\mathrm{CO}_{2}$ Controllers“ mit $\mathrm{CO}_{2}$ versorgt. Zur Untersuchung der Invasion wurden in 630-facher Vergrößerung Phasenkontrast-Bilder und Fluoreszenzbilder mit maximaler Geschwindigkeit (1,3 sec/ Bild) aufgenommen. Wie in Abb. $3.7 \mathrm{zu}$ sehen, ist die Invasion ein sehr schneller Prozess (siehe A, 1,3 sec). Unmittelbar nach der Invasion erscheint die PVM als DilC $16^{-}$ markierte Struktur im Fluoreszenzkanal $(1,3 \mathrm{sec})$. Dies zeigt, dass die PVM während des Invasionsprozesses entsteht, und nicht erst in den ersten Minuten nach der Invasion. Erstaunlicherweise ist aber auch der Penetrationskanal des polaren Filaments (Tub.) markiert, also die Region, in der der Endbereich des herausgeschleuderten Tubulus in Kontakt mit der Wirtszelle steht. Die in B dargestellte Invasion ist etwas langsamer, daher konnte hier die Entstehung der Vakuolenmembran mit weiteren Zwischenschritten dokumentiert werden. Nach 1,3 sec ist zunächst nur der Penetrationskanal des polaren Filaments (Tub.) markiert. Erst danach beginnt der Transport des Sporoplasmas durch den Tubulus in die Zelle, und die ebenfalls markierte Vakuolenmembran entsteht (2,6 und 3,9 sec). Nach 5,2 sec ist der Transport des Sporoplasmas abgeschlossen, und die PVM hat ihre vorläufige Endgröße erreicht. Die Entstehung eines fluoreszenzmarkierten Penetrationskanals kurz vor der Bildung der eigentlichen PVM lässt sich mit dem herkömmlichen Invasionsmodell nur unzureichend 
erklären und deutet auf eine Modifikation dieses Models hin, die in der Diskussion ausführlich erläutert wird.

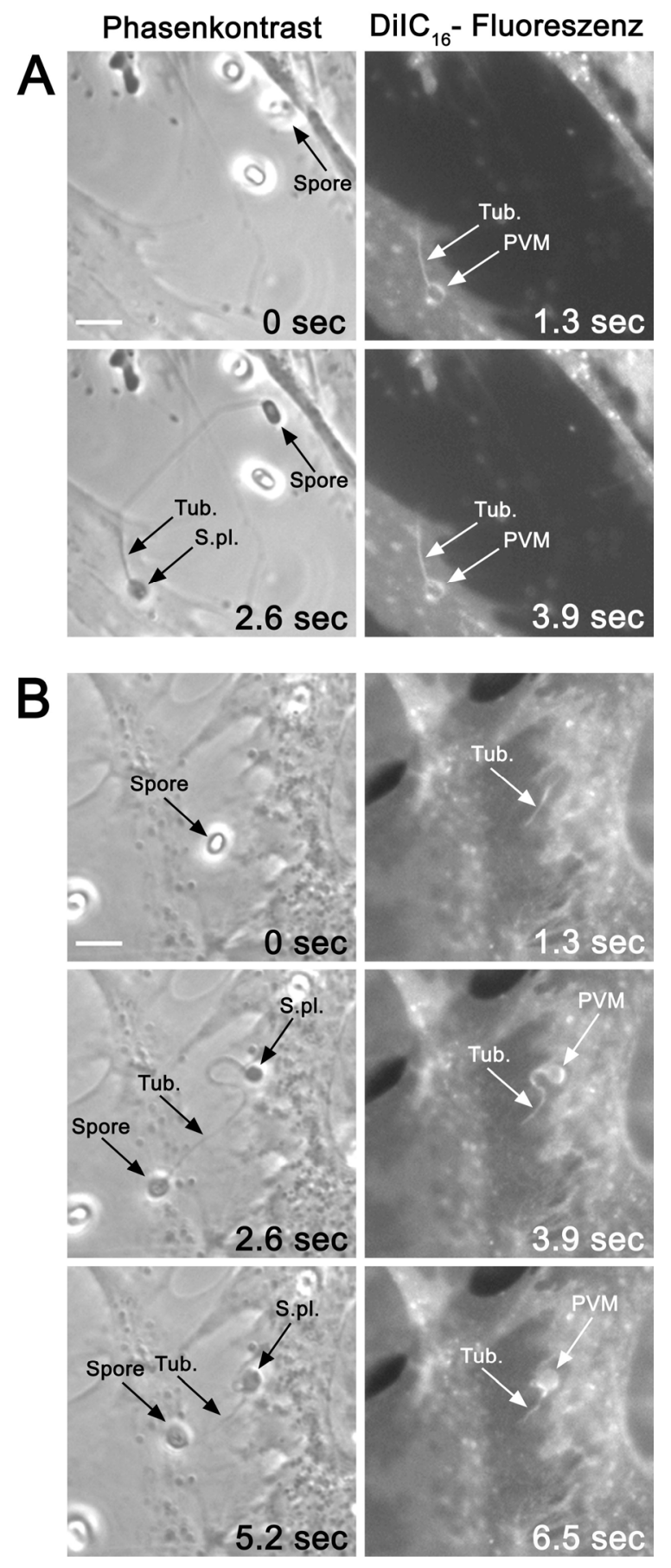

Abb. 3.7: Untersuchung der Invasion mit Hilfe der „time-lapse“- Mikroskopie. Lebende, DiIC $_{16}$-markierte HFF-Zellen wurden mit E. cuniculi infiziert und die Invasion durch Phasenkontrast- und Fluoreszenzaufnahmen in Intervallen von 1,3 sec festgehalten. Die Pfeile der Phasenkontrast-Bilder zeigen die Spore vor und nach der Sporulation (0 sec und 2,6 sec), sowie den ausgeschleuderten Tubulus (Tub.) und das Sporoplasma (S.pl.), das nach Transport durch den Tubulus direkt in die Wirtszelle injiziert wird. Die Pfeile in der DiIC 16 -Fluoreszenz zeigen den Penetrationskanal (Tub.), sowie die entstehende Vakuolenmembran (PVM). A) Die Bildung der PVM ist ein sehr schneller Prozess, und benötigt in diesem Fall nur 
1,3 sec. Zusätzlich trägt auch die Kontaktregion zwischen Tubulus und Wirtszelle (Tub.) eine Fluoreszenzmarkierung (1,3 und 3,9 sec). B) Diese Invasion ist etwas langsamer und erst nach 5,2 sec abgeschlossen. Die aufgenommenen Zwischenschritte zeigen, dass zuerst die Kontaktregion zwischen Tubulus und Wirtszelle die Fluoreszenzmarkierung erhält (siehe 1,3 sec). Erst danach beginnt der Transport des Sporoplasmas durch den Tubulus, und die fluoreszierende PVM entsteht $(2,6$ und 3,9 sec). Nach 5,2 sec hat die PVM ihre vorläufige Endgröße erreicht. Maßstabsbalken $5 \mu \mathrm{m}$.

\subsubsection{Vorkommen von Wirtszell-Oberflächenproteinen in der Vakuolenmembran}

In vorangegangenen Arbeiten wurde die Vakuolenmembran auf das Vorhandensein einzelner kompartimentspezifischer Wirtszell-Markerproteine wie EEA1, LAMP1, Calnexin und den Oberflächen-Marker Transferrin-Rezeptor überprüft, wobei keines dieser Proteine in der PVM nachgewiesen werden konnte (Fasshauer et al., 2005). Da die bisherigen Ergebnisse allerdings auf einen Ursprung der PVM von der Plasmamembran der Wirtszelle hindeuten, sollte die PVM auf das generelle Fehlen von Wirtszell-Oberflächenproteinen untersucht werden.

Hierzu wurden die Oberflächenproteine der Wirtszelle mit Biotin markiert und nach erfolgter E. cuniculi-Infektion mit Hilfe von Cy3-konjugiertem Streptavidin überprüft, ob die Vakuolenmembran biotinylierte Oberflächenproteine enthält. Um die Aufnahme von freiem Sporoplasma über Phagocytose $\mathrm{zu}$ inhibieren, wurde der Versuch in Anwesenheit von Cytochalasin-D durchgeführt. Die Infektion mit E. cuniculi wurde zu unterschiedlichen Zeitpunkten durch Fixierung der Zellen in PFA gestoppt. Nach erfolgter Permeabilisierung wurden die Meronten mit Hilfe des Meronten-spezifischen Antikörpers 6G2 und einem Cy2gekoppelten Sekundärantikörper detektiert und konfokale Bilder zur Auswertung angefertigt (Abb. 3.8). Als Positivkontrolle diente ein Cytochalasin-D unbehandelter Ansatz, bei dem ein geringer Anteil an unsporulierten E. cuniculi-Sporen über Phagocytose internalisiert wurde (siehe auch Kap. 1.7). Dieser Vorgang wurde für den positiven Nachweis von endosomalen und lysosomalen Markerproteinen genutzt, wobei die phagocytierten Sporen selbst mit dem Sporen-spezifischen anti-SWP1-Antikörper detektiert wurden. Während die Phagosomenmembran der phagocytierten Sporen in allen Fällen sehr intensiv mit StrepavidinCy3 markiert ist (Ak SWP1, merge) trägt die den Meronten umgebene Vakuolenmembran in mehr als $90 \%$ aller untersuchten Vakuolen keine Markierung (Ak 6G2, merge). Die natürliche injektions-basierte Infektion unterscheidet sich somit deutlich von der Phagocytose ganzer Sporen. Während bei der natürlichen Infektion keine Wirtszell-Oberflächenproteine 
auf der PVM nachweisbar sind, enthält die durch eine Phagocytose entstehende Phagosomenmembran sehr viele Wirtszell-Oberflächenproteine.

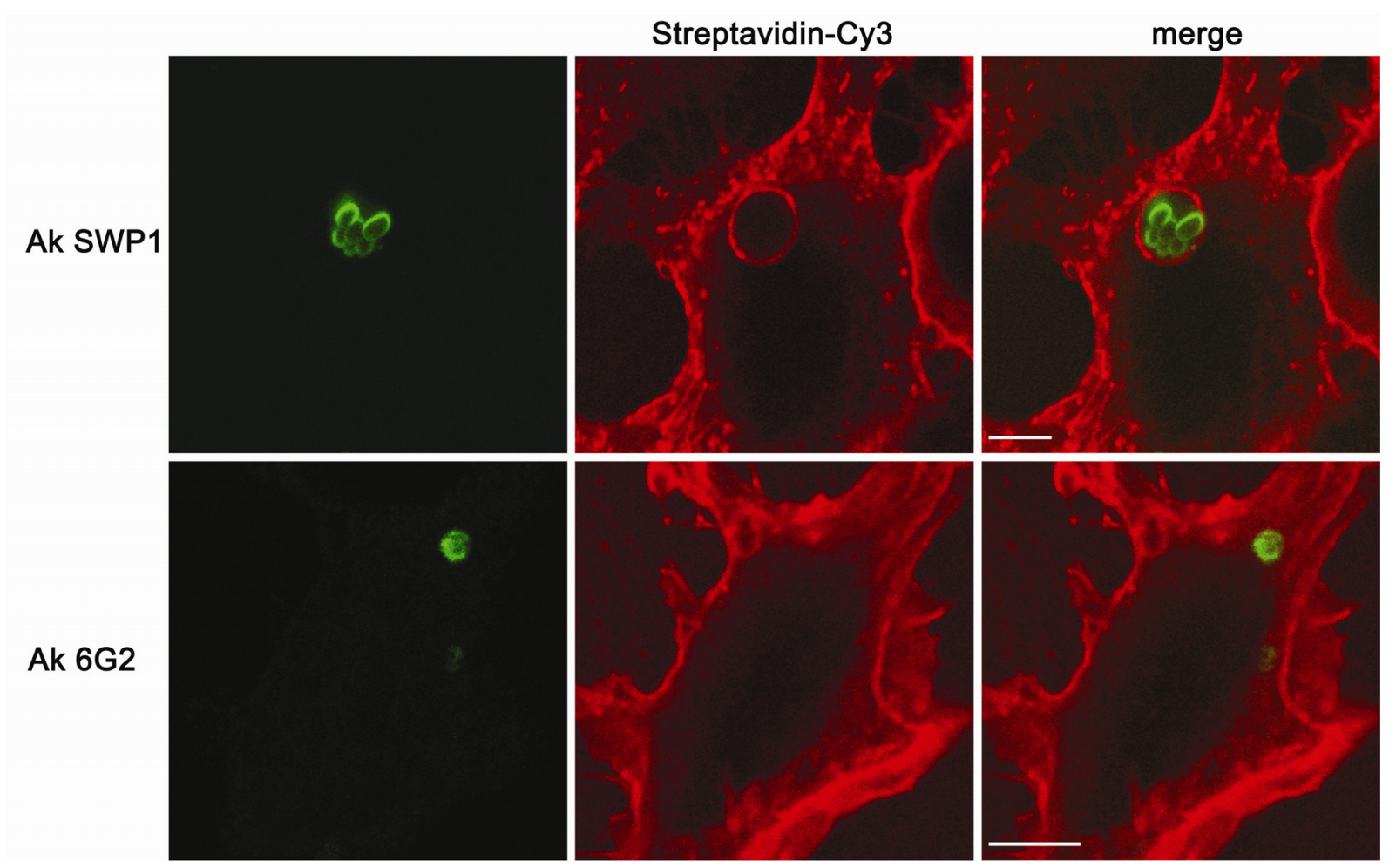

Abb. 3.8: Die entstehende PVM enthält keine Wirtszell-Oberflächenproteine. Oberflächenproteine von BHK-Zellen wurden mit Biotin markiert, und die Zellen anschließend mit E. cuniculi infiziert. $9 \mathrm{~h}$ nach der Infektion wurden die Zellen mit PFA fixiert, permeabilisiert und anschließend mit einer Immunfluoreszenzfärbung angefärbt. Der Nachweis von E. cuniculi erfolgte im Falle der Sporenphagocytose mit einem Antikörper gegen das Sporenwandprotein 1 (Ak SWP1), im Falle der injektions-basierten natürlichen Infektion mit dem Meronten-spezifischen Antikörper 6G2 (Ak 6G2). Als Sekundärantikörper diente ein Cy2-anti-Maus-Konjugat (grün). Die biotinylierten Wirtszellproteine wurden mit Cy3-gekoppeltem Streptavidin (rot) nachgewiesen. Die Auswertung erfolgte im KonfokalMikroskop. Phagocytierte Sporen sind von einer stark mit Biotin-Streptavidin markierten Phagosomenmembran umgeben, während die den Meronten umgebende Vakuolenmembran keine Markierung aufweist. Maßstabsbalken $5 \mu \mathrm{m}$.

Zusätzlich wurde der Versuch auch statistisch, durch Auszählen der biotinylierten bzw. unbiotinylierten Vakuolenmembranen ausgewertet (Abb. 3.9). Um zu den verschiedenen Zeitpunkten (1 - $60 \mathrm{~min})$ auch die Anzahl an phagocytiertem Sporoplasma zu ermitteln, wurden in parallelen Ansätzen Phagocytosekontrollen durchgeführt. Dazu wurde überprüft, ob die 6G2-positiven Meronten mit den endosomalen und lysosomalen Markerproteinen EEA1 und LAMP1 kolokalisierten. Für die statistische Auswertung wurden in Doppelwerten jeweils ca. 50 Vakuolen ausgezählt. Anschließend wurde der Anteil an 6G2-positiven, 
biotinylierten bzw. unbiotinylierten Vakuolen und der Anteil EEA1- oder LAMP1-positiver bzw. negativer Vakuolen in Prozent ermittelt (Abb. 3.9).

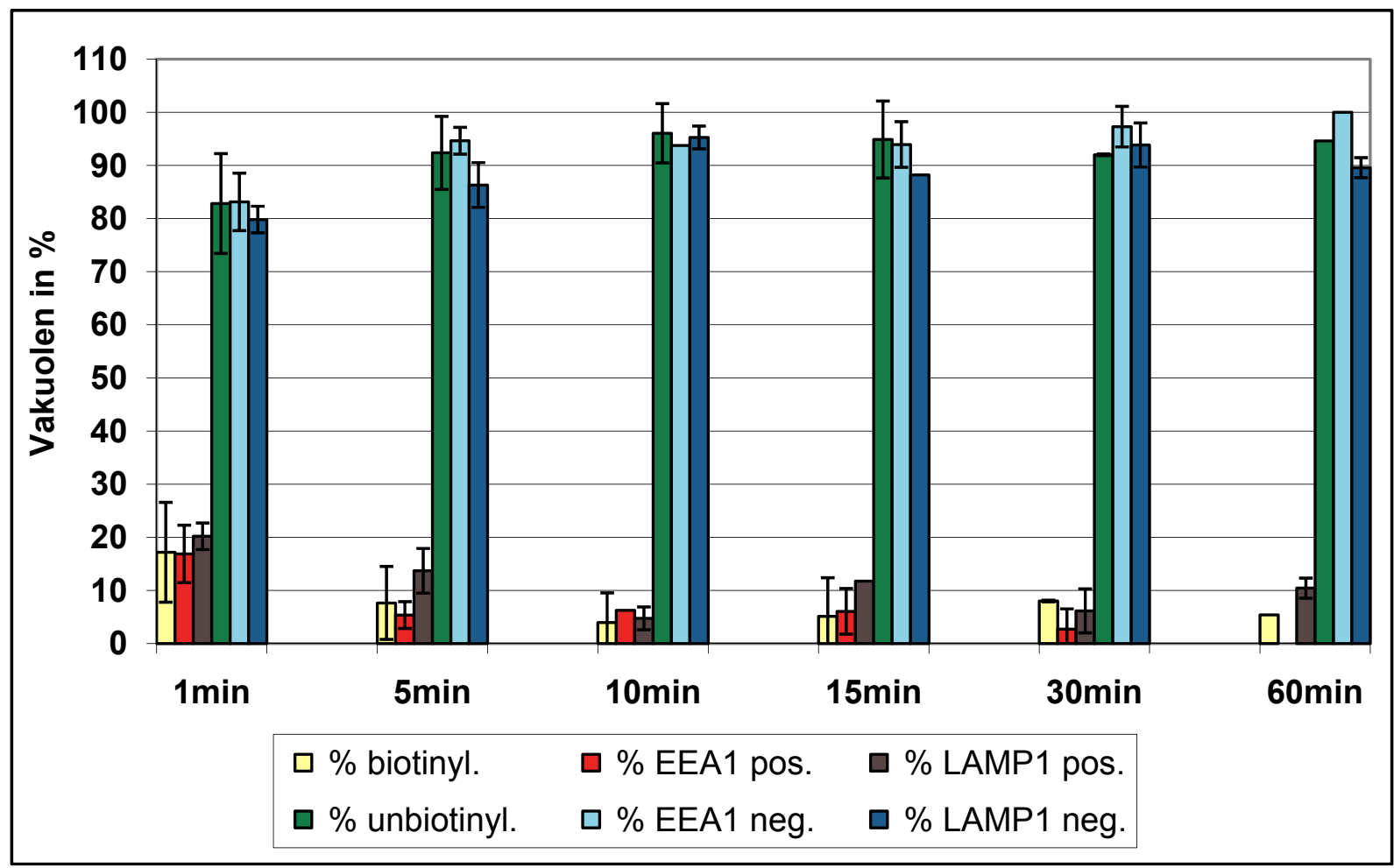

Abb. 3.9: Statistische Auswertung der Biotinylierung. L929-Zellen wurden mit $1 \mu \mathrm{M}$ Cytochalasin-D für $1 \mathrm{~h}$ vorinkubiert, anschließend mit Biotin markiert und in Anwesenheit von $5 \mu \mathrm{M}$ CytD mit E. cuniculi infiziert. Zu unterschiedlichen Zeitpunkten (1 - 60 min) wurde die Infektion durch Inkubation in PFA gestoppt, die Zellen permeabilisiert und eine Immunfluoreszenzfärbung durchgeführt. Dabei wurden Meronten mit dem Merontenspezifischen Antikörper 6G2 und einem Cy2-konjugierten Sekundärantikörper nachgewiesen. Biotinylierte Oberflächenproteine wurden mit Streptavidin-Cy3 angefärbt, und die PVM anschließend auf ein Cy3-Signal hin untersucht. Um zusätzlich den Anteil an Sporoplasma zu ermitteln, der durch Phagocytose aufgenommen wurde, wurden in parallelen Ansätzen die 6G2-gefärbten Meronten auf Kolokalisation mit EEA1 und LAMP1 untersucht. Anschließend wurde der Anteil an biotinylierten bzw. unbiotinylierten Vakuolen und der Anteil EEA1- oder LAMP1-positiver bzw. negativer Vakuolen in Prozent ermittelt. Nach 1 min sind ca. 83 \% der 6G2-positiven Vakuolen unbiotinyliert, also frei von Wirtszell-Oberflächenproteinen. Nach 5 min steigt der Anteil unbiotinylierter Vakuolen sogar auf ca. $90 \%$. Trotz der CytD Behandlung sind EEA1-positive und LAMP1-positive Vakuolen vorhanden.

Die statistische Auswertung zeigt, dass die Vakuolenmembran in den ersten Minuten nach der Infektion zu $80-90 \%$ frei von Wirtszell-Oberflächenproteinen ist. Nach $1 \mathrm{~h}$ sind sogar ca. $95 \%$ der Vakuolen Biotin-negativ (Abb. 3.9). Dieser Wert bleibt auch zu späteren Zeitpunkten der Infektion ( $3 \mathrm{~h}-9 \mathrm{~h})$ konstant, nach $24 \mathrm{~h}$ sind alle Vakuolen unbiotinyliert und enthalten damit keine Wirtszell-Oberflächenproteine (Daten nicht gezeigt). Somit werden 
trotz des Ursprungs der PVM von der Wirtszell-Plasmamembran die WirtszellOberflächenproteine von der überwiegenden Anzahl entstehender Vakuolen ausgeschlossen. Für eine kleinere Vakuolenpopulation $(<20 \%$ ) sind jedoch $\mathrm{zu}$ frühen Zeitpunkten WirtszellOberflächenproteine nachweisbar. Auffällig ist auch, dass trotz einer Inhibierung der Phagocytose durch Cytochalasin-D noch EEA1- und LAMP1-positive Vakuolen vorkommen. Der Anteil biotinylierter Vakuolen deckt sich in etwa mit dem Anteil EEA1- und LAMP1positiver Vakuolen. 


\subsection{Die parasitophore Vakuolenmembran enthält Poren}

Die parasitophore Vakuolenmembran ist entscheidend für die Wechselwirkungen zwischen Mikrosporidium und Wirtszelle, vor allem für Transport-Prozesse und Metabolit-Austausch. Um zu überprüfen, ob die E. cuniculi-PVM Poren enthält, die einen Stoffaustausch ermöglichen, sollten Membran-impermeable Fluoreszenzfarbstoffe in das Cytosol der infizierten Wirtszelle mikroinjiziert und die anschließende Fluoreszenzverteilung untersucht werden. Mikroinjektion in das Wirtszell-Cytosol gilt allgemein als geeignete Methode zur Identifizierung von Poren in der PVM, und wurde auch zur Identifizierung der Poren von Toxoplasma gondii, Plasmodium berghei und Eimeria nieschulzii angewandt (Bano et al., 2007; Werner-Meier und Entzeroth, 1997; Schwab et al., 1994).

\subsubsection{Mikroinjektion in das Cytosol der infizierten Wirtszelle}

Für die Mikroinjektion wurden Membran-impermeable Fluoreszenzfarbstoffe und fluoreszenzmarkierte Peptide verschiedener Größen und verschiedener Ladungen ausgewählt (siehe Tab. 3.1). Die Mikroinjektion wurde wie unter 2.2.2.6 beschrieben an infizierten HFFZellen durchgeführt.

Tab. 3.1: Eigenschaften der für die Mikroinjektion verwendeten Fluoreszenzfarbstoffe und Peptide

\begin{tabular}{|l|c|c|c|}
\hline Fluoreszenzfarbstoff & Molekülgröße [kDa] & Ladung & Diffusion über die PVM \\
\hline Alexa Fluor 488 hydrazide & 0,5 & -1 & ++ \\
\hline RSR-Carboxyfluorescein (5-FAM) & 0,7 & +2 & ++ \\
\hline $\begin{array}{l}\text { SGALDVLQ-Carboxyfluorescein } \\
\text { 5-FAM) }\end{array}$ & 1,1 & -1 & ++ \\
\hline $\begin{array}{l}\text { 3000 MW Dextran, Alexa Fluor 488 } \\
\text { 10.000 MW Dextran, } \\
\text { Tetramethylrhodamine }\end{array}$ & $1,5-3$ & -1 & - \\
\hline $\begin{array}{l}\text { 70.000 MW Dextran, } \\
\text { Tetramethylrhodamine }\end{array}$ & $9-11$ & neutral & - \\
\hline
\end{tabular}


Nach der Injektion wurde die Farbstoffverteilung über die Vakuolenmembran zu unterschiedlichen Zeitpunkten durch Einzelfotos oder mit „time-lapse“-Aufnahmen dokumentiert (Abb. 3.10). Der 0,5 kDa große Farbstoff Alexa Fluor 488 hydrazide ist sehr schnell nach der Injektion sowohl im Cytosol der Wirtszelle als auch in der parasitophoren Vakuole zu finden. Die Freiräume in der Vakuole zwischen den Parasiten waren unmittelbar nach der Injektion vollständig vom Farbstoff ausgefüllt (Alexa Fluor 0,5 kDa, Pfeile), so dass davon auszugehen ist, das die PVM für dieses Molekül keine Diffusionsbarriere darstellt und demnach Poren besitzt, die einen Stoffaustausch ermöglichen. Die mit Alexa Fluor 488 konjugierten $3 \mathrm{kDa}$ großen Dextran-Moleküle zeigen bei dem Eintritt in die Vakuole einen verzögerten Phänotyp. Während nach 30 sec noch nicht alle Parasiten von Farbstoff umgeben sind, ist die Verteilung nach 10 min abgeschlossen, und Freiräume in der Vakuole werden ausgefüllt (Dextran $3 \mathrm{kDa}$, Pfeile). Im Gegensatz dazu wird die Tetramethylrhodaminekonjugierten 10 kDa Dextran-Moleküle vollständig von der Vakuole ausgeschlossen. Die Vakuole erscheint nur als dunkler Schatten in der ansonsten fluoreszierenden Zelle (Dextran $10 \mathrm{kDa}$, Pfeile). Die Größenabhängigkeit des Farbstoffeintritts in die Vakuole wurde außerdem anhand einer Mischung aus Alexa Fluor 488 hydrazide und dem 10 kDa DextranFarbstoff untersucht, die in das Cytosol einer infizierten HFF-Zelle mikroinjiziert wurden (Abb. 3.11). Auch dieser Versuch zeigt, dass nur das $0,5 \mathrm{kDa}$ große Alexa Fluor (grün) Zugang zur Vakuole hat, während die $10 \mathrm{kDa}$ Dextran-Moleküle (rot) von der Vakuole ausgeschlossen bleiben. Die unterschiedliche Eintrittskinetik der verwendeten Farbstoffe zeigt, dass die PVM von E. cuniculi Poren mit einer Ausschlussgröße zwischen 3 und 10 kDa besitzt. Um zu überprüfen ob auch physiologisch relevante und zudem geladene Moleküle die Poren passieren können, wurden fluoreszenzmarkierte Peptide unterschiedlicher Ladungen mikroinjiziert. Dazu wurden die mit Carboxyfluorescein (5-FAM) gekoppelten Peptide RSR (0,7 kDa, Ladung + 2) und SGALDVLQ (1,1 kDa, Ladung - 1) (JPT Peptide Technologies, Berlin) ausgewählt (Schwab et al., 1994). Ungeachtet ihrer Ladung haben sowohl das 0,7 kDa als auch das 1,1 kDa Peptid sofortigen Zugang zur Vakuole (Abb. 3.10) und bestätigen somit das Vorhandensein von Poren in der PVM, die in der Lage sind einen Metabolitaustausch zwischen dem Wirtszell-Cytosol und der Vakuole zu gewährleisten. 


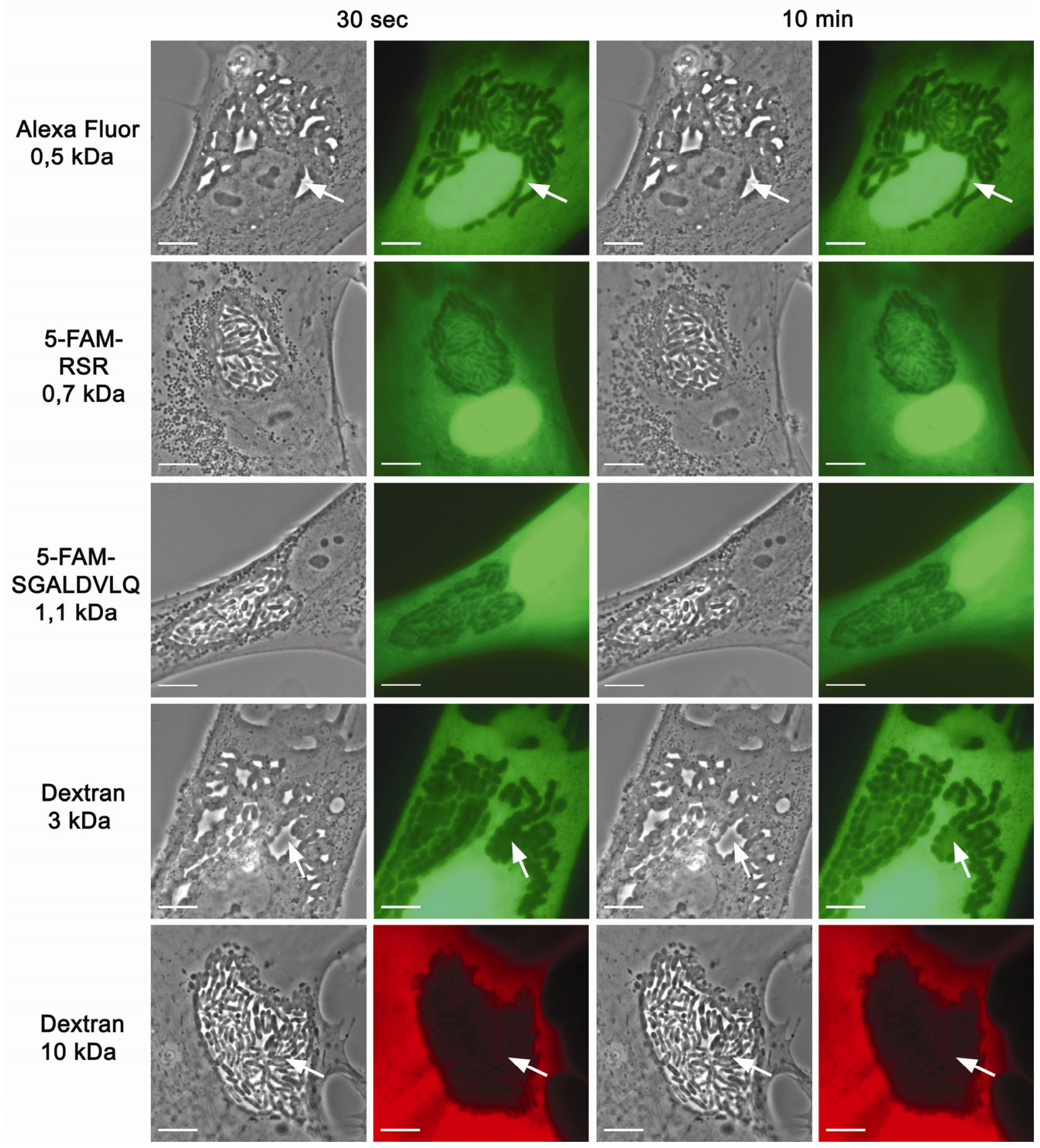

Abb. 3.10: Die E. cuniculi PVM besitzt Poren mit einer Ausschlussgröße von 3-10 kDa. HFF-Zellen wurden mit E. cuniculi infiziert und 36 - 40 h nach Infektion wurden Membranimpermeable Farbstoffe verschiedener Größen in das Cytosol mikroinjiziert. Nach der Injektion wurde die Farbstoffverteilung über die PVM beobachtet, und nach $30 \mathrm{sec}$, sowie nach 10 min dokumentiert. Alexa Fluor 488 hydrazide (Alexa Fluor 0,5 kDa), sowie die fluoreszenzmarkierten Peptide (5-FAM-RSR, 0,7 kDa und 5-FAM-SGALDVLQ, 1,1 kDa) treten sehr schnell in die Vakuole ein (siehe $30 \mathrm{sec}$ ). Die Mikrosporidien sind vollständig von den Farbstoffen umhüllt, und Freiräume in der Vakuole werden vom Farbstoff ausgefüllt (Alexa Fluor, Pfeile). Die Verteilung der $3 \mathrm{kDa}$ Dextran-Moleküle zeigt einen verzögerten Phänotyp. Während nach $30 \mathrm{sec}$ Freiräume der Vakuole noch nicht ausgefüllt sind (siehe Pfeile), sind die Mikrosporidien nach 10 min vollständig umhüllt. Die 10 kDa DextranMoleküle bleiben von der Vakuole ausgeschlossen. Sowohl nach $30 \mathrm{sec}$ als auch nach $10 \mathrm{~min}$ erscheint die Vakuole nur als dunkler Schatten (Pfeile) in der ansonsten fluoreszierenden Zelle. Maßstabsbalken $10 \mu \mathrm{m}$. 


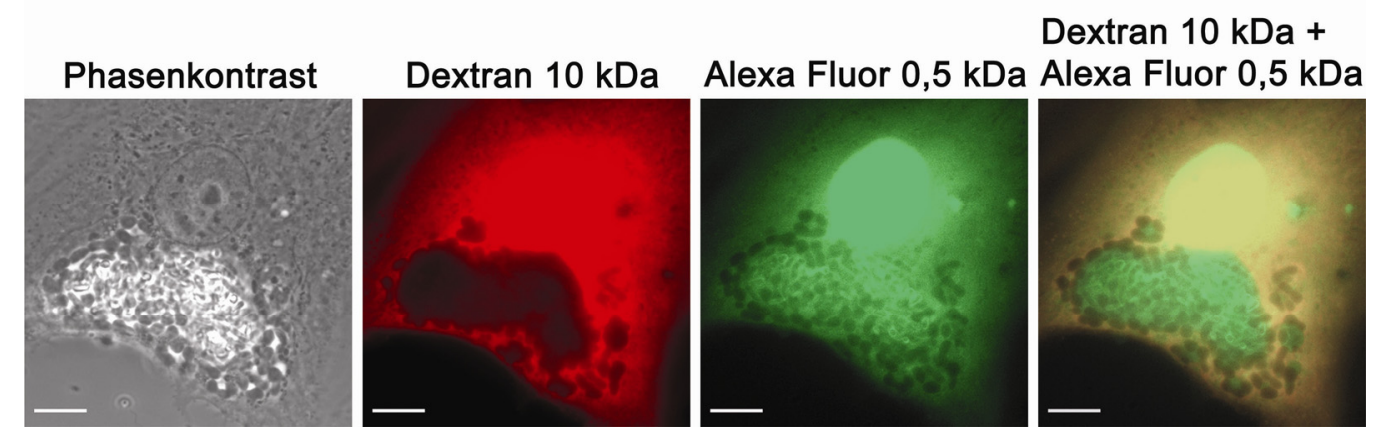

Abb. 3.11: Mikroinjektion einer Farbstoffmischung aus Alexa Fluor 488 hydrazide (0,5 kDa) und dem 10 kDa Dextran-Farbstoff. Die Farbstoffe Alexa Fluor 488 hydrazide und Tetramethylrhodamine-Dextran $(10 \mathrm{kDa})$ wurden gemischt und die Mischung in das Cytosol einer infizierten HFF-Zelle injiziert. $30 \mathrm{sec}$ nach Injektion wurde die Farbstoffverteilung dokumentiert. Während die 0,5 kDa großen Alexa Fluor 488-Moleküle (grün) sehr schnell in die Vakuole eintreten, bleiben die $10 \mathrm{kDa}$ TetramethylrhodamineDextran-Moleküle (rot) von der Vakuole ausgeschlossen. Maßstabsbalken $10 \mu \mathrm{m}$.

Ferner wurde untersucht, ob die Expression der Poren und deren Ausschlussgröße möglicherweise von Alter oder Größe der Vakuole abhängig ist. Dazu wurden HFF-Zellen in einer Kinetik zu unterschiedlichen Zeitpunkten nach der Infektion mit den 0,5 kDa und den $10 \mathrm{kDa}$ Molekülen mikroinjiziert. Die Mikroinjektion wurde am Tag 1, Tag 2, Tag 3 und Tag 4 nach der Infektion durchgeführt. Spätere Zeitpunkte konnten aufgrund der Größe der Vakuole nicht mehr untersucht werden. Nach der Injektion wurde die Verteilung des Farbstoffes über die PVM im Fluoreszenzkanal dokumentiert (Abb. 3.12). Die Farbstoffverteilung war zu allen untersuchten Zeitpunkten identisch. Das 0,5 kDa große Alexa Fluor 488 hydrazide hat sofort nach Injektion Zutritt zur Vakuole, während die $10 \mathrm{kDa}$ Dextran-Moleküle ausgeschlossen bleiben. Die Poren in der Vakuolenmembran sind demnach sowohl zu frühen als auch zu späteren Zeitpunkten der Entwicklung (Tag 1 - 4) vorhanden, besitzen eine konstante Ausschlussgröße und ermöglichen somit vermutlich eine gleichbleibende Versorgung des Parasiten mit Nährstoffen von der Wirtszelle. 


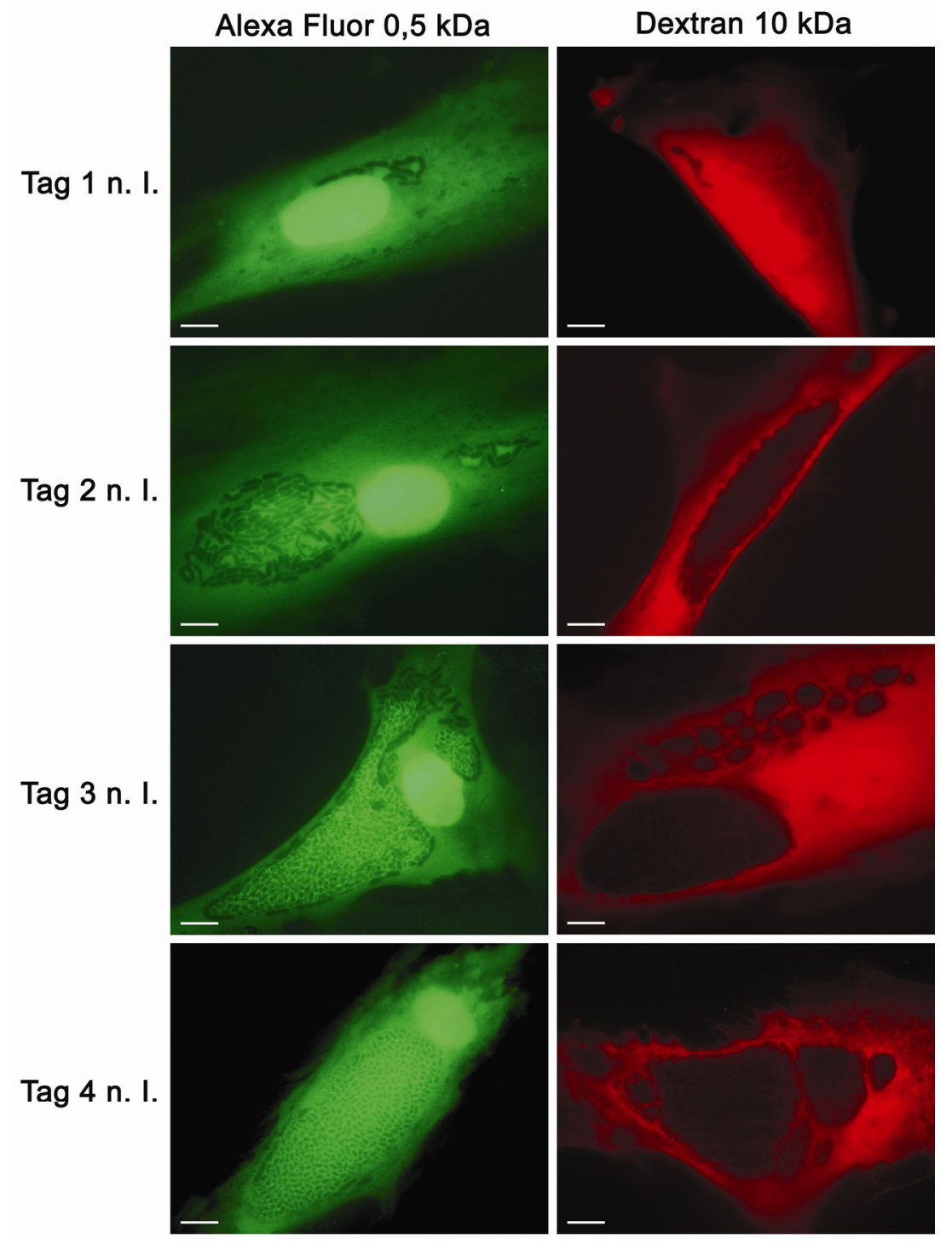

Abb. 3.12: Die Expression der Poren ist unabhängig von Alter oder Größe der Vakuole. HFF-Zellen wurden mit E. cuniculi infiziert und zu unterschiedlichen Zeitpunkten (Tag 1 - 4 nach Infektion (n. I.)) mit Alexa Fluor 488 hydrazide oder den 10 kDa Tetramethylrhodamine-Dextran-Molekülen mikroinjiziert. $30 \mathrm{sec}$ nach Injektion wurde die Farbstoffverteilung im Fluoreszenzkanal dokumentiert. Das Alexa Fluor hydrazide hat zu allen untersuchten Zeitpunkten sofortigen Zugang zur Vakuole, während die 10 kDa DextranMoleküle ausgeschlossen bleiben. Man beachte, dass die Zellen teilweise mehrere Vakuolen enthalten (siehe Tag 3 n. I., Dextran $10 \mathrm{kDa}$ ). Nach 4 Tagen ist fast die gesamte Zelle mit der Vakuole ausgefüllt. Maßstabsbalken $10 \mu \mathrm{m}$. 


\subsubsection{Mikroinjektion in die parasitophore Vakuole}

In einem „time-lapse“-Experiment, bei dem die Entwicklung der Vakuole von E. cuniculi im Phasenkontrast untersucht wurde, konnte beobachtet werden, dass die Vakuole eine dynamische Struktur besitzt, und möglicherweise Tochtervakuolen abschnürt (Abb. 3.13; gelbe Pfeile) oder mit anderen Vakuolen verschmilzt (rote Pfeile).
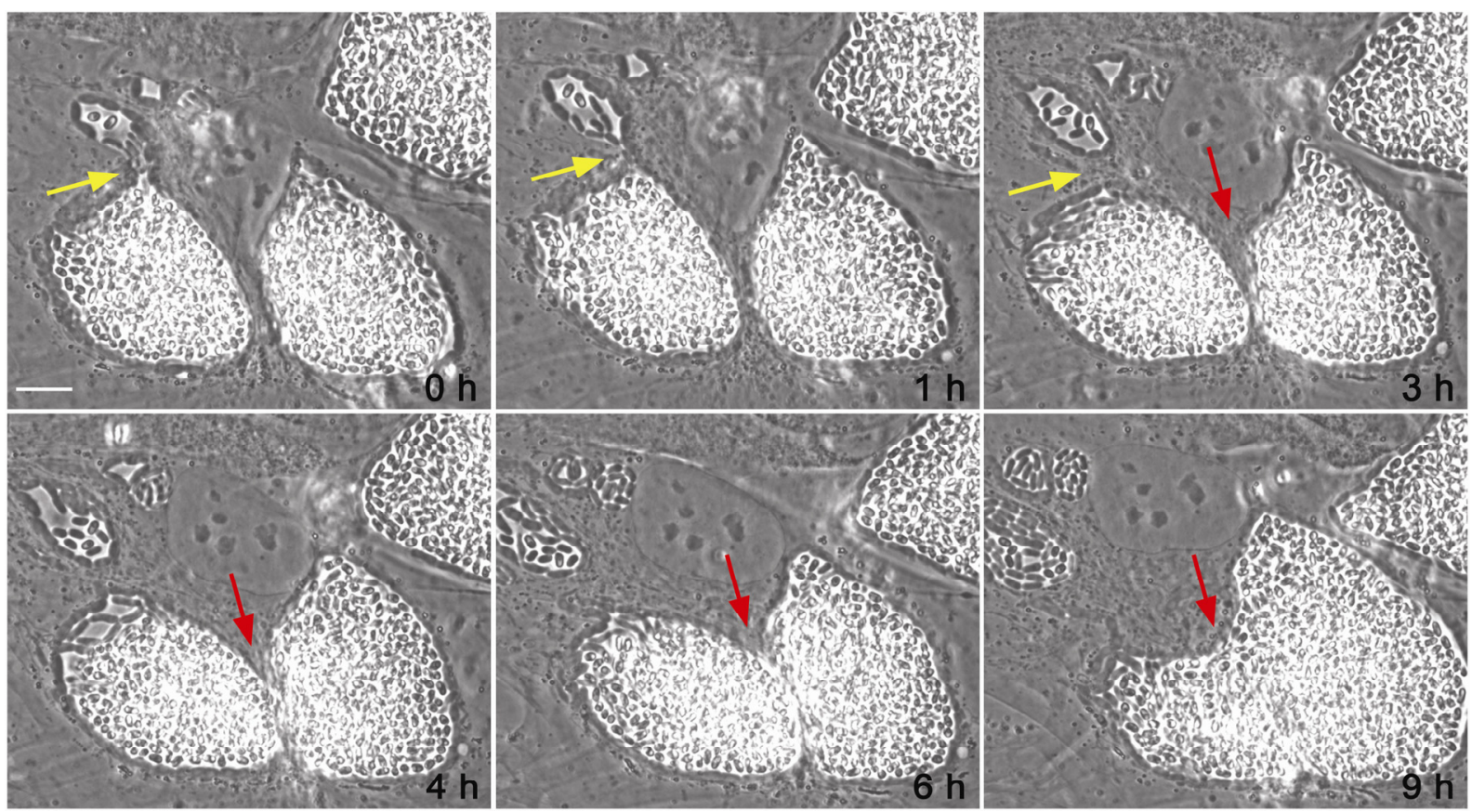

Abb. 3.13: „Time-lapse“-Aufnahmen der parasitophoren Vakuole im Phasenkontrast. Ein HFF-Monolayer wurde mit E. cuniculi infiziert und die Entwicklung der Vakuolen im Phasenkontrast mit einem Zeitintervall von $1 \mathrm{~h}$ verfolgt. Dargestellt sind exemplarisch einige Aufnahmen von ca. 2,5 Tage alten Vakuolen. Die Zeitangabe entspricht der relativen Zeit, verglichen mit dem ersten Bild der Abbildung. Die parasitophore Vakuole scheint in der Lage zu sein, Tochtervakuolen abzuspalten (gelbe Pfeile) und mit anderen Vakuolen zu verschmelzen (rote Pfeile). Maßstabsbalken $10 \mu \mathrm{m}$.

Um zu untersuchen, ob die einzelnen Vakuolen innerhalb einer Zelle miteinander verbunden sind, oder vollständig eigenständige Vakuolen bilden, wurde eine Mikroinjektion von Farbstoff direkt in das Lumen der parasitophoren Vakuole durchgeführt. Dazu wurde der $10 \mathrm{kDa}$ Dextran-Farbstoff, der aufgrund seiner Größe nicht durch die Poren der PVM diffundieren kann, ausgewählt. HFF-Zellen wurden semikonfluent ausgesät, mit E. cuniculi infiziert und die ca. $40 \mathrm{~h}$ alten Vakuolen mit dem $10 \mathrm{kDa}$ Tetramethylrhodamine-DextranFarbstoff mikroinjiziert. Die parasitophore Vakuole wurde vor der Injektion im Phasenkontrast und nach der Injektion im Phasenkontrast und Fluoreszenzkanal untersucht. 


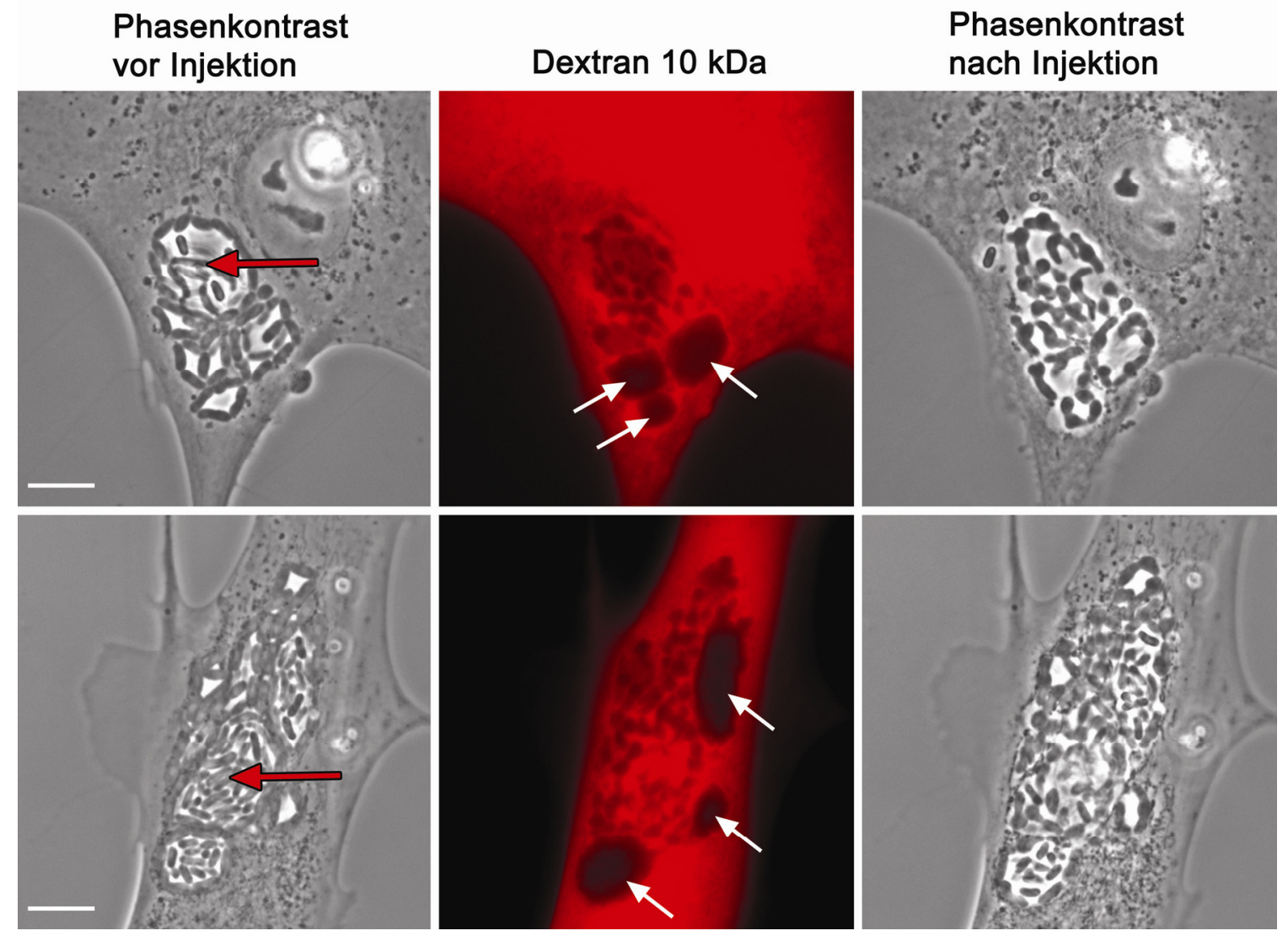

Abb. 3.14: Mikroinjektion des 10 kDa Tetramethylrhodamine-Dextran-Farbstoffs in die parasitophore Vakuole. HFF-Zellen wurden infiziert und die entstandenen Vakuolen $40 \mathrm{~h}$ nach Infektion mit den 10 kDa Dextran-Molekülen, die aufgrund ihrer Größe nicht durch die Poren diffundieren können, mikroinjiziert. Vor der Injektion wurde die Vakuole im Phasenkontrast, nach der Injektion im Phasenkontrast und im Fluoreszenzkanal untersucht. Die Stelle, an der die Mikroinjektion durchgeführt wurde ist im Phasenkontrast vor der Injektion mit einem roten Pfeil gekennzeichnet. Während vor der Mikroinjektion eine Unterteilung der Vakuole erahnt werden konnte, wurde diese Architektur durch den Druck bei der Mikroinjektion verändert. Nichtsdestotrotz zeigt die Verteilung der 10 kDa DextranMoleküle, dass der Farbstoff zu einigen Teilbereichen der Vakuole keinen Zugang hat. Diese erscheinen als dunkle Schatten im Fluoreszenzkanal (Dextran $10 \mathrm{kDa}$, weiße Pfeile). Die neben der Färbung der Vakuole auftretende cytosolische Färbung wurde vermutlich durch auslaufenden Farbstoff verursacht. Maßstabsbalken $10 \mu \mathrm{m}$.

Das Aussehen der Vakuole war nach der Mikroinjektion durch den Injektionsdruck deutlich verändert. Vor der Injektion konnte eine mögliche Unterteilung der Vakuole anhand der Lage der Meronten, die immer außen an der PVM liegen und die stärker differenzierten Formen umranden, beobachtet werden. Nach der Injektion scheint diese Architektur verändert, selbst die Meronten scheinen zum Teil verformt (Abb. 3.14). Bei Analyse der Verteilung der $10 \mathrm{kDa}$ Dextran-Moleküle fällt jedoch auf, dass nicht alle Teile der Vakuole fluoreszieren. Teile der Vakuole hatten keinen Zugang zum Farbstoff und erscheinen im Fluoreszenzkanal als dunkle Bereiche. Eine mögliche Erklärung für dieses Verteilungsmuster ist, dass die in Abb. 3.14 
gezeigten Vakuolen aus eigenständigen Teilvakuolen aufgebaut sind, zwischen denen eine Diffusionsbarriere besteht. Obwohl die $10 \mathrm{kDa}$ Dextrane aufgrund ihrer Größe nicht durch die Poren diffundieren können (vgl. Abb. 3.10), ist nach der PV-Injektion neben dem Fluoreszenzsignal in der Vakuole auch Farbstoff im Cytosol der HFF-Zellen zu sehen. Dies liegt möglicherweise darin begründet, dass an der Injektionsnadel ein ständiger Kompensationsdruck anliegt. Somit fließen fortwährend kleine Mengen Farbstoff aus der Nadelöffnung aus. Dies verhindert ein ausschließliches Injizieren in die Vakuole, da die Injektionsnadel bei der PV-Injektion zunächst das Cytosol der Wirtszelle durchqueren muss, bevor sie die Vakuole erreicht.

\subsubsection{Das E. cuniculi-Hämolysin III als mögliches Poren-bildendes Protein}

Im Folgenden sollte versucht werden, das Protein, welches die Poren in der PVM bildet, zu identifizieren. Das Genom von E. cuniculi ist zwar vollständig sequenziert (Katinka et al., 2001), bisher konnte allerdings noch kein Protein identifiziert werden, das in der Vakuolenmembran lokalisiert ist. Auch Poren-bildende Proteine anderer intrazellulärer Erreger, wie z. B. von T. gondii oder $P$. falciparum sind bisher noch nicht identifiziert worden. Deswegen sollte aufgrund der Ähnlichkeit zu anderen Poren-bildenden Proteinen wie z. B. Porinen in der äußeren Membran von Gram-negativen Bakterien oder Mitochondrien, Poren-bildenden Toxinen und cytolytischen Proteinen anderer Protozoen nach putativen E. cuniculi-Porinen gesucht werden. Dazu wurde eine so genannte „PFAM-HMM“- Suche durchgeführt, die auf der Ähnlichkeit von Proteinfamilien bzw. Domänen basiert (Finn et al., 2006). Die Stichwort-Suche nach den Begriffen ,pore“ und „porin“ in der PFAM-Datenbank (pfam.janelia.org/) lieferte Modelle von 53 Proteinfamilien. Die Suche mit diesen Modellen im E. cuniculi-Proteom ergab nur einen einzigen signifikanten Treffer $\left(E=3.3 \mathrm{e}^{-69}\right)$, die Proteinfamilie Hämolysin III (HlyIII). Das E. cuniculi Hämolysin III (EcHlyIII) zeigt große Ähnlichkeit zu Hämolysinen verschiedener Bakterien, z. B. zum Hämolysin III von Leifsonia xyli (LxHlyIII) (Abb. 3.15). 


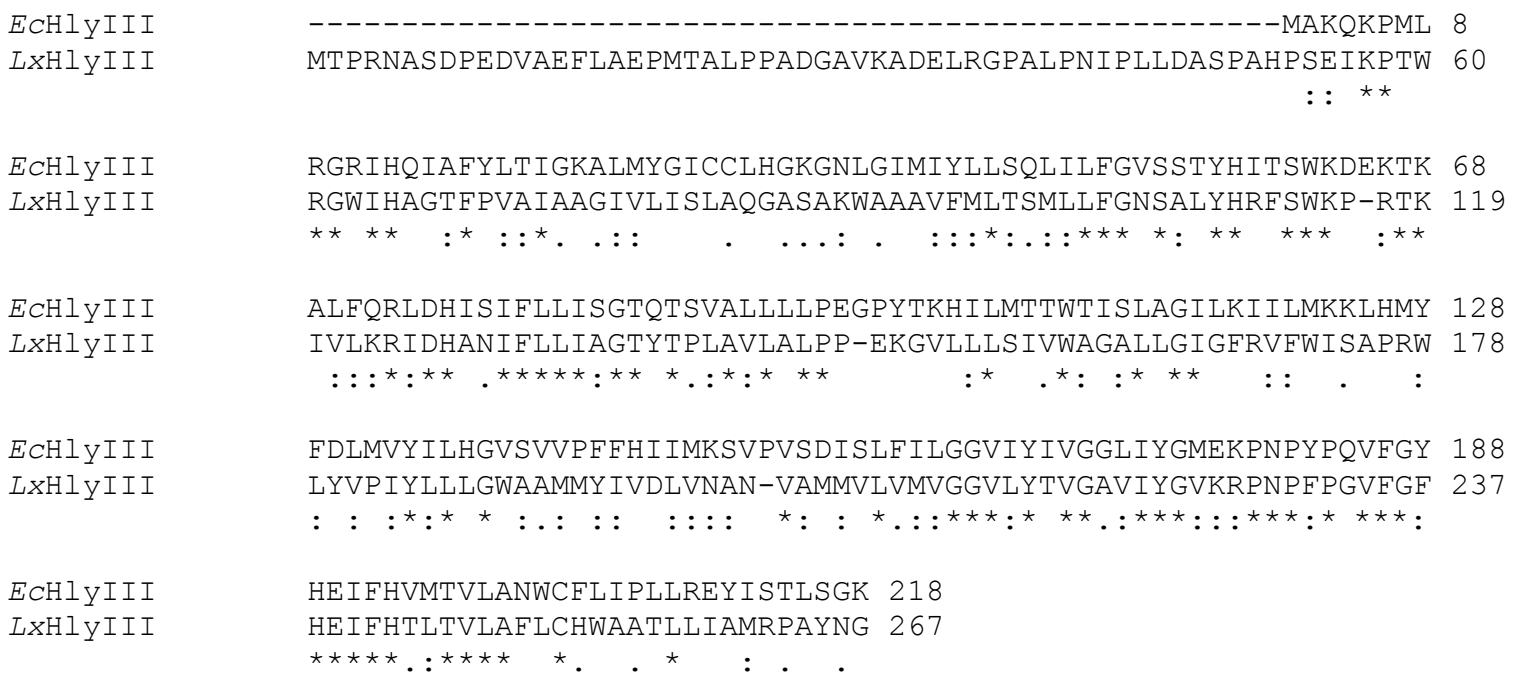

Abb. 3.15: Aminosäuresequenzvergleich des E. cuniculi HlyIII mit einem Hämolysin III von Leifsonia xyli (LxHlyIII). ( * identische Aminosäure, : konservierte AminosäureSubstitution, . semikonservierte Aminosäure-Substitution).

Das E. cuniculi Hämolysin III (,NCBI accession no." NP_585907; „locus identifier“ ECU06_1500) ist $24 \mathrm{kDa}$ groß und besitzt als integrales Membranprotein sieben Transmembranregionen (Abb. 3.16). N-terminal besitzt EcHlyIII mit einer Wahrscheinlichkeit von $58,8 \quad \%$ eine Signalankersequenz (,SignalP“, www.cbs.dtu.dk/services/).

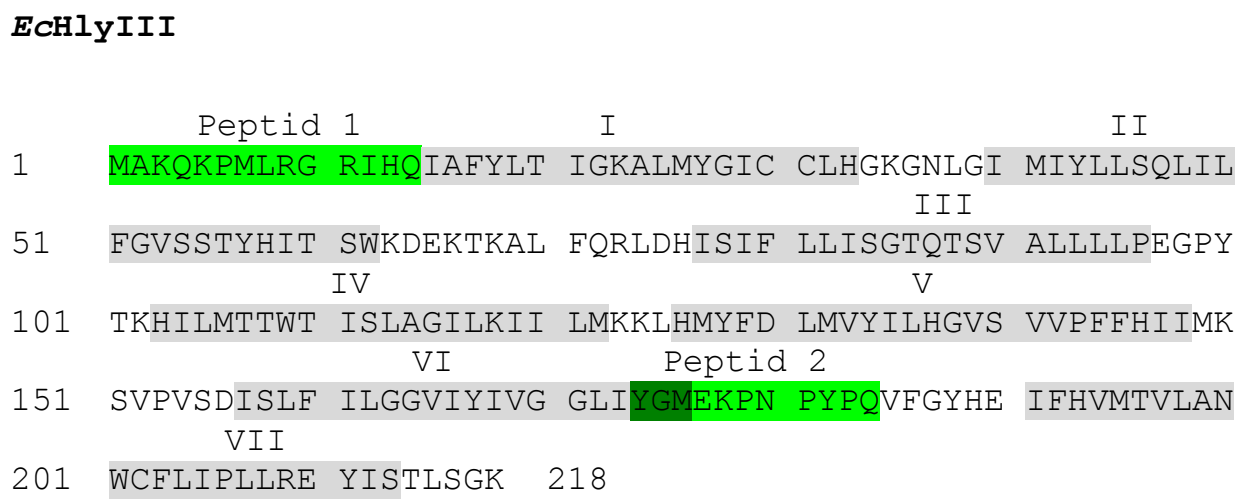

Abb. 3.16: Sequenz und Transmembranregionen von EcHlyIII. Transmembranregionen sind in grau markiert und fortlaufend nummeriert. Die Sequenzen der für die Immunisierung verwendeten Peptide 1 und 2 sind in grün gekennzeichnet. Überlappende Bereiche erscheinen dunkelgrün.

Um zu überprüfen, ob die EcHlyIII-mRNA exprimiert und möglicherweise zu unterschiedlichen Zeitpunkten der Infektion hoch- oder herunterreguliert wird, sollte eine quantitative Real-time-PCR-Analyse durchgeführt werden. Dazu wurde zunächst die Gesamt- 
RNA der E. cuniculi-Kultur 12 h, 24 h, 48 h und 72 h nach der Infektion isoliert und in cDNA umgeschrieben. Anschließend erfolgte die PCR mit echlyIII-genspezifischen Primern im LightCycler. Dabei diente aktin als housekeeping-Gen zur Normalisierung der cDNAMengen. Wie in Abb. 3.17 gezeigt, wird die EcHlyIII-mRNA exprimiert. Zu frühen Zeitpunkten der Infektion (12 h - $24 \mathrm{~h})$ ist die Expression gleichbleibend. Zu späteren Zeitpunkten (48 h - 72 h), wenn die Größe der Vakuole zunimmt, wird die EcHlyIII-mRNA um den Faktor 3 - 3,5 hochreguliert.

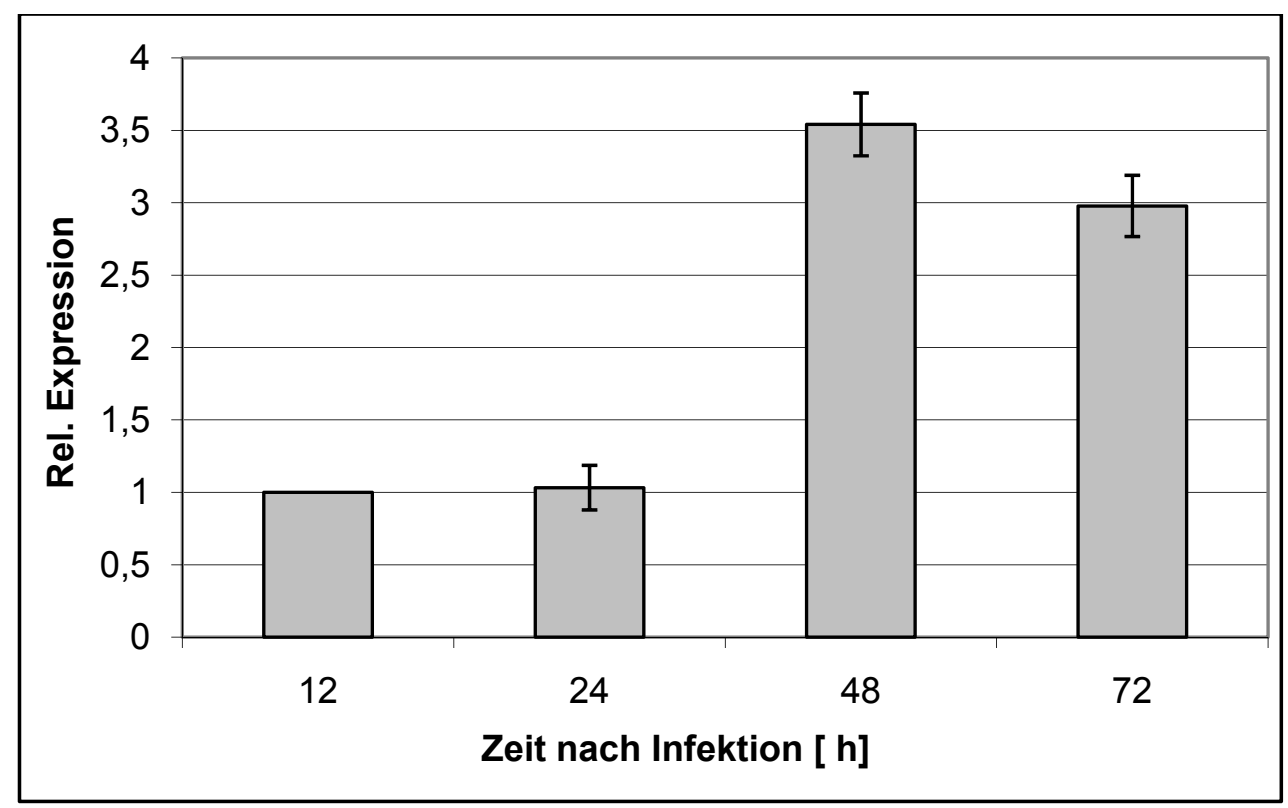

Abb. 3.17: Analyse der EcHlyIII-mRNA-Expression mit der quantitativen Real-timePCR. 12 h, 24 h, 48 h und 72 h nach der Infektion wurde die Gesamt-RNA der E. cuniculiKultur isoliert, in cDNA umgeschrieben und die PCR im LightCyler mit genspezifischen Primern durchgeführt. Die Werte stammen von zwei unabhängigen cDNA-Präparationenen. Um unterschiedliche cDNA-Mengen der Proben auszugleichen, wurde gegen die Expression von aktin normalisiert. Zur Ermittlung der relativen Expression wurden die $12 \mathrm{~h}$-Werte als Referenz verwendet. $\mathrm{Zu}$ frühen Zeitpunkten nach der Infektion (12 h und $24 \mathrm{~h}$ ) wird echlyIII gleichbleibend stark exprimiert. Nach $48 \mathrm{~h}$ bzw. nach $72 \mathrm{~h}$ ist die Expression um den Faktor $3-3,5$ erhöht.

Da nun gesichert war, dass es sich bei echlyIII um ein aktiv transkribiertes Gen handelte, sollte im Folgenden die Lokalisation des Proteins mit Hilfe von anti-Peptid-Antikörpern analysiert werden. Zur Herstellung von anti-Peptid-Antikörpern wurden zwei Teilregionen des zu untersuchenden Proteins ausgewählt, die Peptide synthetisiert, an ein Trägerprotein (KLH) gekoppelt und als Antigen zur Immunisierung von zwei Ratten verwendet. Die Peptide wurden so gewählt, dass sie nicht in Membrandomänen liegen, damit spätere Antikörper im 
IFT Zugang zu den Bindungsstellen haben (Abb. 3.16, grün markierte Sequenzen). Die Herstellung des anti-Peptid-Antikörpers wurde von Eurogentec (Köln) durchgeführt.

Zunächst sollte getestet werden, ob die erhaltenen Seren im Western Blot ein Antigen erkennen. Da vermutet wurde, dass EcHlyIII möglicherweise in der Vakuolenmembran lokalisiert sein könnte, wurde kein Sporenlysat, sondern Zelllysat von uninfizierten und mit E. cuniculi infizierten HFF in einer SDS-PAGE aufgetrennt. Mit der anschließenden Western Blot-Analyse und der Immundetektion konnte allerdings keine spezifische Bande in der Spur der infizierten HFF-Zellen nachgewiesen werden (Daten nicht gezeigt). Im nächsten Schritt wurde ein konzentriertes Sporenlysat für den Western Blot verwendet, um zu testen, ob das Serum möglicherweise ein Sporenprotein erkennt. Um eine unspezifische Reaktion der Seren mit Wirtszell-Antigenen zu untersuchen, wurde auch hier ein HFF-Zelllysat mit aufgetragen.

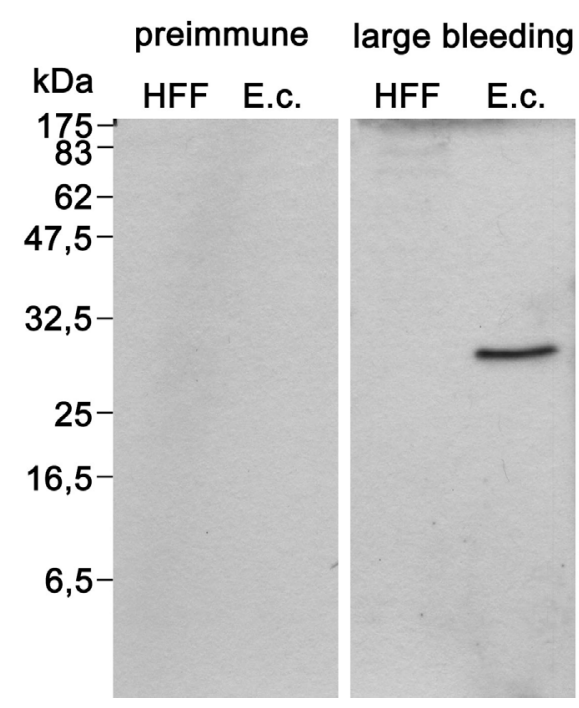

Abb. 3.18: Reaktivität der EcHlyIII-Seren von Ratte 2 gegen HFF- und $E$. cuniculiProteine im Western Blot. HFF-Zelllysat $\left(2 \times 10^{5}\right.$ Zellen/Spur) (HFF) und E. cuniculiSporenlysat ( $4 \times 10^{7}$ Sporen/Spur) (E.c.) wurden in einer SDS-PAGE aufgetrennt, auf eine Membran geblottet und der Blot entsprechend der Anzahl an Seren kleingeschnitten. Die einzelnen Membranteile wurden in einer anschließenden Immunfärbung mit den Seren von Ratte 2 (Verdünnung 1:100) inkubiert. Die Detektion erfolgte mit einem Peroxidasegekoppelten anti-Ratte Sekundärantikörper und einer ECL-Färbung. Während das PräimmunSerum kein Sporenprotein erkennt, ist mit dem Serum der großen Blutung (large bleeding) eine spezifische Bande bei ca. $29 \mathrm{kDa}$ zu erkennen. Das large bleeding-Serum zeigt jedoch auch eine leichte Reaktivität mit Wirtszellproteinen (Spur HFF).

Während die Seren von Ratte 1 keine Reaktivität gegenüber E. cuniculi-Proteinen besitzen (Daten nicht gezeigt), zeigt das Serum der großen Blutung (large bleeding) von Ratte 2 eine deutliche Bande bei ca. $29 \mathrm{kDa}$ (Abb. 3.18). Die erhaltene $29 \mathrm{kDa}-B a n d e$ ist zwar etwas größer als die für $E c H l y I I I$ errechnete Größe von 24 kDa, möglicherweise enthält EcHlyIII 
aber posttranslationelle Modifikationen, die den Größenunterschied verursachen können. Da das Signal in einem Sporenlysat nachgewiesen wurde, und nicht im Zelllysat infizierter Zellen, könnte es sich bei EcHlyIII möglicherweise um ein nicht sezerniertes, integrales Sporenprotein handeln. Denkbar ist jedoch auch, dass die Antigenmenge im vorherigen Versuch mit Zelllysat infizierter Zellen nicht ausreichend war.

Da das large bleeding-Serum noch eine leichte Reaktivität mit Wirtszellproteinen zeigte, sollte das Serum im Folgenden aufgereinigt werden, um es für eine spätere Immunlokalisierung einsetzen zu können. Dazu wurde von Eurogentec (Köln) mit Hilfe der für die Immunisierung verwendeten Peptide eine Affinitätschromatographie durchgeführt. Die Aufreinigung erfolgte für die beiden Peptide in getrennten Chromatographiesäulen, so dass ein Serum gegen Peptid 1 und ein Serum gegen Peptid 2 resultierte. Von diesen beiden Seren erkennt jedoch nur das Serum, das gegen Peptid 2 gerichtet ist, die 29 kDa- Bande im Sporenlysat (Abb. 3.19). Das Serum gegen Peptid 1 zeigt keine Reaktivität. Somit wirkte bei der Herstellung des Antikörpers nur Peptid 2 immunogen.

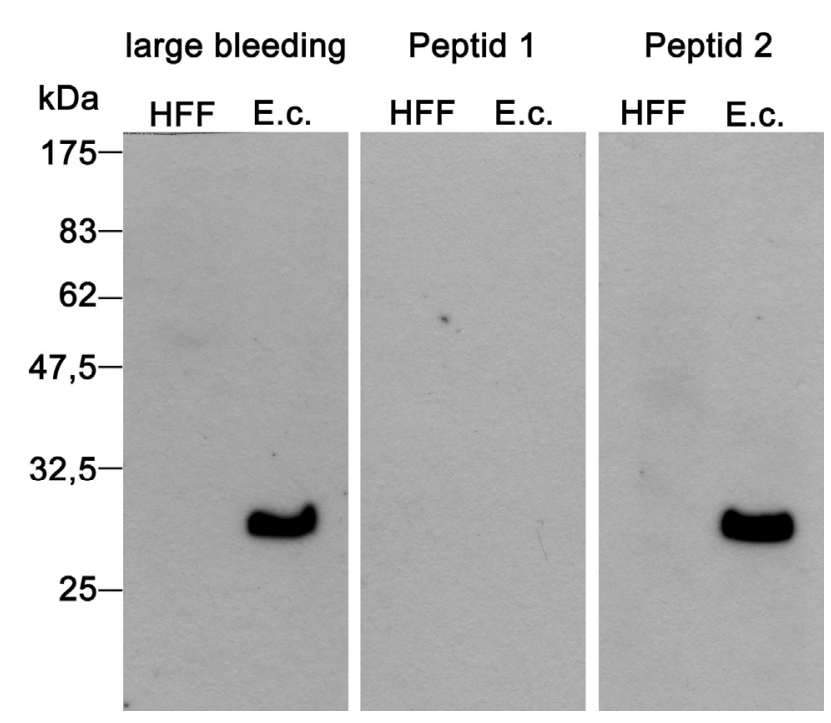

Abb. 3.19: Reaktivität des EcHlyIII-Serums nach Affinitätsreinigung gegen Peptid 1 und Peptid 2 im Western Blot. HFF-Zelllysat (HFF) und E. cuniculi-Sporenlysat (E.c.) wurden in einer SDS-PAGE aufgetrennt, auf eine Membran geblottet und der Blot entsprechend der Anzahl an Seren kleingeschnitten. Die einzelnen Membranteile wurden in einer anschließenden Immunfärbung mit den gegen Peptid 1 oder Peptid 2 affinitätsgereinigten Seren von Ratte 2 (Verdünnung 1:100) inkubiert. Die Detektion erfolgte mit einem Peroxidase-gekoppelten anti-Ratte Sekundärantikörper und einer ECL-Färbung. Nur das gegen Peptid 2 aufgereinigte Serum erkennt die 29 kDa Bande von EcHlyIII. Das gegen Peptid 1 aufgereinigte Serum erkennt kein E. cuniculi-Protein. 
Für die anschließende Immunlokalisierung wurden HFF-Zellen infiziert und nach ca. $30 \mathrm{~h}$ mit $4 \%$ PFA fixiert. Die Permeabilisierung erfolgte mit 0,25\% TritonX-100. Obwohl das Präimmun-Serum im Western Blot nicht reagierte, zeigt es in der Immunfluoreszenz ein relativ starkes Signal mit Meronten (Abb. 3.20). Da die Immunfluoreszenzen mit dem large bleeding-Serum und dem affinitätsgereinigten Serum eine ähnliche Färbung zeigen, kann nicht zwischen dem Signal des Präimmun-Serums und dem spezifischen Signal gegen EcHlyIII unterschieden werden.

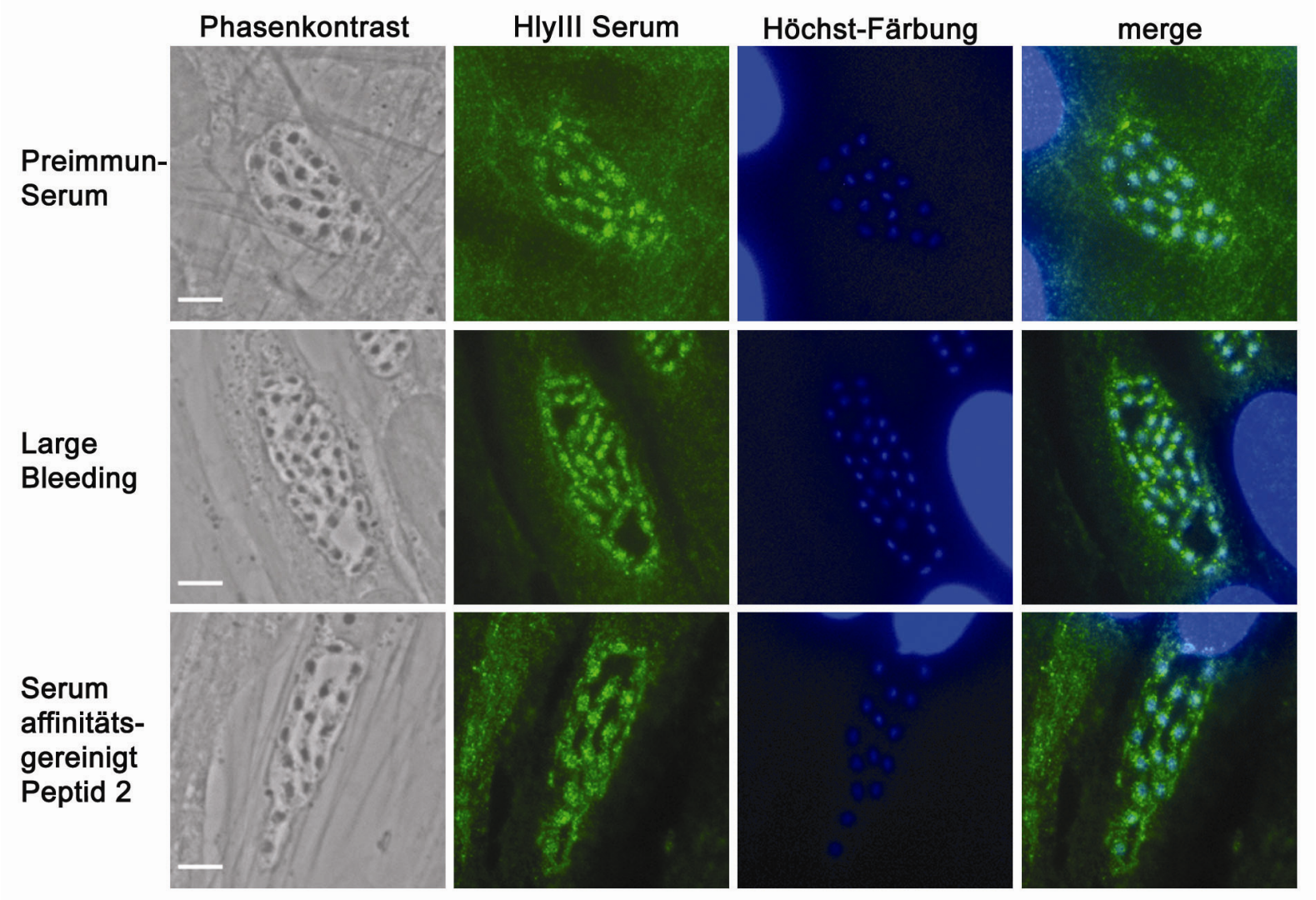

Abb. 3.20: Reaktivität der $E c$ HlyIII-Seren von Ratte 2 in der Immunfluoreszenz. HFFZellen wurden mit E. cuniculi infiziert, ca. $30 \mathrm{~h}$ nach Infektion mit $4 \%$ PFA fixiert und mit $0,25 \%$ TritonX-100 permeabilisiert. Nach Blockierung in $1 \%$ BSA erfolgte die Inkubation mit den Seren (Verdünnung Präimmun-Serum + large bleeding 1:50; Serum affinitätsgereinigt 1:25) für 1,5 h bei RT. Nach Inkubation mit einem Cy2-gekoppelten antiRatte Sekundärantikörper (Verdünnung 1:500) erfolgte die Hoechst-Färbung mit $100 \mathrm{ng} / \mathrm{ml}$ Hoechst 33258-Farbstoff für $30 \mathrm{~min}$ bei RT. Das Präimmun-Serum zeigt eine relativ starke Reaktivität gegen Meronten von E. cuniculi. Das Signal ist dabei teilweise im Cytosol und im Zellkern lokalisiert (Präimmun-Serum, merge). Das large bleeding-Serum sowie das gegen Peptid 2 affinitätsgereinigte Serum zeigen ähnlich starke Signale mit gleicher Lokalisation. Maßstabsbalken $5 \mu \mathrm{m}$.

Da einige Antikörper nicht in Kombination mit einer PFA-Fixierung funktionieren, wurden zusätzlich Immunfluoreszenzen nach Fixierung durch Aceton, Methanol, Ethanol und 
$4 \%$ PFA mit 0,1 \% Glutardialdehyd durchgeführt. Diese zeigten jedoch dasselbe relativ starke Signal mit dem Präimmun-Serum und ähnliche Signale mit den spezifischen Seren (Daten nicht gezeigt). Da es sich bei EcHlyIII um ein Membranprotein handelt, wurden ebenfalls mildere Permeabilisierungs-Bedingungen wie geringere TritonX-Konzentrationen oder eine Saponin-Permeabilisierung angewendet, um ein Wegwaschen des Signals zu verhindern. Auch diese Immunfluoreszenzen zeigten für die drei Seren ähnliche Signale (Daten nicht gezeigt). Mit Hilfe der Immunfluoreszenz kann somit keine Aussage über die Lokalisation von $E c$ HlyIII getroffen werden.

Da der EcHlyIII-Antikörper jedoch im Western Blot funktioniert, sollte im Folgenden untersucht werden, ob EcHlyIII im Western Blot in einer Membranfraktion von E. cuniculi aufzufinden ist. Zur Herstellung einer Fraktion mit löslichen Proteinen und einer Fraktion mit Membranproteinen wurden die Sporen wie unter 2.2.4.4 beschrieben mit Hilfe von Glassbeads aufgeschlossen. Ein Teil des so erhaltenen Sporenlysats wurde für den Western Blot als Gesamtprotein-Probe aufbewahrt. Der Rest wurde bei 100.000 x g abzentrifugiert und somit in eine lösliche Fraktion (Überstand) und eine Membranfraktion (Pellet) aufgetrennt. Äquimolare Mengen dieser Proteinfraktionen wurden auf einem SDS-Gel aufgetrennt, geblottet und mit dem affinitätsgereinigten EcHlyIII-Antikörper inkubiert. Das EcHlyIII Signal von $29 \mathrm{kDa}$ ist in der Gesamtprotein-Probe sowie in der Membranfraktion nachzuweisen (Abb. 3.21). In der löslichen Fraktion ist keine Bande sichtbar. Somit konnte bestätigt werden, dass EcHlyIII ein Membranprotein ist. Es konnte nicht geklärt werden, in welcher Membran EcHlyIII lokalisiert ist. Damit bleibt auch weiterhin unklar, ob EcHlyIII ein Porenprotein ist, oder ob es möglicherweise eine andere Funktion ausübt. 


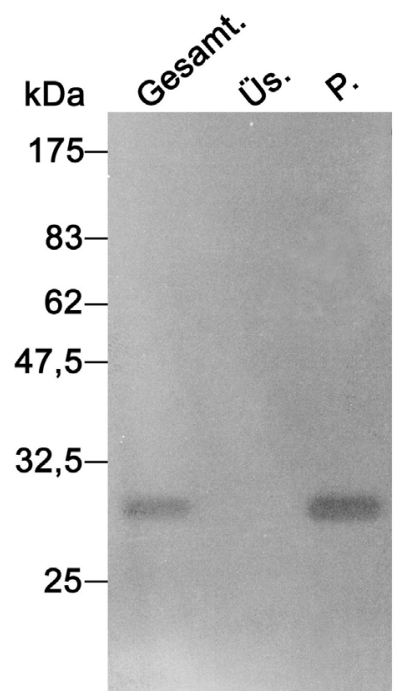

Abb. 3.21: Nachweis von $E c$ HlyIII in einer Membranfraktion im Western Blot. Sporen wurden mit Hilfe von Glassbeads aufgeschlossen und anschließend bei 100.000 x g abzentrifugiert. Der Überstand (Üs.) enthält die löslichen Proteine, während das Pellet (P.) die Membranfraktion enthält. Äqimolare Mengen $\left(2 \times 10^{7}\right.$ Sporen/Spur) einer GesamtproteinFraktion (Gesamt.), der löslichen Fraktion und der Membranfraktion wurden in einer SDSPage aufgetrennt, geblottet und mit dem affinitätsgereinigten EcHlyIII-Antikörper (1:30) inkubiert. Die Detektion erfolgte mit einem Peroxidase-gekoppelten anti-Ratte Sekundärantikörper und einer ECL-Färbung. Das $29 \mathrm{kDa}$ große EcHlyIII-Signal ist in der Gesamtprotein-Fraktion sowie in der Membranfraktion nachzuweisen. In der löslichen Fraktion befindet sich kein HlyIII-Protein. 


\subsection{E. cuniculi ist auf eine externe Versorgung mit Aminosäuren angewiesen}

E. cuniculi besitzt aufgrund seiner kleinen Genomgröße einen sehr stark reduzierten Stoffwechsel. Für die Synthese von Aminosäuren konnten für E. cuniculi bislang nur zwei Enzyme identifiziert werden, eine Asparagin-Synthetase und eine SerinHydroxymethyltransferase (Katinka et al., 2001). Dem Import von Aminosäuren aus der Wirtszelle scheint daher eine große Bedeutung zuzukommen. Hierbei ist zu beachten, dass die importierten Aminosäuren entweder von der Wirtszelle selbst synthetisiert werden, oder aber insbesondere bei essentiellen Aminosäuren, zuvor von der Wirtszelle aus dem Medium aufgenommen werden müssen. Im Folgenden sollte durch die gezielte Depletion einzelner Aminosäuren im Zellkulturmedium ermittelt werden, wie E. cuniculi auf AminosäureMangelbedingungen reagiert. Hierzu wurde sowohl die Wachstumsrate als auch das Differenzierungsverhalten untersucht.

\subsubsection{Etablierung eines Wachstumsassays für E. cuniculi}

Um das Wachstum von E. cuniculi unter Aminosäure-Mangelbedingungen zu untersuchen, sollte zunächst ein zuverlässiger Wachstums-Test etabliert werden. Ein Auszählen der Mikrosporidien ist aufgrund der großen Anzahl von Sporen in einer Vakuole zu späten Infektionszeitpunkten nicht möglich. Da in unserem Labor stadienspezifische monoklonale Antikörper zur Verfügung stehen, die sowohl Meronten als auch Sporonten und Sporen erkennen, wurde ein Zell-ELISA (Enzyme-linked Immunosorbent Assay) als Wachstums-Test ausgewählt (siehe auch 2.2.1.6). Im Gegensatz zu dem für E. intestinalis beschriebenen ELISA (Bouladoux et al., 2003), wurden für die Detektion von E. cuniculi zwei monoklonale Antikörper eingesetzt, um sowohl Meronten als auch Sporenstadien zu erkennen und damit die Gesamtheit aller Mikrosporidien besser zu erfassen. Bei einem Zell-ELISA dient ein ZellMonolayer als Basis für eine enzymatische Nachweisreaktion. Um das Wachstum von E. cuniculi mit einem Zell-ELISA nachzuweisen, wurden 24-Well-Platten, die mit einer konfluenten Schicht aus HFF-Zellen bewachsen waren, mit unterschiedlichen Mengen einer E. cuniculi Sporensuspension infiziert. Nach einer 64 stündigen Wachstumsphase wurden die Zellen mit 4 \% PFA fixiert und anschließend mit TritonX-100 permeabilisiert. Nach einer Blockierung unspezifischer Bindestellen mit BSA erfolgte eine gleichzeitige Inkubation der Proben mit dem Meronten-spezifischen Antikörper 6G2 und dem Sporen-spezifischen anti- 
SWP1-Antikörper. Der Nachweis erfolgte mit Hilfe eines Peroxidase-gekoppelten anti-Maus Sekundärantikörpers und einer Substratreaktion. Wie in der Eichkurve (Abb. 3.22) zu sehen, korreliert die Absorption (Abs.) im Zell-ELISA mit der eingesetzten Sporenmenge. Die Werte von $0,6-2,4 \times 10^{5}$ Sporen bilden einem annähernd linearen Kurvenbereich. Diese Sporenmengen liefern außerdem im Photometer gut messbare Werte, die unter eins liegen. Für die folgenden Versuche wurde mit einer Sporenmenge von 2,4 x $10^{5}$ Sporen pro Well weitergearbeitet.

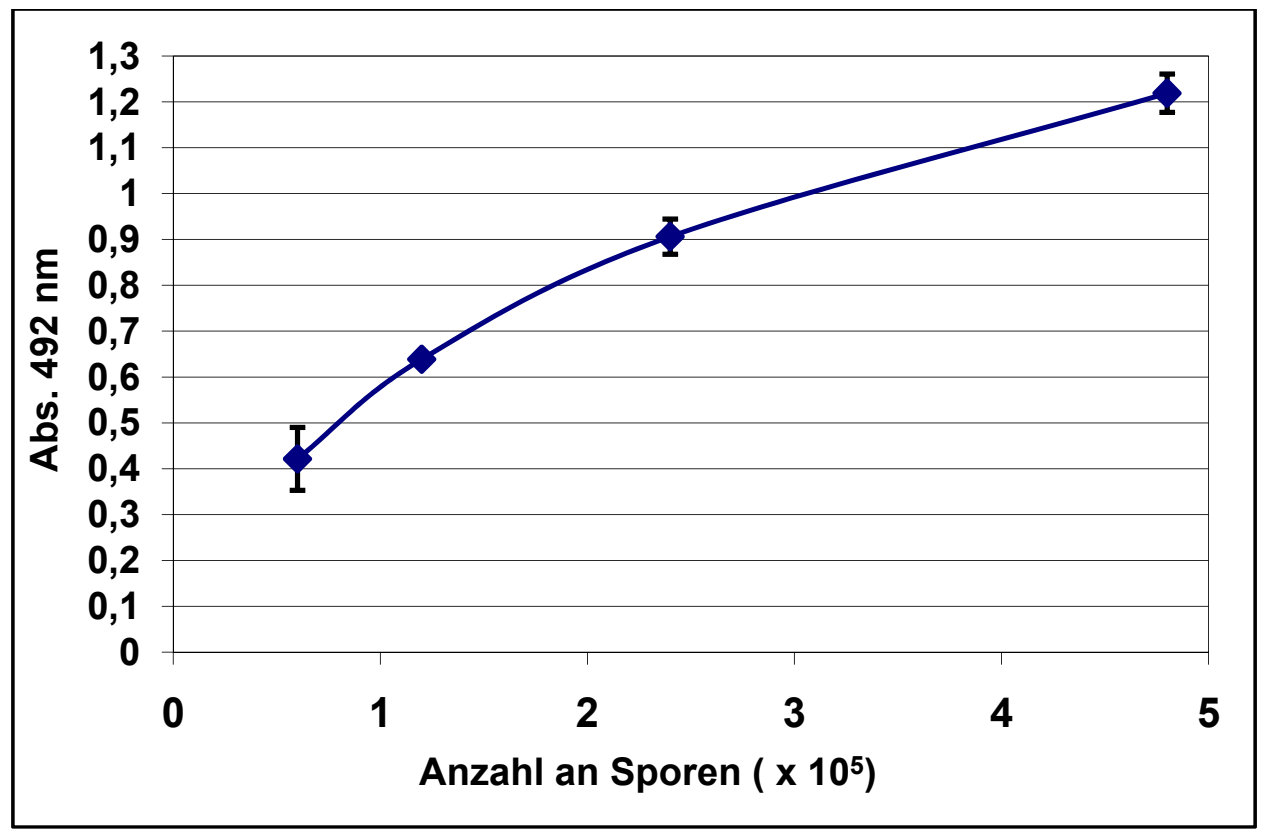

Abb. 3.22: Eichkurve zur Etablierung des Zell-ELISAs als Wachstums-Test für E. cuniculi. HFF-Zellen in 24-Well-Platten wurden mit einer unterschiedlichen Anzahl an Sporen infiziert, nach $64 \mathrm{~h}$ fixiert und permeabilisiert. Nach einer Blockierung mit BSA erfolgte die Inkubation mit einer Mischung der monoklonalen Primärantikörper 6G2 und SWP1. Als Sekundärantikörper diente ein Peroxidase-gekoppelter anti-Maus Antikörper. Die Detektion erfolgte mit Hilfe der Umsetzung des farblosen Substrates OPD durch die Peroxidase. Das entstehende gelbe Produkt ist im Photometer bei $492 \mathrm{~nm}$ nachzuweisen. Die Absorption (Abs.) im Zell-ELISA korreliert mit der für die Infektion eingesetzten Sporenmenge. Die Absorptionswerte für 0,6 - 2,4 x $10^{5}$ Sporen bilden einen annähernd linearen Kurvenbereich und liefern im Photometer gut messbare Werte. 


\subsubsection{Depletion essentieller Aminosäuren führt zu einer Wachstumsinhibierung von E. cuniculi}

Das Wachstum von E. cuniculi unter verschiedenen Aminosäure-Mangelbedingungen wurde im Folgenden mit Hilfe des Zell-ELISAs untersucht. Dazu wurde beim Ansetzen des DMEMZellkulturmediums jeweils eine Aminosäure weggelassen, und das Wachstum im Mangelmedium mit dem Wachstum in DMEM-Komplettmedium verglichen. Da die Kultur von E. cuniculi üblicherweise mit 10 \% Fötalem Kälberserum (FKS) erfolgte, wurde für die Aminosäure-Mangelmedien dialysiertes FKS verwendet, das keine freien Aminosäuren enthält. Der Austausch des DMEM gegen Mangelmedium erfolgte nach einem Waschschritt mit PBS gleichzeitig mit der Infektion. Nach einer 64-stündigen Inkubation wurde der ZellELISA durchgeführt. Als Wirtszellen für den Zell-ELISA dienten auch hier HFF-Zellen, die als humane Zellen nicht die Fähigkeit zur Synthese essentieller Aminosäuren besitzen. Die Auswirkungen des Mangels an essentiellen Aminosäuren auf das relative Wachstum von E. cuniculi sind in Abb. 3.23 dargestellt. Bei fast allen essentiellen Aminosäuren wird das Wachstum massiv um ca. 90 \% reduziert. Lediglich ein Isoleucin- und ein TryptophanMangel haben einen weniger starken Effekt. Während ein Isoleucin-Mangel das Wachstum um ca. 80 \% reduziert, reduziert ein Tryptophan-Mangel das Wachstum nur um ca. 60 \%. 


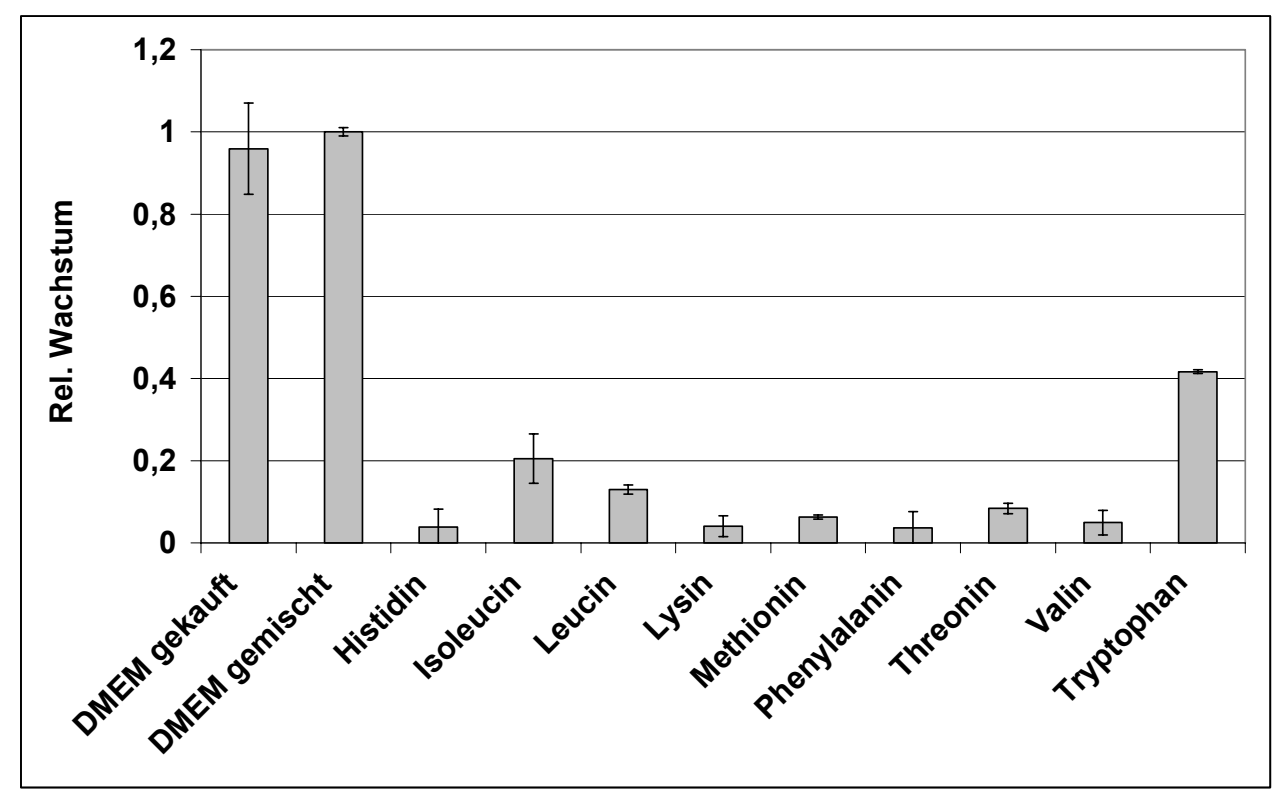

Abb. 3.23: Einfluss eines Mangels individueller essentieller Aminosäuren auf das Wachstum von E. cuniculi. HFF-Zellen in 24-Well-Platten wurden mit PBS gewaschen, das Medium gegen Mangelmedium, in dem eine essentielle Aminosäure fehlt, ausgetauscht und mit E. cuniculi infiziert. Nach $64 \mathrm{~h}$ wurde ein Zell-ELISA durchgeführt, um das Wachstum im Mangelmedium mit dem Wachstum in Komplettmedium (DMEM gekauft und DMEM gemischt) $\mathrm{zu}$ vergleichen. Die im Zell-ELISA erhaltenen Absorptionen wurden in ein relatives Wachstum (Rel. Wachstum) umgerechnet, wobei das selbst gemischte DMEMKomplettmedium als Referenz diente. Der Mangel fast aller essentieller Aminosäuren führt zu einem starken Wachstumsdefekt. Das Wachstum ist in diesen Fällen um ca. 90 \% reduziert. Lediglich Isoleucin- und Tryptophan-Mangel haben einen weniger starken Effekt. Während das Wachstum ohne Isoleucin noch $20 \%$ beträgt, resultiert bei einem Tryptophan-Mangel noch ein Wachstum von ca. $40 \%$.

Der Zell-ELISA wurde daraufhin noch einmal mit 3 Tagen Vorinkubation der HFF-Zellen in den jeweiligen essentiellen Aminosäure-Mangelmedien wiederholt. Mit Vorinkubation haben alle Mangelbedingungen einen noch stärkeren negativen Effekt auf das Wachstum von E. cuniculi (Abb. 3.24). Es ist fast gar kein Wachstum mehr festzustellen, selbst der Tryptophan-Mangel inhibierte das E. cuniculi-Wachstum in diesem Versuch vollständig. 


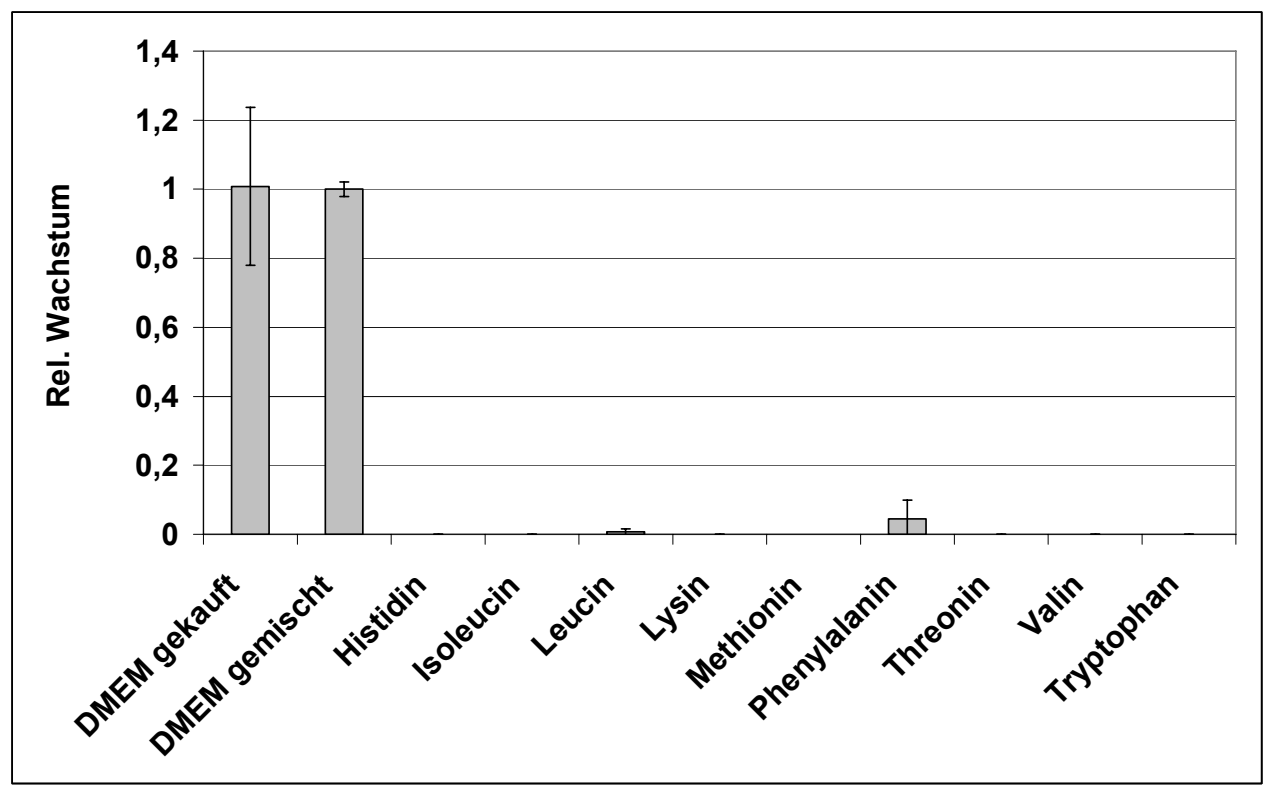

Abb. 3.24: Einfluss eines Mangels individueller essentieller Aminosäuren auf das Wachstum von $E$. cuniculi nach Vorinkubation der Wirtszellen in Mangelmedium. HFFZellen in 24-Well-Platten wurden mit PBS gewaschen, dann wurde das Medium gegen Mangelmedium ausgetauscht und die Zellen für 3 Tage weiterinkubiert. $64 \mathrm{~h}$ nach der Infektion wurde ein Zell-ELISA durchgeführt, um das Wachstum im Mangelmedium mit dem Wachstum in Komplettmedium (DMEM gekauft und DMEM gemischt) zu vergleichen. Die im Zell-ELISA erhaltenen Absorptionen wurden in ein relatives Wachstum (Rel. Wachstum) umgerechnet, wobei das selbst gemischte DMEM-Komplettmedium als Referenz diente. Das Wachstum von E. cuniculi ist in nahezu allen Mangelmedien vollständig inhibiert.

Tryptophan nimmt unter den essentiellen Aminosäuren eine besondere Rolle ein, denn ein Tryptophan-Mangel wirkt im Allgemeinen als Effektormechanismus gegen intrazelluläre Erreger wie z. B. gegen T. gondii und Chlamydien (Rottenberg et al., 2002; Habara-Ohkubo et al., 1993). Bei diesem durch Interferon- $\gamma$ ausgelösten Mechanismus wird das Enzym Indoleamine 2,3-Dioxygenase (IDO) induziert, das als Teil des Tryptophan-Katabolismus Tryptophan in der Zelle abbaut. Der so induzierte Tryptophan-Mangel verhindert ein weiteres Wachstum der intrazellulären Erreger. Um zu überprüfen, ob E. cuniculi sensitiv gegenüber Interferon- $\gamma$-induzierten Abwehrmechanismen ist, wurde der Zell-ELISA unter verschiedenen Tryptophan-Mangelbedingungen durchgeführt. Dazu wurden die HFF-Zellen, die für den Zell-ELISA verwendet wurden, 3 Tage in Tryptophan-freiem Medium mit und ohne Interferon- $\gamma$ vorinkubiert. Während ohne Vorinkubation lediglich eine Wachstumsreduktion um $60 \%$ erreicht wird, verursacht die Vorinkubation in Tryptophan-freiem Medium in diesem Versuch eine Reduktion des Wachstums um ca. 80 \% (Abb. 3.25). Da Tryptophan als essentielle Aminosäure von den HFF nicht selbst synthetisiert werden kann, wurde während der 3 tägigen Vorinkubation höchstwahrscheinlich Tryptophan verbraucht, so dass nach 
Infektion weniger für die Mikrosporidien zur Verfügung stand. Werden dem Tryptophanfreien Medium zusätzlich $100 \mathrm{U} / \mathrm{ml}$ Interferon- $\gamma$ zugefügt, so ist ein weiterer leichter Rückgang der Wachstumsrate auf unter $20 \% \mathrm{zu}$ beobachten. Ein Interferon- $\gamma$-induzierter Tryptophan-Mangel hat somit einen negativen Effekt auf das E. cuniculi Wachstum.

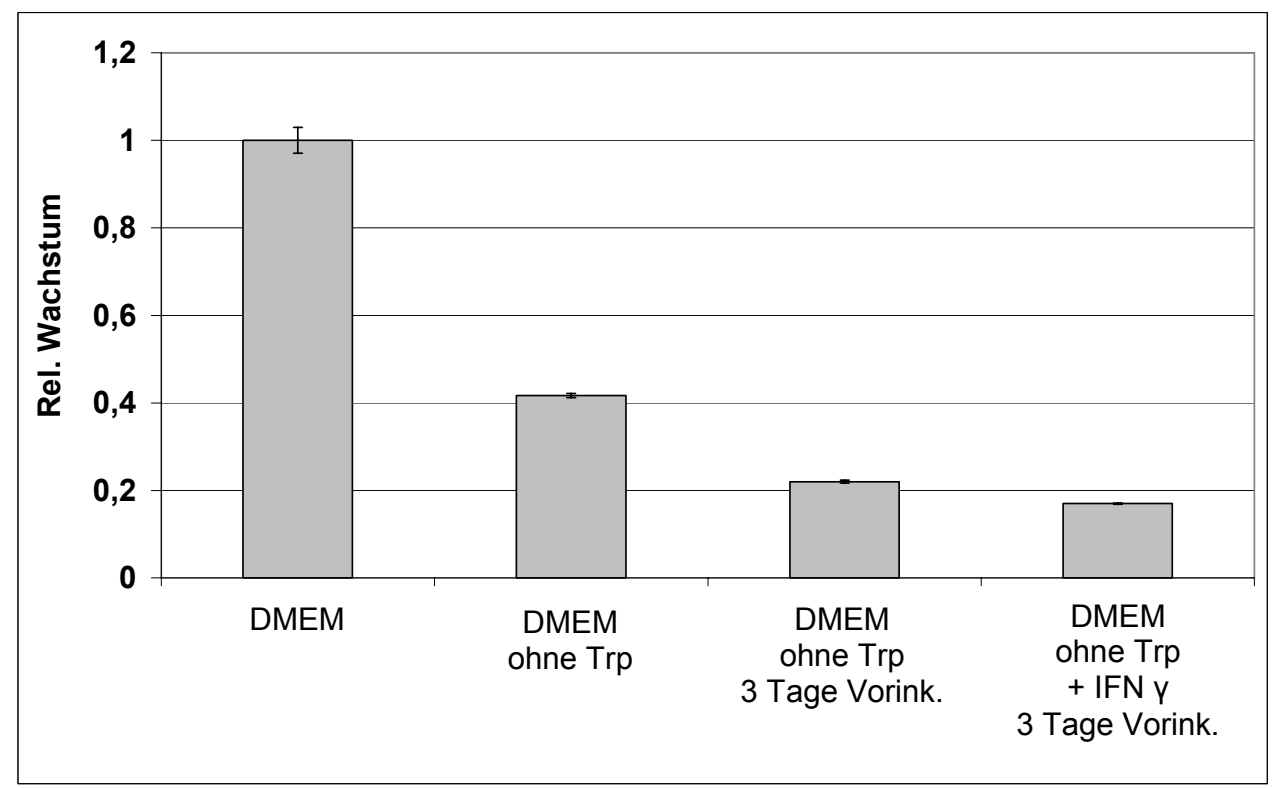

Abb. 3.25: Empfindlichkeit von $E$. cuniculi gegenüber verschiedenen TryptophanMangelbedingungen. Um die Tryptophan (Trp)-Mangelbedingungen zu verstärken, wurden die für den Zell-ELISA verwendeten HFF für 3 Tage in Tryptophan-freiem Medium mit und ohne Interferon- $\gamma$ (IFN $\gamma$ ) vorinkubiert. Der Zell-ELISA zur Messung des Wachstums wurde nach $64 \mathrm{~h}$ durchgeführt, und die erhaltenen Absorptionen in das relative Wachstum (Rel. Wachstum) umgerechnet. Während das Wachstum von E. cuniculi in Tryptophan-freiem Medium ohne Vorinkubation (Vorink.) noch $40 \%$ beträgt, reduziert eine 3 tägige Vorinkubation das E. cuniculi Wachstum um weitere $20 \%$. Wird dem Medium während der Vorinkubation noch zusätzlich Interferon- $\gamma(100 \mathrm{U} / \mathrm{ml})$ zugefügt, kann das Wachstum sogar unter $20 \%$ gesenkt werden.

\subsubsection{Depletion nichtessentieller Aminosäuren führt zu einer Wachstumsinhibierung von E. cuniculi}

Die Auswirkungen des Mangels der sechs nichtessentiellen Aminosäuren, die Bestandteil des DMEM-Mediums sind, sind in Abb. 3.26 dargestellt. Ein Arginin-, Cystein-, Glutamin- und Tyrosin-Mangel reduzieren das E. cuniculi Wachstum um ca. 90 \%. Obwohl die Wirtszelle in der Lage sein sollte, diese nichtessentiellen Aminosäuren selbst zu synthetisieren, reicht die Biosynthese zur Versorgung von Wirtszelle und Mikrosporidien offenbar nicht aus. Ein 
Mangel an Glycin oder Serin hat keinen negativen Effekt auf das Wachstum. Da E. cuniculi mit dem interkonvertierenden Enzym Serin-Hydroxymethyltransferase die Fähigkeit besitzt, Serin in Glycin umzuwandeln, und umgekehrt, wurde ebenfalls der Effekt eines Mediums getestet, in dem sowohl Glycin als auch Serin fehlt. Doch auch dieses Medium hat keinen ausgeprägten Effekt auf das E. cuniculi Wachstum.

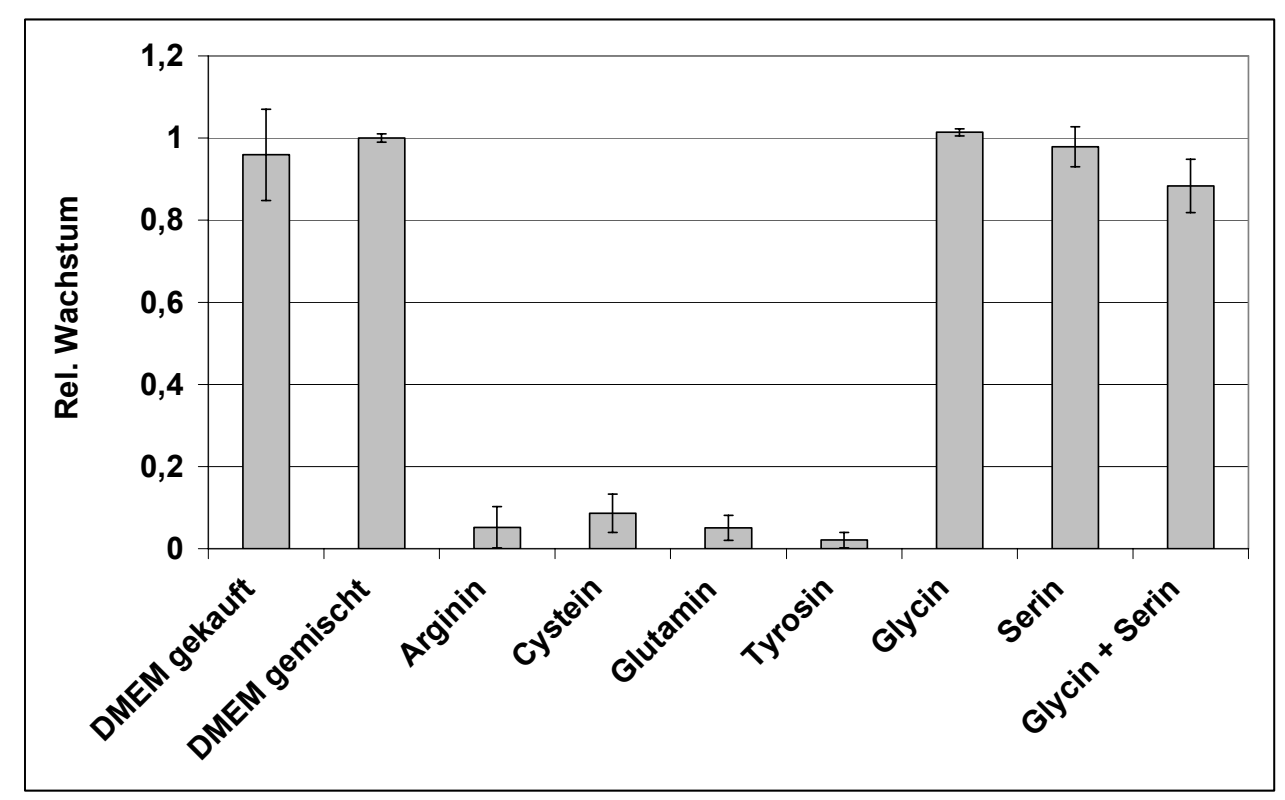

Abb. 3.26: Einfluss eines Mangels individueller nichtessentieller Aminosäuren auf das Wachstum von E. cuniculi. HFF-Zellen in 24-Well-Platten wurden mit PBS gewaschen, das Medium gegen Mangelmedium, in dem eine nichtessentielle Aminosäure fehlt, ausgetauscht und mit E. cuniculi infiziert. Nach $64 \mathrm{~h}$ wurde ein Zell-ELISA durchgeführt, um das Wachstum im Mangelmedium mit dem Wachstum in Komplettmedium (DMEM gekauft und DMEM gemischt) zu vergleichen. Die im Zell-ELISA erhaltenen Absorptionen wurden in ein relatives Wachstum (Rel. Wachstum) umgerechnet, wobei das selbst gemischte DMEMKomplettmedium als Referenz diente. Das Wachstum von E. cuniculi ist unter Arginin-, Cystein-, Glutamin- und Tyrosin-Mangel um ca. $90 \%$ reduziert. Unter Glycin- und SerinMangel zeigt sich keine Inhibition des Wachstums. Auch ein Medium, in dem sowohl Glycin als auch Serin fehlt, hat keinen ausgeprägten Effekt auf das E. cuniculi Wachstum.

Der Versuch wurde auch mit 3 tägiger Vorinkubation der HFF-Zellen in den nichtessentiellen Aminosäure-Mangelmedien durchgeführt. Während unter Arginin-, Cystein-, Glutamin- und Tyrosin-Mangel kein Wachstum mehr messbar war, reduzierte sich das Wachstum in Glycinfreiem, Serin-freiem und Glycin- und Serin-freiem Medium auf ca. 40 \% (Abb. 3.27). Das ein Glycin- und Serin-Mangel ohne Vorinkubation keinen Einfluss auf das Wachstum von E. cuniculi hat, ist somit wahrscheinlich auf einen Rest-Gehalt an Glycin und Serin in der Zelle zurückzuführen. Während der Vorinkubation werden diese Aminosäuren von der 
Wirtszelle teilweise verbraucht, so dass den Mikrosporidien anschließend weniger zur Verfügung steht.

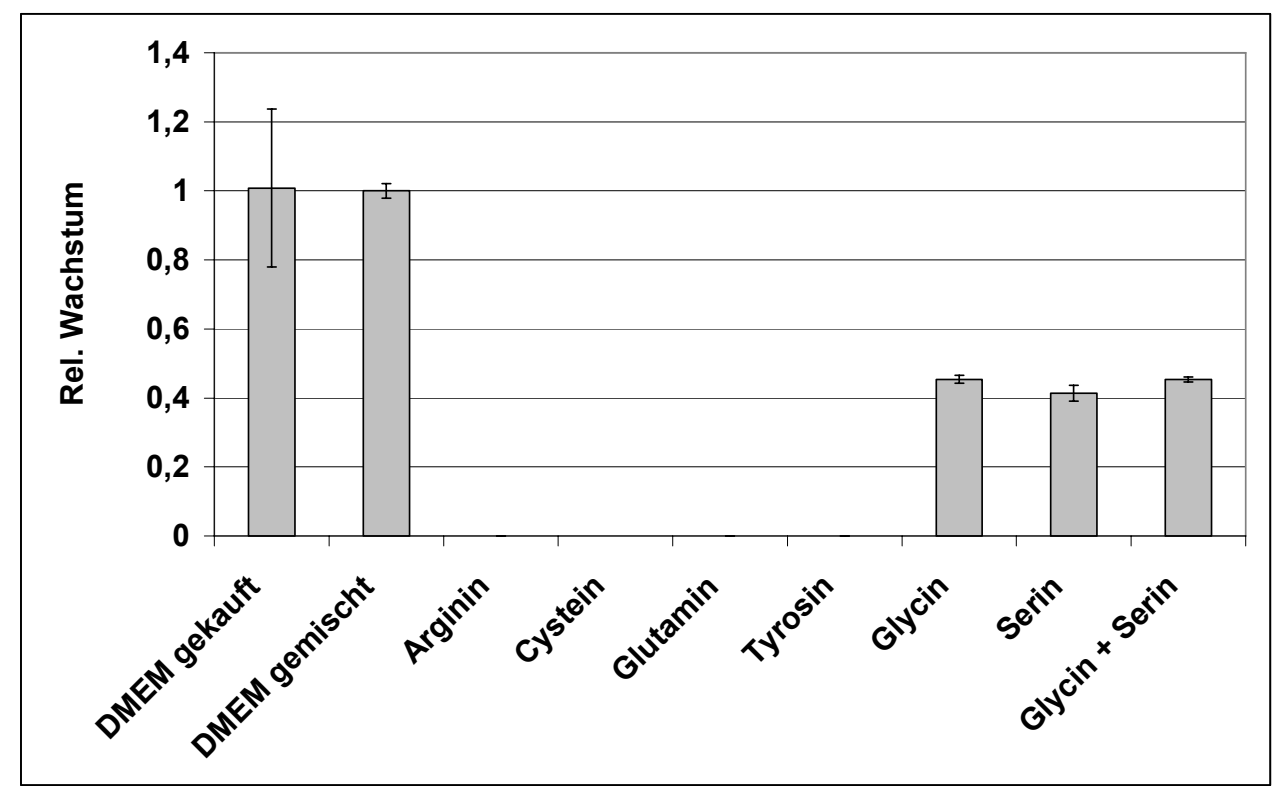

Abb. 3.27: Einfluss eines Mangels individueller nichtessentieller Aminosäuren auf das Wachstum von $E$. cuniculi nach Vorinkubation der Wirtszellen in Mangelmedium. HFFZellen in 24-Well-Platten wurden mit PBS gewaschen, dann wurde das Medium gegen Mangelmedium ausgetauscht und die Zellen für 3 Tage weiterinkubiert. $64 \mathrm{~h}$ nach der Infektion wurde ein Zell-ELISA durchgeführt, um das Wachstum im Mangelmedium mit dem Wachstum in Komplettmedium (DMEM gekauft und DMEM gemischt) zu vergleichen. Die im Zell-ELISA erhaltenen Absorptionen wurden in ein relatives Wachstum (Rel. Wachstum) umgerechnet, wobei das selbst gemischte DMEM-Komplettmedium als Referenz diente. In Arginin-, Cystein-, Glutamin- und Tyrosin-Mangelmedium ist kein Wachstum von E. cuniculi mehr nachzuweisen. Das Wachstum in Glycin- und Serin-freiem Medium sowie das Wachstum in Kombinationsmangelmedium ohne Glycin und Serin beträgt noch ca. 40 \%.

Zusätzlich wurde auch die Abwesenheit eines eigenen Synthesewegs von E. cuniculi für Glycin und Serin überprüft. Dazu wurden mit Hilfe der KEGG PATHWAY Database (www.genome.ad.jp/kegg/pathway.html) alle Enzyme identifiziert, die an einer möglichen Synthese von Glycin oder Serin beteiligt sein könnten. Das Proteom von E. cuniculi wurde daraufhin mit Hilfe einer „BLAST“-Suche und einer „PFAM HMM“-Suche noch einmal durchsucht. Bis auf die schon erwähnte Serin-Hydroxymethyltransferase konnte kein Enzym der Glycin- oder Serin-Biosynthese bei E. cuniculi identifiziert werden.

Zusammenfassend kann festgehalten werden, dass E. cuniculi außerordentlich abhängig von der externen Versorgung mit Aminosäuren ist. E. cuniculi ist auxotroph für alle hier untersuchten Aminosäuren. 


\subsubsection{Langzeitversuche}

Um das Wachstum unter Aminosäure-Mangel über einen längeren Zeitraum zu untersuchen, wurde überprüft, ob E. cuniculi in der Lage ist, den HFF-Monolayer zu lysieren. Mit diesem relativ einfachen Test kann untersucht werden, ob E. cuniculi einen vollständigen Lebenszyklus durchläuft und die reifen Sporen in der Lage sind, neue Wirtszellen zu infizieren. Der Versuch wurde in Doppelwerten mit und ohne 3 tägiger Vorinkubation der HFF-Zellen in Aminosäure-freiem Medium durchgeführt, die Daten sind in Tab. 3.2 dargestellt. Zur Auswertung wurde zwischen einer schnellen Lyse des Monolayers nach ca. 11 Tagen $(++)$ und einer langsamen Lyse nach $14-28$ Tagen $(+)$ unterschieden. War der HFF-Monolayer nach 30 Tagen nicht lysiert, so wurde dies als negativ gewertet ( - ). In vielen Fällen, vor allem bei den Werten mit Vorinkubation, sind die HFF-Zellen während des Versuches abgestorben, ohne dass eine Vermehrung der Mikrosporidien stattgefunden hatte (HFF †). Ohne eine Vorinkubation der HFF-Zellen ist E. cuniculi entsprechend den vorherigen Ergebnissen in der Lage, in Tryptophan-, Glycin-, Serin- und Glycin- und Serinfreiem Medium eine schnelle Lyse des Monolayers herbeizuführen. E. cuniculi verursacht ohne Vorinkubation jedoch auch unter Histidin-, Leucin-, Lysin- und Glutamin-Mangel eine Lyse. Mit einer 3 tägigen Vorinkubation der HFF-Zellen in Aminosäure-freien Medien führt E. cuniculi lediglich unter Glycin-, Serin- und Glycin- und Serin-Mangel eine langsame Lyse des HFF-Monolayers herbei. Während E. cuniculi in Histidin-freiem Medium den Monolayer nicht mehr lysieren kann, konnten die Werte für Leucin, Lysin und Glutamin leider nicht ausgewertet werden, da in diesen Ansätzen die HFF-Zellen abgestorben waren. Die Langzeitversuche machen deutlich, dass das E. cuniculi-Wachstum unter AminosäureMangelbedingungen dauerhaft unterdrückt wird. Es kommt zu keiner Reaktivierung des Wachstums. 
Tab. 3.2: Einfluss verschiedener Aminosäure-Mangelmedien auf die Fähigkeit von E. cuniculi einen HFF-Monolayer zu lysieren. Essentielle Aminosäuren sind grau unterlegt. $(++$ Lyse nach ca. 11 Tagen, + Lyse nach 14 - 28 Tagen, - keine Lyse nach 30 Tagen, HFF $†$ HFF Zellen während des Versuches abgestorben)

\begin{tabular}{|c|c|c|}
\hline $\begin{array}{l}\text { Medium bzw. } \\
\text { fehlende Aminosäure }\end{array}$ & $\begin{array}{c}\text { Lyse des Monolayers } \\
\text { ohne Vorinkubation der HFF }\end{array}$ & $\begin{array}{l}\text { Lyse des Monolayers } \\
\text { mit } 3 \text { tägiger Vorinkubation der HFF }\end{array}$ \\
\hline DMEM gekauft & ++ & ++ \\
\hline DMEM gemischt & ++ & ++ \\
\hline Histidin & + & - \\
\hline Isoleucin & - & - \\
\hline Leucin & + & $\mathrm{HFF} \dagger$ \\
\hline Lysin & + & $\mathrm{HFF} \dagger$ \\
\hline Methionin & $\mathrm{HFF} \dagger$ & $\mathrm{HFF} \dagger$ \\
\hline Phenylalanin & - & - \\
\hline Threonin & - & - \\
\hline Valin & - & - \\
\hline Tryptophan & ++ & - \\
\hline Arginin & - & $\mathrm{HFF} \dagger$ \\
\hline Cystein & $\mathrm{HFF} \dagger$ & $\mathrm{HFF} \dagger$ \\
\hline Glutamin & + & $\mathrm{HFF} †$ \\
\hline Tyrosin & - & - \\
\hline Glycin & ++ & + \\
\hline Serin & ++ & + \\
\hline Glycin + Serin & ++ & + \\
\hline
\end{tabular}

\subsubsection{Aminosäure-Mangelbedingungen haben keine Auswirkung auf die Differenzierung} von E. cuniculi

Während der intrazellulären Entwicklung differenziert E. cuniculi vom Meronten über ein Sporonten- und Sporoblasten-Stadium zu reifen Sporen. Während der Differenzierung vom Meronten zur Spore verändert sich die intrazelluläre Architektur grundlegend. Der für die Infektion der Wirtszelle wichtige Invasionsapparat wird aufgebaut, und eine umweltresistente Sporenwand aus Chitin und Proteinen wird synthetisiert (Keeling und Fast, 2002). Da Mikrosporidien für diese Proteinsynthese viele Aminosäuren benötigen, sollte überprüft werden, ob E. cuniculi auch unter verschiedenen Aminosäure-Mangelbedingungen noch zu 
Sporen differenzieren kann. Der Nachweis von Meronten und Sporen erfolgte durch eine Immunfluoreszenz-Färbung mit den stadienspezifischen Antikörpern 6G2 und SWP1. Der Austausch des Mediums gegen die verschiedenen Aminosäure-Mangelmedien erfolgte gleichzeitig mit der Infektion. Da das Wachstum in den verschiedenen Mangelmedium unterschiedlich schnell ist, wurden die Proben nach einer für die individuellen AminosäureMangelmedien geeigneten Inkubationszeit (2,5 - 6,5 Tage) fixiert und der ImmunfluoreszenzFärbung unterzogen. In Abb. 3.28 und 3.29 sind die erhaltenen Immunfluoreszenzbilder exemplarisch für jeweils zwei essentielle und zwei nichtessentielle Aminosäuren dargestellt. In allen Aminosäure-Mangelmedien waren sowohl Meronten als auch Sporenstadien nachzuweisen. Die Differenzierung findet somit auch unter Aminosäure-Mangel unbeeinträchtigt statt.

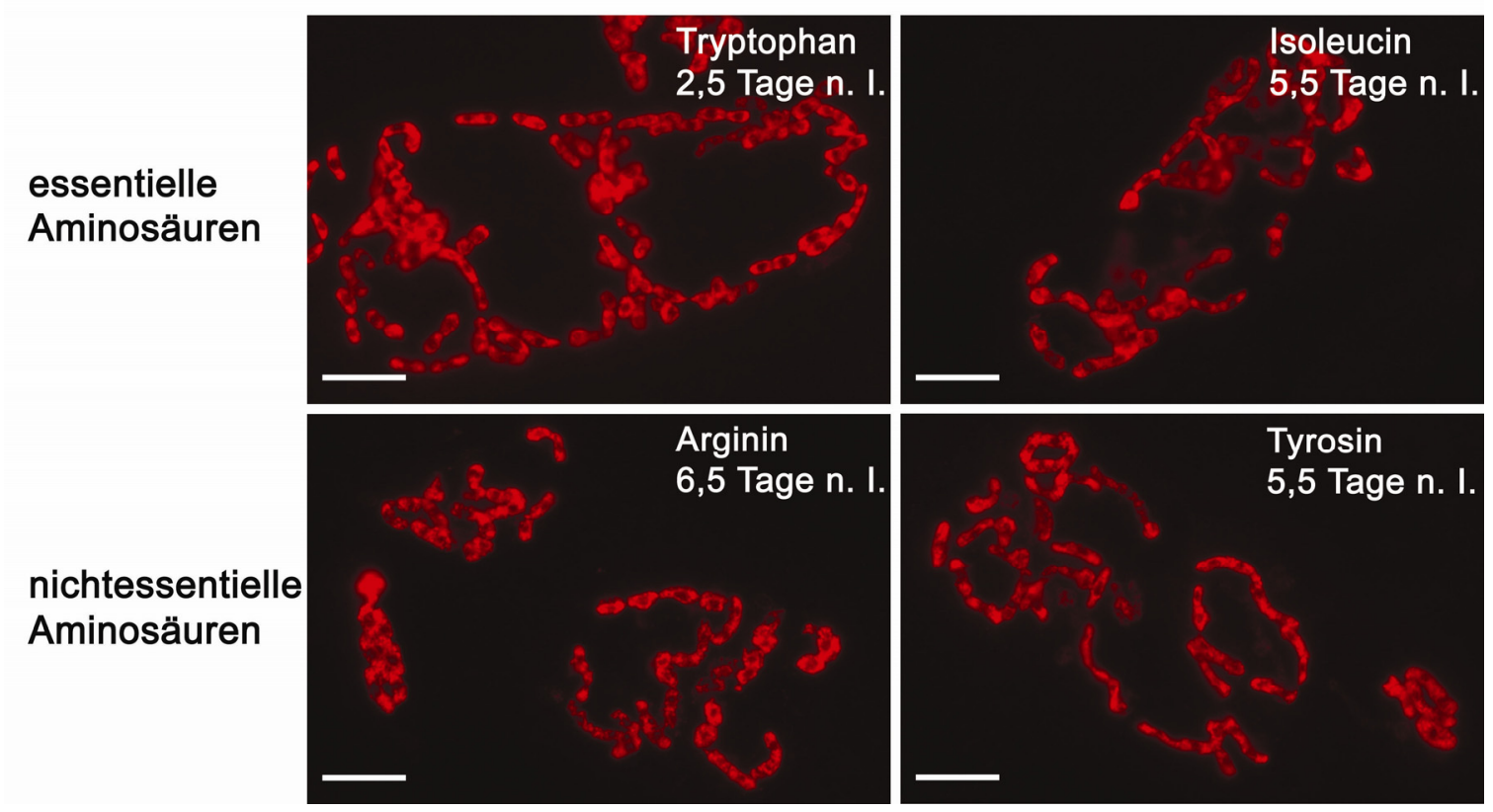

Abb. 3.28: Nachweis von Meronten nach Kultur von E. cuniculi in den AminosäureMangelmedien. Das HFF-Zellkulturmedium wurde gegen Aminosäure-Mangelmedium ausgetauscht und die HFF-Zellen mit E. cuniculi infiziert. Je nach Aminosäure wurde 2,5 6,5 Tage nach Infektion (n. I.) fixiert und zum Nachweis der Meronten eine Immunfluoreszenz-Färbung mit dem Meronten-spezifischen Antikörper 6G2 und einem Cy3gekoppelten Sekundärantikörper durchgeführt. Dargestellt sind exemplarisch nur jeweils zwei essentielle und zwei nichtessentielle Aminosäuren. In allen Aminosäure-Mangelmedien waren 6G2-positive Meronten nachzuweisen. Maßstabsbalken $10 \mu \mathrm{m}$. 


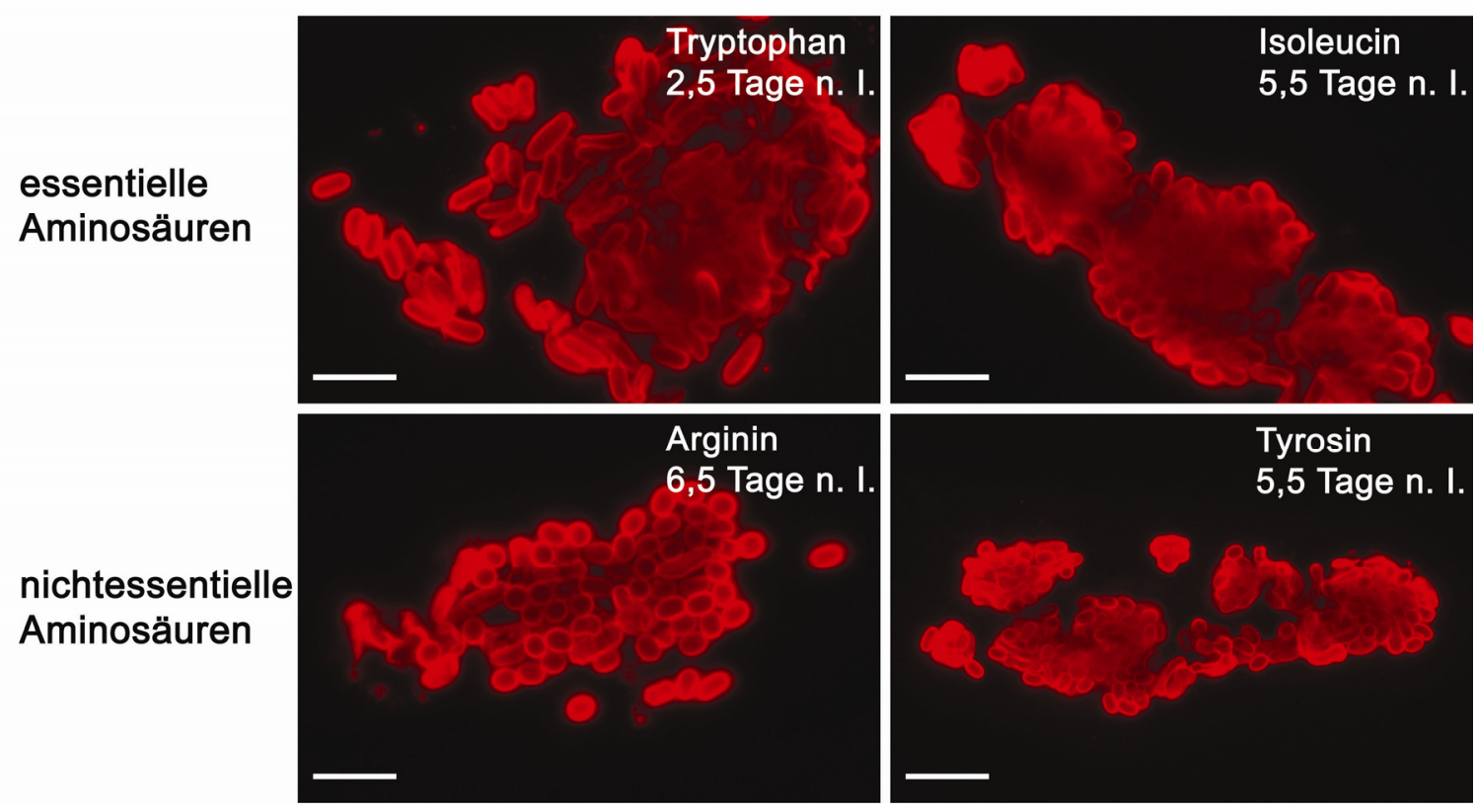

Abb. 3.29: Nachweis von Sporenstadien nach Kultur von E. cuniculi in den AminosäureMangelmedien. Das HFF-Zellkulturmedium wurde gegen Aminosäure-Mangelmedium ausgetauscht und die HFF-Zellen mit E. cuniculi infiziert. Je nach Aminosäure wurde 2,5 6,5 Tage nach Infektion (n. I.) fixiert und zum Nachweis der Sporenstadien eine Immunfluoreszenz-Färbung mit dem anti-SWP1-Antikörper und einem Cy3-gekoppelten Sekundärantikörper durchgeführt. Dargestellt sind exemplarisch nur jeweils zwei essentielle und zwei nichtessentielle Aminosäuren. In allen Aminosäure-Mangelmedien waren SWP1positive Sporenstadien nachzuweisen. Maßstabsbalken $10 \mu \mathrm{m}$.

In Threonin- und Methionin-freiem Medium zeigten die Sporen teilweise jedoch starke morphologische Veränderungen. Während die Sporen normalerweise eine Breite von ca. $1 \mu \mathrm{m}$ und eine Länge von ca. $2 \mu \mathrm{m}$ haben, waren die Sporen nach Kultur ohne Threonin und ohne Methionin mit einer Länge von $7-12 \mu \mathrm{m}$ stark vergrößert (Abb. 3.30). Auch die typische ovale Form war teilweise verändert.
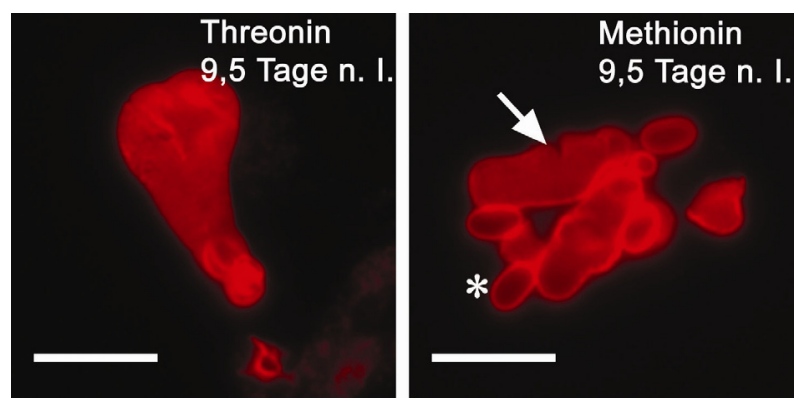

Abb. 3.30: Nach Wachstum in Threonin- und Methionin-freiem Medium zeigen die Sporen starke morphologische Veränderungen. Während E. cuniculi-Sporen normalerweise eine Breite von ca. $1 \mu \mathrm{m}$ und eine Länge von ca. $2 \mu \mathrm{m}$ haben (*), sind die Sporen in Threonin- und Methionin-freiem Medium stark formverändert und teilweise extrem vergrößert $(\rightarrow)$. Maßstabsbalken $5 \mu \mathrm{m}$. 


\subsubsection{E. cuniculi besitzt für die Aufnahme von Aminosäuren sechs Aminosäure- Transportproteine}

Da E. cuniculi auf eine externe Versorgung mit Aminosäuren angewiesen ist (siehe Kap. 3.3.2 - 4), sollte im Folgenden auf die Aminosäure-Transporter von E. cuniculi eingegangen werden. Eine Analyse des Genoms ergab, dass E. cuniculi insgesamt 5 putative AminosäureTransporter, eine Methionin-Permease und einen Oligopeptid-Transporter besitzt (Katinka et al., 2001). Für den weiteren Gebrauch wurden die Transporter mit den Abkürzungen AsTrans1 - 5, MetPer und OligoTrans benannt. Die Zuordnung der Transporter zur „NCBIaccession “-Nummer bzw. zum für E. cuniculi gebräuchlichen „locus-identifier“ ist in Tab. 3.3 dargestellt.

Tab. 3.3: Interne Abkürzung, „NCBI-accession“, „locus identifier" und allgemeingültiger Name für die 7 Transportproteine

\begin{tabular}{|c|c|c|c|}
\hline $\begin{array}{c}\text { interne } \\
\text { Abkürzung }\end{array}$ & „NCBI-accession“ & $\begin{array}{c}\text { E. cuniculi } \\
\text {,locus identifier“ }\end{array}$ & allgemeingültiger Name \\
\hline AsTrans1 & NP_584803 & ECU04_1190 & putativer Aminosäure-Transporter \\
\hline AsTrans2 & NP_597356 & ECU05_0160 & putativer Aminosäure-Transporter \\
\hline AsTrans3 & NP_597400 & ECU05_0580 & putativer Aminosäure-Transporter \\
\hline AsTrans4 & XP_955670 & ECU09_1190 & putativer Aminosäure-Transporter \\
\hline AsTrans5 & NP_586480 & ECU11_1740 & putativer Aminosäure-Transporter \\
\hline MetPer & NP_585905 & ECU06_1480 & Methionin-Permease \\
\hline OligoTrans & NP_586411 & ECU11_1050 & Oligopeptid-Transporter \\
\hline
\end{tabular}

Die 7 Transporter wurden daraufhin auf die Molekülgröße, die Anzahl an Transmembranhelices, das Vorkommen eines Signalpeptides oder Signalankers und die Zugehörigkeit zu einer Proteinfamilie untersucht (Tab. 3.4). Die Vorhersage der Membranhelices und des Signalpeptids bzw. Signalankers wurde dabei mit Hilfe der Programme „TMHMM“ und „SignalP“ des „CBS-Vorhersage-Servers“ (www.cbs.dtu.dk/services/) durchgeführt. Die Proteinfamilie der Transporter wurde durch eine „BLAST-Suche“ in der PFAM-Datenbank (pfam.janelia.org/) ermittelt. Die AminosäureTransporter haben alle eine Größe von 43 - 47 kDa. Der Oligopeptid-Transporter ist mit $53 \mathrm{kDa}$ etwas größer. Alle Transporter enthalten 9-11 Transmembranhelices und sind damit integrale Membranproteine. Fünf der 7 Transporter sind sekretorische Proteine und enthalten entweder ein Signalpeptid oder eine Signalanker-Sequenz. Während die Aminosäure- 
Transporter alle zur gleichen Proteinfamilie der Transmembran-Aminosäure-Transporter gehören, gehört die Methionin-Permease zu den Aminosäure-Permeasen.

Tab. 3.4: Molekülgröße, Anzahl von Transmembranhelices, Vorkommen eines Signalpeptids oder Signalankers und Proteinfamilie der 7 Transportproteine

\begin{tabular}{|c|c|c|c|l|}
\hline $\begin{array}{c}\text { interne } \\
\text { Bezeichnung }\end{array}$ & $\begin{array}{c}\text { Molekül- } \\
\text { größe }\end{array}$ & $\begin{array}{c}\text { Anzahl } \\
\text { Transmembran- } \\
\text { helices } \\
\text { (,TMHMM“) }\end{array}$ & $\begin{array}{c}\text { Signalpeptid } \\
\text { oder Signalanker } \\
\text { (,SignalP“) }\end{array}$ & Proteinfamilie \\
\hline AsTrans1 & $\sim 44 \mathrm{kDa}$ & 9 & Signalpeptid & $\begin{array}{l}\text { Transmembran-Aminosäure- } \\
\text { Transporter-Protein (Aa_trans) }\end{array}$ \\
\hline AsTrans2 & $\sim 47 \mathrm{kDa}$ & 10 & Signalanker & $\begin{array}{l}\text { Transmembran-Aminosäure- } \\
\text { Transporter-Protein (Aa_trans) }\end{array}$ \\
\hline AsTrans3 & $\sim 43 \mathrm{kDa}$ & 9 & Signalanker & $\begin{array}{l}\text { Transmembran-Aminosäure- } \\
\text { Transporter-Protein (Aa_trans) }\end{array}$ \\
\hline AsTrans5 & $\sim 45 \mathrm{kDa}$ & 10 & Signalanker & $\begin{array}{l}\text { Transmembran-Aminosäure- } \\
\text { Transporter-Protein (Aa_trans) }\end{array}$ \\
\hline MetPer & $\sim 43 \mathrm{kDa}$ & 10 & Signalanker & $\begin{array}{l}\text { Aminosäure-Permease } \\
\text { (AA_permease) }\end{array}$ \\
\hline OligoTrans & $\sim 53 \mathrm{kDa}$ & 10 & nicht sekretorisch & $\begin{array}{l}\text { Protonen-abhängige } \\
\text { Oligopeptid-Transportfamilie } \\
\text { (POT oder PTR2) }\end{array}$ \\
\hline
\end{tabular}

Im Folgenden sollte nun untersucht werden, ob die Transporter möglicherweise differentiell reguliert, ob also die Genaktivitäten zu unterschiedlichen Zeitpunkten der Entwicklung hochoder runter reguliert werden. Dazu sollte die Transkription der Gene 12 h, 24 h, 48 h und 72 h nach Infektion mit Hilfe einer quantitativen Real-time-PCR verglichen werden. Zu den entsprechenden Zeitpunkten wurde die Gesamt-RNA der E. cuniculi-Kultur isoliert, in cDNA umgeschrieben und die PCR im LightCycler mit genspezifischen Primern durchgeführt. Actin diente dabei als housekeeping-Gen zur Normalisierung der cDNA-Mengen in den Proben. Zur Ermittlung der relativen mRNA-Mengen wurden die jeweiligen $72 \mathrm{~h}$-Werte als Referenz verwendet. Die relativen mRNA-Mengen der sechs Aminosäure-Transporter unterscheiden sich zwischen frühen Stadien (12 h) und späteren Stadien (72 h) nicht mehr als um den Faktor 2 (Abb. 3.31). Eine nennenswerte differentielle Regulation findet also nicht statt. 


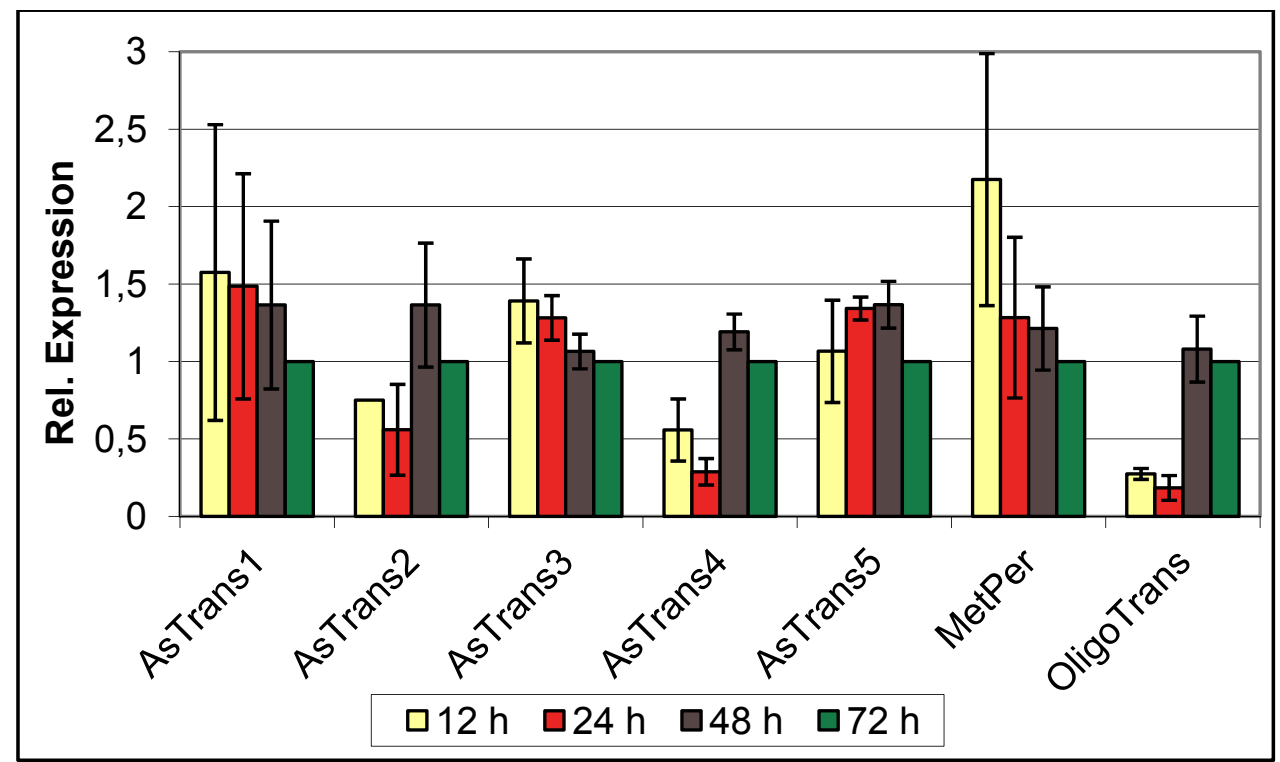

Abb. 3.31: Untersuchung der Aminosäure-Transporter auf eine differentielle Regulation. 12 h, 24 h, 48 h und 72 h nach der Infektion wurde die Gesamt-RNA der Kultur isoliert, in cDNA umgeschrieben und die quantitative Real-time-PCR im LightCyler mit genspezifischen Primern durchgeführt. Die Werte stammen von zwei unabhängigen cDNAPräparationenen. Um unterschiedliche cDNA-Mengen der Proben auszugleichen, wurde gegen die Expression von aktin normalisiert. Zur Ermittlung des relativen mRNA-Gehalts wurden die $72 \mathrm{~h}$-Werte als Referenz verwendet.

Des Weiteren sollte getestet werden, ob E. cuniculi auf die Aminosäure-Mangelbedingungen mit einer Hochregulierung der Transportproteine reagiert, um die Versorgung mit Aminosäuren aufrecht $\mathrm{zu}$ erhalten. So ermittelte Expressionsänderungen auf individuelle Mangelbedingungen könnten eventuell auch Hinweise auf die Spezifität der einzelnen Transporter geben. Um zunächst zu testen, ob unter Aminosäure-Mangel eine Hochregulation der mRNA-Expression erfolgt, wurden ein Arginin-Mangelmedium und ein Mangelmedium, in dem insgesamt sechs Aminosäuren fehlen, verwendet. Dazu wurden HFF-Zellen in T25Flaschen mit frischen Sporen infiziert und zunächst für $48 \mathrm{~h}$ weiter inkubiert. So sollte sichergestellt werden, dass genügend Mikrosporidien für die spätere RNA-Analyse in den Proben enthalten waren. Dann wurde der Aminosäure-Mangel durch Mediumwechsel herbeigeführt, und nach insgesamt $72 \mathrm{~h}$ wurde die Gesamt-RNA der Kultur isoliert. Nach Umschreiben der RNA in cDNA erfolgte die Bestimmung der relativen mRNA-Menge im LightCycler mit den genspezifischen Primern. Zur Ermittlung der relativen mRNAExpression wurde nun der mRNA-Gehalt in DMEM-Komplettmedium als Referenz verwendet. 


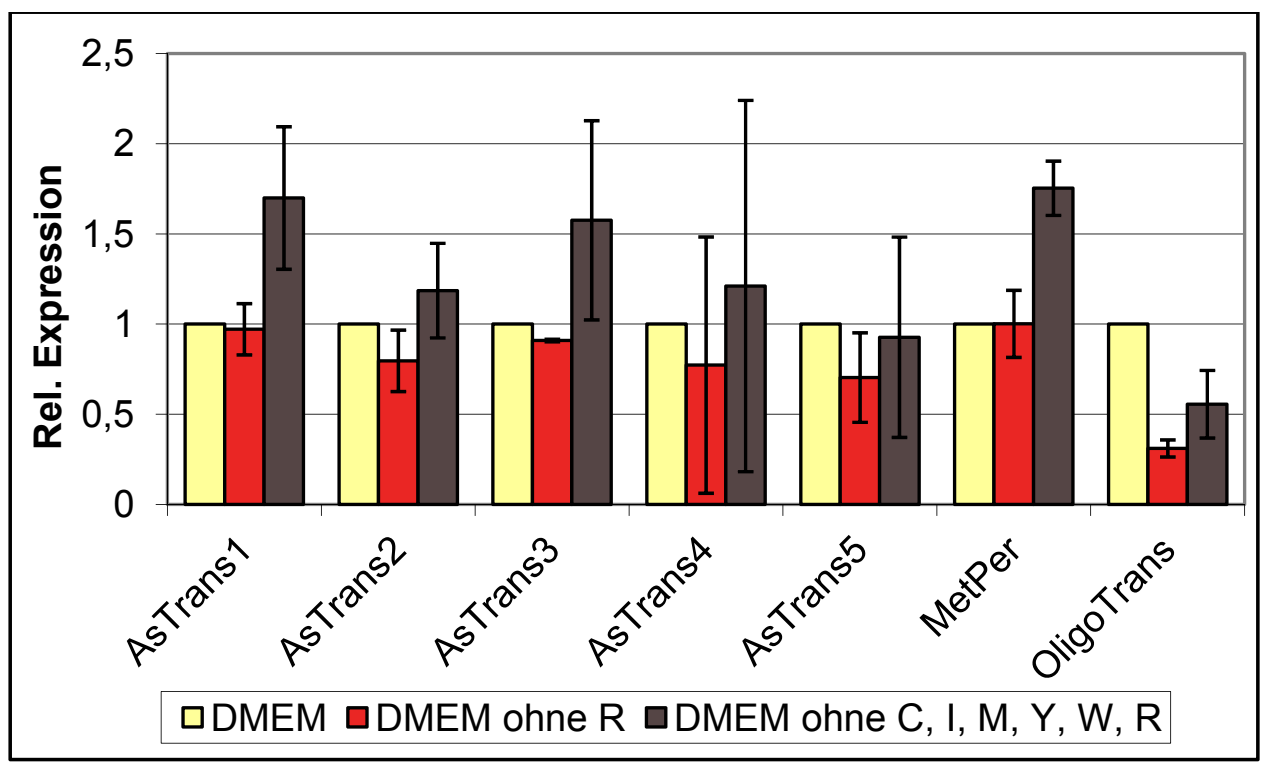

Abb. 3.32: Expressionsanalyse der Aminosäure-Transporter in AminosäureMangelmedien. HFF-Zellen wurden zunächst $48 \mathrm{~h}$ mit E. cuniculi infiziert, bevor das Komplettmedium (DMEM) gegen Mangelmedium ausgetauscht wurde. Als Mangelmedien dienten ein Medium ohne Arginin (R) und ein Medium, in dem Cystein (C), Isoleucin (I), Methionin (M), Tyrosin (Y), Tryptophan (W) und Arginin fehlen. Nach insgesamt $72 \mathrm{~h}$ wurde die Gesamt-RNA isoliert, in cDNA umgeschrieben und die quantitative Real-time-PCR im LightCyler mit genspezifischen Primern durchgeführt. Die Werte stammen von zwei unabhängigen cDNA-Präparationenen. Um unterschiedliche cDNA-Mengen der Proben auszugleichen, wurde gegen den aktin-mRNA-Gehalt normalisiert. Zur Ermittlung der relativen mRNA-Menge wurde der Ansatz in DMEM als Referenz verwendet.

Auch unter Aminosäuremangel wird der steady-state-level der Aminosäure-Transporter kaum reguliert (Abb.3.32). Im Vergleich zum DMEM-Komplettmedium ergibt sich höchstens eine Hochregulation um den Faktor 1,5 - 2. Die mRNA des Oligopeptid-Transporters wird unter Aminosäuremangel um den Faktor 2 herunterreguliert. Die Verfügbarkeit einzelner Aminosäuren scheint somit keinen Einfluss auf die mRNA-Regulation der untersuchten Transporter zu haben. 


\section{Diskussion}

\subsection{Die Biogenese der parasitophoren Vakuolenmembran und der Invasionsmechanismus von $E$. cuniculi}

Der Invasionsmechanismus von Mikrosporidien ist einzigartig und beruht auf dem explosionsartigen Ausschleudern eines als polaren Filaments bezeichneten Tubulus aus der Spore. Trifft das polare Filament eine Zelle, so wird das infektiöse Sporoplasma durch den hohlen Tubulus in die neue Wirtszelle injiziert, während die entleerte Sporenhülle extrazellulär verbleibt. Sehr schnell nach der Invasion sind Mikrosporidien der Gattung Encephalitozoon von einer parasitophoren Vakuolenmembran umgeben. Aufgrund des ungewöhnlichen Invasionsmechanismus von Mikrosporidien und der Abwesenheit von Wirtszell-Markerproteinen in der PVM von E. cuniculi (Fasshauer et al., 2005) ist der Ursprung der Vakuolenmembran bisher noch ungeklärt. Für die Entstehung der PVM gibt es prinzipiell zwei Möglichkeiten. Die PVM könnte bei der Infektion mit dem Sporoplasma übertragen werden, und somit von E. cuniculi selbst stammen, oder aber von der Wirtszelle gebildet werden.

Um die Herkunft der Lipide für die PVM zu untersuchen, wurden selektiv E. cuniculiMembranen oder Membranen der Wirtszelle mit Lipidfarbstoffen markiert. Nach erfolgter Infektion wurde ermittelt, ob die entstandene Vakuolenmembran eine FluoreszenzMarkierung trug. Wurden E. cuniculi-Membranen mit dem fluoreszierenden Phospholipid $\beta$ BODIPY 500/510 $\mathrm{C}_{12}$-HPC (BODIPY-PC) markiert, so war in der entstandenen parasitophoren Vakuolenmembran kein Fluoreszenzsignal nachzuweisen (Abb. 3.3). Unter der Annahme, dass BODIPY-PC markierte Membranen nicht von der entstehenden PVM ausgeschlossen werden, deutet dies darauf hin, dass der Großteil an Phospholipiden für die Vakuolenmembran nicht von E. cuniculi selbst stammt. Ein geringer Beitrag von E. cuniculi zur entstehenden PVM kann jedoch nicht vollkommen ausgeschlossen werden, da der von E. cuniculi beigesteuerte Lipid-Anteil auch unter der Nachweisgrenze dieser Fluoreszenzbasierten Methode liegen könnte. Auch wenn die Lipide für die initiale Bildung der PVM vermutlich ausschließlich von der Wirtszelle stammen, ist E. cuniculi möglicherweise doch an der Vergrößerung der Vakuolenmembran beteiligt. E. cuniculi besitzt zwar keine eigene Fettsäuresynthese, so dass Fettsäuren wahrscheinlich von der Wirtszelle aufgenommen werden müssen, aber einige Gene für die Synthese und Modifikation von Phospholipiden (El Alaoui et al., 2001; Katinka et al., 2001). 
Um die Beteiligung der Wirtszelle an der Biogenese der PVM zu untersuchen, wurden Wirtszellmembranen mit den Carbocyanin-Farbstoffen DiIC ${ }_{16}$ und SPEEDY DiO markiert. Die Kohlenwasserstoff-Seitenketten dieser Farbstoffe weisen einen unterschiedlichen Sättigungsgrad auf, so dass sie sich präferentiell entweder in raft- oder nonraft-Domänen der Membran einlagern. Nach Infektion der markierten Zellen für drei Minuten wiesen die entstandenen Vakuolenmembranen sowohl beim raft- als auch beim nonraft-Farbstoff eine intensive Fluoreszenzmarkierung auf (Abb. 3.5 und 3.6). Das Fluoreszenzsignal in der PVM trat dabei unabhängig von einer Behandlung der Zellen mit Cytochalasin-D auf, so dass ausgeschlossen werden kann, dass das Signal durch eine phagocytotische Aufnahme von Sporoplasma entstanden ist. Da die PVM keine Fluoreszenz-Markierung trägt, wenn die Infektion der Zelle vor der Markierung mit DiIC $_{16}$ oder SPEEDY DiO stattfand, kann auch eine unspezifische Diffusion des Farbstoffs in die Vakuole ausgeschlossen werden. Die Ergebnisse deuten somit darauf hin, dass die PVM von der Wirtszelle stammt und während der Invasion oder in den ersten Minuten nach der Invasion durch einen Cytochalasin-Dunabhängigen Mechanismus gebildet wird. Dabei tragen sowohl raft- als auch nonraft- Lipide zur Biogenese der PVM bei.

Ähnliche Markierungsexperimente hatten auch Hinweise auf den Wirtszell-Ursprung der Vakuolenmembran bei Toxoplasma gondii gegeben. Wird die Wirtszell-Plasmamembran vor der Infektion mit $T$. gondii mit raft- oder nonraft-Lipidfarbstoffen markiert, so trägt die resultierende Vakuolenmembran dieser Parasiten ebenfalls in beiden Fällen eine FluoreszenzMarkierung (Charron und Sibley, 2004). Lipid-rafts sind stark geordnete Membrandomänen, die sehr viel Cholesterin und Sphingolipide sowie viele GPI (Glykosyl-Phospatidylinositol)verankerte Proteine enthalten. Viele Pathogene, darunter Bakterien, Viren und Parasiten nutzen raft-Domänen der Zelle als Portal für die Invasion aus (Rosenberger et al., 2000; Manes et al., 2003). Dabei dienen die Lipid-raft Bestandteile als Rezeptor, um die Aufnahme in die Zelle $\mathrm{zu}$ induzieren, und über bislang wenig charakterisierte Mechanismen der Immunantwort zu entgehen (Rosenberger et al., 2000). Da sowohl raft- als auch nonraftLipide zur Biogenese der PVM von E. cuniculi beitragen (Abb. 3.5 und 3.6) gehört E. cuniculi, ähnlich wie T. gondii nicht zu den Parasiten, die für die Invasion der Wirtszelle auf raft-Domänen angewiesen sind (Charron und Sibley, 2004).

Die im Rahmen dieser Arbeit durchgeführten Versuche konnten zeigen, dass die Lipide für die Bildung der E. cuniculi-PVM von der Wirtszelle stammen. Der exakte Mechanismus, der zur Bildung der PVM führt, bleibt durch diese Versuche allerdings auch weiterhin ungeklärt. 
Im allgemein anerkannten Modell der Mikrosporidien-Invasion durchschlägt der Polartubulus die Plasmamembran angrenzender Wirtszellen, so dass das Sporoplasma anschließend direkt in das Cytosol der neuen Wirtszelle injiziert werden kann (Weidner, 1972; Weidner, 1976; Bigliardi und Sacchi, 2001; Keeling und Fast, 2002; Franzen, 2005). Dieser Mechanismus liefert allerdings keine direkte Erklärung für die Entstehung und den Ursprung der Vakuolenmembran bei der Gattung Encephalitozoon.

Um den Invasionsmechanismus von E. cuniculi besser zu charakterisieren, wurde die Invasion sowie die Entstehung der parasitophoren Vakuolenmembran in Echtzeit mit Hilfe der ,timelapse“-Mikroskopie an lebenden DiIC $_{16}$-gefärbten Zellen untersucht (Abb. 3.7). Trifft ein ausgeschleudertes polares Filament eine Zelle, so entsteht an der Filament-Zell-Kontaktstelle zunächst ein DiIC ${ }_{16}$-gefärbter Penetrationskanal. Kurz danach beginnt die Injektion des Sporoplasmas in die Zelle, was zur Bildung einer ebenfalls gefärbten Vakuolenmembran führt. Die Bildung der Vakuolenmembran geschieht also während der Invasion, und nicht in den ersten Minuten nach Invasion. Der Invasionsprozess ist sehr schnell, und benötigt je nach Invasion nur 1,3-5,2 sec.

Die Entstehung des DiIC $_{16}$-gefärbten Penetrationskanals vor der Bildung der PVM legt die Vermutung nahe, dass die Wirtszell-Plasmamembran vom polaren Filament nicht durchstoßen, sondern möglicherweise eingedrückt wird, so dass eine lange Kanal-ähnliche Invagination entsteht. Das polare Filament wird dabei von Fluoreszenz-markierter Plasmamembran umhüllt. Die PVM entsteht in diesem modifizierten Modell durch die Injektion des Sporoplasmas in die Membran-Invagination aus Plasmamembran-Material (siehe Abb. 4.1). Da der Penetrationskanal bei der Infektion durchgängig gefärbt ist, und keine Unterbrechungen aufweist (siehe Abb. 3.7), wird von der Plasmamembran vermutlich genügend Material zur Bildung der PVM zur Verfügung gestellt. Die Plasmamembran besitzt daher anscheinend eine gewisse Elastizität, so dass es zu keinem „Abreißen“ der MembranInvagination von der Außenmembran kommt.

Käme es doch zu einem Durchschlagen der Plasmamembran, so wäre die plötzliche Umhüllung des polaren Filaments mit intrazellulären DiIC 16 -gefärbten Vesikeln eine alternative Erklärungsmöglichkeit für den gefärbten Penetrationskanal. Dieser Mechanismus kann zwar nicht vollkommen ausgeschlossen werden, ist jedoch eher unwahrscheinlich, da das polare Filament die Markierung bereits nach 1,3 sec trägt, und die Zeitspanne für eine Umhüllung mit intrazellulären Vesikeln daher außerordentlich kurz ist. Während des Versuchs befand sich außerdem ein Großteil des DiIC ${ }_{16}$-Farbstoffs auf der Plasmamembran und nicht in intrazellulären Vesikeln. 

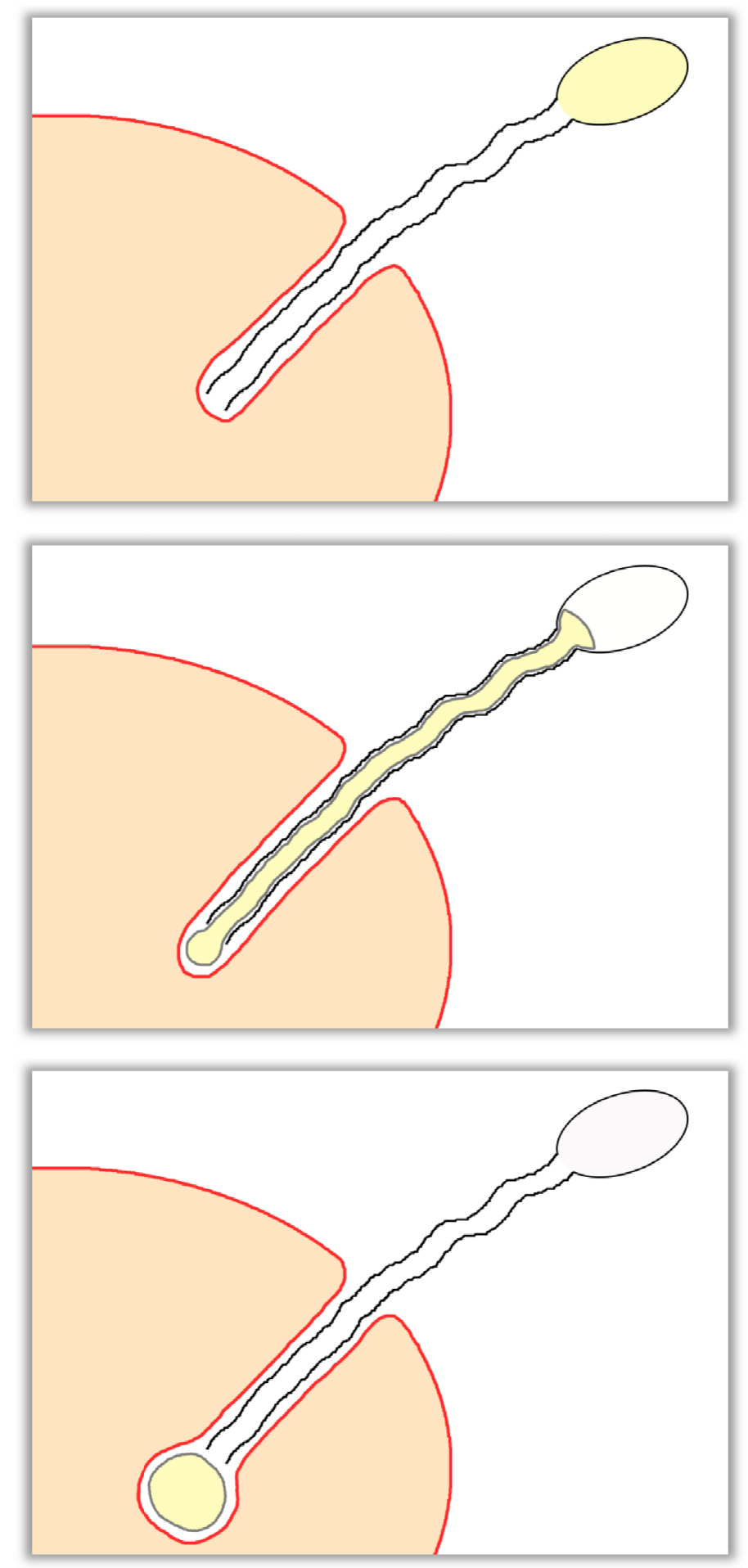

Abb. 4.1: Schematische Darstellung des modifizierten Invasionsmodells von E cuniculi. Die Wirtszell-Plasmamembran wird durch das ausgeschleuderte polare Filament nicht durchstoßen, wie es das herkömmliche Modell vorsieht, sondern eingedrückt, so dass es zu einer langen, Kanal-ähnlichen Invagination kommt. Die parasitophore Vakuolenmembran entsteht daraufhin durch die Injektion des Sporoplasmas in die Membran-Invagination aus Plasmamembran-Material. Die Plasmamembran stellt dabei genügend Material für die Bildung der PVM zur Verfügung, so dass es nicht zu einem „Abreißen“ des InvaginationsKanals von der Außenmembran kommt. 
Auch elektronenmikroskopische Untersuchungen von Mikrosporidien der Gattung Encephalitozoon zeigen, dass der ausgeschleuderte Polartubulus eine Membran-Invagination verursacht (Magaud et al., 1997; Schottelius et al., 2000; Bigliardi und Sacchi, 2001). Die Autoren deuten die Membran-Invagination jedoch als das Ergebnis eines phagocytotischen Prozesses, für den die Umgestaltung des Wirtszell-Cytoskeletts notwendig ist. In dem von ihnen vorgeschlagenen Modell geschieht die Infektion der Zelle durch eine induzierte Phagocytose des Sporoplasmas. Die Wechselwirkung des Polartubulus mit der Zelle löst dabei die phagocytotische Aufnahme des Sporoplasmas in der Membran-Invagination aus. Die im Rahmen dieser Arbeit durchgeführte Untersuchung der Invasion an lebenden Zellen zeigt jedoch die enorme Geschwindigkeit des Infektionsprozesses, die es unwahrscheinlich macht, dass die Invasion über eine langsame, auf die Umgestaltung des Cytoskeletts angewiesene Phagocytose geschieht. Auch die Unabhängigkeit der Invasion von Cytochalasin-D (siehe Abb. 3.5 und 3.6) spricht gegen einen phagocytotischen Prozess. Die E. cuniculi-PV besitzt außerdem nicht die typischen Eigenschaften eines Phagosoms, da die PVM keine endosomalen und lysosomalen Wirtszell-Markerproteine enthält und auch nicht mit endocytotischen Vesikeln verschmilzt (Fasshauer et al., 2005; Weidner, 1975). Die durchgeführten Versuche unterstützen daher eher die These, dass die Membran-Invagination bei der Infektion allein durch die physikalische Kraft des ausgeschleuderten polaren Filaments entsteht.

Wie die PVM nun von der Membran-Invagination abgeschnürt, und damit vom polaren Filament und dem extrazellulären Raum abgetrennt wird, konnten die bisherigen Versuche noch nicht zeigen. Auffällig bei den untersuchten Infektionen war jedoch, dass das polare Filament und die entleerte Spore immer einige Minuten bis zum Ende des jeweiligen „timelapse“-Experiments mit der infizierten Wirtszelle verbunden blieben. Auch bei der Musterung eines mit E. cuniculi infizierten Monolayers fallen viele Zellen auf, die über das polare Filament noch mit der leeren Sporenhülle verbunden sind. Diese Beobachtungen deuten darauf hin, dass die Abtrennung der Zelle vom polaren Filament ein langsamerer Prozess ist, der möglichweise durch eine längere Untersuchung der Zellen in einem „time-lapse“Mikroskop mit verbesserter Auflösung aufgeklärt werden könnte.

Mikrosporidien der unterschiedlichen Gattungen besitzen teilweise recht verschiedene intrazelluläre Lebensweisen. Das häufigste humanpathogene Mikrosporidium, E. bieneusi lebt ohne Vakuolenmembran direkt im Cytosol der Wirtszelle (Desportes et al., 1985; Vavra und Larsson, 1999; Cali und Takvorian, 1999). Elektronenmikroskopische Aufnahmen von Mikrosporidien der Gattung Trachipleistophora, die ebenfalls bei AIDS-Patienten 
vorkommen, deuten an, dass frühe Meronten-Stadien die Hüllmembran selbst sekretieren. $\mathrm{Zu}$ Beginn der Sporogonie ziehen sich die Mikrosporidien von dieser Hüllmembran in das Innere des Vesikels zurück, so dass ein so genanntes „sporophores Vesikel“ entsteht (Vavra und Larsson, 1999; Juarez et al., 2005). Ob diese Mikrosporidien die Wirtszell-Plasmamembran bei der Invasion möglicherweise doch durchschlagen, und so ohne Hüllmembran direkt ins Wirtszell-Cytosol gelangen, oder ob sie die durch die Invasion entstandene Vakuolenmembran sehr schnell abbauen, ist noch ungeklärt.

Ein Versuch die intrazelluläre Lebensweise der einzelnen Mikrosporidienspezies in verschiedene Gruppen einzuteilen wurde von Ann Cali unternommen (Cali, 1971; Cali und Takvorian, 1999). Die Aufteilung erfolgte hierbei in Mikrosporidien die entweder direkt im Wirtszell-Cytosol leben, oder vom Wirtszell-Cytosol durch eine Hüllmembran getrennt sind, wobei diese von der Wirtszelle, vom Mikrosporidium oder von beiden stammen kann. Diese formale Einteilung in die vier theoretisch möglichen Kategorien, wurde aber mit keinerlei weiteren Experimenten, die den dynamischen Vorgängen bei der Invasion oder der späteren intrazellulären Entwicklung gerecht würden, belegt.

Obwohl der Invasionsmechnismus der Mikrosporidien einzigartig ist, ist die Invasion vieler anderer Erreger besser charakterisiert. In jedem Fall hängt die Entstehung der parasitophoren Vakuolenmembran jedoch vom Invasionsmechanismus ab. Die zur Gruppe der Apikomplexa gehörenden Parasiten Toxoplasma gondii und Plasmodium falciparum dringen über einen aktiven, Aktin-abhängigen Mechanismus, der so genannten ,gliding motility“ in die Wirtszelle ein (Sibley, 2004). Bei der Invasion von T. gondii wird die WirtszellPlasmamembran durch die aktive Vorwärtsbewegung des Parasiten ins Zellinnere eingedrückt. Dabei entsteht zwischen Parasit und Plasmamembran eine als „,moving junction“ bezeichnete Verbindung, die durch die weitere Vorwärtsbewegung zum apikalen Ende des Parasiten wandert. Ist die Invasion abgeschlossen, fusioniert die „,moving junction“ hinter dem Parasiten, und schließt diesen in eine parasitophore Vakuole aus Wirtszell-Plasmamembran ein (Charron und Sibley, 2004). Während dieses Vorgangs wird außerdem Material aus Organellen des Parasiten, den so genannten Rhoptrien freigesetzt, das die Vakuolenmembran zusätzlich modifiziert (Hakansson et al., 2001). Intrazelluläre Protozoen der Gattung Leishmania sowie intrazellulär lebende Bakterien gelangen über Phagocytose oder induzierte Phagocytose in die Wirtszelle, so dass ihre Vakuolenmembran der Plasmamembran der Wirtszelle entstammt (Sacks und Sher, 2002; Zaas et al., 2005; Cossart und Sansonetti, 2004). Der parasitische Protozoa Trypanosoma cruzi hingegen nutzt den zellulären Mechanismus der Wundheilung aus, um in die Wirtszelle einzudringen. Die Wundheilung in eukaryotischen 
Zellen beruht auf der $\mathrm{Ca}^{2+}$-gesteuerten Exocytose von Lysosomen an der Verletzungsstelle (Reddy et al., 2001). T. cruzii rekrutiert mit Hilfe dieses $\mathrm{Ca}^{2+}$-abhängigen Mechanismus Wirtszell-Lysosomen an die Parasit-Zell-Kontaktstelle, so dass die entstehende PVM aus Membranen lysosomalen Ursprungs entsteht (Burleigh und Woolsey, 2002).

\subsection{Die parasitophore Vakuole bildet eine optimale Nische für $E$. cuniculi}

\subsubsection{Die PVM enthält keine Wirtszell-Oberflächenproteine}

Eine primäre Abwehrfunktion eukaryotischer Zellen gegen internalisierte Pathogene ist die Fusion von Lysosomen mit der parasitophoren Vakuolenmembran, so dass die Vakuole angesäuert, und der enthaltene Erreger durch lysosomale Enzyme abgebaut wird. Bei Infektionsversuchen von Makrophagen mit E. cuniculi wurde mit Hilfe von Ferritinmarkierten Vesikeln gezeigt, dass die E. cuniculi Vakuolenmembran nicht mit Endosomen oder Lysosomen verschmilzt (Weidner, 1975). Neuere Untersuchungen zeigten außerdem, dass die Vakuolenmembran keine endosomalen oder lysosomalen Markerproteine enthält. Auch der Transferrin-Rezeptor, ein Markerprotein für frühe Endosomen und die Zelloberfläche ist in der Vakuolenmembran nicht zu finden (Fasshauer et al., 2005).

Da die vorangegangenen Ergebnisse darauf hindeuten, dass die PVM durch eine Invagination der Wirtszellplasmamembran entsteht, wurde mit Hilfe der Biotinylierung von WirtszellOberflächenproteinen, gefolgt von der Infektion mit E. cuniculi untersucht, ob die entstehende Vakuolenmembran generell Wirtszell-Oberflächenproteine enthält. Die Auswertung zeigte, dass die entstandenen Vakuolenmembranen größtenteils frei von WirtszellOberflächenproteinen sind, und deutet somit darauf hin, dass E. cuniculi einen Ausschlussmechanismus für Oberflächenproteine besitzt. Vor allem zu frühen Zeitpunkten nach der Infektion finden sich aber doch vereinzelt Vakuolen, die Oberflächenproteine enthalten. Nach 1 min enthalten ca. $20 \%$, nach 5 min ca. $10 \%$, nach 10 min ca. $5 \%$ der Vakuolen Oberflächenproteine. Dies deutet darauf hin, dass der Ausschluss der Oberflächenproteine während der Infektion und in den ersten Minuten nach der Infektion geschieht. Ein kleiner Teil der Vakuolen ( $<5 \%$ ) bleibt auch zu späteren Zeitpunkten positiv für Oberflächenproteine. Für das Vorhandensein von Vakuolenmembranen mit Oberflächenproteinen gibt es zwei Erklärungsmöglichkeiten. Es könnte sich bei den Vakuolen trotz Cytochalasin-D-Behandlung um phagocytiertes Sporoplasma handeln, da CytD die 
Phagocytose nicht vollständig inhibiert (Orlik, 2007). Es wäre aber auch ein teilweise fehlerhafter Ausschlussmechanismus denkbar.

Im Zuge der elektronenmikroskopischen Studien, die zuerst eine PlasmamembranInvagination zeigten, sprachen $\mathrm{Xu}$ und Weiss davon, dass durch die Invagination eine Mikroumgebung (,microenvironment ${ }^{\star *}$ ) für die Interaktion des Sporoplasmas mit der Wirtszell-Plasmamembran entsteht (Xu und Weiss, 2005). Der Ausschlussmechanismus für Membranproteine könnte möglicherweise auf einer engen Wechselwirkung des Sporoplasmas bzw. der Meronten-Plasmamembran mit der Wirtszell-Plasmamembran in dieser Mikroumgebung beruhen.

Bei T. gondii wird ebenfalls ein Großteil der Wirtszell-Membranproteine von der Vakuolenmembran ausgeschlossen. Der Ausschlussmechanismus beruht hier auf einer engen Wechselwirkung zwischen der Plasmamembran des Parasiten und der WirtszellPlasmamembran in einer Struktur, die als „,moving junction“ bezeichnet wird (Mordue et al., 1999). Die „moving junction“ bildet dabei für bestimmte Membranproteine eine Diffusionsbarriere, bisher konnte allerdings noch kein universelles Modell für die Proteinsortierung erstellt werden, da einige Proteine, wie z. B. GPI-verankerte Proteine und bestimmte Transmembranproteine die ,moving junction“ passieren, während andere Transmembranproteine von der PVM ausgeschlossen werden (Charron und Sibley, 2004). Die Eigenschaft Wirtszell-Plasmamembranproteine auszuschließen, wird jedoch generell für die Inkompetenz der Vakuole mit endosomalen oder lysosomalen Vesikeln zu verschmelzen, verantwortlich gemacht, da die für die Membranfusion notwendigen Proteine fehlen (Sinai und Joiner, 1997). Die E. cuniculi-Vakuole ist somit einerseits mit Wirtszell-eigenen Lipiden maskiert, und andererseits durch den Ausschluss der Wirtszell-Membranproteine vor der Fusion mit lysosomalen Vesikeln geschützt, so dass das intrazelluläre Überleben von E. cuniculi optimal gesichert wird. Obwohl sich der Invasionsmechanismus von E. cuniculi sehr deutlich von dem aktiven, Aktin-abhängigen Invasionsmechanismus von T. gondii unterscheidet, weisen die Vakuolen dieser beiden Erreger hinsichtlich der nicht-fusiogenen Eigenschaften doch eine erstaunliche Ähnlichkeit auf.

Auch andere intrazelluläre Erreger, wie z.B. Chlamydien oder Mykobakterien sowie die fakultativ intrazellulären Legionellen besitzen die Fähigkeit, die Fusion mit Lysosomen zu modulieren oder zu blockieren. Die als inclusion bezeichnete Vakuole der Chlamydien wird weder angesäuert, noch mit Lysosomen fusioniert (Sinai und Joiner, 1997; Wyrick, 2000), wobei die Inhibierung dieser Prozesse möglicherweise von einem Oberflächen-Molekül der Elementarkörperchen abhängig ist (Eissenberg und Wyrick, 1981). Chlamydien sind 
außerdem in der Lage, das Wirtszell-Cytoskelett zu beeinflussen, was zu einer Translokation der inclusion in die perinukleäre Region führt (Clausen et al., 1997; Wyrick, 2000). Auch eine frühe Genexpression der Chlamydien ist wahrscheinlich an der Fusions-Inkompetenz mit Endosomen und Lysosomen beteiligt, da früh exprimierte Proteine vermutlich die inclusionMembran modifizieren (Scidmore et al., 1996). Die Fusionseigenschaften der inclusion werden jedoch als „selektiv fusiogen“ bezeichnet, denn sie verschmilzt sowohl mit anderen inclusions in einer homotypischen Fusion (Ward, 1988), als auch mit exocytotischen Vesikeln des Golgi-Apparates (Hackstadt et al., 1996).

Die Vakuole von Mykobakterien, die sich überwiegend in Makrophagen vermehren, besitzt die Eigenschaften früher Endosomen, deren Entwicklung zu späten Endosomen oder Lysosomen blockiert ist (Sturgill-Koszycki et al., 1996; Rohde et al., 2007). Die Vakuolenmembran enthält nur wenige aktive $\mathrm{H}^{+}$-ATPasen, die für die Ansäuerung von Phagosomen verantwortlich sind (Sturgill-Koszycki et al., 1994). Lysosomale Hydrolasen wie Cathepsin D sind in der Vakuole nicht enthalten (Clemens und Horwitz, 1995; SturgillKoszycki et al., 1996). Die Blockierung der Phagosomen-Lysosomen-Fusion beruht nach neuesten Erkenntnissen vermutlich auf einer Kombination aus Oberflächenmolekülen der Zellwand von Mykobakterien und sekretierten Faktoren, die in die Signaltransduktion der Wirtszelle eingreifen (Pieters, 2008). So verhindert z. B. das in der Zellwand enthaltene Lipid Lipoarabinomannan (LAM) eine Akkumulation von Phosphatidyl-Inositol-3-Phosphat (PI3P) in der Phagosomenmembran, das für die weitere Reifung des Phagosoms benötigt wird (Fratti et al., 2003; Vergne et al., 2003).

Die fakultativ intrazellulären Legionellen werden über Phagocytose in professionelle Phagocyten aufgenommen, die ihnen als Wirtszelle dienen (Horwitz, 1984). Zur Bildung einer vermehrungsfähigen Vakuole wird die Vakuolenmembran mit Wirtszell-Ribosomen besetzt (Horwitz und Silverstein, 1983), und vom Endoplasmatischem Retikulum (ER) der Wirtszelle umhüllt (Swanson und Isberg, 1995; Robinson und Roy, 2006). Die FusionsInkompetenz der Legionella-Vakuole ist wahrscheinlich von mehreren durch ein Typ-IVSekretionssystem sekretierten Faktoren abhängig (Roy et al., 1998; Shin und Roy, 2008).

Auch wenn viele Pathogene die Fusion der Vakuole mit Endosomen und Lysosomen verhindern, werden von den verschiedenen Organismen individuelle Strategien angewendet, um dieses Ziel zu erreichen. Neben der Bildung einer Fusions-inkompetenten Vakuole gibt es noch weitere Strategien, das intrazelluläre Überleben zu sichern. Der parasitische Protozoa Trypanosoma cruzi gehört zu einer Gruppe von Pathogenen, die die sie umhüllende Vakuolenmembran lysieren, und sich anschließend frei im Cytosol der Wirtszelle vermehren 
(Sacks and Sher, 2002; Mott und Burleigh, 2008). Für die Aufnahme in die Zelle rekrutiert T. cruzi Wirtszell-Lysosomen an die Wirt-Parasit-Kontaktstelle, so dass die Vakuolenmembran aus Lysosomen-Membranen entsteht (siehe auch 4.1) (Burleigh und Woolsey, 2002). Die vorübergehende saure Umgebung im Lysosom ist notwendig für das intrazelluläre Überleben von T. cruzi, da das Poren-bildende Toxin, das die LysosomenMembran lysiert, bei einem niedrigen pH-Wert funktioniert (Andrews et al., 1990; Andrews and Whitlow, 1989). Andere Parasiten, wie Leishmanien sind in der Lage, in Phagolysosomen zu überleben (Burchmore und Barrett, 2001). Phagolysosomen fusionieren mit späten Endosomen und Lysosomen, und weisen einen sauren $\mathrm{pH}-$ Wert sowie hydrolytische Aktivitäten auf. Um in diesem Milieu zu überleben, differenziert Leishmania von einem promastigoten Stadium in Hydrolase-resistente Amastigoten. Diese besitzen eine rigide Zellwand und sekretieren viele Glykokonjugate, die die Zelle vor einem proteolytischen Angriff schützen (Sacks und Sher, 2002).

\subsubsection{Die parasitophore Vakuolenmembran enthält Poren, um Nährstoffe zur Versorgung von $E$. cuniculi bereitzustellen}

Aufgrund der kleinen Genomgröße und des damit verbundenen Verlustes von Stoffwechselwegen benötigt E. cuniculi sehr viele Nährstoffe von seiner Wirtszelle (Katinka et al., 2001; Keeling, 2001). Um für E. cuniculi zugänglich zu sein, müssen diese Nährstoffe jedoch zunächst über die parasitophore Vakuolenmembran in die Vakuole transportiert werden. Bislang konnte allerdings noch kein Protein in der Vakuolenmembran identifiziert werden, und auch über die Ernährungsstrategien von E. cuniculi ist wenig bekannt. Die PVM ist vermutlich außerordentlich wichtig für die Rekrutierung von Nährstoffen. Elektronenmikroskopische Aufnahmen zeigten, dass die PVM sehr viele Vesikel ins Innere der Vakuole abschnürt (Weidner, 1975). Außerdem ist die PVM in der Lage, WirtszellMitochondrien an die Membran rekrutiert, um möglicherweise das ATP dieser Organellen in die Vakuole zu importieren (Scanlon et al., 2004).

Proteinfreie, synthetische Lipidmembranen sind permeabel für hydrophobe und kleine ungeladene polare Moleküle wie Sauerstoff, Kohlendioxid oder Wasser. Für große ungeladene polare Moleküle wie Kohlenhydrate und für Ionen bildet die Lipid-Doppelschicht eine Permeabilitätsbarriere (Alberts et al., 2004). 
Poren in der Vakuolenmembran sind eine relativ weit verbreitete Strategie intrazellulärer Erreger, um Kontakt mit Nährstoffen zu ermöglichen (Sinai und Joiner, 1997; Saliba und Kirk, 2001a). Um zu untersuchen, ob die E. cuniculi-PVM Poren enthält, die einen Stoffaustausch der Vakuole mit dem Wirtszell-Cytosol ermöglichen, wurden Membranimpermeable Fluoreszenzfarbstoffe verschiedener Größen und Ladungen in das Cytosol infizierter Wirtszellen mikroinjiziert. Diese Mikroinjektions-Technik ist eine anerkannte Methode, um Poren in Vakuolenmembranen nachzuweisen, und wurde auch zum Nachweis der PVM-Poren von anderen Pathogenen angewandt (Schwab et al., 1994; Bano et al., 2007; Werner-Meier und Entzeroth, 1997). Bei der Untersuchung der E. cuniculi-PVM konnte gezeigt werden, dass geladene Moleküle der Größe 0,5-1,1 kDa die PVM ungehindert passieren (Abb. 3.10). Die PVM besitzt somit veränderte Permeabilitätseigenschaften, die auf die Existenz von Poren hindeuten. Der verzögerte Eintritt einer Dextran-Präparation der Größe 1,5 - 3 kDa und der Ausschluss der 10 kDa-Dextran Moleküle deutet darauf hin, dass die Ausschlussgröße der Poren vermutlich zwischen 3 und $10 \mathrm{kDa}$ liegt. Da nach Mikroinjektion der 1,5 - 3 kDa-Dextrane in der Vakuole eine etwas geringere Fluoreszenzintensität als im Cytosol auftritt (vgl. Abb. 3.10), könnte die Ausschlussgröße der Poren möglicherweise sogar zwischen 1,5 und $3 \mathrm{kDa}$ liegen. Die PVM sollte somit für Nährstoffe wie Kohlenhydrate, Aminosäuren und ATP durchlässig sein. Da die Permeabilitätseigenschaften der PVM zu unterschiedlichen Zeitpunkten der Infektion gleich sind, kann davon ausgegangen werden, dass E. cuniculi permanent Zugang zu den Nährstoffen der Wirtszelle hat.

Auch frühere Experimente deuteten an, dass die PVM der Mikrosporidien veränderte Permeabilitätseigenschaften besitzt, und damit der PVM von T. gondii ähnelt (Leitch et al., 1995). Bei diesen Versuchen wurden mit Encephalitozoon hellem infizierte Zellen mit dem Farbstoff Calcein-Acetoxymethyl (-AM) inkubiert, und der Eintritt des Farbstoffes in die Vakuole untersucht. Konfokale Bilder zeigen, dass Mikrosporidien in der Vakuole von Fluoreszenzfarbstoff umhüllt sind, Calcein-AM ist jedoch ein Zell-permeabler Farbstoff, der als solches auch die PVM passieren kann. Intrazelluläre Esterasen spalten die AcetoxymethylGruppe des nicht-fluoreszierenden Calcein-AM ab, so dass fluoreszierendes, Membranimpermeables Calcein entsteht. Die Autoren mutmaßten, dass die Spaltung des Membranpermeablen in den Membran-impermeablen Farbstoff vor der Passage der PVM geschah. Dies ist allerdings nur schwer nachweisbar. Durch die cytosolische Mikroinjektion Membranimpermeabler Farbstoffe konnte die Existenz von Poren in der PVM nun eindeutig nachgewiesen werden. 
Die zu den Apikomplexa gehörenden Parasiten Plasmodium falciparum, P. berghei, T. gondii und Eimeria nieschulzii besitzen ebenfalls Poren in der parasitophoren Vakuolenmembran (Desai et al., 1993; Bano et al., 2007; Schwab et al., 1994; Werner-Meier und Entzeroth, 1997). Neben den PVM-Poren existieren jedoch auch andere Ernährungsstrategien bei intrazellulären Erregern. Für Chlamydia trachomatis konnte durch cytosolische Mikroinjektion gezeigt werden, dass die inclusion-Membran keine Poren enthält (Heinzen und Hackstadt, 1997). Elektronenmikroskopische Studien zeigen jedoch, dass die metabolisch aktiven Retikularkörperchen vermehrt an der inclusion-Membran liegen und dass die Bakterienmembran von Elementar- und Retikularkörperchen hohle Anhängsel, (projections) besitzt, die die inclusion-Membran durchbrechen und eine Verbindung zum Wirtszell-Cytosol herstellen (Nichols et al., 1985; Raulston, 1995). Möglicherweise dienen diese projections dem Austausch von Nährstoffen und ATP mit der Wirtszelle (Sinai und Joiner, 1997; Wyrick, 2000). Im Zuge der Weiterentwicklung molekularbiologischer Methoden wurde entdeckt, dass das Genom von C. psittaci für ein Typ-III-Sekretionssystem kodiert (Hsia et al., 1997). Neueste Untersuchungen bei C. trachomatis zeigen, dass das Nadel-Protein des Injektisoms in den projections lokalisiert ist. Daher ist es möglich, dass die projections möglicherweise auch als Typ-III-Sekretionssystem für die Sekretion von Effektorproteinen in die Wirtszelle fungieren (Betts et al., 2008). Mit Hilfe des Golgi-spezifischen fluoreszierenden Sphingolipids NBD-Ceramid konnte gezeigt werden, dass Chlamydien Sphingolipide der Wirtszelle nutzen, indem sie mit exocytorischen Vesikeln des GolgiApparates fusionieren (Hackstadt et al., 1995; Rockey et al., 1996).

Bei Legionellen sind die Ernährungsstrategien noch nicht so gut charakterisiert. Es gibt jedoch Experimente, die darauf hindeuten, dass Legionellen, die vorwiegend Aminosäuren und Peptide von ihrer Wirtszelle aufnehmen, eine Autophagie der Wirtszelle stimulieren (Swanson und Isberg, 1995; Dorn et al., 2002). Dabei kommt es durch Abbau wirtseigener Bestandteile zu einer Erhöhung der intrazellulären Aminosäure- bzw. Peptid-Konzentration, was sich positiv auf das bakterielle Wachstum auswirkt. Für Legionella pneumophila konnte außerdem gezeigt werden, dass die Bakterien die Proteinsynthese der Wirtszelle inhibieren, was ebenfalls zu einer Erhöhung des intrazellulären Aminosäure-Spiegels beitragen könnte (McCusker et al., 1991). Die intrazelluläre Replikation von L. pneumophila ist jedoch nicht nur von der Autophagocytose sondern auch vom Aminosäure-Import in die Wirtszelle durch Wirtszell-Aminosäure-Transporters abhängig (Wieland et al., 2005).

Neben den fusions-inkompetenten Vakuolen von E. cuniculi und T. gondii und den Vakuolen von Chlamydien und Legionellen weisen die Phagolysosomen von Leishmania-Parasiten 
sicherlich die extremsten intrazellulären Bedingungen auf. Durch die Fusion mit späten Endosomen, Phagosomen und Autophagosomen kommt es zu einer Ansäuerung der Vakuole auf einen $\mathrm{pH}-$ Wert von $\sim 5$ und einer Anreicherung mit Hydrolasen und Proteasen (Veras et al., 1994; Schaible et al., 1999; Antoine et al., 1990). Gleichzeitig ist das Phagolysosom aber auch extrem nährstoffreich, da die enthaltenen Makromoleküle von hydrolytischen Enzymen in ihre Bestandteile zerlegt werden. So stehen für die Leishmanien zwar immer genügend Nährstoffe zur Verfügung, die Parasiten müssen jedoch mit den Transportproteinen der Wirtszelle um die Nährstoffe konkurrieren. Für den Import von Nährstoffen besitzen Leishmanien daher sehr viele, an einen niedrigen $\mathrm{pH}$-Wert angepasste Transportproteine (Burchmore und Barrett, 2001). Da das Cytosol der Amastigoten einen neutralen pH-Wert besitzt, kann der über der Plasmamembran existierende Protonengradient als Energiequelle für den Import von Nährstoffen durch sekundäre Transporter genutzt werden (Zilberstein und Dwyer, 1985; Naderer und McConville, 2008).

Zusätzlich zum Import von Nährstoffen in die Vakuole stellt die Vakuolenmembran häufig auch enge Wechselwirkungen zu Wirtszell-Organellen her, um die Pathogene in räumliche Nähe zu benötigten Nährstoffen zu bringen. Eine Organell-Assoziation konnte allerdings bisher nur für nicht-fusiogene Vakuolen nachgewiesen werden, wo die Assoziation neben der Versorgung mit Nährstoffen vermutlich zusätzlich einen Schutz vor der Fusion mit endosomalen Vesikeln bietet (Sinai und Joiner, 1997). Eine Assoziation mit WirtszellMitochondrien, wie sie für E. cuniculi gezeigt wurde (Scanlon et al., 2004), aber auch eine Assoziation mit dem Endoplasmatischen Retikulum (ER) der Wirtszelle ist bei verschiedenen Erregern zu finden. Während die inclusion-Membran von C. psittaci mit Mitochondrien assoziiert ist (Matsumoto et al., 1991; Wyrick, 2000), zeigt die PVM von T. gondii sowohl eine Assoziation mit Mitochondrien als auch mit dem ER (Sinai et al., 1997). Bei L. pneumophila ist eine transiente Wechselwirkung mit Mitochondrien, gefolgt von einer Assoziation der Vakuolenmembran mit Ribosomen und dem Wirtszell-ER sogar unabdingbar für die Bildung einer Replikations-fähigen Vakuole (Horwitz, 1983; Swanson und Isberg, 1995; Robinson und Roy, 2006).

Ähnlich zu den Retikularkörperchen der Chlamydien sind auch die metabolisch aktiven Meronten von E. cuniculi vorwiegend an der PVM lokalisiert. Elektronenmikroskopische Untersuchungen deuten darauf hin, dass die Meronten über tight junction-ähnliche Verbindungen an die PVM gebunden werden (Weidner, 1975). Wie eine Mikroinjektion der 10 kDa-Dextran-Moleküle in die Vakuole zeigen konnte, können Vakuolen von E. cuniculi aus unabhängigen Teilvakuolen aufgebaut sein (Abb. 3.14). Unabhängige Teilvakuolen haben 
im Gegensatz zu Einzelvakuolen eine größere Membranfläche und besitzen vermutlich eine größere Anzahl an Poren-Proteinen. Somit können Teilvakuolen in Kombination mit der Lokalisation der Meronten an der PVM zu einer verbesserten Nährstoffversorgung von E. cuniculi beitragen.

\subsubsection{Das E. cuniculi-Hämolysin III als mögliches Poren-bildendes Protein}

Hämolysine sind wasserlösliche, sekretierte Proteine, die Poren in Zielmembranen bilden. Dazu lagern sich mehrere Hämolysin-Monomere in einer $\beta$-barrel-Struktur in der Membran zusammen, bei der hydrophobe Seitenketten benachbart zur Lipiddoppelschicht und hydrophile Seitenketten im Inneren der Pore lokalisiert sind (Menestrina et al., 2001). Die Funktion von Hämolysinen wird generell in drei Schritte unterteilt: Bindung an die Zielmembran, Porenbildung und Zelllyse (Honda et al., 1992). Viele Bakterien produzieren hämolytische Toxine, die als Virulenzfaktoren Effektorzellen des Immunsystems lysieren, und den Bakterien Zugang $\mathrm{zu}$ den in der Zelle enthaltenen Nährstoffen ermöglichen (Menestrina et al., 2003). Der Prototyp bakterieller Toxine ist dabei das $\alpha$-Hämolysin der Staphylokokken (Menestrina et al., 2001). Andere Hämolysine intrazellulärer Erreger, wie das Listeriolysin O oder Hämolysine von T. cruzii lysieren keine Zielzellen, sondern lagern sich nach Aufnahme durch die Wirtszelle in die sie umgebende Phagosomenmembran ein (Glomski et al., 2002; Andrews und Whitlow, 1989). Durch die Lyse der Phagosomenmembran entkommen die Erreger in das Wirtszell-Cytosol, wo sie sich frei replizieren können. Diese Hämolysine besitzen ein Aktivitätsoptimum bei saurem pH, so dass die Phagosomenmembran lysiert wird, während die Plasmamembran der Wirtszelle geschützt bleibt (Glomski et al., 2002).

Proteine, die die Poren in der Vakuolenmembran von E. cuniculi bilden, könnten sich prinzipiell mit einem ähnlichen Mechanismus in die PVM einlagern, wie Listeriolysin O oder das Hämolysin von T. cruzii, mit dem Unterschied, dass sie keine Lyse herbeiführen, sondern das Wirtszell-Cytosol mit dem Lumen der Vakuole verbinden. Bisher konnte der PVM von E. cuniculi allerdings noch kein Protein zugeordnet werden, und auch die Proteine, die die PVM-Poren von T. gondii, P. falciparum oder P. berghei bilden, sind noch nicht identifiziert. Bei der Suche nach möglichen Poren-bildenden Proteinen von E. cuniculi wurde ein Hämolysin III (HlyIII) identifiziert. Die HlyIII-Proteinfamilie ist jedoch bislang relativ schlecht charakterisiert. Bacillus cereus und Vibrio vulnificus besitzen ein Hämolysin III mit 
cytolytischer Aktivität (Chen et al., 2004; Baida und Kuzmin, 1996), aber andere Mitglieder dieser Proteinfamilie wie YOL002c von Saccharomyces cerevisiae sind regulatorische Proteine (Karpichev et al., 2002). Nichtsdestotrotz besitzen aber sowohl T. gondii als auch P. falciparum und P. berghei ein Hämolysin III-Homolog, so dass EcHlyIII näher charakterisiert werden sollte. Die Realtime-PCR-Analyse ergab, dass die EcHlyIII-mRNA $48 \mathrm{~h}$ und $72 \mathrm{~h}$ nach der Infektion um den Faktor 3 - 3,5 hochreguliert wird. Diese Hochregulation zum Zeitpunkt des größten Massenzuwachses der Vakuole würde mit einer Funktion von EcHlyIII als putativem Poren-Protein zusammenpassen. Mit Hilfe der generierten anti-Peptid-Antikörper konnte im Western Blot nach Membranfraktionierung bestätigt werden, dass es sich bei EcHlyIII um ein Membranprotein handelt (siehe Abb. 3.21). Aufgrund der fehlenden Reaktivität des Antikörpers im Immunfluoreszenz-Test (siehe Abb. 3.20) konnte allerdings eine Lokalisation von EcHlyIII in der Vakuolenmembran und damit eine mögliche Funktion als putatives Poren-Protein nicht nachgewiesen werden.

\subsection{E. cuniculi ist metabolisch in hohem Maße auf seine Wirtszelle angewiesen}

Die unter verschiedenen Aminosäure-Mangelbedingungen durchgeführten Wachstumsassays konnten experimentell bestätigen, dass E. cuniculi aufgrund seiner reduzierten StoffwechselSynthesewege in hohem Maße von Nährstoffen der Wirtszelle abhängig ist. E. cuniculi ist auf eine externe Zufuhr von Aminosäuren durch die Wirtszelle oder das Zellkulturmedium angewiesen. Der Zell-ELISA zeigte für nahezu alle essentiellen AminosäurenMangelbedingungen eine deutliche Inhibierung des E. cuniculi-Wachstums, lediglich die Effekte eines Tryptophan-Mangels waren weniger stark ausgeprägt (Abb. 3.23). Unter den nichtessentiellen Aminosäuren reduzieren ebenfalls nahezu alle Mangelbedingungen das E. cuniculi-Wachstum vollständig. Ein Glycin- und ein Serin-Mangel haben dagegen keinen Einfluss auf das Wachstum (Abb. 3.26). Durch eine drei tägige Vorinkubation der Wirtszellen in den Aminosäure-Mangelmedien kann jedoch das Wachstum in Tryptophan-freiem Medium fast vollständig und das Wachstum in Glycin- und Serin-freiem Medium auf $40 \%$ reduziert werden (Abb. 3.24 und 3.27). Dies macht deutlich, dass die weniger stark ausgeprägten Wachstumseffekte vermutlich auf einen Restgehalt der jeweiligen Aminosäuren in der Wirtszelle zurückzuführen sind. Während der Vorinkubation in Mangelmedium wurde dieser Restgehalt durch den Stoffwechsel der Wirtszelle reduziert oder aufgebraucht, so dass für die Mikrosporidien anschließend weniger dieser Aminosäuren zur Verfügung stand. Vermutlich 
sind in der Wirtszelle unterschiedliche Mengen der verschiedenen Aminosäuren enthalten, denn andere essentielle und nichtessentielle Mangelbedingungen zeigen auch ohne Vorinkubation einen starken Effekt auf das E. cuniculi-Wachstum. Auch eine unterschiedlich stark ausgeprägte Synthese der einzelnen nichtessentiellen Aminosäuren durch die Wirtszelle kann für eine Erklärung der unterschiedlichen Effekte herangezogen werden.

Die Induktion eines Tryptophan-Mangels ist gleichzeitig auch ein genereller Effektormechanismus eukaryotischer Zellen gegen intrazelluläre Pathogene, wie z. B. gegen T. gondii oder Chlamydien (Rottenberg et al., 2002; Habara-Ohkubo et al., 1993). Bei diesem durch Interferon- $\gamma$ ausgelösten Prozess baut das Enzym Indoleamine 2,3-Dioxygenase (IDO) Tryptophan in der Zelle ab, so dass der entstehende Tryptophan-Mangel das Wachstum der Erreger begrenzt. Unter Zusatz von Interferon- $\gamma$ konnte das E. cuniculi-Wachstum noch weiter reduziert werden (Abb. 3.25). Dies zeigt einerseits, dass E. cuniculi ebenfalls sensitiv gegenüber einem Interferon- $\gamma$ induzierten Tryptophan-Mangel ist, bestätigt andererseits aber auch, dass der zunächst erhaltene schwach ausgeprägte Effekt des Tryptophan-Mangels ohne Vorinkubation auf einen Restgehalt Tryptophan in der Zelle zurückzuführen war.

Mit Hilfe der Langzeitexperimente konnte zudem gezeigt werden, dass das E. cuniculiWachstum auch zu späteren Zeitpunkten inhibiert bleibt (Tab. 3.2).

Andere intrazelluläre Erreger zeigen eine weniger ausgeprägte Abhängigkeit gegenüber der externen Zufuhr von Aminosäuren. P. falciparum ist in der Lage, eine mangelnde externe Aminosäurezufuhr durch den Abbau des roten Blutfarbstoffs Hämoglobin auszugleichen (Liu et al., 2006). Der Abbau des Hämoglobins erfolgt nach endocytotischer Aufnahme in der Nahrungsvakuole, die verschiedene Proteasen enthält. Dadurch ist der Parasit lediglich auxotroph für Isoleucin, die einzige Aminosäure, die im Hämoglobin nicht vorkommt. Aminosäuren nehmen auch eine zentrale Rolle im Stoffwechsel von Legionellen ein, da diese Aminosäuren auch für die Lipidsynthese und die Synthese von Nukleinsäuren verwenden (Tesh et al., 1983; Wieland et al., 2005). Um den intrazellulären Aminosäure-Spiegel der Wirtszelle anzuheben, sind Legionellen in der Lage, die Autophagocytose der Wirtszelle zu induzieren (Swanson und Isberg, 1995), gleichzeitig kann L. pneumophila die Proteinbiosynthese der Wirtszelle inhibieren (McCusker et al., 1991), so dass die Bakterien bei der Konkurrenz um Aminosäuren in eine bessere Position gelangen. Das E. cuniculiWachstum steigt aber zu späteren Zeitpunkten nicht wieder an, daher scheint E. cuniculi derartige Strategien nicht zu verfolgen.

Die mit Hilfe der stadienspezifischen Antikörper durchgeführten Immunfluoreszenzen machen außerdem deutlich, dass die Differenzierung von E. cuniculi vom metabolisch aktiven 
Meronten zur umweltresistenten Spore durch die verschiedenen AminosäureMangelbedingungen nicht beeinflusst wird. In allen Aminosäure-Mangelmedien waren sowohl 6G2-positive Meronten, als auch SWP1 exprimierende Sporenstadien nachzuweisen (Abb. 3.28 und 3.29). Das genetische Programm, das die Differenzierung reguliert, wird somit trotz Aminosäure-Mangel aktiviert.

Chlamydien sind für die Differenzierung vom metabolisch aktiven Retikularkörperchen zum Elementarkörperchen auf Cystein angewiesen, weil die äußere Membran der Elementarkörperchen viele Proteine mit Disulfidbrücken enthält (Allan et al., 1985; Bavoil et al., 1984). Disulfidbrücken sind wahrscheinlich auch für die Sporenhülle von Mikrosporidien wichtig, da in der Exospore Sulfhydryl-Proteine nachgewiesen wurden (Vavra und Larsson, 1999). E. cuniculi besitzt außerdem mit EnP1 mindestens ein Cystein-reiches Protein in der Endospore (Peuvel-Fanget et al., 2006), und auch das in der Exospore enthaltene Sporenwandprotein 1 (SWP1) (Bohne et al., 2000), das als Marker für die Differenzierung verwendet wurde, enthält Cysteine. Ein Cystein-Mangel hat jedoch keinen Einfluss auf das Differenzierungsverhalten, zumindest nicht im Bezug auf die SWP1-Expression.

Nachdem die Nährstoffe die parasitophore Vakuolenmembran passiert haben, müssen sie noch eine weitere Membran, die Plasmamembran der Meronten durchqueren, bevor sie durch E. cuniculi genutzt werden können. Für den Import von Nährstoffen in den metabolisch aktiven Meronten besitzt E. cuniculi verschiedenste Transportsysteme wie ABC-Transporter, Glukose- und Fruktose-Transporter, Nukleosid-Transporter, ATP/ADP-Translokatoren und Aminosäure-Transporter in der Meronten-Plasmamembran (Katinka et al., 2001). Im E. cuniculi-Genom wurden des Weiteren einige Gene, die für Proteine der EndocytoseMaschinerie kodieren, identifiziert, und vermutlich kann diese zur Aufnahme von Fettsäuren, Cholesterin und Eisen verwendet werden (Katinka et al., 2001). Ähnlich wie bei E. cuniculi ist auch für P. falciparum, T. gondii und Leishmania bekannt, dass sie eine Kombination aus Endocytose und spezifischen Transportprozessen für den Import von Nährstoffen über die Plasmamembran nutzen (Saliba und Kirk, 2001a; Burchmore und Barrett, 2001).

Um den aktiven Membran-Transport mit Energie zu versorgen, besitzen mehrzellige tierische Eukaryoten eine $\mathrm{Na}^{+}-\mathrm{K}^{+}$-ATPase in der Plasmamembran, die Natrium aus der Zelle und Kalium in die Zelle transportiert. Der so generierte Natrium-Gradient wird genutzt, um sekundäre Membran-Transporter wie Antiporter oder Symporter anzutreiben (Kirk, 2001). Im Gegensatz dazu nutzen Pflanzen, Hefen und einige Protozoen eher einen Protonen-Gradienten um sekundäre Transportprozesse anzutreiben (Kirk, 2001). Die Nutzung eines ProtonenGradienten konnte bisher für Saccharomyces cerevisiae, Trypanosomen, Leishmanien und 
Plasmodium nachgewiesen werden (Horak, 1997; de Koning und Jarvis, 1997; Burchmore und Barrett, 2001; Saliba und Kirk, 2001b). Auch für T. gondii ist die Nutzung eines Protonengradienten denkbar (Saliba und Kirk, 2001a). E. cuniculi besitzt ebenfalls eine vakuolare ATPase oder V-Typ ATPase, die Protonen, die als Stoffwechselprodukte anfallen, aus dem Meronten transportieren könnte (Katinka et al., 2001). Somit könnte der pH-Wert des Meronten konstant gehalten werden, gleichzeitig würde aber vermutlich auch ein Protonen-Gradient entstehen, der genutzt werden könnte, um sekundäre Transporter mit Energie zu versorgen.

Für die Aufnahme von Aminosäuren bzw. Peptiden besitzt E. cuniculi fünf putative Aminosäure-Transporter, eine Methionin-Permease und einen Oligopeptid-Transporter. Da die Vakuolenmembran Poren enthält, und somit für Aminosäuren und Peptide keine Diffusionsbarriere darstellt, sind diese Transporter wahrscheinlich in der MerontenPlasmamembran lokalisiert. Fünf der Proteine tragen entweder ein N-terminales Signalpeptid, oder eine N-terminale Signalankersequenz, so dass sie vermutlich sekretiert und anschließend in die Plasmamembran eingelagert werden. Zwei der Transporter sollen der Vorhersage nach nicht sekretiert werden. Möglicherweise konnte bei diesen Transportern das Signalpeptid aber aufgrund der allgemeinen Verkürzung und der daher teilweise ungewöhnlichen Primärstruktur von Proteinen bei E. cuniculi nicht erkannt werden.

Die Aminosäure-Transporter werden $\mathrm{zu}$ allen untersuchten Zeitpunkten gleichbleibend transkribiert, so dass eine Versorgung mit Aminosäuren während des intrazellulären Lebenszyklus durchgängig gewährleistet ist. Selbst verschiedene AminosäureMangelbedingungen beeinflussen die Transkription nicht in ausgeprägter Weise. Möglicherweise wurde bei Mikrosporidien im Zuge der Genomreduktion auch die Fähigkeit, bestimmte Gene zu regulieren, reduziert.

Im Vergleich zu anderen Pilzen, wie z. B. der Bäckerhefe S. cerevisiae ist die AminosäureTransporter-Ausstattung von E. cuniculi sehr stark reduziert und spiegelt so die Genomreduktion auf molekularer Ebene wieder. S. cerevisiae besitzt insgesamt 24 Aminosäure-Transporter aus der Familie der Aminosäure-Permeasen (AA_permease) (Paulsen et al., 1998; Andre, 1995) und 7 Peptid-Transporter (Hauser et al., 2001). Unter den Aminosäure-Permeasen sind sowohl Transporter mit breiter Substratspezifität, wie die generelle Aminosäure-Permease GAP1, die alle 20 Aminosäuren transportiert, sowie Transporter mit engerer Substratspezifität (Grenson et al., 1970; Jauniaux und Grenson, 1990; Regenberg et al., 1999). Die S. cerevisiae-Permeasen sind sekundäre Transporter, deren Aktivität wahrscheinlich an den Protonengradienten gekoppelt ist (Horak, 1997). 
E. cuniculi besitzt mit der Methionin-Permease lediglich ein Protein der Familie AA_permease. Die anderen 5 Aminosäure-Transporter gehören zur Familie der Transmembran-Aminosäure-Transporter (Aa_trans). Im Vergleich zu den 24 AminosäurePermeasen und den 7 Peptid-Transportern von S. cerevisiae besitzt E. cuniculi mit insgesamt 6 Aminosäure-Transportern und einem Oligopeptid-Transporter eine stark reduzierte Ausstattung an Transportproteinen, die möglicherweise in der Anpassung von E. cuniculi an die intrazelluläre Lebensweise begründet liegt. Um alle metabolischen Bedürfnisse von E. cuniculi abzudecken, besitzen die Aminosäure-Transporter daher unter Umständen ein breites Substratspektrum, ähnlich zu GAP1 von S. cerevisiae.

Die Analyse von Aminosäure-Transportern anderer Erreger zeigt, dass E. cuniculi selbst im Vergleich mit anderen intrazellulären Pathogenen eine reduzierte Ausstattung besitzt. Für T. gondii, dessen Genom ebenfalls vollständig sequenziert ist, wurden insgesamt 19 Aminosäure-Transporter identifiziert (ToxoDB 4.3, 2007). Allerdings sind diese Transporter, ebenso wie die Aminosäure-Transporter anderer intrazellulärer Erreger bisher relativ wenig charakterisiert. Erregerspezifische Aminosäure-Transporter stellen prinzipiell gute Angriffspunkte für Medikamente dar. So ermöglichen z. B. Aminosäure-Transporter von Trypanosoma brucei eine selektive Aufnahme bestimmter Medikamente in den Parasiten, ohne die Zellen des Wirtes zu beeinflussen (Hasne und Barrett, 2000). Die Untersuchung von Aminosäure-Transportern ist daher besonders aufgrund der Nutzung als potentielles drug target ein interessantes Forschungsfeld. 


\section{Zusammenfassung}

Mikrosporidien besitzen einen einzigartigen Invasionsmechanismus, bei dem ein so genannter Polartubulus explosionsartig aus der Mikrosporidien-Spore geschleudert wird. Das bisherige Infektionsmodell postuliert, dass der Polartubulus beim Herausschleudern die Plasmamembran einer benachbarten Wirtszelle durchschlägt und das infektiöse Sporoplasma durch den schlauchartigen Polartubulus direkt in das Cytosol der Wirtszelle injiziert wird. Mikrosporidien der Gattung Encephalitozoon sind sehr schnell nach der Invasion von einer parasitophoren Vakuolenmembran (PVM) umgeben. Aufgrund des ungewöhnlichen Invasionsmechanismus von Mikrosporidien und der Abwesenheit von WirtszellMarkerproteinen in der PVM von Encephalitozoon cuniculi direkt nach der Invasion (Fasshauer et al., 2005) war es bisher unklar, ob die PVM mit dem Sporoplasma übertragen wird, und somit vom Mikrosporidium selbst stammt, oder aber von der Wirtszelle gebildet wird. In dieser Arbeit wurde eine selektive Fluoreszenzmarkierung von entweder E. cuniculiMembranen oder Wirtszell-Plasmamembran genutzt, um die Beteiligung von Mikrosporidium und Wirtszelle an der Biogenese der PVM zu untersuchen. Wurden E. cuniculi-Membranen mit dem fluoreszierenden Lipid BODIPY-500/510- $\mathrm{C}_{12}-$ Phosphocholine markiert, und die markierten Sporen für die Infektion von Wirtszellen verwendet, so war das Fluoreszenzsignal nur in den entstandenen Meronten, nicht aber in der parasitophoren Vakuolenmembran zu finden. E. cuniculi-Membranen tragen somit nicht signifikant zur Bildung der PVM bei. Wurde allerdings die Wirtszell-Plasmamembran mit den raft- und nonraft-spezifischen Lipiden DiIC 16 und SPEEDY DiO markiert, so waren beide Farbstoffe sehr schnell nach der Infektion in den entstandenen Vakuolenmembranen nachweisbar. Die Lipide für die Bildung der PVM stammen somit von der Wirtszelle, wobei sowohl raft- als auch nonraft-Lipide zur Biogenese beitragen.

Um den zeitlichen Ablauf der PVM-Biogenese zu verfolgen, wurde die Invasion von E. cuniculi in lebenden, Fluoreszenz-markierten Wirtszellen mittels „time-lapse“-Mikroskopie untersucht. Trifft ein polares Filament eine Wirtszelle, entsteht an der Kontaktstelle kurze Zeit vor der Entstehung der parasitophoren Vakuole eine Fluoreszenz-markierte Invagination der Plasmamembran. Diese Beobachtung deutet auf eine Modifikation des bisherigen Invasionsmodells für E. cuniculi hin. Diesem neuen Modell zufolge wird die Plasmamembran nicht durchschlagen, sondern vom Polartubulus eingedrückt, so dass eine lange Kanalähnliche Invagination entsteht. Das Sporoplasma wird dann nicht in das Cytosol, sondern in 
diese Invagination injiziert, so dass die parasitophore Vakuole aus Plasmamembran-Material entsteht.

In früheren Kolokalisationsstudien wurde gezeigt, dass die PVM den humanen TransferrinRezeptor, der als Markerprotein für Wirtszell-Oberflächenproteine gilt, nicht enthält (Fasshauer et al., 2005). Da in dieser Arbeit nachgewiesen wurde dass die PVM aus der Wirtszell-Plasmamembran entsteht, wurde im Folgenden überprüft, ob auch andere WirtszellOberflächenproteine auf der PVM fehlen. Eine Biotinylierung der WirtszellOberflächenproteine, gefolgt von einer Infektion mit E. cuniculi zeigte, dass in der überwiegenden Anzahl ( $>90 \%$ \%) der entstandenen Vakuolen keine WirtszellOberflächenproteine nachweisbar waren. Es scheint somit ein Mechanismus zu existieren, der Wirtszell-Oberflächenproteine entweder während der Entstehung der parasitophoren Vakuole oder aber in den ersten Minuten nach der Invasion aussortiert. Der Ausschluss von Wirtszellproteinen von der PVM ist bei E. cuniculi wahrscheinlich ähnlich wie bei Toxoplasma gondii für die Fusions-Inkompetenz der Vakuole mit Endosomen und Lysosomen verantwortlich, da die für die Membranfusion notwendigen Proteine in der PVM fehlen.

Das Genom von E. cuniculi gehört mit einer Größe von ca. 2,9 Millionen Basenpaaren zu den kleinsten bisher bekannten eukaryotischen Genomen. Im Zuge der Anpassung an die intrazelluläre Lebensweise hat E. cuniculi viele Biosynthese-Wege, unter anderem auch die Aminosäure-Biosynthese verloren (Katinka et al., 2001). Dies deutet auf eine extreme metabolische Abhängigkeit von der Wirtszelle hin. Um für E. cuniculi zugänglich zu sein, müssen Nährstoffe jedoch zunächst die parasitophore Vakuolenmembran passieren. Die Mikroinjektion verschiedener Membran-impermeabler Dextran-Farbstoffe und Fluoreszenzgekoppelter Peptide in das Cytosol infizierter Zellen zeigte, dass die PVM Poren enthält, die eine Ausschlussgröße von 3-10 kDa besitzen. Die PVM sollte somit für Nährstoffe wie z. B. Kohlenhydrate, Aminosäuren und ATP durchlässig sein. Die Permeabilitätseigenschaften der PVM sind dabei unabhängig von Alter oder Größe der Vakuole, so dass E. cuniculi während des intrazellulären Zyklus gleichbleibend Zugang zu den Nährstoffen der Wirtszelle hat. Bei der Durchsuchung des E. cuniculi-Genoms nach möglichen Poren-bildenden Proteinen wurde ein Hämolysin III (EcHlyIII) identifiziert. Mit Hilfe eines anti-Peptid-Antikörpers konnte im Western Blot nach Membranfraktionierung gezeigt werden, dass EcHlyIII ein Membranprotein ist.

Um die Abhängigkeit von E. cuniculi gegenüber einzelnen Aminosäuren systematisch zu untersuchen, wurde E. cuniculi in verschiedenen Aminosäure-Mangelmedien kultiviert, und 
das Wachstum mit Hilfe eines neu etablierten Zell-ELISAs untersucht. Die stark negativen Wachstumseffekte konnten experimentell bestätigen, dass E. cuniculi auf die externe Zufuhr von essentiellen und nichtessentiellen Aminosäuren durch die Wirtszelle bzw. das Zellkulturmedium angewiesen ist. Die Differenzierung vom Meronten zur Spore, die anhand der Expression des Sporenwandproteins 1 (SWP1) überprüft wurde, wird durch AminosäureMangelbedingungen nicht beeinflusst. Eine Genomanalyse zeigte, dass E. cuniculi für die Aufnahme von Aminosäuren sechs Aminosäure-Transporter sowie einen OligopeptidTransporter besitzt. Im Vergleich mit Saccharomyces cerevisiae und anderen intrazellulären Erregern wie T. gondii ist diese Ausstattung sehr stark reduziert und spiegelt so die Genomreduktion auf molekularer Ebene wieder. Eine quantitative Real-time-PCR-Analyse zeigte, dass die mRNA-Menge der E.cuniculi-Aminosäure-Transporter während der intrazellulären Entwicklung kaum reguliert und die Gene somit konstitutiv exprimiert werden. 


\section{Summary}

Microsporidia possess a unique invasion mechanism, which is based on the explosive extrusion of a hollow tube, the so called polar tube, from the microsporidian spore. The common infection model postulates that during extrusion the polar tube pierces the plasma membrane of an adjacent host cell and the infectious sporoplasma is susequently injected through the polar tube into the cytosol of the host cell. After invasion, microsporidia of the genus Encephalitozoon are very quickly surrounded by a parasitophorous vacuole membrane (PVM). Due to the special invasion mechanism of microsporidia and the absence of host cell marker proteins in the PVM directly after invasion (Fasshauer et al., 2005), it was unclear up to now, if the PVM is transferred with the sporoplasm and therefore derived from the microsporidium itself, or if the PVM is derived from the host cell. In this work, a selective labelling of either E. cuniculi membranes or the host cell plasma membrane was used to investigate microsporidia and host cell participation on PVM biogenesis. When E. cuniculi membranes were labelled with the fluorescent lipid BODIPY-500/510- $\mathrm{C}_{12}$-phosphocholine and the labelled spores were used to infect host cells, the fluorescent signal was only detected in the emerging meronts but not in the parasitophorous vacuole membrane. Therefore, E. cuniculi membranes do not significantly participate in the biogenesis of the PVM. In contrast, if the host cell plasma membrane was labelled with the raft and nonraft specific lipids DiIC $_{16}$ and SPEEDY DiO, both tracers were detectable in the nascent vacuole membrane shortly after invasion. The lipids for the PVM thus originate from the host cell and raft as well as nonraft lipids participate in the biogenesis.

To understand the chronology of PVM biogenesis, the invasion of E. cuniculi into living fluorescently labelled host cells was analysed by time lapse microscopy. When a polar tube striked a cell, a fluorescently labelled plasma membrane invagination emerged at the contact site shortly before PVM formation. This observation suggests a modification for the invasion mode of E. cuniculi. According to the new model, the plasma membrane is not pierced but forced to form a long channel-like invagination. Afterwards, the sporoplasm is not injected into the cytosol but into this invagination, followed by parasitophorous vacuole formation from plasma membrane material.

Previous colocalization studies showed that the PVM is devoid of the transferrin receptor, a marker for early endosomes and the cell surface (Fasshauer et al., 2005). Since our investigations reveal that the PVM originates from the host cell plasma membrane, the absence or presence of other host cell surface proteins in the PVM was analyzed. A 
biotinylation of host cell surface proteins and subsequent infection with E. cuniculi showed that host cell surface proteins are absent from the majority $(>90 \%)$ of the emerging vacuoles. It is likely that during PVM formation or in the first minutes after invasion an exclusion mechamism for host cell surface proteins exists. Exclusion of host cell proteins from the PVM in E. cuniculi is as in Toxoplasma gondii most likely responsible for the fusion incompetence with endosomes and lysosomes, since the PVM lacks proteins necessary for membrane fusion.

The genome of E. cuniculi is with $\sim 2.9$ million basepairs one of the smallest eucaryotic genomes known so far. Due to adaptation to the intracellular lifestyle, E. cuniculi lacks many biosynthetic pathways, for instance amino acid biosynthesis (Katinka et al., 2001). This suggests that E. cuniculi is metabolically extremely dependent on its host cell. Nutrients initially have to pass the parasitophorous vacuole membrane to become available for E. cuniculi. Microinjection of different membrane impermeable dextran dyes and fluorescently labelled peptides into the cytosol of infected host cells revealed that the PVM possesses pores with an exclusion size of 3-10 kDa. The PVM should therefore be permeable to nutrients like carbohydrates, amino acids and ATP. The PVM permeability properties are independent of age or size of the vacuole. During intracellular development, E. cuniculi has thus permanent access to the host cell nutrient pool. A search for possible pore forming proteins in the E. cuniculi genome database identified a hemolysin III (EcHlyIII). With the aid of an anti-peptide-antibody it was shown in a western blot after membrane fractionation that EcHlyIII is a membrane protein.

To test the dependency of E. cuniculi towards individual amino acids systematically, E. cuniculi was cultured in different media lacking individual amino acids, followed by growth rate quantification with a new established cell ELISA. The strong negative growth effects confirmed experimentally that E. cuniculi is dependent on external supply of essential and non essential amino acids by the host cell or by the cell culture medium. The differentiation from meront to spore was not affected by amino acid depletion as controlled by expression of the spore wall protein 1 (SWP1). A genome analysis showed that E. cuniculi possesses six amino acid transporters and one oligonucleotide transporter for the uptake of amino acids. In comparison to Saccharomyces cerevisiae and other intracellular pathogens as $T$. gondii the amount of transporters is strongly reduced, reflecting genome reduction on a molecular level. A quantitative real-time PCR analysis showed that the mRNA level of the E. cuniculi amino acid transporters is not stage specifically regulated. 


\section{Literatur}

Akiyoshi, D.E., Weiss, L.M., Feng, X., Williams, B.A., Keeling, P.J., Zhang, Q. and Tzipori, S. (2007) Analysis of the beta-tubulin genes from Enterocytozoon bieneusi isolates from a human and rhesus macaque. $J$ Eukaryot Microbiol. 54: 38-41.

Alberts, B., Johnson, A., Lewis, J., Raff, M., Roberts, K. and Walter, P. (2004) Molekularbiologie der Zelle. Weinheim: WILEY-VCH Verlag.

Allan, I., Hatch, T.P. and Pearce, J.H. (1985) Influence of cysteine deprivation on chlamydial differentiation from reproductive to infective life-cycle forms. J Gen Microbiol. 131: 31713177 .

Andre, B. (1995) An overview of membrane transport proteins in Saccharomyces cerevisiae. Yeast. 11: 1575-1611.

Andrews, N.W. and Whitlow, M.B. (1989) Secretion by Trypanosoma cruzi of a hemolysin active at low pH. Mol Biochem Parasitol. 33: 249-256.

Andrews, N.W., Abrams, C.K., Slatin, S.L. and Griffiths, G. (1990) A T. cruzi-secreted protein immunologically related to the complement component $\mathrm{C} 9$ : evidence for membrane pore-forming activity at low pH. Cell. 61: 1277-1287.

Antoine, J.C., Prina, E., Jouanne, C. and Bongrand, P. (1990) Parasitophorous vacuoles of Leishmania amazonensis-infected macrophages maintain an acidic $\mathrm{pH}$. Infect Immun. 58: 779-787.

Arguelles, J.C. (2000) Physiological roles of trehalose in bacteria and yeasts: a comparative analysis. Arch Microbiol. 174: 217-224.

Baida, G.E. and Kuzmin, N.P. (1996) Mechanism of action of hemolysin III from Bacillus cereus. Biochim Biophys Acta. 1284: 122-124.

Bano, N., Romano, J.D., Jayabalasingham, B. and Coppens, I. (2007) Cellular interactions of Plasmodium liver stage with its host mammalian cell. Int J Parasitol. 37: 1329-1341.

Bartelsman, M. and Veeken, H. (2007) [The HIV pandemic in the year 2007, an overview]. Ned Tijdschr Geneeskd. 151: 2655-2660.

Bavoil, P., Ohlin, A. and Schachter, J. (1984) Role of disulfide bonding in outer membrane structure and permeability in Chlamydia trachomatis. Infect Immun. 44: 479-485.

Becnel, J. and Andreadis, T. (eds.) (1999) Microspordia in Insects. Washington D.C.: ASM Press.

Betts, H.J., Twiggs, L.E., Sal, M.S., Wyrick, P.B. and Fields, K.A. (2008) Bioinformatic and biochemical evidence for the identification of the type III secretion system needle protein of Chlamydia trachomatis. J Bacteriol. 190: 1680-1690. 
Bigliardi, E. and Sacchi, L. (2001) Cell biology and invasion of the microsporidia. Microbes Infect. 3: 373-379.

Bigliardi, E., Selmi, M.G., Lupetti, P., Corona, S., Gatti, S., Scaglia, M. and Sacchi, L. (1996) Microsporidian spore wall: ultrastructural findings on Encephalitozoon hellem exospore. $J$ Eukaryot Microbiol. 43: 181-186.

Bohne, W., Ferguson, D.J., Kohler, K. and Gross, U. (2000) Developmental expression of a tandemly repeated, glycine- and serine-rich spore wall protein in the microsporidian pathogen Encephalitozoon cuniculi. Infect Immun. 68: 2268-2275.

Bouladoux, N., Biligui, S. and Desportes-Livage, I. (2003) A new monoclonal antibody enzyme-linked immunosorbent assay to measure in vitro multiplication of the microsporidium Encephalitozoon intestinalis. J Microbiol Methods. 53: 377-385.

Bryan, R. and Schwartz, D.A. (eds.) (1999) Epidemiology of Microsporidiosis. Washington D.C.: ASM Press.

Burchmore, R.J. and Barrett, M.P. (2001) Life in vacuoles--nutrient acquisition by Leishmania amastigotes. Int J Parasitol. 31: 1311-1320.

Burleigh, B.A. and Woolsey, A.M. (2002) Cell signalling and Trypanosoma cruzi invasion. Cell Microbiol. 4: 701-711.

Cali, A. (1971) Morphogenesis in the genus Nosema. In Proceedings of the IVth International Colloquium in Insect Pathology. College Park, Md., pp. 431-438.

Cali, A. (ed.) (1986) Comparison of the biology and pathology of microsporidia from different host groups. Wageningen, The Netherlands.

Cali, A. and Owen, R.L. (eds.) (1988) Microsporidiosis. New York, N. Y.: Springer-Verlag. Cali, A. and Takvorian, P.M. (eds.) (1999) Developmental Morphology and life cycles of the microsporidia. Washington D.C.: American Society for Microbiology.

Calvo, M., Carazo, M., Arias, M.L., Chaves, C., Monge, R. and Chinchilla, M. (2004) [Prevalence of Cyclospora sp., Cryptosporidium sp, microsporidia and fecal coliform determination in fresh fruit and vegetables consumed in Costa Rica]. Arch Latinoam Nutr. 54: 428-432.

Canning, E. and Lom, J. (1986) The microsporidia of Vertebrates. London, United Kingdom: Academic Press.

Canning, E.U. and Hollister, W.S. (1991) In vitro and in vivo investigations of human microsporidia. J Protozool. 38: 631-635.

Canning, E.U. and Hollister, W.S. (1992) Human infections with microsporidia. Rev. Med. Microbiol. 3: 35-42.

Cavalier-Smith, T. (ed.) (1983) A six-kingdom classification and a unified phylogeny. Berlin: de Gruyter. 
Charron, A.J. and Sibley, L.D. (2004) Molecular partitioning during host cell penetration by Toxoplasma gondii. Traffic. 5: 855-867.

Chen, Y.C., Chang, M.C., Chuang, Y.C. and Jeang, C.L. (2004) Characterization and virulence of hemolysin III from Vibrio vulnificus. Curr Microbiol. 49: 175-179.

Clausen, J.D., Christiansen, G., Holst, H.U. and Birkelund, S. (1997) Chlamydia trachomatis utilizes the host cell microtubule network during early events of infection. Mol Microbiol. 25: 441-449.

Clemens, D.L. and Horwitz, M.A. (1995) Characterization of the Mycobacterium tuberculosis phagosome and evidence that phagosomal maturation is inhibited. $J$ Exp Med. 181: 257-270.

Cooper, J.A. (1987) Effects of cytochalasin and phalloidin on actin. J Cell Biol. 105: 14731478.

Corradi, N., Gangaeva, A. and Keeling, P.J. (2008) Comparative profiling of overlapping transcription in the compacted genomes of microsporidia Antonospora locustae and Encephalitozoon cuniculi. Genomics. 91: 388-393.

Cossart, P. and Sansonetti, P.J. (2004) Bacterial invasion: the paradigms of enteroinvasive pathogens. Science. 304: 242-248.

Couzinet, S., Cejas, E., Schittny, J., Deplazes, P., Weber, R. and Zimmerli, S. (2000) Phagocytic uptake of Encephalitozoon cuniculi by nonprofessional phagocytes. Infect Immun. 68: 6939-6945.

Coyle, C.M., Weiss, L.M., Rhodes, L.V., 3rd, Cali, A., Takvorian, P.M., Brown, D.F., et al (2004) Fatal myositis due to the microsporidian Brachiola algerae, a mosquito pathogen. $N$ Engl J Med. 351: 42-47.

de Koning, H.P. and Jarvis, S.M. (1997) Hypoxanthine uptake through a purine-selective nucleobase transporter in Trypanosoma brucei brucei procyclic cells is driven by protonmotive force. Eur J Biochem. 247: 1102-1110.

del Aguila, C., Izquierdo, F., Granja, A.G., Hurtado, C., Fenoy, S., Fresno, M. and Revilla, Y. (2006) Encephalitozoon microsporidia modulates p53-mediated apoptosis in infected cells. Int J Parasitol. 36: 869-876.

Desai, S.A., Krogstad, D.J. and McCleskey, E.W. (1993) A nutrient-permeable channel on the intraerythrocytic malaria parasite. Nature. 362: 643-646.

Desportes, I., Le Charpentier, Y., Galian, A., Bernard, F., Cochand-Priollet, B., Lavergne, A., et al (1985) Occurrence of a new microsporidan: Enterocytozoon bieneusi n.g., n. sp., in the enterocytes of a human patient with AIDS. J Protozool. 32: 250-254.

Didier, E.S. and Weiss, L.M. (2006) Microsporidiosis: current status. Curr Opin Infect Dis. 19: 485-492.

Didier, E.S., Maddry, J.A., Brindley, P.J., Stovall, M.E. and Didier, P.J. (2005) Therapeutic strategies for human microsporidia infections. Expert Rev Anti Infect Ther. 3: 419-434. 
Didier, E.S., Vossbrinck, C.R., Baker, M.D., Rogers, L.B., Bertucci, D.C. and Shadduck, J.A. (1995) Identification and characterization of three Encephalitozoon cuniculi strains. Parasitology. 111 ( Pt 4): 411-421.

Dorn, B.R., Dunn, W.A., Jr. and Progulske-Fox, A. (2002) Bacterial interactions with the autophagic pathway. Cell Microbiol. 4: 1-10.

Edlind, T.D., Li, J., Visvesvara, G.S., Vodkin, M.H., McLaughlin, G.L. and Katiyar, S.K. (1996) Phylogenetic analysis of beta-tubulin sequences from amitochondrial protozoa. Mol Phylogenet Evol. 5: 359-367.

Eissenberg, L.G. and Wyrick, P.B. (1981) Inhibition of phagolysosome fusion is localized to Chlamydia psittaci-laden vacuoles. Infect Immun. 32: 889-896.

El Alaoui, H., Bata, J., Peyret, P. and Vivares, C.P. (2001) Encephalitozoon cuniculi (Microspora): characterization of a phospholipid metabolic pathway potentially linked to therapeutics. Exp Parasitol. 98: 171-179.

Fasshauer, V., Gross, U. and Bohne, W. (2005) The parasitophorous vacuole membrane of Encephalitozoon cuniculi lacks host cell membrane proteins immediately after invasion. Eukaryot Cell. 4: 221-224.

Findley, A.M., Weidner, E.H., Carman, K.R., Xu, Z. and Godbar, J.S. (2005) Role of the posterior vacuole in Spraguea lophii (Microsporidia) spore hatching. Folia Parasitol (Praha). 52: 111-117.

Finn, R.D., Mistry, J., Schuster-Bockler, B., Griffiths-Jones, S., Hollich, V., Lassmann, T., et al (2006) Pfam: clans, web tools and services. Nucleic Acids Res. 34: D247-251.

Fogla, R., Padmanabhan, P., Therese, K.L., Biswas, J. and Madhavan, H.N. (2005) Chronic microsporidial stromal keratitis in an immunocompetent, non-contact lens wearer. Indian $J$ Ophthalmol. 53: 123-125.

Foucault, C. and Drancourt, M. (2000) Actin mediates Encephalitozoon intestinalis entry into the human enterocyte-like cell line, Caco-2. Microb Pathog. 28: 51-58.

Franzen, C. (2004) Microsporidia: how can they invade other cells? Trends Parasitol. 20: 275-279.

Franzen, C. (2005) How do microsporidia invade cells? Folia Parasitol (Praha). 52: 36-40. Franzen, C., Muller, A., Hartmann, P. and Salzberger, B. (2005) Cell invasion and intracellular fate of Encephalitozoon cuniculi (Microsporidia). Parasitology. 130: 285-292.

Fratti, R.A., Chua, J., Vergne, I. and Deretic, V. (2003) Mycobacterium tuberculosis glycosylated phosphatidylinositol causes phagosome maturation arrest. Proc Natl Acad Sci U S A. 100: 5437-5442.

Frixione, E., Ruiz, L., Santillan, M., de Vargas, L., Tejero, J. and Undeen, A. (1992) Dynamics of polar filament discharge and sporoplasm expulsion by microsporidian spores. Cell Motil. Cytoskelet. 22: 38-50. 
Germot, A., Philippe, H. and Le Guyader, H. (1997) Evidence for loss of mitochondria in Microsporidia from a mitochondrial-type HSP70 in Nosema locustae. Mol Biochem Parasitol. 87: 159-168.

Ghosh, K., Cappiello, C.D., McBride, S.M., Occi, J.L., Cali, A., Takvorian, P.M., et al (2006) Functional characterization of a putative aquaporin from Encephalitozoon cuniculi, a microsporidia pathogenic to humans. Int J Parasitol. 36: 57-62.

Glomski, I.J., Gedde, M.M., Tsang, A.W., Swanson, J.A. and Portnoy, D.A. (2002) The Listeria monocytogenes hemolysin has an acidic $\mathrm{pH}$ optimum to compartmentalize activity and prevent damage to infected host cells. J Cell Biol. 156: 1029-1038.

Goldberg, A.V., Molik, S., Tsaousis, A.D., Neumann, K., Kuhnke, G., Delbac, F., et al (2008) Localization and functionality of microsporidian iron-sulphur cluster assembly proteins. Nature. 452: 624-628.

Grenson, M., Hou, C. and Crabeel, M. (1970) Multiplicity of the amino acid permeases in Saccharomyces cerevisiae. IV. Evidence for a general amino acid permease. J Bacteriol. 103: 770-777.

Habara-Ohkubo, A., Shirahata, T., Takikawa, O. and Yoshida, R. (1993) Establishment of an antitoxoplasma state by stable expression of mouse indoleamine 2,3-dioxygenase. Infect Immun. 61: 1810-1813.

Hackstadt, T., Scidmore, M.A. and Rockey, D.D. (1995) Lipid metabolism in Chlamydia trachomatis-infected cells: directed trafficking of Golgi-derived sphingolipids to the chlamydial inclusion. Proc Natl Acad Sci U S A. 92: 4877-4881.

Hackstadt, T., Rockey, D.D., Heinzen, R.A. and Scidmore, M.A. (1996) Chlamydia trachomatis interrupts an exocytic pathway to acquire endogenously synthesized sphingomyelin in transit from the Golgi apparatus to the plasma membrane. Embo J. 15: 964977.

Hakansson, S., Charron, A.J. and Sibley, L.D. (2001) Toxoplasma evacuoles: a two-step process of secretion and fusion forms the parasitophorous vacuole. Embo J. 20: 3132-3144.

Hao, M., Mukherjee, S. and Maxfield, F.R. (2001) Cholesterol depletion induces large scale domain segregation in living cell membranes. Proc Natl Acad Sci U S A. 98: 13072-13077.

Hasne, M. and Barrett, M.P. (2000) Drug uptake via nutrient transporters in Trypanosoma brucei. J Appl Microbiol. 89: 697-701.

Hauser, M., Narita, V., Donhardt, A.M., Naider, F. and Becker, J.M. (2001) Multiplicity and regulation of genes encoding peptide transporters in Saccharomyces cerevisiae. Mol Membr Biol. 18: 105-112.

Hayman, J.R., Southern, T.R. and Nash, T.E. (2005) Role of sulfated glycans in adherence of the microsporidian Encephalitozoon intestinalis to host cells in vitro. Infect Immun. 73: 841848. 
Heinzen, R.A. and Hackstadt, T. (1997) The Chlamydia trachomatis parasitophorous vacuolar membrane is not passively permeable to low-molecular-weight compounds. Infect Immun. 65: 1088-1094.

Hendrick, R. (1991) Experimental infections with Nucleospora salmonis n. g., n. sp.: an intranuclear microsporidium from chinook salmon (Oncorhynchus tshawitscha). . Fish Health Sect./ Am. Fish. Soc. Newsl. 19: 5.

Hibbett, D.S., Binder, M., Bischoff, J.F., Blackwell, M., Cannon, P.F., Eriksson, O.E., et al (2007) A higher-level phylogenetic classification of the Fungi. Mycol Res. 111: 509-547.

Higuchi, R., Dollinger, G., Walsh, P.S. and Griffith, R. (1992) Simultaneous amplification and detection of specific DNA sequences. Biotechnology (N Y). 10: 413-417.

Hirt, R.P., Healy, B., Vossbrinck, C.R., Canning, E.U. and Embley, T.M. (1997) A mitochondrial Hsp70 orthologue in Vairimorpha necatrix: molecular evidence that microsporidia once contained mitochondria. Curr Biol. 7: 995-998.

Honda, T., Ni, Y., Miwatani, T., Adachi, T. and Kim, J. (1992) The thermostable direct hemolysin of Vibrio parahaemolyticus is a pore-forming toxin. Can J Microbiol. 38: 11751180 .

Horak, J. (1997) Yeast nutrient transporters. Biochim Biophys Acta. 1331: 41-79.

Horwitz, M.A. (1983) Formation of a novel phagosome by the Legionnaires' disease bacterium (Legionella pneumophila) in human monocytes. J Exp Med. 158: 1319-1331.

Horwitz, M.A. (1984) Phagocytosis of the Legionnaires' disease bacterium (Legionella pneumophila) occurs by a novel mechanism: engulfment within a pseudopod coil. Cell. 36: 27-33.

Horwitz, M.A. and Silverstein, S.C. (1983) Intracellular multiplication of Legionnaires' disease bacteria (Legionella pneumophila) in human monocytes is reversibly inhibited by erythromycin and rifampin. J Clin Invest. 71: 15-26.

Hsia, R.C., Pannekoek, Y., Ingerowski, E. and Bavoil, P.M. (1997) Type III secretion genes identify a putative virulence locus of Chlamydia. Mol Microbiol. 25: 351-359.

Hutin, Y.J., Sombardier, M.N., Liguory, O., Sarfati, C., Derouin, F., Modai, J. and Molina, J.M. (1998) Risk factors for intestinal microsporidiosis in patients with human immunodeficiency virus infection: a case-control study. J Infect Dis. 178: 904-907.

Ishihara, R. (1968) Some observations on the fine structure of sporoplasm discharged from spores of a microsporidian, Nosema bombycis. J Invertebr Pathol. 12: 245-258.

Jauniaux, J.C. and Grenson, M. (1990) GAP1, the general amino acid permease gene of Saccharomyces cerevisiae. Nucleotide sequence, protein similarity with the other bakers yeast amino acid permeases, and nitrogen catabolite repression. Eur J Biochem. 190: 39-44. 
Juan-Salles, C., Garner, M.M., Didier, E.S., Serrato, S., Acevedo, L.D., Ramos-Vara, J.A., et al (2006) Disseminated encephalitozoonosis in captive, juvenile, cotton-top (Saguinus oedipus) and neonatal emperor (Saguinus imperator) tamarins in North America. Vet Pathol. 43: 438-446.

Juarez, S.I., Putaporntip, C., Jongwutiwes, S., Ichinose, A., Yanagi, T. and Kanbara, H. (2005) In vitro cultivation and electron microscopy characterization of Trachipleistophora anthropophthera isolated from the cornea of an AIDS patient. J Eukaryot Microbiol. 52: 179190.

Karpichev, I.V., Cornivelli, L. and Small, G.M. (2002) Multiple regulatory roles of a novel Saccharomyces cerevisiae protein, encoded by YOL002c, in lipid and phosphate metabolism. J Biol Chem. 277: 19609-19617.

Katinka, M.D., Duprat, S., Cornillot, E., Metenier, G., Thomarat, F., Prensier, G., et al (2001) Genome sequence and gene compaction of the eukaryote parasite Encephalitozoon cuniculi. Nature. 414: 450-453.

Keeling, P.J. (2001) Parasites go the full monty. Nature. 414: 401-402.

Keeling, P.J. and Doolittle, W.F. (1996) Alpha-tubulin from early-diverging eukaryotic lineages and the evolution of the tubulin family. Mol Biol Evol. 13: 1297-1305.

Keeling, P.J. and Fast, N.M. (2002) Microsporidia: biology and evolution of highly reduced intracellular parasites. Annu Rev Microbiol. 56: 93-116.

Keohane, E. and Weiss, L.M. (eds.) (1999) The structure, function and composition of the microsporidian polar tube. Washington D.C.: ASM Press.

Keohane, E.M. and Weiss, L.M. (1998) Characterization and function of the microsporidian polar tube: a review. Folia Parasitol (Praha). 45: 117-127.

Kirk, K. (2001) Membrane transport in the malaria-infected erythrocyte. Physiol Rev. 81: 495-537.

Kodjikian, L., Garweg, J.G., Nguyen, M., Schaffner, T., Deplazese, P. and Zimmerli, S. (2005) Intraocular microsporidiosis due to Encephalitozoon cuniculi in a patient with idiopathic CD4+ T-lymphocytopenia. Int J Med Microbiol. 294: 529-533.

Kyhse-Andersen, J. (1984) Electroblotting of multiple gels: a simple apparatus without buffer tank for rapid transfer of proteins from polyacrylamide to nitrocellulose. $J$ Biochem Biophys Methods. 10: 203-209.

Laemmli, U.K. (1970) Cleavage of structural proteins during the assembly of the head of bacteriophage T4. Nature. 227: 680-685.

Larsson, J. (ed.) (1986) Ultrastructure, function and classification of microsporidia. Bristol, U.K.: Biopress, Ltd. 
Leitch, G.J., Scanlon, M., Visvesvara, G.S. and Wallace, S. (1995) Calcium and hydrogen ion concentrations in the parasitophorous vacuoles of epithelial cells infected with the microsporidian Encephalitozoon hellem. J Eukaryot Microbiol. 42: 445-451.

Leitch, G.J., Ward, T.L., Shaw, A.P. and Newman, G. (2005) Apical spore phagocytosis is not a significant route of infection of differentiated enterocytes by Encephalitozoon intestinalis. Infect Immun. 73: 7697-7704.

Liu, J., Istvan, E.S., Gluzman, I.Y., Gross, J. and Goldberg, D.E. (2006) Plasmodium falciparum ensures its amino acid supply with multiple acquisition pathways and redundant proteolytic enzyme systems. Proc Natl Acad Sci U S A. 103: 8840-8845.

Lom, J. and Vavra, J. (1963) The mode of sporoplasm extrusion in microsporidian spores. Acta Protozool. 1: 81-92.

Loubes, C. (1979) [Meiosis in Microsporidia: effects on biological cycles]. J Protozool. 26: 200-208.

MacDonald, L.M., Armson, A., Thompson, A.R. and Reynoldson, J.A. (2004) Characterisation of benzimidazole binding with recombinant tubulin from Giardia duodenalis, Encephalitozoon intestinalis, and Cryptosporidium parvum. Mol Biochem Parasitol. 138: 89-96.

Magaud, A., Achbarou, A. and Desportes-Livage, I. (1997) Cell invasion by the microsporidium Encephalitozoon intestinalis. J Eukaryot Microbiol. 44: 81S.

Manes, S., del Real, G. and Martinez, A.C. (2003) Pathogens: raft hijackers. Nat Rev Immunol. 3: 557-568.

Mathis, A. (2000) Microsporidia: emerging advances in understanding the basic biology of these unique organisms. Int J Parasitol. 30: 795-804.

Matsubayashi, H., Koike, T., Mikata, I., Takei, H. and Hagiwara, S. (1959) A case of Encephalitozoon-like body infection in man. AMA Arch Pathol. 67: 181-187.

Matsumoto, A., Bessho, H., Uehira, K. and Suda, T. (1991) Morphological studies of the association of mitochondria with chlamydial inclusions and the fusion of chlamydial inclusions. J Electron Microsc (Tokyo). 40: 356-363.

McCusker, K.T., Braaten, B.A., Cho, M.W. and Low, D.A. (1991) Legionella pneumophila inhibits protein synthesis in Chinese hamster ovary cells. Infect Immun. 59: 240-246.

Menestrina, G., Serra, M.D. and Prevost, G. (2001) Mode of action of beta-barrel poreforming toxins of the staphylococcal alpha-hemolysin family. Toxicon. 39: 1661-1672.

Menestrina, G., Dalla Serra, M., Comai, M., Coraiola, M., Viero, G., Werner, S., et al (2003) Ion channels and bacterial infection: the case of beta-barrel pore-forming protein toxins of Staphylococcus aureus. FEBS Lett. 552: 54-60. 
Mordue, D.G., Desai, N., Dustin, M. and Sibley, L.D. (1999) Invasion by Toxoplasma gondii establishes a moving junction that selectively excludes host cell plasma membrane proteins on the basis of their membrane anchoring. J Exp Med. 190: 1783-1792.

Morpeth, S.C. and Thielman, N.M. (2006) Diarrhea in patients with AIDS. Curr Treat Options Gastroenterol. 9: 23-37.

Mott, G.A. and Burleigh, B.A. (2008) The role of host cell lysosomes in Trypanosoma cruzi invasion. Subcell Biochem. 47: 165-173.

Mouritsen, O.G. and Jorgensen, K. (1995) Micro-, nano- and meso-scale heterogeneity of lipid bilayers and its influence on macroscopic membrane properties. Mol Membr Biol. 12: $15-20$.

Naderer, T. and McConville, M.J. (2008) The Leishmania-macrophage interaction: a metabolic perspective. Cell Microbiol. 10: 301-308.

Nägeli, K. (1857) Über die neue Krankheit der Seidenraupe und verwandte Organismen. Bot. Ztg. 15: 760-761.

Nichols, B.A., Setzer, P.Y., Pang, F. and Dawson, C.R. (1985) New view of the surface projections of Chlamydia trachomatis. J Bacteriol. 164: 344-349.

Orenstein, J.M., Russo, P., Didier, E.S., Bowers, C., Bunin, N. and Teachey, D.T. (2005) Fatal pulmonary microsporidiosis due to Encephalitozoon cuniculi following allogeneic bone marrow transplantation for acute myelogenous leukemia. Ultrastruct Pathol. 29: 269-276.

Orlik, J. (2007) Untersuchungen zur induzierten Phagocytose als möglicher Invasionsmechanismus des humanpathogenen Mikrosporidiums Encephalitozoon cuniculi. In Medizische Mikrobiologie: Universität Göttingen.

Paulsen, I.T., Sliwinski, M.K., Nelissen, B., Goffeau, A. and Saier, M.H., Jr. (1998) Unified inventory of established and putative transporters encoded within the complete genome of Saccharomyces cerevisiae. FEBS Lett. 430: 116-125.

Peuvel-Fanget, I., Polonais, V., Brosson, D., Texier, C., Kuhn, L., Peyret, P., et al (2006) EnP1 and EnP2, two proteins associated with the Encephalitozoon cuniculi endospore, the chitin-rich inner layer of the microsporidian spore wall. Int J Parasitol. 36: 309-318.

Pierce Biotechnology, I. (2005) Avidin-Biotin-Products.

Pieters, J. (2008) Mycobacterium tuberculosis and the macrophage: maintaining a balance. Cell Host Microbe. 3: 399-407.

Rabinovitch, M. (1995) Professional and non-professional phagocytes: an introduction. Trends Cell Biol. 5: 85-87.

Raulston, J.E. (1995) Chlamydial envelope components and pathogen-host cell interactions. Mol Microbiol. 15: 607-616. 
Reddy, A., Caler, E.V. and Andrews, N.W. (2001) Plasma membrane repair is mediated by $\mathrm{Ca}(2+)$-regulated exocytosis of lysosomes. Cell. 106: 157-169.

Regenberg, B., During-Olsen, L., Kielland-Brandt, M.C. and Holmberg, S. (1999) Substrate specificity and gene expression of the amino-acid permeases in Saccharomyces cerevisiae. Curr Genet. 36: 317-328.

Robinson, C.G. and Roy, C.R. (2006) Attachment and fusion of endoplasmic reticulum with vacuoles containing Legionella pneumophila. Cell Microbiol. 8: 793-805.

Rockey, D.D., Fischer, E.R. and Hackstadt, T. (1996) Temporal analysis of the developing Chlamydia psittaci inclusion by use of fluorescence and electron microscopy. Infect Immun. 64: 4269-4278.

Rohde, K., Yates, R.M., Purdy, G.E. and Russell, D.G. (2007) Mycobacterium tuberculosis and the environment within the phagosome. Immunol Rev. 219: 37-54.

Rosenberger, C.M., Brumell, J.H. and Finlay, B.B. (2000) Microbial pathogenesis: lipid rafts as pathogen portals. Curr Biol. 10: R823-825.

Rottenberg, M.E., Gigliotti-Rothfuchs, A. and Wigzell, H. (2002) The role of IFN-gamma in the outcome of chlamydial infection. Curr Opin Immunol. 14: 444-451.

Roy, C.R., Berger, K.H. and Isberg, R.R. (1998) Legionella pneumophila DotA protein is required for early phagosome trafficking decisions that occur within minutes of bacterial uptake. Mol Microbiol. 28: 663-674.

Sacks, D. and Sher, A. (2002) Evasion of innate immunity by parasitic protozoa. Nat Immunol. 3: 1041-1047.

Saliba, K.J. and Kirk, K. (2001a) Nutrient acquisition by intracellular apicomplexan parasites: staying in for dinner. Int J Parasitol. 31: 1321-1330.

Saliba, K.J. and Kirk, K. (2001b) H+-coupled pantothenate transport in the intracellular malaria parasite. J Biol Chem. 276: 18115-18121.

Scanlon, M., Leitch, G.J., Visvesvara, G.S. and Shaw, A.P. (2004) Relationship between the host cell mitochondria and the parasitophorous vacuole in cells infected with Encephalitozoon microsporidia. J Eukaryot Microbiol. 51: 81-87.

Scanlon, M., Shaw, A.P., Zhou, C.J., Visvesvara, G.S. and Leitch, G.J. (2000) Infection by microsporidia disrupts the host cell cycle. J Eukaryot Microbiol. 47: 525-531.

Schaible, U.E., Schlesinger, P.H., Steinberg, T.H., Mangel, W.F., Kobayashi, T. and Russell, D.G. (1999) Parasitophorous vacuoles of Leishmania mexicana acquire macromolecules from the host cell cytosol via two independent routes. J Cell Sci. 112 ( Pt 5): 681-693.

Schottelius, J., Schmetz, C., Kock, N.P., Schuler, T., Sobottka, I. and Fleischer, B. (2000) Presentation by scanning electron microscopy of the life cycle of microsporidia of the genus Encephalitozoon. Microbes Infect. 2: 1401-1406. 
Schroeder, R., London, E. and Brown, D. (1994) Interactions between saturated acyl chains confer detergent resistance on lipids and glycosylphosphatidylinositol (GPI)-anchored proteins: GPI-anchored proteins in liposomes and cells show similar behavior. Proc Natl Acad Sci US A. 91: 12130-12134.

Schwab, J.C., Beckers, C.J. and Joiner, K.A. (1994) The parasitophorous vacuole membrane surrounding intracellular Toxoplasma gondii functions as a molecular sieve. Proc Natl Acad Sci U S A. 91: 509-513.

Schwartz, D.A., Bryan, R.T., Hewan-Lowe, K.O., Visvesvara, G.S., Weber, R., Cali, A. and Angritt, P. (1992) Disseminated microsporidiosis (Encephalitozoon hellem) and acquired immunodeficiency syndrome. Autopsy evidence for respiratory acquisition. Arch Pathol Lab Med. 116: 660-668.

Scidmore, M.A., Rockey, D.D., Fischer, E.R., Heinzen, R.A. and Hackstadt, T. (1996) Vesicular interactions of the Chlamydia trachomatis inclusion are determined by chlamydial early protein synthesis rather than route of entry. Infect Immun. 64: 5366-5372.

Shadduck, J.A. and Pakes, S. (1971) Encephalitozoonosis (nosematosis) and toxoplasmosis. Am. J. Pathol. 64: 657-671.

Shaw, R. and Kent, M. (eds.) (1999) Fish Microsporidia. Washington D.C.: ASM Press.

Shin, S. and Roy, C.R. (2008) Host cell processes that influence the intracellular survival of Legionella pneumophila. Cell Microbiol. 10: 1209-1220.

Sibley, L.D. (2004) Intracellular parasite invasion strategies. Science. 304: 248-253.

Sinai, A.P. and Joiner, K.A. (1997) Safe haven: the cell biology of nonfusogenic pathogen vacuoles. Annu Rev Microbiol. 51: 415-462.

Sinai, A.P., Webster, P. and Joiner, K.A. (1997) Association of host cell endoplasmic reticulum and mitochondria with the Toxoplasma gondii parasitophorous vacuole membrane: a high affinity interaction. J Cell Sci. 110 ( Pt 17): 2117-2128.

Snowden, K. and Shadduck, J. (eds.) (1999) Microsporidia in higher vertebrates. Washington D.C.: ASM Press.

Southern, T.R., Jolly, C.E., Lester, M.E. and Hayman, J.R. (2007) EnP1, a microsporidian spore wall protein that enables spores to adhere to and infect host cells in vitro. Eukaryot Cell. 6: $1354-1362$.

Sparfel, J.M., Sarfati, C., Liguory, O., Caroff, B., Dumoutier, N., Gueglio, B., et al (1997) Detection of microsporidia and identification of Enterocytozoon bieneusi in surface water by filtration followed by specific PCR. J Eukaryot Microbiol. 44: 78S.

Sprague, V., Ormieres, R. and Manier, J.-F. (1972) Creation of a new genus and a new family in the Microsporidia. J Invertebr Pathol. 20: 228-231.

Sprague, V., Becnel, J.J. and Hazard, E.I. (1992) Taxonomy of phylum microspora. Crit Rev Microbiol. 18: 285-395. 
Sturgill-Koszycki, S., Schaible, U.E. and Russell, D.G. (1996) Mycobacterium-containing phagosomes are accessible to early endosomes and reflect a transitional state in normal phagosome biogenesis. Embo J. 15: 6960-6968.

Sturgill-Koszycki, S., Schlesinger, P.H., Chakraborty, P., Haddix, P.L., Collins, H.L., Fok, A.K., et al (1994) Lack of acidification in Mycobacterium phagosomes produced by exclusion of the vesicular proton-ATPase. Science. 263: 678-681.

Swanson, M.S. and Isberg, R.R. (1995) Association of Legionella pneumophila with the macrophage endoplasmic reticulum. Infect Immun. 63: 3609-3620.

Takizawa, H., Vivier, E. and Petitprez, A. (1973) Developpment intranucleaire de la microsporidie Nosema bombycis dans les cellules de vers a soie apres infestation experimentale. C. R. Acad. Sci. 277: 1769-1772.

Takvorian, P.M. and Cali, A. (1994) Enzyme histochemical identification of the Golgi apparatus in the microsporidian, Glugea stephani. J Eukaryot Microbiol. 41: 63S-64S.

Takvorian, P.M. and Cali, A. (1996) Polar tube formation and nucleoside diphosphatase activity in the microsporidian, Glugea stephani.J Eukaryot Microbiol. 43: 102S-103S.

Tesh, M.J., Morse, S.A. and Miller, R.D. (1983) Intermediary metabolism in Legionella pneumophila: utilization of amino acids and other compounds as energy sources. $J$ Bacteriol. 154: 1104-1109.

Thomas, J.L., Holowka, D., Baird, B. and Webb, W.W. (1994) Large-scale co-aggregation of fluorescent lipid probes with cell surface proteins. J Cell Biol. 125: 795-802.

Tsaousis, A.D., Kunji, E.R., Goldberg, A.V., Lucocq, J.M., Hirt, R.P. and Embley, T.M. (2008) A novel route for ATP acquisition by the remnant mitochondria of Encephalitozoon cuniculi. Nature. 453: 553-556.

Undeen, A.H. and Frixione, E. (1990) The role of osmotic pressure in the germination of Nosema algerae spores. J Protozool. 37: 561-567.

Undeen, A.H. and Vander Meer, R. (1994) Conversion of intrasporal trehalose into reducing sugars during germination of Nosema algerae (Protista: Microspora) spores: a quantitative stucy. . J Eukaryot Microbiol. 41: 129-132.

Undeen, A.H. and Vander Meer, R.K. (1999) Microsporidian intrasporal sugars and their role in germination. J Invertebr Pathol. 73: 294-302.

Undeen, A.H., Elgazzar, L., Vander Meer, R. and Narang, S. (1987) Trahalose levels and trehalase activity in germinated and ungerminated spores of Nosema algerae (Microsporidia: Nosematidae). J Invertebr. Pathol. 50: 230-237.

Vavra, J. (1963) Spore projection in microsporidia. Acta Protozool. 1: 153-155.

Vavra, J. (2005) "Polar vesicles" of microsporidia are mitochondrial remnants ("mitosomes")? Folia Parasitol (Praha). 52: 193-195. 
Vavra, J. and Larsson, J. (eds.) (1999) Structure of the microsporidia. Washington, DC: ASM Press.

Venkatesan, P. (1998) Albendazole. J Antimicrob Chemother. 41: 145-147.

Veras, P.S., de Chastellier, C., Moreau, M.F., Villiers, V., Thibon, M., Mattei, D. and Rabinovitch, M. (1994) Fusion between large phagocytic vesicles: targeting of yeast and other particulates to phagolysosomes that shelter the bacterium Coxiella burnetii or the protozoan Leishmania amazonensis in Chinese hamster ovary cells. J Cell Sci. 107 ( Pt 11): 3065-3076.

Vergne, I., Chua, J. and Deretic, V. (2003) Tuberculosis toxin blocking phagosome maturation inhibits a novel Ca2+/calmodulin-PI3K hVPS34 cascade. $J$ Exp Med. 198: 653659.

Visvesvara, G.S. (2002) In vitro cultivation of microsporidia of clinical importance. Clin Microbiol Rev. 15: 401-413.

Ward, M. (ed.) (1988) The chlamydial developmental cycle. Boca Raton, FL, USA.

Watson, D., Asmuth, D. and Wanke, C. (1996) Environmental risk factors for aquisition of microsporidia in HIV-infected persons. Clin. Infect. Dis. 23: 903.

Weber, R., Bryan, R.T., Schwartz, D.A. and Owen, R.L. (1994) Human microsporidial infections. Clin Microbiol Rev. 7: 426-461.

Weidner, E. (1972) Ultrastructural study of microsporidian invasion into cells. Z Parasitenkd. 40: $227-242$.

Weidner, E. (1975) Interactions between Encephalitozoon cuniculi and macrophages. Parasitophorous vacuole growth and the absence of lysosomal fusion. Z Parasitenkd. 47: 1-9.

Weidner, E. (1976) The microsporidian spore invasion tube. The ultrastructure, isolation, and characterization of the protein comprising the tube. J Cell Biol. 71: 23-34.

Weidner, E., Byrd, W., Scarborough, A., Pleshinger, J. and Sibley, L.D. (1984) Microsporidian spore discharge and the transfer of polaroplast organelle into plasma membrane. . J Protozool. 31: 195-198.

Weissenberg, R. (ed.) (1976) Microsporidian interactions with host cells. New York: Plenum Press.

Werner-Meier, R. and Entzeroth, R. (1997) Diffusion of microinjected markers across the parasitophorous vacuole membrane in cells infected with Eimeria nieschulzi (Coccidia, Apicomplexa). Parasitol Res. 83: 611-613.

Wichro, E., Hoelzl, D., Krause, R., Bertha, G., Reinthaler, F. and Wenisch, C. (2005) Microsporidiosis in travel-associated chronic diarrhea in immune-competent patients. Am J Trop Med Hyg. 73: 285-287. 
Wieland, H., Ullrich, S., Lang, F. and Neumeister, B. (2005) Intracellular multiplication of Legionella pneumophila depends on host cell amino acid transporter SLC1A5. Mol Microbiol. 55: $1528-1537$.

Williams, B.A., Hirt, R.P., Lucocq, J.M. and Embley, T.M. (2002) A mitochondrial remnant in the microsporidian Trachipleistophora hominis. Nature. 418: 865-869.

Williams, B.A., Cali, A., Takvorian, P.M. and Keeling, P.J. (2008) Distinct localization patterns of two putative mitochondrial proteins in the microsporidian Encephalitozoon cuniculi. J Eukaryot Microbiol. 55: 131-133.

Wiwanitkit, V. (2006) Intestinal parasite infestation in HIV infected patients. Curr HIV Res. 4: 87-96.

Wright, J. and Craighead, E. (1922) Infectious motor paralysis in young rabbits. J Exp Med. 36: 135-149.

Wyrick, P.B. (2000) Intracellular survival by Chlamydia. Cell Microbiol. 2: 275-282.

$\mathrm{Xu}, \mathrm{Y}$. and Weiss, L.M. (2005) The microsporidian polar tube: a highly specialised invasion organelle. Int J Parasitol. 35: 941-953.

Zaas, D.W., Duncan, M., Rae Wright, J. and Abraham, S.N. (2005) The role of lipid rafts in the pathogenesis of bacterial infections. Biochim Biophys Acta. 1746: 305-313.

Zhang, H., Huang, H., Cali, A., Takvorian, P.M., Feng, X., Zhou, G. and Weiss, L.M. (2005) Investigations into microsporidian methionine aminopeptidase type 2: a therapeutic target for microsporidiosis. Folia Parasitol (Praha). 52: 182-192.

Zilberstein, D. and Dwyer, D.M. (1985) Protonmotive force-driven active transport of Dglucose and L-proline in the protozoan parasite Leishmania donovani. Proc Natl Acad Sci U S A. 82: 1716-1720. 


\section{Kongressbeiträge}

Rönnebäumer, K., Groß, U. and Bohne, W. (2006) Nutrient acquisition in Encephalitozoon cuniculi - a microsporidian with extreme reduction of biosynthetic pathways. 58. Tagung der Deutschen Gesellschaft für Hygiene und Mikrobiologie, Würzburg, 01.-04.10.2006.

Rönnebäumer, K. (2006) Features of the parasitophorous vacuole of the microsporidian Encephalitozoon cuniculi. DFG-Zwischenkolloquium, Jena, 26. - 27.10.2006.

Rönnebäumer, K., Faßhauer, V., Groß, U. and Bohne, W. (2007) The parasitophorous vacuole membrane of Encephalitozoon cuniculi contains pores which should allow an extensive participation on the host cell metabolite pool. V European Congress of Protistology and XI European Conference on Ciliate Biology, Sankt Petersburg (Russland), 23.-27.07.2007.

Rönnebäumer, K., Faßhauer, V., Groß, U. and Bohne, W. (2007) The parasitophorous vacuole membrane of the microsporidian pathogen Encephalitozoon cuniculi possesses pores for metabolite exchange. 59. Tagung der Deutschen Gesellschaft für Hygiene und Mikrobiologie, Göttingen, 30.09.-04.10.2007.

Rönnebäumer, K. (2007) New insights into the biogenesis of the parasitophorous vacuole membrane of the microsporidian Encephalitozoon cuniculi. DFG-Zwischenkolloquium, Jena, 08.-09.11.2007.

Rönnebäumer, K., Groß, U. and Bohne, W. (2008) Characterization of the parasitophorous vacuole of the microsporidian pathogen Encephalitozoon cuniculi. 23. Tagung der Deutschen Gesellschaft für Parasitologie e.V. (DGP), Hamburg, 05. - 07. 03.2008. 


\section{Veröffentlichungen}

Rönnebäumer, K., Wagener, J., Groß, U. and Bohne, W. (2006) Identification of novel developmentally regulated genes in Encephalitozoon cuniculi: an endochitinase, a chitinsynthase, and two subtilisin-like proteases are induced during meront-to-sporont differentiation. J Eukaryot Microbiol. 53 Suppl 1:S74-6.

Rönnebäumer, K., Bohne, W., Lugert, R., und Groß, U. (2007) Mikrosporidien ungewöhnliche Pilze als Erreger von opportunistischen Infektionen des Menschen. Der Mikrobiologe 17: 132-138.

Rönnebäumer, K., Groß, U. and Bohne, W. (2008) The nascent parasitophorous vacuole membrane of Encephalitozoon cuniculi is formed by host cell lipids and contains pores which allow nutrient uptake. Eukaryot Cell. 7: 1001-1008. 


\section{Lebenslauf}

Name: $\quad$ Karin Rönnebäumer

Geburtsdatum: $\quad 12.06 .1980$

Geburtsort: Coesfeld

Familienstand: ledig

Nationalität: deutsch

Schule: $\quad$ 08/1985 - 06/1989 Besuch der St. Martinus Grundschule in Nottuln

08/1989 - 06/1996 Besuch der Liebfrauen Realschule in Nottuln

08/1996 - 08/1999 Besuch des Städtischen Heriburg Gymnasiums in Coesfeld

Studium:

10/1999 - 02/2005 Studium der Biologie an der Westfälischen Wilhelms-Universität Münster

11/2001 Diplom-Vorprüfung

03/2004 Diplom-Hauptprüfung

04/2004 - 02/2005 Diplomarbeit am Institut für Infektiologie des Universitätsklinikums Münster unter Anleitung von Prof. M. Alexander Schmidt mit dem Thema: Regulation von extracytoplasmatischem Stress in Yersinia enterocolitica

Promotion: $\quad$ ab 05/2005 am Institut für Medizinische Mikrobiologie des Universitätsklinikums Göttingen über das Thema: Die parasitophore Vakuole des Mikrosporidiums Encephalitozoon cuniculi: Biogenese und Metabolitaustausch 